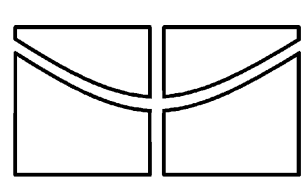

UNIVERSIDADE DE BRASÍLIA

FACULDADE DE TECNOLOGIA

DEPARTAMENTO DE ENGENHARIA ELÉTRICA

ESTUDO DE UMA REDE DE ACESSO VIA FIBRA ÓPTICA

\author{
LUÍZA BASÍLIO LAGE \\ MARIA CLARA ALCÂNTARA DE OLIVEIRA
}

ORIENTADOR: ANTÔNIO JOSÉ MARTINS SOARES

PROJETO FINAL DE GRADUAÇÃO

BRASÍLIA/DF: DEZEMBRO/2006 


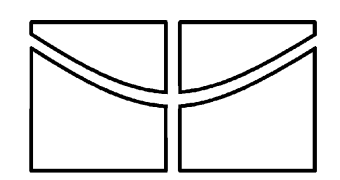

UNIVERSIDADE DE BRASÍLIA FACULDADE DE TECNOLOGIA DEPARTAMENTO DE ENGENHARIA ELÉTRICA

\title{
ESTUDO DE UMA REDE DE ACESSO VIA FIBRA ÓPTICA
}

\author{
LUÍZA BASÍLIO LAGE \\ MARIA CLARA ALCÂNTARA DE OLIVEIRA
}

PROJETO FINAL DE GRADUAÇÃO SUBMETIDA AO DEPARTAMENTO DE ENGENHARIA ELÉTRICA DA FACULDADE DE TECNOLOGIA DA UNIVERSIDADE DE BRASÍLIA, COMO PARTE DOS REQUISITOS NECESSÁRIOS PARA A OBTENÇÃO DO GRAU DE ENGENHEIRO.

APROVADA POR:

ANTÔNIO JOSÉ MARTINS SOARES, ENE/UnB

(ORIENTADOR)

FRANKLIN DA COSTA SILVA, ENE/UnB (EXAMINADOR)

MARCO ANTÔNIO BRASIL TERADA, ENE/UnB (EXAMINADOR)

DATA: BRASÍLIA/DF, 18 DE DEZEMBRO DE 2006 
LAGE, LUÍZA BASÍLIO

Estudo de uma Rede de Acesso via Fibra Óptica

[Distrito Federal] 2006

(ENE/FT/UnB, Engenheira, Engenharia Elétrica, 2006).

Projeto Final de Graduação - Universidade de Brasília, Faculdade de Tecnologia. Departamento de Engenharia Elétrica.

OLIVEIRA, MARIA CLARA ALCÂNTARA DE

Estudo de uma Rede de Acesso via Fibra Óptica

[Distrito Federal] 2006

(ENE/FT/UnB, Engenheira, Engenharia Elétrica, 2006).

Projeto Final de Graduação - Universidade de Brasília, Faculdade de Tecnologia. Departamento de Engenharia Elétrica.

\section{REFERÊNCIA BIBLIOGRÁFICA}

LAGE, LUÍZA BASÍLIO (2006). Estudo de uma Rede de Acesso via Fibra Óptica (Projeto Final de Graduação), Departamento de Engenharia Elétrica, Universidade de Brasília, Brasília, DF.

OLIVEIRA, MARIA CLARA ALCÂNTARA DE (2006). Estudo de uma Rede de Acesso via Fibra Óptica. (Projeto Final de Graduação), Departamento de Engenharia Elétrica, Universidade de Brasília, Brasília, DF. 


\section{CESSÃO DE DIREITOS}

NOME DO AUTOR: Luíza Basílio Lage, Maria Clara Alcântara de Oliveira TÍTULO DA DISSERTAÇÃO: Estudo de uma Rede de Acesso via Fibra Óptica GRAU/ANO: Engenheiro/2006.

É concedida à Universidade de Brasília permissão para reproduzir cópias deste Projeto Final de Graduação e para emprestar ou vender tais cópias somente para propósitos acadêmicos e científicos. Os autores reservam outros direitos de publicação e nenhuma parte desta dissertação de graduação pode ser reproduzida sem a autorização por escrito dos autores.

Luíza Basílio Lage

Condomínio Mansões Itaipú

CEP XXXXX-XX - Brasília - DF - Brasil

Maria Clara Alcântara de Oliveira SQS 114 Bloco A apartamento 605

CEP 70377-010 - Brasília - DF - Brasil 


\section{AGRADECIMENTOS}

Agradeço a Deus, por todas as bênçãos em minha vida, por sempre ter iluminado o meu caminho, muitas vezes difícil, mas gratificante, tornando meus sonhos realidade.

Agradeço ao meu pai e à minha mãe, por serem meus exemplos de vida, de luta e dedicação à família e por terem estado sempre presentes, me apoiando e incentivando para que eu pudesse passar com êxito por cada etapa dessa caminhada. À minha irmã Fernanda, meu irmão Filipe e à sobrinha Isabela, pela alegria que trazem à minha vida. A todos os meus familiares: avós, tios, primos e agregados, pelo apoio em todos os momentos.

À avó Vaína (in memorian), grande incentivadora, que sempre vibrou com cada pequena conquista minha.

Grandes agradecimentos aos meus amigos, que souberam entender os momentos em que abri mão da convivência para me dedicar à Engenharia: as Amigaaas: Ana Teresa, Ariane, Cintia, Clarice, Fernanda, Juliana, Larissa e Thaís; os Amigooos: Thiago, Rodrigo, Fabiano e Diego e as amigas super animadas Luana, Patrícia e Elaine.

Agradeço também aos amigos da UnB, que passaram tantas horas ao meu lado, sendo grandes companhias, dentro e fora de sala, e que continuarão fazendo parte dessa história e, sem dúvida, da minha vida: Ana Ravena, Walkíria, Maria Clara, Izumi, Fernanda e Viviane (as EletroGirls), Débora, Andréia, Marcos, Thompson, Francisco, Samuel, Otávio, Danilo Branquinho, André Sterf, Marcello Sasaki, Humberto Bruno e Rodrigo. Tenho que agradecer muito à Clara, minha querida amiga inseparável, pela presença sempre constante na qual pude contar, pelas risadas que demos de tudo e de todos, por me entender sempre e principalmente, pela amizade, que tenho certeza, será eterna.

Agradeço também aos professores pela dedicação e conhecimento não só na realização desta monografia, mas também em minha formação acadêmica.

A todos que verdadeiramente acreditaram que eu era capaz e sempre me deram força e incentivo para continuar lutando. Amo vocês!

Luíza Basílio Lage 


\section{AGRADECIMENTOS}

Primeiramente agradeço a Deus pela vida, pela saúde e pela inteligência. Por ter me dado força nos momentos em que o único pensamento era desistir.

Agradeço a meus pais que me ensinaram a viver com dignidade e iluminaram meu caminho com afeto e dedicação constantes.

Agradeço também a todos os meus professores da Universidade de Brasília, que foram pessoas imprescindíveis que transformaram a ingenuidade em experiência.

Àqueles amigos incondicionais: Andréia, Luana, Amanda, Bruno, Júlia, Camila e Lizane que conseguiram entender minha ausência e me apoiaram na luta por mais esse sonho. Obrigada por estarem sempre presentes.

Agradeço a todos os meu grandes e queridos amigos feitos na Engenharia. As eletrogirls Luíza, Izumi, Ana Ravena, Fernanda, Walkíria e Viviane; os queridos Francisco, Marcos, Thompson, Otávio, Samuel, Danilo Branquinho, Guilherme Solino e Marcello Sasaki todos vocês foram imprecindíveis para essa conquista, amo todos vocês! Um especial para a Luíza, amiga companheira que caminhou junto comigo todo esse tempo, inclusive nesse trabalho, e fez meus dias mais engraçados e felizes.

Não poderia deixar de agradecer também ao meu namorado e também colega de curso Rodrigo, que com sua dedicação e presença tornaram esses dias de luta mais belos.

A todos, que de alguma forma passaram pela minha vida e influenciaram positivamente nessa conquista. O sucesso também é de vocês!! 


\section{DEDICATÓRIA}

Eu, Maria Clara Alcântara de

Eu, Luíza Basílio Lage, dedico este trabalho ao meu pai Luciano, à minha mãe Márcia, aos meus irmãos Fernanda e Filipe, à minha sobrinha Isabela, à minha amiga Clara e aos meus amigos da Elétrica, que tanto me ajudaram nesses cinco anos.
Oliveira, dedico este trabalho a meus amados pais Ataíde e Maria Helena, a meu irmão João, ao meu namorado Rodrigo, as minhas amigas de sempre Luíza, Luana e Andréia e aos meus queridos amigos da Elétrica. Todos foram essenciais para que esse sonho pudesse ser realizado. 



\section{ESTUDO DE UMA REDE DE ACESSO VIA FIBRA ÓPTICA}

\section{RESUMO}

As redes de acesso via fibra óptica já são uma realidade. Por esse motivo, o trabalho que segue se propõe a realizar um estudo das aplicações práticas da fibra óptica com objetivo final de mostrar e exemplificar a rede de acesso óptica.

Para que esses objetivos sejam alcançados, seguem conceituações do sistema de comunicação óptico, dos elementos de uma rede óptica, das técnicas de multiplexação utilizadas, das redes ópticas e, por fim, das redes de acesso via fibra óptica. Além disso, exemplos de redes já implementadas fazem parte do desfecho do trabalho.

Em um segundo plano tem-se também a conceituação de outros tipos de rede acesso existentes para que, dessa forma, sejam feitas comparações. Para complementação conceitual tem-se também um resumo das tecnologias de transmissão utilizadas. 


\section{ABSTRACT}

The usage of optical fiber in the access networks already are a reality. For this reason, the work that follows is a study of the practical applications of the optical fiber with the final goal to show and to exemplify the optical access networks.

In order to reach that goal, there are concepts of the optical communication system, of the elements of an optical network, of the used multiplexing techniques, optical networks and, at last, of the optical access networks. Also, there are examples of already implemented optical access networks.

Other existing types of access networks are also explained, so that comparisons may be made. As a complement, a summary of the used technologies of transmission are also mentioned. 


\section{SUMÁRIO}

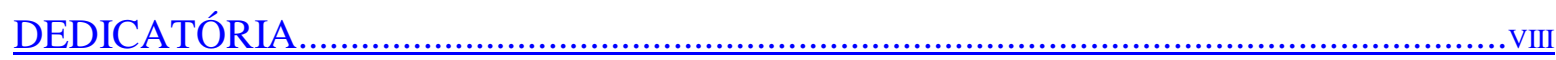

RESUMO.

ABSTRACT.

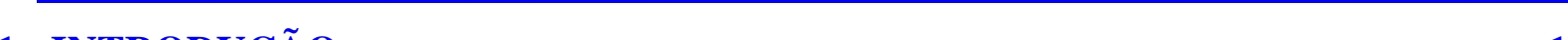

1 - INTRODUCẼ̃

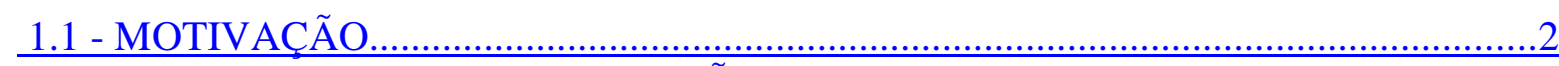

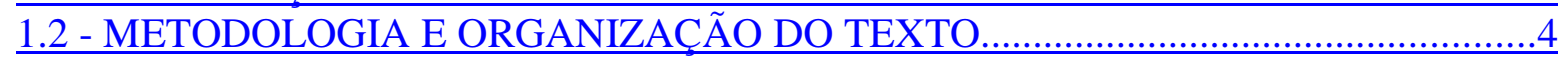

$\underline{2}$ - FUNDAMENTOS DE UM SISTEMA DE COMUNICAÇÃO ÓPTICO..........................5

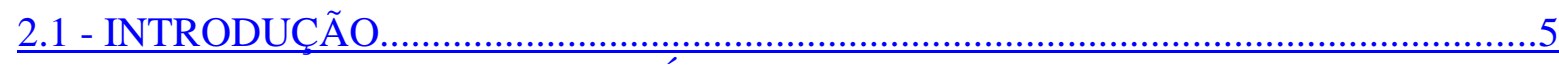

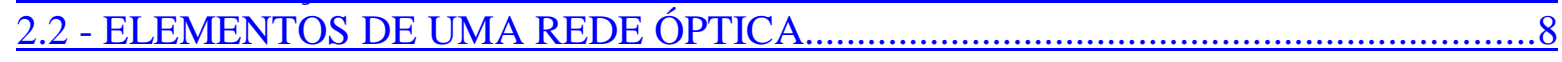

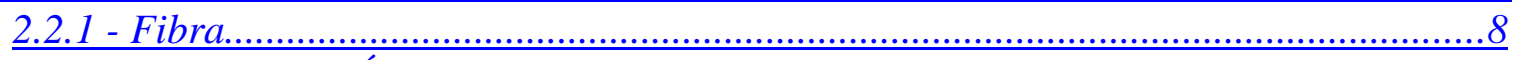

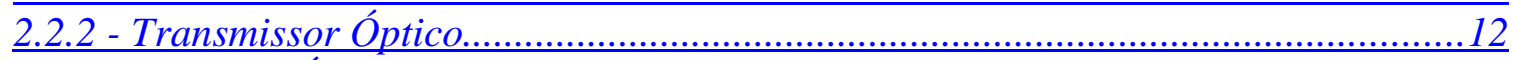

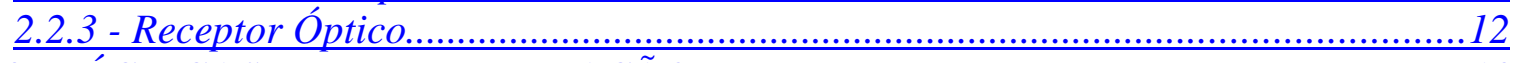

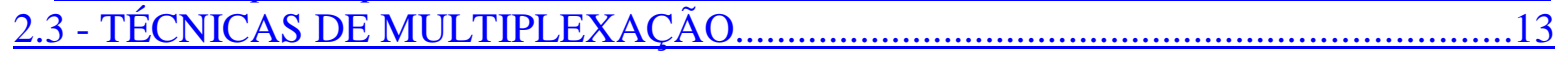

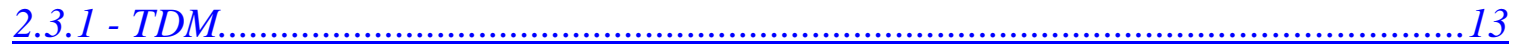

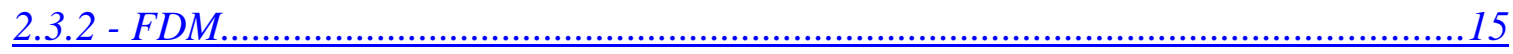

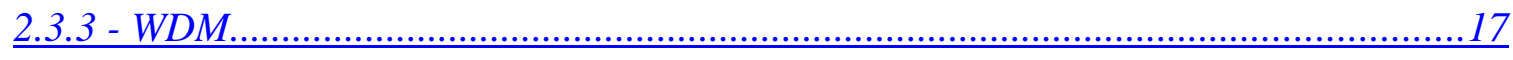

2.3.3.1 - DWDM

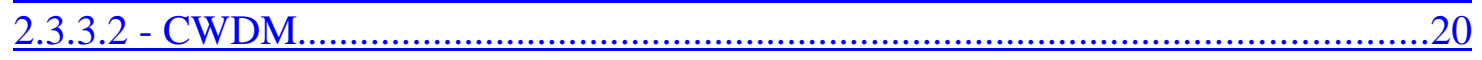

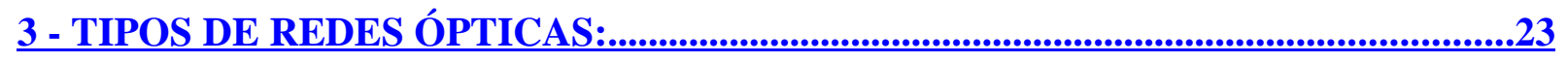

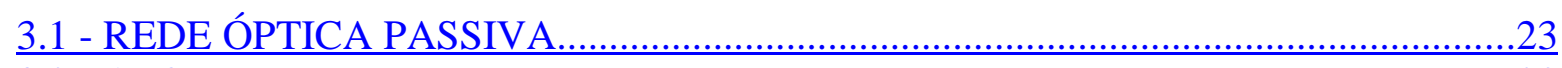

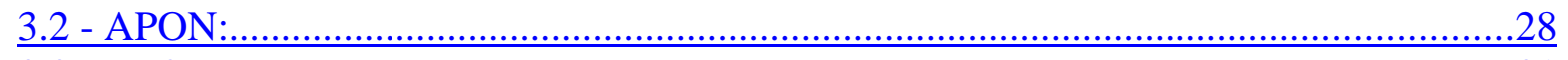

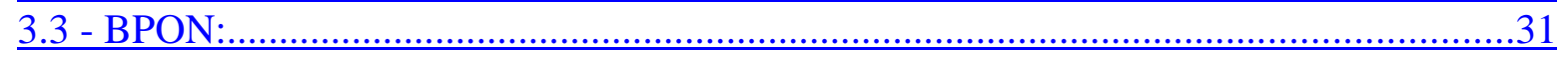

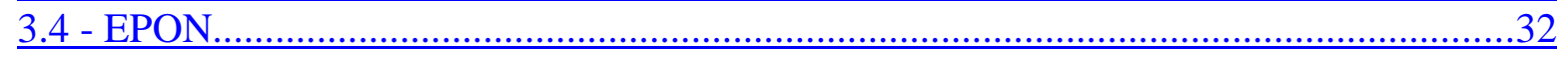

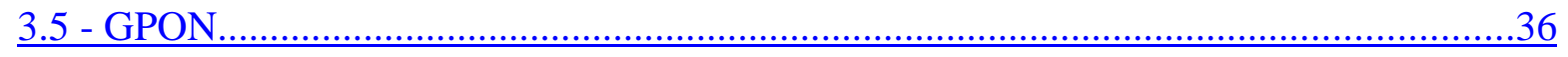

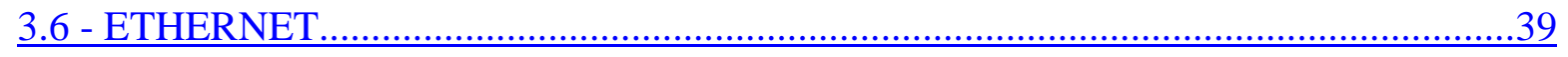

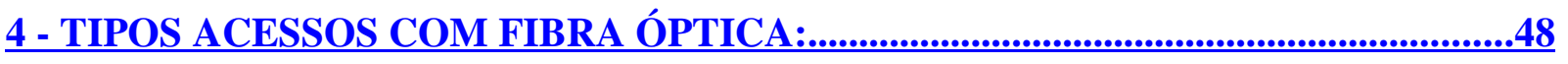

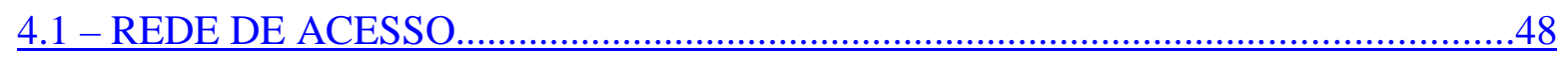

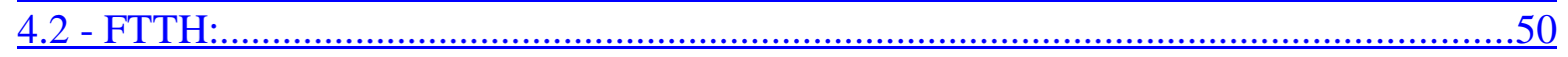

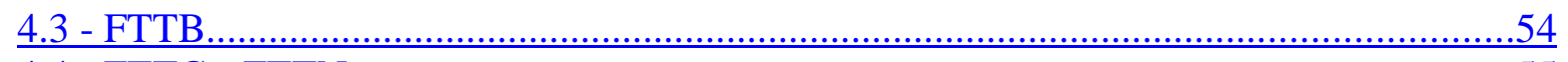

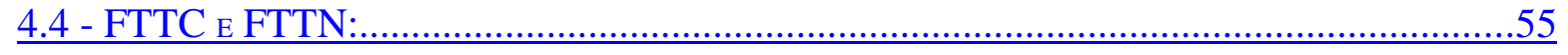

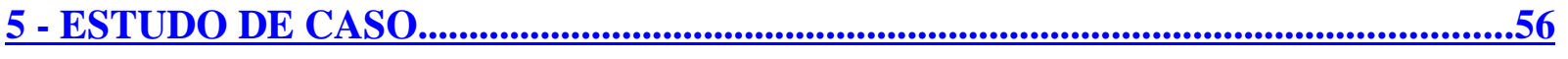

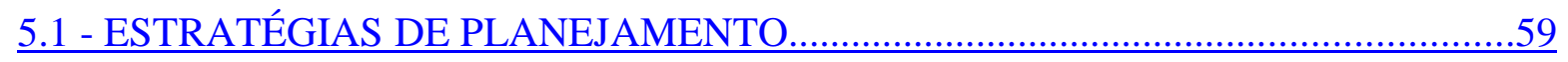

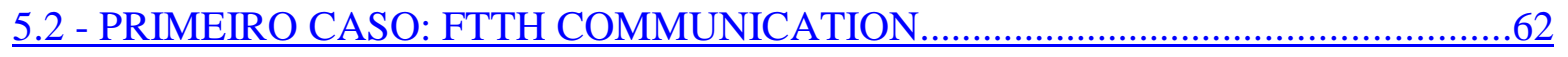

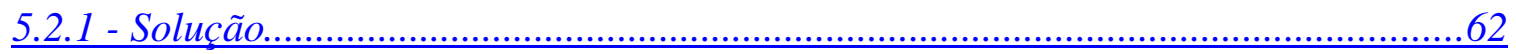

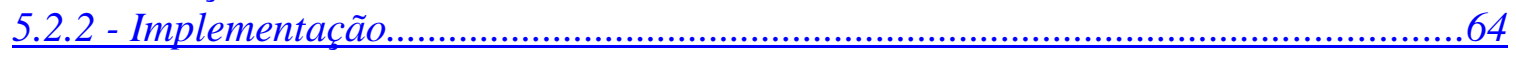

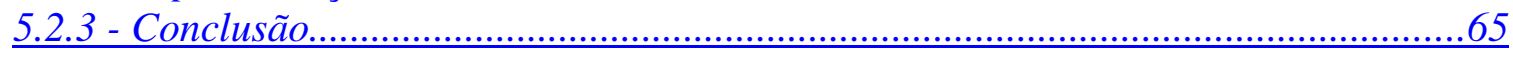

$\underline{5.3 \text { - SEGUNDO CASO: KUTZTOWN - FTTH } \ldots \ldots \ldots \ldots \ldots \ldots \ldots \ldots \ldots \ldots \ldots \ldots \ldots \ldots \ldots \ldots \ldots \ldots \ldots \ldots \ldots \ldots \ldots \ldots \ldots \ldots \ldots \ldots \ldots \ldots \ldots \ldots}$

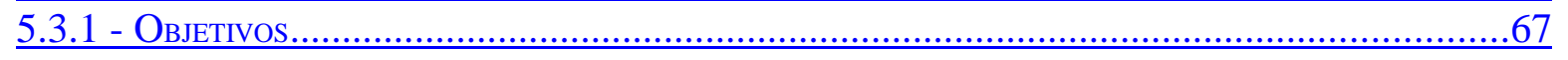

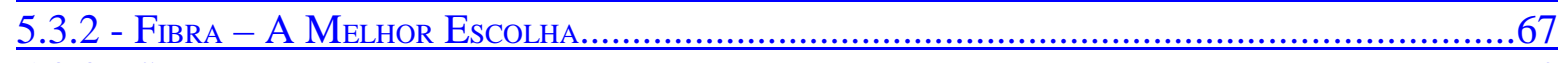

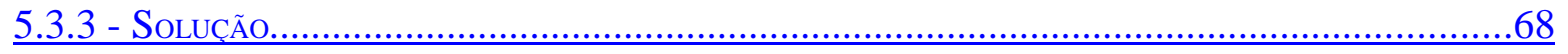




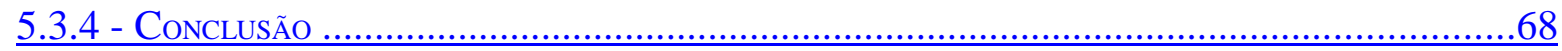

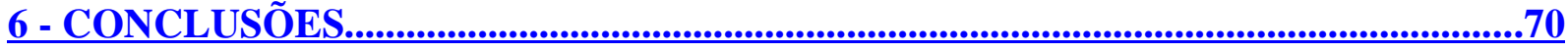

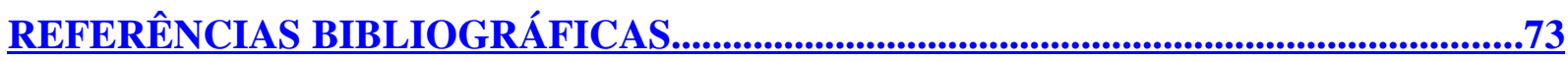

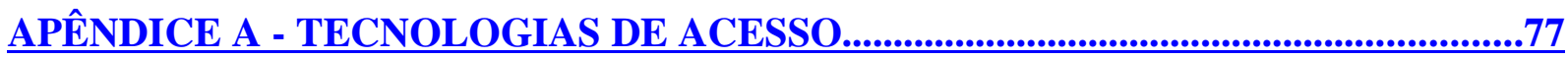

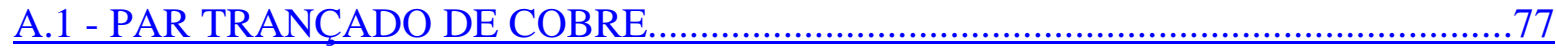

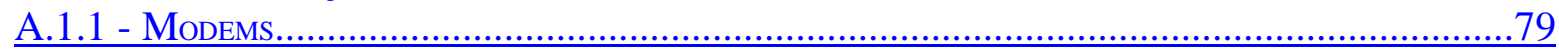

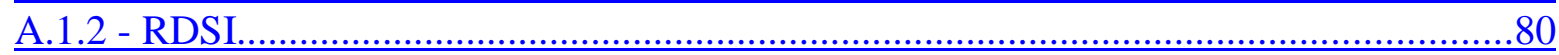

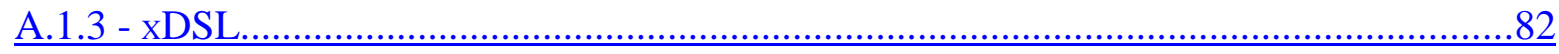

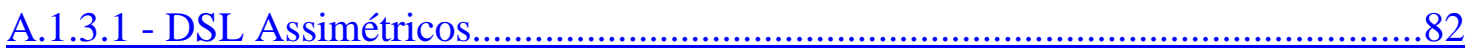

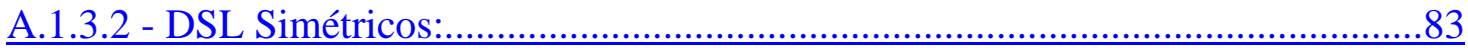

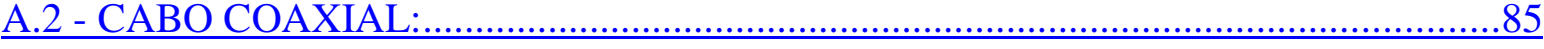

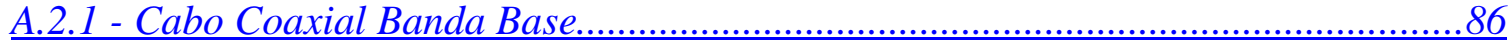

A.2.2 - Cabo Coaxial Banda Larga ...........................................................................

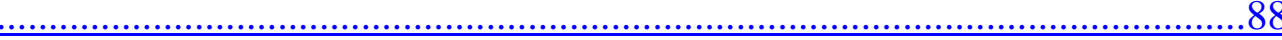

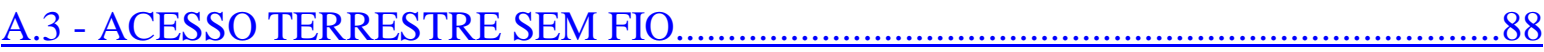

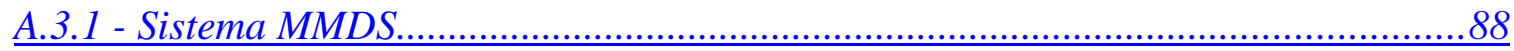

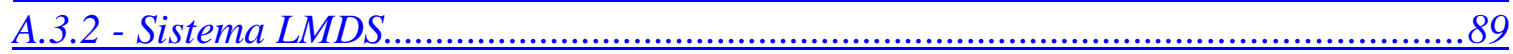

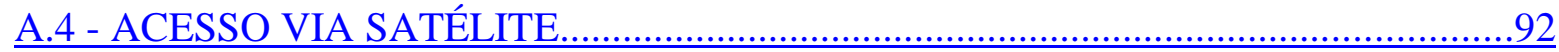

A.5 - SISTEMA PCS (PERSONAL CELLULAR SYSTEM) ......................................93

A.5.1 - Arquitetura do sistema faixa estreita..........................................................95

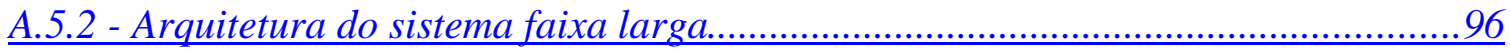

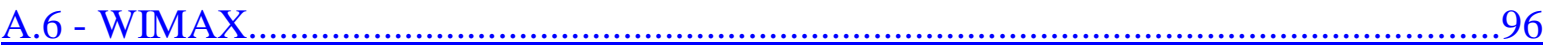

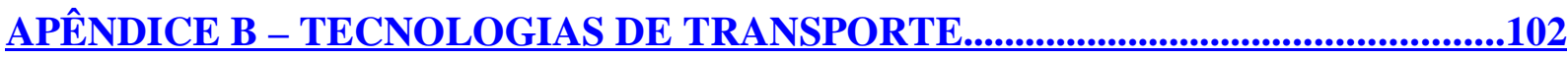

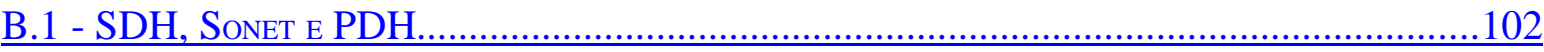

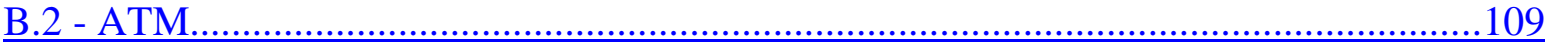

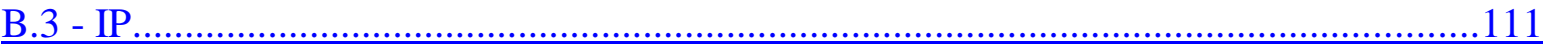

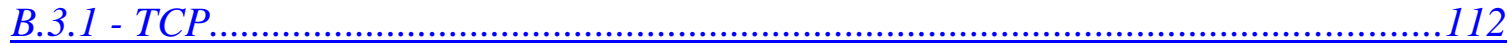

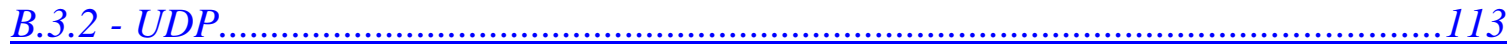

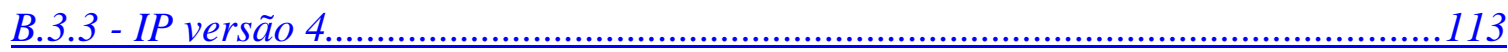

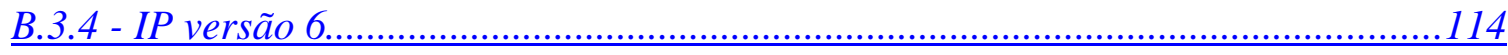

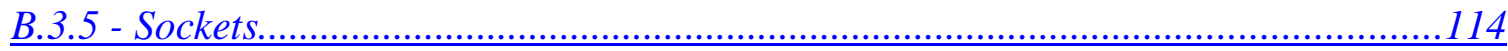

\section{ÍNDICE DE TABELAS}




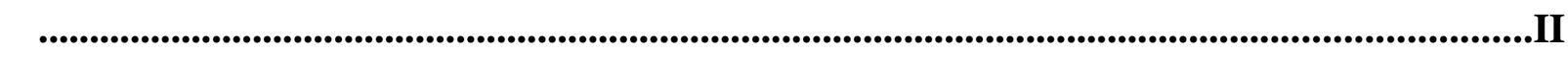

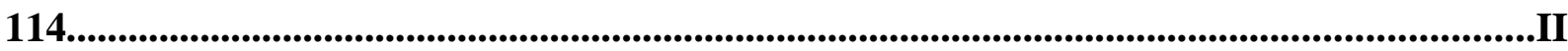

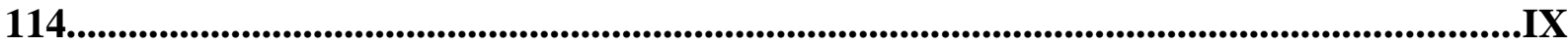

TABELA 3.1 RECOMENDAÇÕES IEEE PARA O PADRÃO ETHERNET..................39

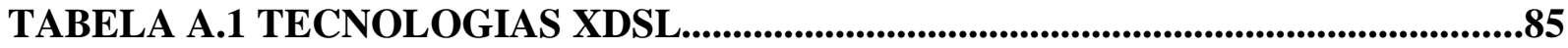

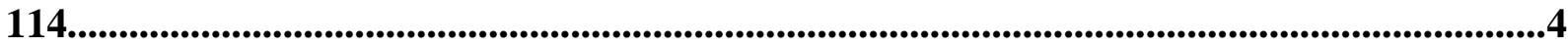

TABELA A.2 ESPECIFICAÇÕES DA RECOMENDAÇÃO IEEE 802.16......................97

TABELA B.1 COMPARAÇÃO ENTRE AS TAXAS DA SONET E DA SDH...............104 


\section{ÍNDICE DE FIGURAS}

FIGURA 2.1 SISTEMA DE COMUNICAÇÕES ELÉTRICA..............................................6

FIGURA 2.2 ELEMENTOS CONSTITUINTES DE UMA REDE DE COMUNICAÇÃO.

FIGURA 2.3 ELEMENTOS BÁSICOS DE UMA REDE ÓPTICA......................................8

FIGURA 2.4 ESTRUTURA DA FIBRA ÓPTICA..........................................................99

FIGURA 2.5 SISTEMA DE MULTIPLEXAÇÃO TDM SÍNCRONO.............................14

FIGURA 2.6 SISTEMA QUE UTILIZA FDM...................................................16

FIGURA 2.7 ESPECTRO OCUPADO POR SINAIS EM UM SISTEMA FDM..............16

FIGURA 2.8 TÍPICO ENLACE DE TRANSMISSÃO WDM..............................................17

FIGURA 2.9 DIAGRAMA DE UM SISTEMA WDM SIMPLES........................................18

FIGURA 2.10 CANAIS WDM SENDO DEMULTIPLEXADOS POR UM FILTRO

ÓPTICO.................................................................................................................................19

FIGURE 2.11 BANDA PASSANTE DO CWDM PARA UM DISPOSITIVO DE 8

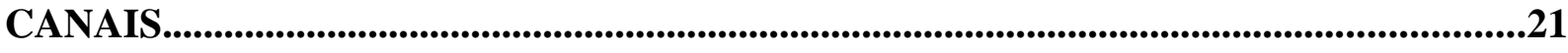

FIGURA 2.12 APLICAÇÃO UNIDIRECIONAL DE CWDM...........................................21

FIGURE 2.13 APLICAÇÃO BIDERECIONAL DO CWDM................................................22

FIGURA 3.1 ESTRUTURA BÁSICA DE UMA REDE PON..............................................23

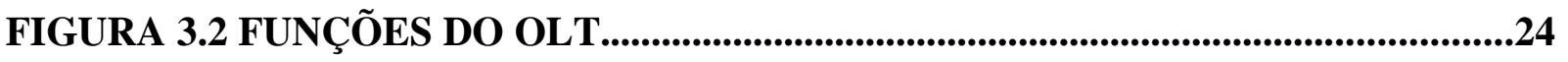

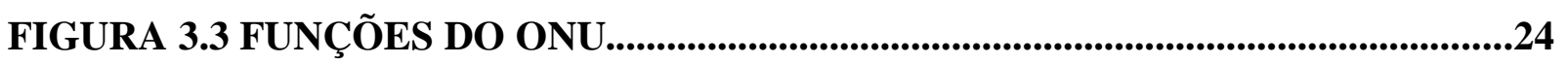

FIGURA 3.4 TOPOLOGIA EM ANEL..........................................................................................26

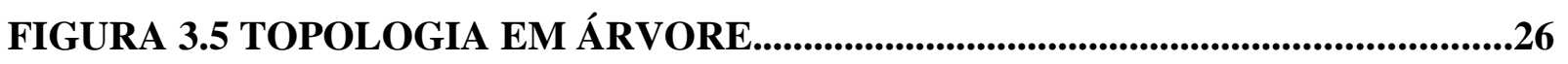

FIGURA 3.6 TOPOLOGIA EM BARRAMENTO.................................................................27

FIGURA 3.7 VISÃO GERAL DE UMA REDE PON COMPLETA.................................27

FIGURA 3.8 ATM-PON ARQUITETURA...................................................................28

FIGURA 3.9 VISÃO GERAL DA FUNCIONALIDADE DA ATM-PON.........................29

FIGURA 3.10 FORMATO BÁSICO DO FRAME ENTRE OLT E ONT..........................30

FIGURA 3.11 REPRESENTAÇÃO DE UMA REDE BPON.................................................32 
FIGURA 3.12 REPRESENTAÇÃO DE UMA REDE EPON.................................................33

FIGURA 3.13 FORMATO DO FRAME DO TRÁFEGO DOWNSTREAM....................34

FIGURA 3.14 FORMATO DO FRAME DO TRÁFEGO DOWNSTREAM......................35

FIGURA 3.15 REDE EPON COM DOIS COMPRIMENTOS DE ONDA...........................35

FIGURA 3.16 REDE EPON COM TRÊS COMPRIMENTOS DE ONDA.........................36

FIGURA 3.17 EXEMPLO DE UMA REDE GPON...............................................................37

FIGURA 3.18 ESTRUTURA DO QUADRO ETHERNET.................................................41

FIGURA 3.19 ANÁLISE ECONÔMICA DO METRO ETHERNET FÓRUM PARA A

TECNOLOGIA ETHERNET NO ACESSO......................................................................45

FIGURA 3.20 COMPARAÇÃO ENTRE O PADRÃO 802.3AH E OS OUTROS

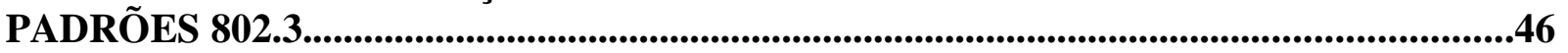

FIGURA 4.1 ELEMENTOS DA REDE DE ACESSO........................................................48

FIGURA 4.2 DIFERENTES ARQUITETURAS DO FTTX..............................................50

FIGURA 4.3 ARQUITETURA PTP EM FTTH..........................................................................51

FIGURA 4.4 ARQUITETURA PON EM FTTH....................................................................52

FIGURA 4.5 REDE PON COM SPLITTER CENTRAL...........................................53

FIGURA 4.6 REDE PON COM SPLITTER DISTRIBUÍDO OU CASCATEADO..........53

FIGURA 5.1 PENETRAÇÃO DO ACESSO BANDA LARGA ....................................56

FIGURA 5.2: ESTIMATIVA DE USUÁRIOS DE FTTH...................................................56

FIGURA 5.3: PREVISÃO DE IMPLEMENTAÇÃO DE FTTH NA EUROPA................57

FIGURA 5.4 SITUAÇÃO DE FTTH NO JAPÃO..........................................................58

FIGURA 5.5 NÚMERO DE USUÁRIOS FTTX NOS EUA...............................................58

FIGURA 5.6 DETALHE NO FDH...................................................................................63

FIGURA 5.7 KUTZTOWN...................................................................................................66

FIGURA A.1 TECNOLOGIAS DE ACESSO À REDE DE COMUNICAÇÃO..............77

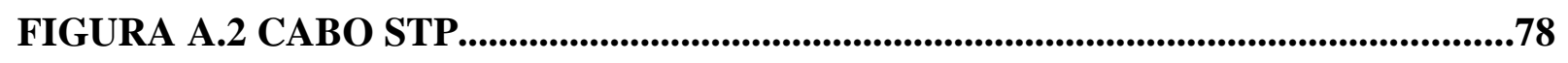

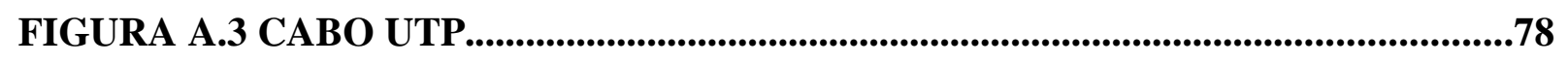

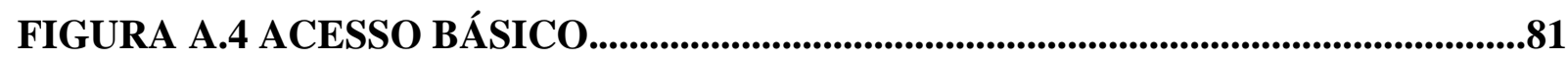

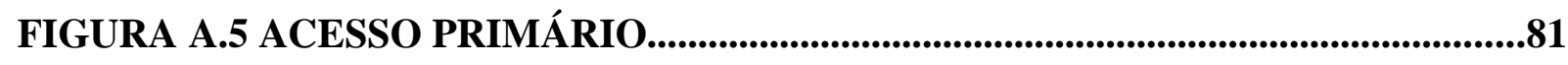

FIGURA A.6 GRÁFICO CAPACIDADE VS DIATÂNCIA (XDSL)................................84

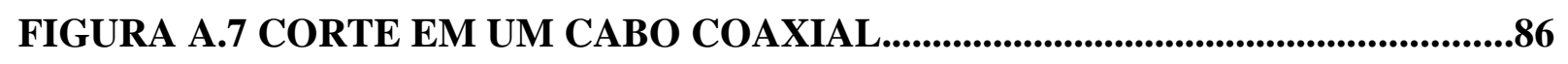

FIGURA A.8 CABO COAXIAL BANDA BASE..........................................................87

FIGURA A.9 CABO COAXIAL BANDA LARGA...........................................................88 
FIGURA A.10 ARQUITETURA TÍPICA DE UMA REDE MMDS. .89

FIGURA A.11 POLARIZAÇÃO DAS ANTENAS EM UMA CÉLULAS LMDS. H (POLARIZAÇÃ̃ HORIZONTAL, V (POLARIZAÇÃO VERTICAL).............................90

FIGURA A.12 ARQUITETURA DO SISTEMA LMDS.......................................................92

FIGURA A.13 CONFIGURAÇÃO TÍPICA PARA SE PROVER DTH INTERNET DELIVERY UTILIZANDO-SE DVB...............................................................................93

FIGURA A.14 MODELO DE UTILIZAÇÃO PARA O WIMAX.........................................99

FIGURA A.15 ESTIMATIVA DE PREÇO DOS CPES WIMAX.........................................100

FIGURA A.16 SERVIÇOS SUPORTADOS PELO WIMAX................................................101

FIGURA B.1 MULTIPLEXAÇÃO DE VÁRIOS CANAIS DE VOZ.................................102

FIGURA B.2 MEIOS DE TRANSMISSÃO DE NOVOS SERVIÇOS.................................103

FIGURA B.3 ESTRUTURA ORGANIZACIONAL DA PDH..............................................103

FIGURA B.4 ESTRUTURA DA REDE SDH.............................................................106

FIGURA B.5 CAMADAS DA REDE SDH...............................................................................106

FIGURA B.6 ESTRUTURA DO QUADRO DA REDE SDH................................................107

FIGURA B.7 TOPOLOGIAS DE REDE.....................................................................109

FIGURA B.8 SEGMENTAÇÃO DE DADOS........................................................................112

\section{LISTAGEM DE SIGLAS}

ADM - Add/Drop Multiplexers 
ADSL - Full Rate Asymmetrical Digital Subscriber Line

AOEN - All-Optical Ethernet Networks

APAC - Asia Pacific

APD - Avalanche Photo Diode

APON - Asynchronous Transfer Mode Passive Optical Network

ARQ - Automatic Retransmission Request

ATM - Asynchronous Transfer Mode

BPON - Broadband Passive Optical Network

CAPEX - Capital expenditures

CATV - Community Antenna Television

CDMA -Code Division Multiple Access

$\mathrm{CO}$ - Central Office

CPE - Customer Premises Equipment

CSMA/CD - Carrier Sense Multiple Access/Colision Detection

CWDM - Coarse Wavelength Division Multiplexing

DCC - Data Country Code

DiffServ - Differentiated Services

DLC - Digital Loop Carrier

DSL - Digital Subscriber Line

DSLAM - Digital Subscriber Line Access Multiplexer

DTH - Direct to Home

DWDM - Dense Wavelength Division Multiplexing

DXC - Digital Cross-Connects

E.164 - Specific Integrated Service Digital Network Number

EDFAs - Erbium Doped Fiber Amplifiers

EFMC - Ethernet in the First Mile Copper

EFMF - Ethernet in the First Mile Fiber

EFMP - Ethernet in the First Mile Passive Optical Network

ELAN - Ethernet Local Area Network

EPON-Ethernet based Passive Optical Network

ER - Estações Remotas 
ERB - Estação Rádio Base

FDD - Frequency Division Duplex

FDM - Frequency Division Multiplexing

FSAN - Full Service Access Network

FTP - File Transfer Protocol

FTTB - Fiber-To-The-Building

FTTC - Fiber-To-The-Curb

FTTCab - Fiber-To-The-Cabinet

FTTH - Fiber-To-The-Home

GFP - Generic Framing Protocol

GPON - Gigabit Passive Optical Network

GE-PON - Ethernet based Passive Optical Network

HDSL - High Data Rate Digital Subscriber Line

HDSL2 - High Data Rate Digital Subscriber Line Second Generation

HDSL4 - High Data Rate Digital Subscriber Line Fourth Generation

HSI - High-Speed Internet

ICD -International Code Designator

IDSL - Integrated Services Digital Network Digital Subscriber Line

IEEE - Institute of Electrical and Electronics Engineers

IP - Internet Protocol

ITU-T - International Telecommunications Union

LASERS - Light Amplification by Estimulated Emission of Radiation

LCP - Local Convergence Point

LED - Light Emitting Diode

LMDS - Local Multipoint Distribution System

LTM - Line Terminal Multiplexer

MMDS - Multipoint Multichannel Distribution System ou Serviço de Distribuição Multiponto

Multicanal

MPEG - Moving Picture Experts Group

NAP - Network Access Point

OEO - Óptico-Elétrico-Óptico 
OFDM - Orthogonal Frequency-Division Multiplexing

OFDMA - Orthogonal Frequency Division Multiplexing Access

OLT - Optical Line Terminal

ONT - Optical Network Terminal

ONU - Optical Network Units

OPEX - Operating Expenditures

PCM - Pulse Code modulation

PCS - Personal Celular System

PIN - Diodo

PMP - Point-Multipoint

PON - Passive Optical Network

PTP - Peer-to-peer

PVCs - Permanent Virtual Circuits

QoS - Quality of Service

RADSL - Rate Adaptive Digital Subscriber Line

RDSI - Rede Digital de Serviços Integrados

RPC - Remote Procedure Call

S/N - Sinal-Ruído

SCMA - Subcarrier Multiple Access

SDH - Synchronous Digital Hierarchy

SDSL - Symmetric Digital Subscriber Line

SHDSL - Symmetric High-Bitrate Digital Subscriber Line

SLA - Service-level Agreement

SMTP - Simple Mail Transfer Protocol

SNMP - Simple Network Management Protocol

SONET - Synchronous Optical Network

STP - Shielded Twisted-Pair

SVCs - Switched Virtual Circuits

TCP - Transmission Control Protocol

TDD - Time Division Duplex

TDM - Time Division Multiplexing 
TDMA - Time Division Multiple Access

TFTP - Trivial File Transfer Protocol

UDP - User Datagram Protocol

UTP - Unshielded Twisted-Pair

VDSL - Very High Bit Rate Digital Subscriber Line

VDSL2 - Very High Bit Rate Digital Subscriber Line Second Generation

VLAN - Virtual Local Area Network

VOD - Video-on-Demand

VoIP - Voice over Internet Protocol

WAN - Wide Area Network

WDM - Wavelength Division Multiplexing

WDM - Wavelength Division Multiplexing

WDMA - Wave Division Multiple Access

WiMax - Worldwide Interoperability for Microwave Access

WMAN - Wireless Metropolitan Area Network 



\section{1 - INTRODUÇÃO}

O mercado atual de telecomunicações, com sua crescente oferta de serviços (tradicionais e de valor agregado) ao usuário final, tem levado as operadoras a migrar suas redes de acesso para tecnologias mais flexíveis e de maior capacidade.

A rede de acesso é a parcela de uma rede pública comutada que conecta o nó de acesso aos usuários individuais. De uma forma mais simples, é a última ligação, em uma rede, entre as premissas do cliente e o primeiro ponto de conexão com a infra-estrutura da rede - a Point Of Presence (PoP) ou a sede (Central Office - CO). A rede de acesso atual é predominantemente constituída de fios de cobre, o par trançado, e foi considerada como tendo um dos mais importantes papéis no ato de prover serviços de transmissão de dados.

A rede de acesso óptica promete uma largura de banda extremamente grande, na casa de diversos gigabits por segundo (Gbps), o que provavelmente aumentará ainda mais com o avanço da tecnologia. Esta maior disponibilidade de largura de banda abre a possibilidades de novas arquiteturas para prover serviços de banda larga. Tomando a rede de acesso como a parte mais importante na entrega dessa largura de banda, é necessário colocar alguma variedade de equipamentos, nas premissas do cliente, para gerenciar ou controlar a quantidade de dados transmitidos sobre uma conexão de acesso.

Há, hoje em dia, uma percepção geral de que a fibra é um recurso escasso. Entretanto, a falta da fibra disponível para serviços de acesso ópticos novos não é o principal fator no mercado. De fato, a fibra é agora um recurso prontamente disponível para as redes de acesso, especialmente em áreas urbanas ou metropolitanas. Estima-se que em 1999 aproximadamente 65 milhões de quilômetros de fibra óptica estavam instaladas nos Estados Unidos e que 70 por cento estavam nos mercados metropolitanos superiores dos ILECs (Incumbent Local Exchange Carriers) e CLECs (Competitive Local Exchange Carriers). A quantidade de fibra instalada por CLECs foi de mais do que o dobro entre 1999 e 2002. Tudo isso aponta para um mercado grande e endereçável para os serviços de alta velocidade baseados no mercado óptico, com potencial de crescimento significativo.

A infra-estrutura óptica está provando ser uma parte vital do ambiente econômico rapidamente mutável de hoje. A movimentação para a interconectividade assim como o crescimento exponencial no tráfego dos dados, em conseqüência das aplicações novas de 
negócio, conduzirá à adoção do acesso óptico, pois esse tipo de acesso ajuda não só os usuários finais como também os fornecedores de serviço a se conectarem de forma cada vez mais rápida e eficiente às informações.

Por esses motivos, este trabalho busca a conceituar e apresentar as vantagens de termos hoje uma rede de acesso via fibra, o que é feito por intermédio de comparações com as demais redes de acesso existentes.

\section{1 - MOTIVAÇÃO}

A motivação surge do fato de acreditarmos ser o acesso via fibra a melhor solução para fornecer serviços de banda larga e serviços agregados, o que faz dessa uma evolução necessária.

Uma tecnologia é atraente quando pode substituir a rede existente assim como aumentar a viabilidade econômica de aplicações novas da rede. Os novos serviços de banda larga estão exigindo a substituição da tecnologia e aumentando a competitividade para que as operadoras os possam entregar com alta velocidade, no acesso local.

A demanda, a busca constante por melhorias tecnológicas e a regulação estão rompendo significativamente com o cenário das telecomunicações, apresentando fornecedores de serviço com tremendas oportunidades, assim como precipitando mudanças enormes na rede.

A infra-estrutura existente não manteve o ritmo do crescimento exponencial de tráfego da rede. As novas aplicações de negócio tais como o e-comércio, a videoconferência de alta qualidade, a tele-medicina, as transferências de grandes pacotes de dados, os espelhos de dados, carrier hotels, e o armazenamento de dados estão guiando a necessidade por serviços de banda cada vez mais larga. Novas espécies de fornecedores de serviço, tais como ISXs (Internet Service Exchanges), ASPs (Application Service Providers) e SSPs (Storage Service Providers) estão emergindo, experimentando um rápido crescimento em seus negócios e formando um mercado a parte.

$\mathrm{O}$ aumento rápido na demanda por largura de banda forçou também provedores a escolher rapidamente entre algumas tecnologias: DSL (Digital Subscriber Line), ATM 
(Asynchronous Transfer Mode) e SONET/SDH, IP (Internet Protocol) sobre uma rede óptica síncrona. Todas essas tecnologias provêm um acesso banda larga. Infelizmente, protocolos mal combinados se desenvolveram entre a empresa e os usuários. A complexidade e a redundância dos equipamentos requeridos e uma falta da integração com o legado complicam mais e mais, tendo por resultado a frustração do usuário e a incerteza em um scramble para suportar as demandas do acesso empregando uma mistura complexa das tecnologias. Os usuários finais e os novos provedores consideram que não há nenhuma alternativa à base de acesso via fibra e esforçam-se dentro dos limites finitos das facilidades de cobre para levar as LAN aos níveis de altíssima velocidade.

O rápido crescimento da rede está forçando os provedores a repensar sobre as plantas de negócio, custo-benefício e as estratégias de distribuição em cima das quais oferecerão produtos futuros aos usuários finais. O ato de telecomunicações de 1996, que abriu eficazmente estes mercados, deu início subitamente a uma nova competição, entre as empresas, pelo acesso. As dimensões do competidor tais como o custo, a qualidade do serviço (QoS), o reconfigurabilidade e a capacidade futura definem os aspectos da batalha por clientes.

Como a regulação abriu as portas para que novos provedores forneçam o serviço local, os modelos econômicos tradicionais estão, também, sendo afetados. $\mathrm{O}$ crescimento do rendimento dos serviços de voz é relativamente fácil e as margens estão caindo rápida e subitamente. Como continuar a fornecer serviços de voz é importante para o fluxo de dinheiro atual, os provedores devem se mover no sentido de fornecer serviços de dados com elevada margem, arquiteturas de multiserviços, e aplicações de valor agregado, a fim de atrair e reter clientes melhorando o custo benefício. Por outro lado, as necessidades dos usuários residem na capacidade do acesso de alta velocidade. Eles necessitam de novas extensões tecnológicas de rede, ou seja, protocolos, topologias e geografias independentes.

As plataformas de acesso ópticas são projetadas para ajudar aos novos fornecedores no rompimento com mercado de telecomunicações atual para seu próprio sucesso. A estrutura do mercado recompensa os produtos e as soluções que têm o poder inerente de empurrar redes ópticas além do domínio dos backbones, fornecendo o acesso via fibra para a ligação de alta performance, o que é crucial para os mais novos serviços em redes de dados. 
Esta nova era do acesso óptico controlado será marcada pelos fornecedores que conseguirem ganhar a vantagem fornecendo as arquiteturas de alta velocidade que elevem o desempenho da rede acima e além das exigências crescentes de tráfego de dados dos clientes.

Estas soluções novas de acesso óptico são projetadas para permitir que os fornecedores de serviço dirijam-se a estas oportunidades eficazmente. Os equipamentos novos podem construir uma ponte entre as arquiteturas de voz e de dados orientados com plataformas de banda larga e protocolos independentes. As novas características de alocação de banda permitem que os provedores suportem protocolos diferentes e possam otimizá-los para uma aplicação particular. Através da separação criada para transmitir protocolos individualmente, cada um em seu próprio comprimento de onda, as necessidades para tunneling ou para na conversão de protocolo são minimizadas. Com estas características novas, os provedores podem fornecer e aumentar largura de banda através de software, melhor do que com equipamentos de reestruturação física. Podem, até mesmo, permitir que os clientes controlem quanta banda adicionam ou removem de sua capacidade da rede.

\section{2 - METODOLOGIA E ORGANIZAÇÃO DO TEXTO}

No capítulo 2 segue uma breve conceituação de sistemas de comunicações ópticos. Em seguida, conceituam-se os elementos de uma rede óptica e as técnicas de multiplexação.

Após esse conceito inicial, segue uma descrição de vários tipos de redes ópticas, capítulo 3, a fim de levantar dados para a rede de acesso óptica que, por sua vez, é detalhada no capítulo 4.

Para fins de ilustrações práticas, o capítulo 5 segue com a apresentação de dois estudos de caso, bem como as considerações econômicas envolvidas, que embasarão as conclusões finais.

Para finalizar, o apêndice A apresenta uma breve conceituação de diferentes tecnologias de acesso, a título de comparação. No apêndice $\mathrm{B}$, tem-se um resumo explicativo sobre as tecnologias de transmissão citadas no texto, a título de complementação. 


\section{2 - FUNDAMENTOS DE UM SISTEMA DE COMUNICAÇÃO ÓPTICO}

\section{1 - INTRODUÇÃO}

Como característica geral, todo sistema de telecomunicações possui os seguintes elementos básicos que formam um canal de transmissão: transmissor, meio de transmissão e receptor. Um equipamento é denominado transceptor quando possui a capacidade de transmitir e receber mensagens.

Os sistemas de telecomunicações podem ser divididos em bidirecional e unidirecional: no sistema bidirecional, há necessidade de troca de informações entre receptor e transmissor, a exemplo de uma simples conversa entre duas pessoas; no sistema unidirecional, não há essa necessidade de troca, como na radiodifusão sonora ou de sons e imagens (televisão).

Os sistemas de telecomunicações também podem ser classificados da forma a seguir:

- Simplex: quando a transmissão é unidirecional no meio de transmissão

- Semi-Duplex: quando a transmissão é bidirecional, porém é executada alternadamente em cada sentido.

- Duplex: quando a transmissão é bidirecional e simultânea.

Um sinal, transmitido via fibra, pode ter sua qualidade de recepção deteriorada por dois principais fatores: interferências e atenuação. As interferências são causadas por outros sinais, os ruídos, que podem deformar o original e torná-lo incompreensível. Para solucionar esse problema, pode-se aumentar a sensibilidade do receptor ou aumentar a intensidade do sinal (aumentar a relação sinal-ruído). A atenuação é devido ao aumento da distância entre transmissor e receptor, sendo a capacidade de recuperar a informação inversamente proporcional à distância.

Para resolver o problema da distância, utilizam-se transprovedores de informação, a chamada portadora. A informação passa a ser traduzida em símbolos que são mais facilmente transportados (codificação). Após o estabelecimento do código a ser utilizado, a informação é então colocada na portadora por intermédio do modulador e, após percorrer o caminho por um 
meio de transmissão, alcança o receptor. A mensagem recebida precisa ser decodificada para que se recuperem os símbolos da portadora, o que é conseguido por meio do demodulador.

Se, mesmo com toda a técnica descrita, a distância for tão grande que a deterioração ainda ocorra, pode-se instalar estações repetidoras, e a distância entre o transmissor e a repetidora é chamada de enlace. Essas estações, apesar de viabilizarem a transmissão da informação, geram algumas desvantagens, a maior delas sendo a demora na transmissão.

Quando se trabalha com sinais elétricos, pode-se dar o mesmo tratamento à voz, dados e imagens, o que permite padronizar, quantificar, transportar, agrupar e distribuir a informação de maneira muito mais rápida e eficiente.

Um sistema de telecomunicação baseado em sinais elétricos pode ser representado pelo diagrama de blocos da figura 2.1:

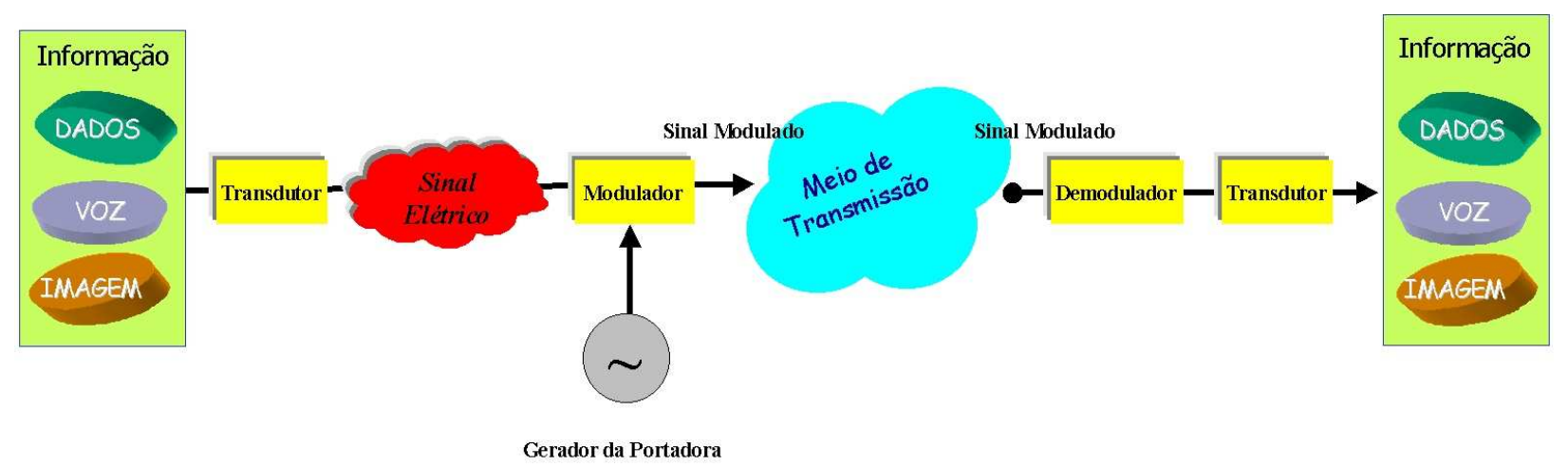

Figura 2.1 Sistema de comunicações elétrica.

Para que haja a troca de dados entre usuários, é criada uma rede de comunicação, que é composta por elementos que farão essa conexão. Há vários meios desses usuários se conectarem, como fibra óptica, par trançado, microondas e tecnologias sem fio. No Apêndice A, são abordados os meios de acesso usando cobre e via rádio. A figura 2.2 ilustra uma visão de uma rede de comunicação.As principais tecnologias de transporte usadas nas redes de comunicação são apresentadas no Apêndice B. 


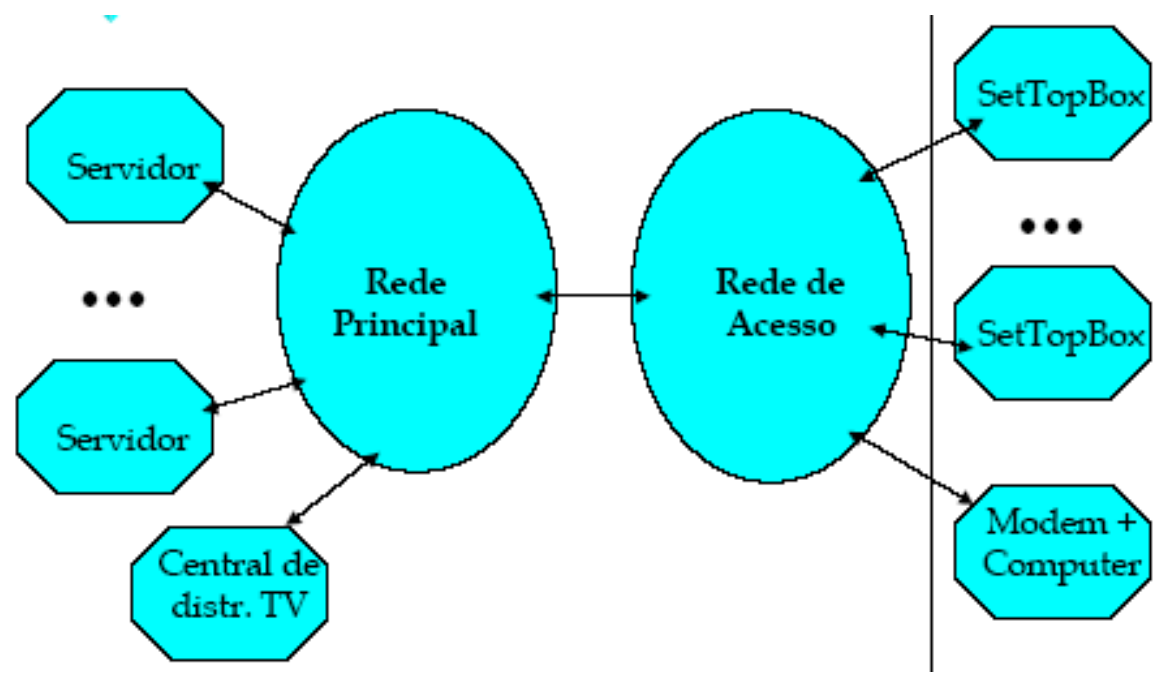

Figura 2.2 Elementos constituintes de uma rede de comunicação.

A enorme capacidade de transmissão dos sistemas ópticos é uma das principais características desses sistemas e também um dos principais motivos de sua utilização e estudo.

As redes ópticas podem utilizar tanto a fibra óptica quanto o ar como meio de transmissão. $\mathrm{O}$ foco desse estudo são as redes com fibra óptica.

As redes de telecomunicações, que até recentemente utilizavam principalmente pares de fios de cobre ou cabos coaxiais, estão mudando para a utilização de fibras ópticas para transmissão. Os tipos de redes ópticas utilizadas em telecomunicações são:

- Acesso: utilizada para usuários que necessitam de banda larga.

- Local (LAN): pequenas redes, no mesmo local, seja ele uma residência, um escritório, etc.

- Metropolitanas (MAN): redes utilizadas em uma metrópole.

- Estaduais: redes de longa distância dentro de um estado.

- Nacionais: redes de longa distância dentro de um país.

- Internacionais: redes de ultralonga distância, que interligam continentes, geralmente usando cabos ópticos submarinos. 


\section{2 - ELEMENTOS DE UMA REDE ÓPTICA}

Um sistema de comunicações óptico é constituído de alguns elementos básicos, Figura 2.3, que serão comentados a seguir:

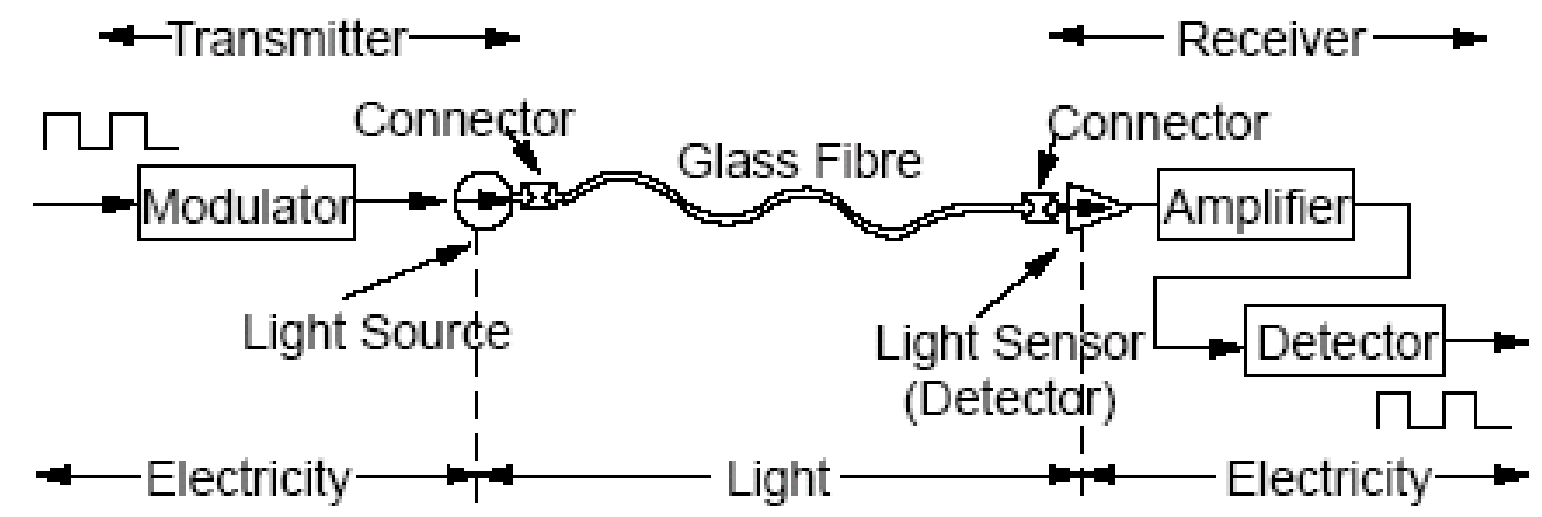

Figura 2.3 Elementos básicos de uma rede óptica.

\subsection{1 - Fibra}

A fibra óptica foi inventada pelo físico indiano Narinder Singh Kanpany, é constituída por um filamento composto de material dielétrico, geralmente plástico ou sílica, com a capacidade de transmitir luz através de sua longa estrutura cilíndrica, transparente e flexível. A fibra tem dimensões variáveis, dependendo da aplicação, mas sempre comparáveis às de um fio de cabelo e apresenta imunidade a interferências eletromagnéticas. [11]

As fibras são utilizadas como meio de transmissão de ondas eletromagnéticas utilizando-se como princípio fundamental, independentemente do material usado ou da aplicação, o fenômeno físico denominado reflexão total da luz. Para tanto, é lançado um feixe de luz em uma extremidade da fibra e, pelas características ópticas do meio, esse feixe percorre a fibra através de consecutivas reflexões. Para reflexão total, a luz deve sair de um meio mais refringente para um meio menos refringente com um ângulo de incidência igual ou maior que o ângulo limite. Esse meio de transmissão é denominado de "guiado". 
A fibra é composta de uma região central chamada de núcleo e uma região periférica denominada de casca. O índice de refração do material do primeiro é maior que o índice do segundo para que seja garantida reflexão total.

A seção em corte transversal mais usual do núcleo é a circular, porém fibras ópticas especiais podem ter um outro tipo de seção (por exemplo, elíptica), figura 2.4.

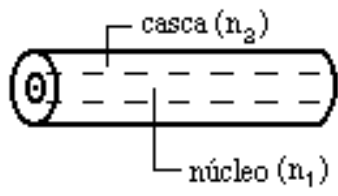

a) estrutura cilindrica

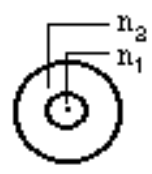

b) seçäo trarswersal

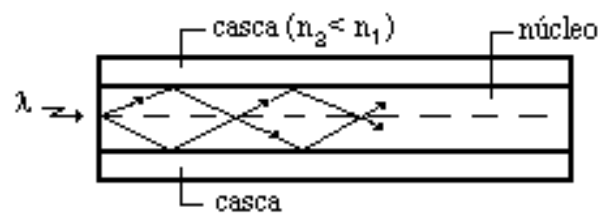

c) corte longitudiral

Figura 2.4 Estrutura da fibra óptica.

A capacidade de transmissão (banda passante) de uma fibra óptica é função do seu comprimento, da sua geometria e do seu perfil de índices de refração. Podem ser definidas duas categorias de fibras dependendo da forma como a luz se propaga no interior de cada núcleo: Multimodais e Monomodais.

As Fibras Multimodais são aquelas onde o diâmetro do núcleo permite que a luz tenha vários modos de propagação. Essas fibras podem também ser classificadas em Índice Gradual ou Degrau dependendo da variação do índice de refração entre o núcleo e a casca.

As Fibras Monomodais requerem conectores de maior precisão e dispositivos de alto custo por isso são mais adequadas para aplicações que envolvam grandes distâncias. O núcleo é feito tão pequeno quanto necessário para que haja apenas um modo de propagação da luz. Também podem ser classificadas quanto ao índice de refração do núcleo em relação à casca: Índice Degrau Standard, Dispersão Deslocada (Dispersion Shifed) ou Non-Zero Dispersion.

Abaixo encontra-se o resumo da vantagens da fibra: 
- A fibra, por ser composta de material dielétrico, é imune a interferências eletromagnéticas, podendo ser utilizada em ambientes nos quais outros tipos de condutores não poderiam ser utilizados;

- Não existe nenhuma possibilidade de ocorrência de incêndios devido ao rompimento de uma fibra, já que somente há luz em seu interior;

- Alto grau de segurança para a informação transportada, pois as fibras não irradiam significativamente a luz propagada;

- Pequeno tamanho e peso, sendo mais facilmente manuseados e instalados. Esse fato também contribui para diminuir o problema de espaço e de congestionamento de dutos nos subsolos das grandes cidades e em grandes edifícios comerciais.

- As fibras ópticas apresentam atualmente perdas de transmissão extremamente baixas. Desse modo, com fibras ópticas, é possível implantar sistemas de transmissão de longa distância com um espaçamento muito grande entre repetidores, o que reduz significativamente a complexidade e custos do sistema.

- A produção de fibras ópticas em larga escala tende a tornar o custo da fibra mais baixo do que outros materiais, como o cobre.

A fibra óptica, como qualquer outro meio, não possui apenas vantagens. Seguem algumas das desvantagens:

- As fibras quando não estão protegidas por encapsulamento são bastante frágeis, quebrando com facilidade;

- Devido ao fato da fibra ter dimensões pequenas, sua instalação é bastante dificultada e, se for feita de forma incorreta, pode causar uma grande atenuação ou até mesmo o bloqueio da transmissão;

- Não há padrões definidos para conectores, interfaces, dispositivos.

- Os sistemas com fibras ópticas requerem alimentação elétrica independente para cada repetidor, não sendo possível a alimentação remota através do próprio meio de transmissão. 
O espalhamento Rayleigh, que é o espalhamento provocado devido a nãohomogeneidades no silício e de natureza aleatória, é a principal causa de atenuação na fibra. Outras causas de atenuação na fibra são:

- Absorção devido a impurezas na fibra, que absorvem parte da energia óptica e a dissipa em forma de calor - esse tipo de atenuação é desprezível, devido às técnicas de purificação do vidro.

- Deformações mecânicas, que provocam a absorção da luz na casca protetora da fibra;

- Perdas por reflexão, que ocorrem na entrada e saída da luz da fibra;

Na fibra há também o fenômeno da dispersão, quando há atrasos relativos na propagação dos modos e componentes espectrais que transportam a energia luminosa. A dispersão é percebida através do alargamento do pulso no sinal digital e na diminuição da variação do sinal no caso analógico.

As fibras ópticas são geralmente encapsuladas pelo cabo óptico para que haja melhor resistência à instalação, manuseio, impacto, esmagamento e vibrações, para que a fibra possua melhor estabilidade das características numa grande faixa de temperatura e também para prevenir as curvaturas que possam causar atenuação.

Deve-se ter cuidado especial com as emendas na fibra, para que a atenuação seja baixa. Existem três tipos de emendas ópticas:

- Emenda por Fusão: as fibras são fundidas entre si;

- Emenda Mecânica: as fibras são unidas por meios mecânicos;

- Emenda por Conectorização: são aplicados conectores ópticos, nas fibras envolvidas na emenda.

As emendas ópticas, sejam por fusão ou mecânicas, apresentam uma atenuação muito menor que um conector óptico. 


\subsection{2 - Transmissor Óptico}

O transmissor óptico é composto por um dispositivo emissor de luz, um modulador e um acoplador. O dispositivo emissor de luz, elemento ativo básico do sistema, é o responsável pela tarefa de conversão eletro-óptica dos sinais. A capacidade de transmissão (assim como a potência emitida por um transmissor óptico) é função do tipo de dispositivo emissor de luz utilizado, sendo os com LASERS (Light Amplification by Estimulated Emission of Radiation) geralmente superiores aos com LED's (Light Emitting Diode), a custo de uma maior complexidade do transmissor.

Inicialmente, nos sistemas ópticos, foram utilizados como fonte de luz LEDs que operavam entorno de $850 \mathrm{~nm}$. Quando surgiram os LASERS, além deste comprimento de onda, começou-se a utilizar comprimentos de onda por volta de $1310 \mathrm{~nm}$ e, posteriormente $1550 \mathrm{~nm}$. As faixas em torno dos comprimentos de onda de 850, 1300 e de $1500 \mathrm{~nm}$ são denominadas de janelas de transmissão. Essas janelas de transmissão são utilizadas por possuírem baixas perdas devido ao espalhamento Rayleigh.

O modulador é responsável por inserir a informação a ser transmitida na portadora óptica e o acoplador é o dispositivo responsável por inserir a luz na fibra óptica.

\subsection{3 - Receptor Óptico}

O receptor óptico compõe-se de um dispositivo fotodetector, de um estágio de amplificação e filtragem, de um acoplador e de um demodulador. O dispositivo que converte o sinal luminoso em sinal elétrico é outro elemento ativo básico do sistema, o fotodetector. Geralmente são utilizados os diodos PIN e os fotodiodos avalanche (APD). O demodulador é o responsável por retirar a informação. A qualidade de um receptor óptico é medida pela sua sensibilidade, que especifica a potência luminosa mínima necessária para determinado desempenho em termos de relação sinal- ruído $(\mathrm{S} / \mathrm{N})$ ou de taxa de erros de transmissão.

Além das fontes convencionais de ruído, associadas aos estágios eletrônicos, afetam o desempenho dos receptores ópticos as fontes de ruído características do processo de conversão opto-eletrônica. De um modo geral, os receptores ópticos com fotodiodos de avalanche, mais complexos, apresentam desempenho superior aos com fotodiodos PIN. 


\section{3 - TÉCNICAS DE MULTIPLEXAÇÃO}

O grande e constante aumento na demanda por largura de banda e o fato de que lançar novas fibras tem um custo muito elevado implicam que se devem encontrar formas de aumentar a capacidade das fibras já instaladas. Existem duas maneiras fundamentais de se aumentar a capacidade de uma fibra. A primeira é aumentar a taxa de bits o que requer equipamentos eletrônicos de alta velocidade, mas muitos dados podem ser multiplexados em uma seqüência de bits de alta velocidade por meio da técnica TDM (Time Division Multiplexing). A outra maneira de aumentar a capacidade do sistema é usando a técnica WDM (Wavelength Division Multiplexing).

\subsection{1 - TDM}

TDM é uma técnica que divide a largura de banda total do enlace em vários canais para permitir o transporte simultâneo de vários sinais. A distribuição da banda por esses canais é

feita pela atribuição de um intervalo de tempo, denominado de Time-Slot, fixo para cada um. É utilizado apenas com sinais binários provenientes de modulação por código de pulso (PCM), sem se importar se a origem do sinal é analógica ou digital.

Uma das escolhas chave no TDM é o modo de transferência que será utilizado. A transferência síncrona é uma modalidade em que os sinais dos dados são emitidos em intervalos precisos que são regulados pelo clock do sistema (mostrado na figura 2.5), ou seja, todos os slots de tempo são de igual tamanho. Não são requeridos pulsos adicionais de começo ou de final. O Asynchronous Transfer Mode (ATM) é um protocolo orientado a conexão que pode distribuir e comutar o tráfego em velocidades mais elevadas. Um TDM também pode ser síncrono e assíncrono ao mesmo tempo. 


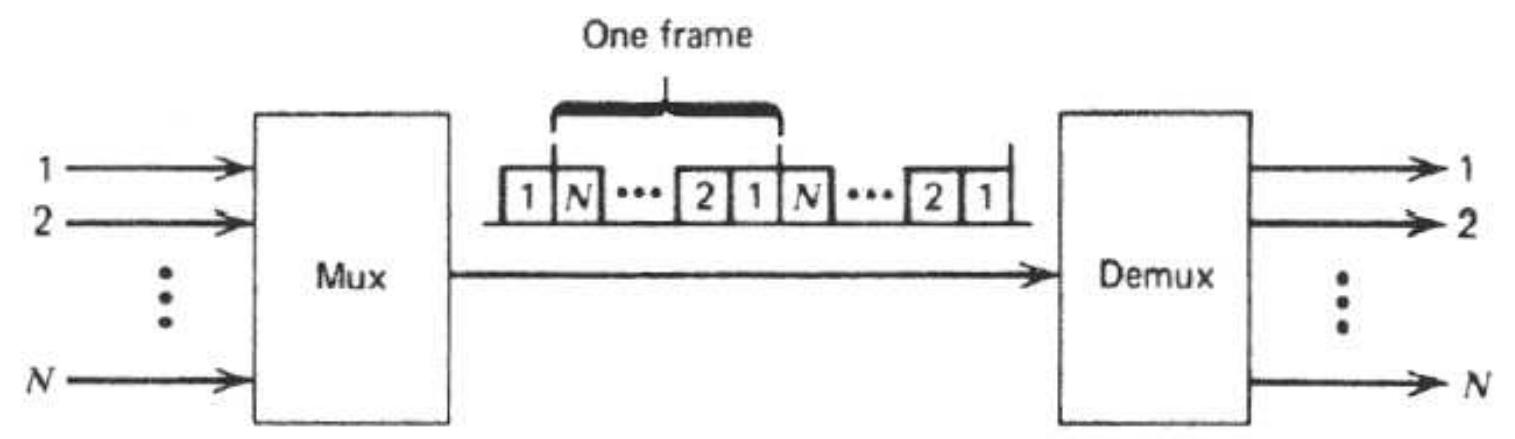

Figura 2.5 Sistema de multiplexação TDM síncrono.

A associação de intervalos é obtida quando cada canal origina a informação de entrada do multiplexador o que é armazenado em um buffer de memória denominado bloco de sincronismo. As funções do multiplexador, como a amostragem de cada canal de entrada a taxas com velocidades compatíveis às requeridas pelo sistema, devem então ser realizadas. Nesta taxa o circuito multiplexador pode amostrar o primeiro bit de informação dos canais 1 a $\mathrm{N}$ (último canal) e adicionar um overhead de informação de volta ao primeiro canal, antes que o próximo bit de informação do canal 1 entre. Este multiplexador pode aceitar um ou mais bits binários de cada canal ao mesmo tempo e gerar, depois, vários pulsos que compensam a transmissão do sinal. O bit de overhead é utilizado para que o demultiplexador, no lado do receptor, possa identificar os canais, que são separados e reconstruídos.

Uma das vantagens do TDM em relação ao FDM é que esse se torna mais eficiente a partir da não utilização de banda de guarda, porém, alguma ineficiência pode ser gerada pois um pequeno número de bits é adicionado ao conjunto de pulsos transmitido, para prover ao multiplexador e demultiplexador sincronismo e detecção de erro, bem como alguns poucos bits extras para gerenciamento em sistemas de comunicação em redes. Um outro aspecto desvantajoso para o TDM é o custo da codificação digital PCM.

Nos circuitos de redes comutadas tais como a rede de telefone comutada pública (PSTN), existe a necessidade transmitir chamadas de múltiplos assinantes ao longo do mesmo meio da transmissão. Para tanto, empregam-se TDM, pois esse permite que os interruptores criem canais dentro do meio de transmissão. Um sinal de voz padrão tem uma largura de faixa de 64 kbit/s, determinado pelo critério da amostragem de Nyquist. TDM captura frames dos sinais de voz e multiplexa eles em um frame de TDM que funcione com uma largura de banda mais elevada. Cada frame de voz dentro de um frame de TDM é chamado de canal. Em 
sistemas europeus, os frames de TDM contêm 30 frames digitais da voz e, em sistemas americanos, os frames de TDM contêm 24 frames digitais da voz. Ambos os padrões contêm também o espaço extra para sinalização e dados de sincronização.

Há três escolhas de cabos para os multiplexadores TDM. A fibra monomodo permite que somente um modo se propague. A fibra tem um diâmetro de núcleo muito pequeno (aproximadamente $8 \mu \mathrm{m}$ ) e permite a transmissão do sinal em larguras de faixa extremamente elevadas e transmissão a longas distâncias. A fibra multimodo suporta a propagação de múltiplos modos e tem um diâmetro de núcleo típico de 50 a $100 \mu \mathrm{m}$ o que permite o uso de fontes de luz baratas como o LED (diodo emissor de luz). O alinhamento e o acoplamento do conector são menos críticos do que com fibra monomodo. As distâncias de transmissão e a largura de banda também são menores do que com a fibra monomodo devido à dispersão.

\subsection{2 - FDM}

Em 1930 as companhias de telefone começaram a combinar sinais de voz analógicos sobre uma linha usando FDM. Durantes os anos 60, FDM foi substituído por métodos digitais utilizando-se TDM. Companhias de TV a cabo também utilizaram o FDM para transmitir vários canais sobre o mesmo fio.

Em um sistema FDM (Frequency Division Multiplexing) pode-se transmitir múltiplos sinais simultaneamente sobre um único caminho de transmissão. Cada canal de informação é associado a uma única freqüência portadora com fase ou amplitudes diferentes, sendo depois multiplexados em um único canal de transmissão através de uma matriz de resistores, depois amplificado.

O sinal resultante é composto por vários outros sinais com portadoras discretas, também chamadas de canais intermediários, que são separadas no receptor por filtros e demoduladores, cada um sintonizado em uma freqüência de portadora específica.

As figuras 2.6 e 2.7 mostram como a divisão da frequiência é feita no caso em que três fontes estão se comunicando com três usuários. Note que cada transmissor modula a informação da sua fonte dentro de um sinal que está em uma sub-banda de freqüência diferente. Os sinais são então transmitidos dentro de um canal comum. 


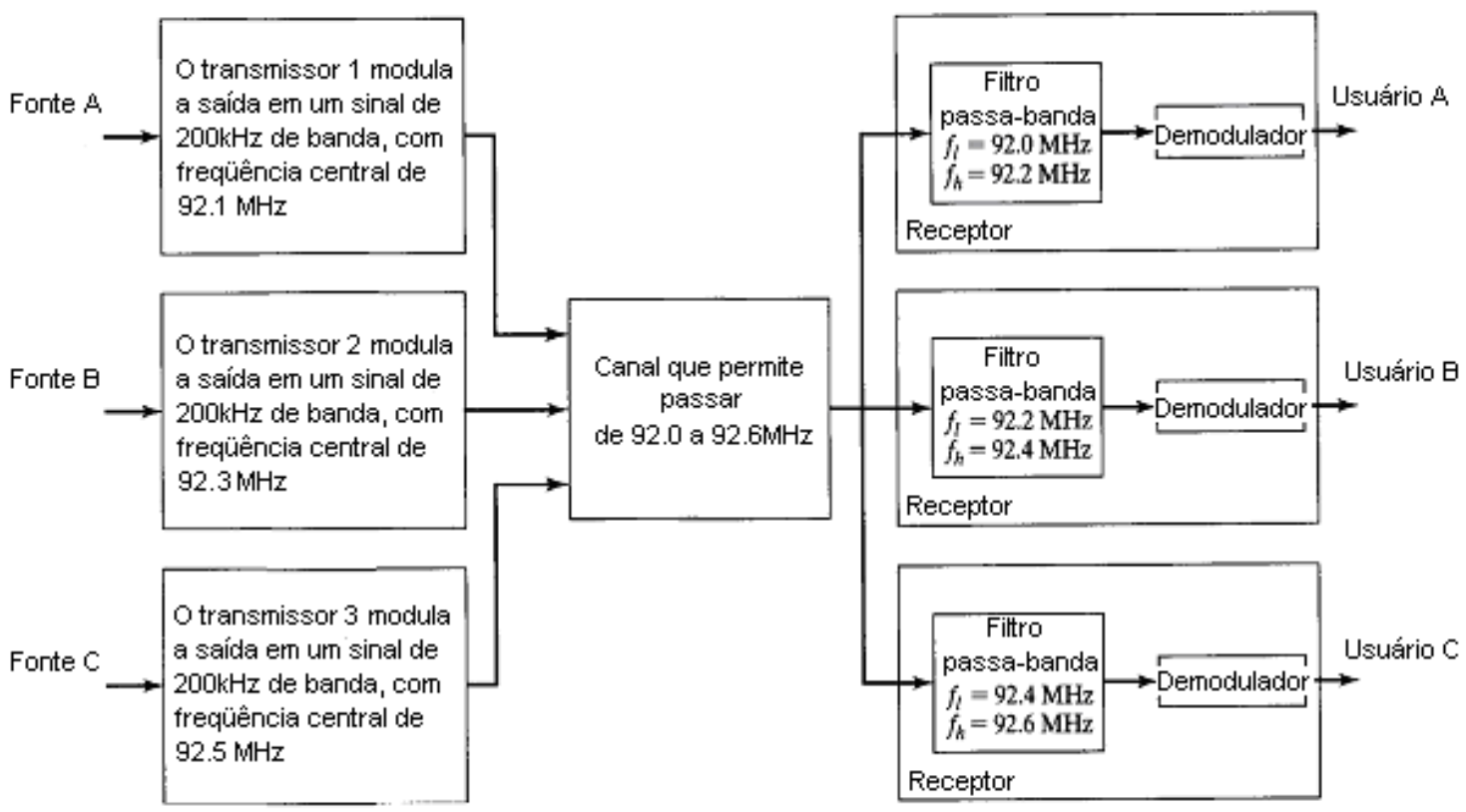

Figura 2.6 Sistema que utiliza FDM.

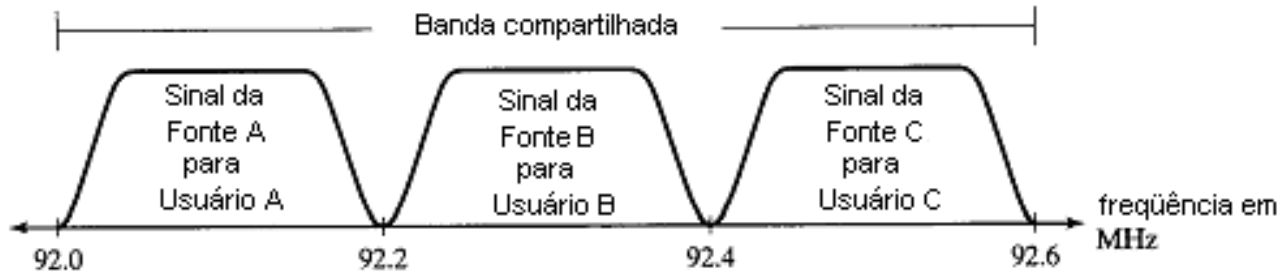

Figura 2.7 Espectro ocupado por sinais em um sistema FDM.

O FDM tem vantagens e desvantagens quando comparado com o TDM. A principal vantagem é que, ao contrário do TDM, o FDM não é sensível a atrasos de propagação. As técnicas de equalização necessárias para o FDM não são tão complexas quanto aquelas necessárias no TDM. Algumas desvantagens incluem a necessidade de um filtro passa-banda o que é relativamente caro e de projeto e construção complicados. Por outro lado, o TDM utiliza circuitos lógicos mais simples e baratos. Outra desvantagem é que em muitos sistemas de comunicações o amplificador do transmissor possui características não-lineares e amplificações não-lineares conduz ao surgimento de componentes espectrais que podem 
interferir em outros canais de FDM. Assim, se faz necessário a utilização de amplificadores lineares mais complexos. Logo, no caso de sistemas ópticos, que possuem fontes não-lineares, o FDM não é muito utilizado.

\subsection{3 - WDM}

WDM (Wavelength Division Multiplexing) é uma técnica de modulação onde múltiplos sinais são carregados juntos por um sinal multiplexado de acordo com a separação por comprimento de onda (cor) da luz, figura 2.8. Os canais do WDM são separados por comprimento de onda para evitar ligação cruzada quando são multiplexados por uma fibra óptica não-linear. Os comprimentos de onda podem ser individualmente distribuídos através de uma rede ou individualmente recuperados por componentes seletivos de comprimento de onda.

O WDM e o FDM são baseados nos mesmos princípios com a diferença que o WDM se aplicada aos comprimentos de onda na fibra óptica e o FDM se aplica na transmissão elétrica analógica. O sistema óptico do WDM é completamente passivo e confiável diferentemente do FDM que é elétrico (ativo).

O WDM permite que se utilize uma ampla largura de banda da fibra, embora vários dispositivos, sistemas e incrementos da rede limitem a utilização da banda completa da fibra.

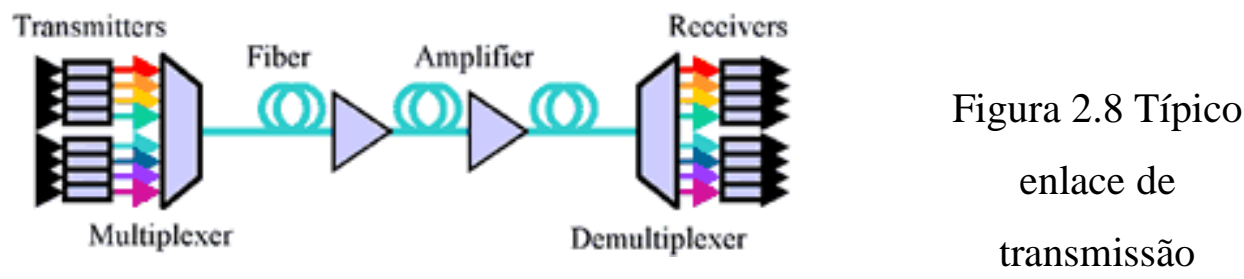

WDM.

O roteamento e a detecção dos diferentes sinais podem ser realizados independentemente, com o comprimento de onda que determina o trajeto de comunicação agindo como o endereço da assinatura da origem, do destino ou da distribuição. Os componentes requeridos são conseqüentemente, seletivo em comprimentos de onda, reservando para a transmissão, a recuperação, ou a distribuição de comprimentos de onda específicos. 
Em um sistema WDM simples, figura 2.9, cada laser deve emitir luz em um comprimento de onda diferente, luz essa multiplexada junto em uma única fibra óptica. Após serem transmitidos através de uma fibra óptica de elevada largura de banda, os sinais ópticos combinados devem ser demultiplexados na extremidade de recepção distribuindo o sinal óptico total a cada ponto de saída e, então, requerendo que cada receptor recupere seletivamente somente um comprimento de onda usando um filtro óptico ajustável.

Cada laser é modulado em uma dada velocidade, e a capacidade agregada total que está sendo transmitida ao longo da fibra é o total da soma das taxas de bits dos lasers individuais. Um exemplo do aumento da capacidade do sistema é a situação em que dez sinais de 2,5 Gbps podem ser transmitidos em uma fibra, produzindo uma capacidade do sistema de 25 Gbps. Este paralelismo no comprimento de onda acaba com o problema dos dispositivos óptico-eletrônicos típicos, que não têm larguras de banda que excedam alguns poucos gigahertz, a menos que sejam complexos e caros. As exigências da velocidade para os componentes óptico-eletrônicos individuais são, conseqüentemente, deixadas de lado, mesmo que uma quantidade significativa de largura de faixa total da fibra esteja sendo utilizada.

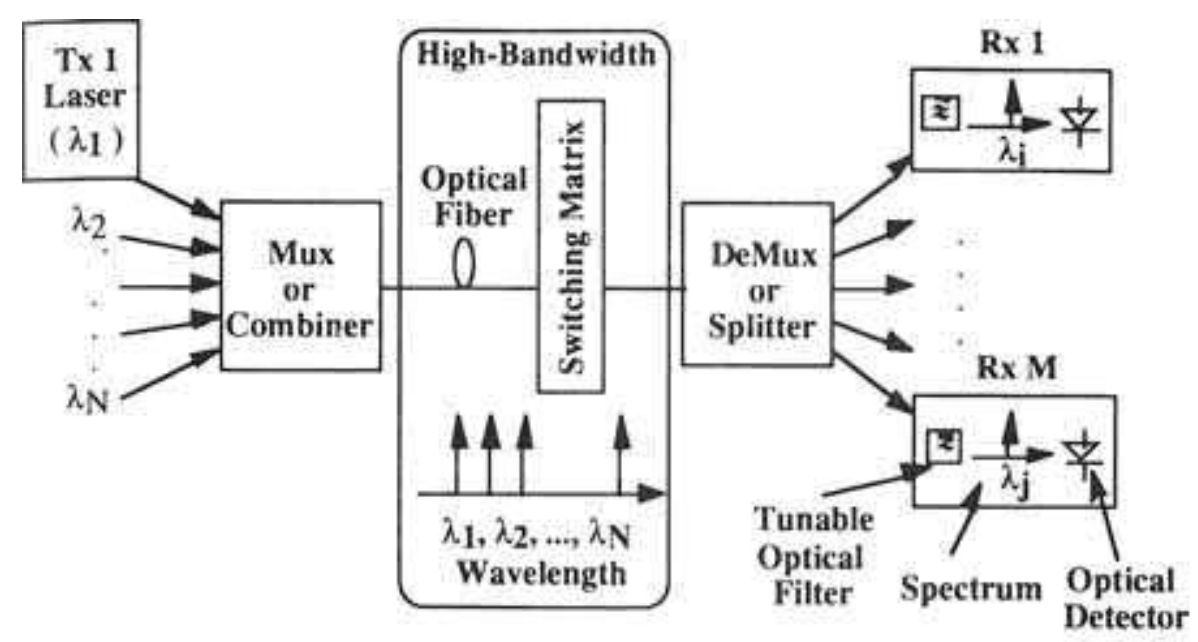

Figura 2.9 Diagrama de um sistema WDM simples.

O conceito de demultiplexação de um comprimento de onda usando um filtro óptico é ilustrado na figura 2.10. A figura mostra quatro canais de entrada (input) de um filtro óptico que tem uma função não-ideal de transmissão. O pico da transmissão do filtro é centrado no canal desejado, neste caso,..desse modo transmite esse canal e bloqueia todos os outros 
restantes. Por causa da função de transmissão não-ideal do filtro, alguma energia óptica da vizinhança do canal escapa através do filtro, e pode causar interferência inter canal ou linha cruzada (cross-talk). Este cross-talk tem o efeito de reduzir a razão de contraste do sinal selecionado, mas pode ser minimizado aumentando a separação espectral entre os canais.

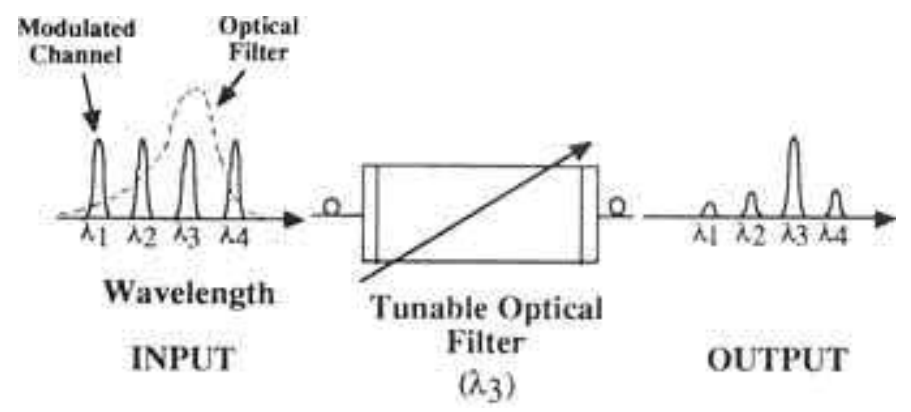

Figura 2.10 Canais WDM sendo demultiplexados por um filtro óptico.

Os sistemas WDM são divididos em dois segmentos: dense and coarse WDM. Sistema com mais de oito comprimentos de onda por fibra são geralmente considerados como Dense WDM (DWDM), enquanto aqueles que possuem menos de oito comprimentos de onda por fibra são classificados em Coarse WDM (CWDM). As tecnologias CWDM e DWDM são baseadas no mesmo conceito de utilizar múltiplos comprimentos de ondas de luz em uma mesma fibra, mas as duas tecnologia diferem quanto a distância entre dois comprimentos de onda diferentes, número de canais e na habilidade de amplificar sinais no espaço óptico.

\subsubsection{1 - DWDM}

O DWDM (Dense Wavelength Division Multiplexing) normalmente se refere aos sinais ópticos multiplexados dentro da faixa de $1550 \mathrm{~nm}$ para que, dessa forma, se aumente as potencialidades (e diminua o custo) dos EDFAs (Erbium Doped Fiber Amplifiers) que são eficazes para comprimentos de ondas entre $1530 \mathrm{~nm}$ e $1560 \mathrm{~nm}$. Os EDFAs foram originalmente desenvolvidos para substituir os regeneradores OEO (óptico-elétrico-óptico) do $\mathrm{SDH}$, que se tornaram praticamente obsoleto. Esses EDFAs podem amplificar todo sinal óptico dentro de sua faixa de operação até mesmo a taxa de bit modulada. Em se tratando de sinais com vários comprimentos de onda, como o EDFA tem energia suficiente disponível, ele 
consegue amplificar qualquer sinal óptico que foi multiplexado na sua banda de amplificação (embora a densidade de sinal seja limitada pela escolha do formato de amplificação). Então, os EDFAs permitem que uma ligação óptica de canal único seja transformada em uma taxa de bit substituindo apenas os equipamentos no final da ligação e retendo o EDFA existente, ou uma série deles, ao longo da rota de transporte. Além disso, ligações ópticas que possuem um único comprimento de onda usando EDFAs podem, similarmente serem transformadas em uma ligação WDM com um custo relativamente baixo. O custos desses EDFAs é compensado pelo número de canais pois, esse número é igual ao número de canais que ele pode multiplexar dentro da faixa de $1500 \mathrm{~nm}$.

\subsubsection{2 - CWDM}

O desenvolvimento do CWDM (Coarse Wavelength Division Multiplexing), uma tecnologia intermediária, respondeu à demanda crescente da rede de fibra óptica. Com uma capacidade menor que o DWDM, CWDM permite que um número modesto de canais, tipicamente oito ou menos, seja empilhado na região de $1550 \mathrm{~nm}$ da fibra chamada de faixa $\mathrm{C}$. Para reduzir dramaticamente o custo, CWDM utiliza lasers com uma ampla tolerância de \pm 3 nm. Os sistemas DWDM utilizam canais espaçados perto de 0,4 nm, o CWDM utiliza um espaçamento de $20 \mathrm{~nm}$. O amplo espaçamento acomoda as variações dos comprimentos de onda do laser, que ocorrem enquanto a temperatura ambiental varia. As variações do laser sobre a transmissão são de $\pm 0,06 \mathrm{~nm} /{ }^{\circ} \mathrm{C}$. A transmissão $\mathrm{CWDM}$ pode ocorrer em um de oito comprimentos de onda: tipicamente $1470 \mathrm{~nm}, 1490 \mathrm{~nm}, 1510 \mathrm{~nm}, 1530 \mathrm{~nm}, 1550 \mathrm{~nm}, 1570$ $\mathrm{nm}, 1590 \mathrm{~nm}, \mathrm{~nm}$ 1610. A figura 2.11 ilustra a banda passante do CWDM para um dispositivo de oito canais. 


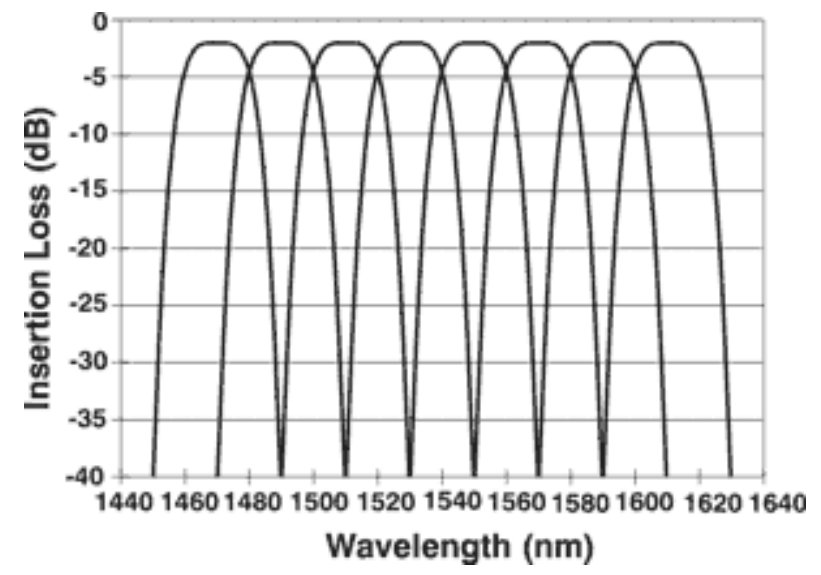

Figure 2.11 Banda passante do CWDM para um dispositivo de 8 canais.

A perda de inserção para um dispositivo de oito canais é aproximadamente $2 \mathrm{~dB}$ por extremidade. A largura da banda passante é em torno de $13 \mathrm{~nm}$ no ponto de perda de $-0,5 \mathrm{~dB}$. Os demultiplexadores de CWDM têm, tipicamente, uma perda de inserção mais elevada e a perda de isolação significativamente melhor. Os multiplexadores têm uma perda de inserção mais baixa e uma perda de isolação mais pobre. A isolação não importa em uma aplicação unidirecional porque o multiplexador combina diversas saídas do transmissor. A figura 2.12 ilustra uma aplicação unidirecional de CWDM.

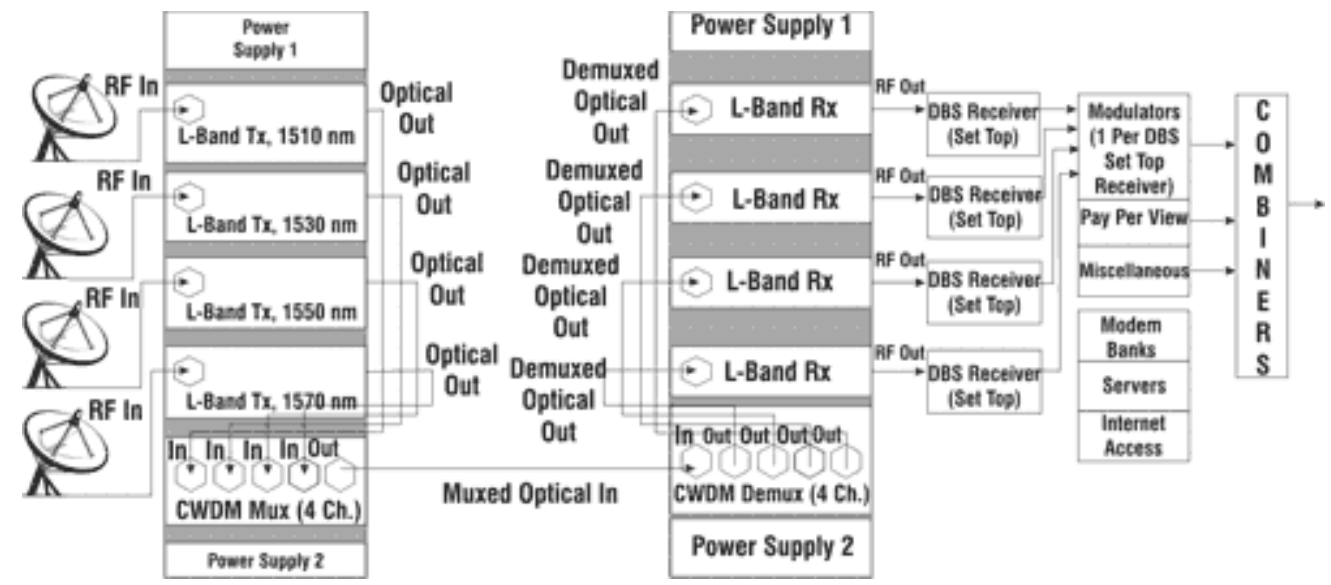

Figura 2.12 Aplicação unidirecional de CWDM.

Em uma aplicação bidirecional, ilustrada na figura 2.13, qualquer entrada em qualquer extremidade da fibra pode ser uma entrada ou uma saída, requerindo alta isolação do demultiplexador para garantir que o sistema irá trabalhar sem interferência entre os canais. 


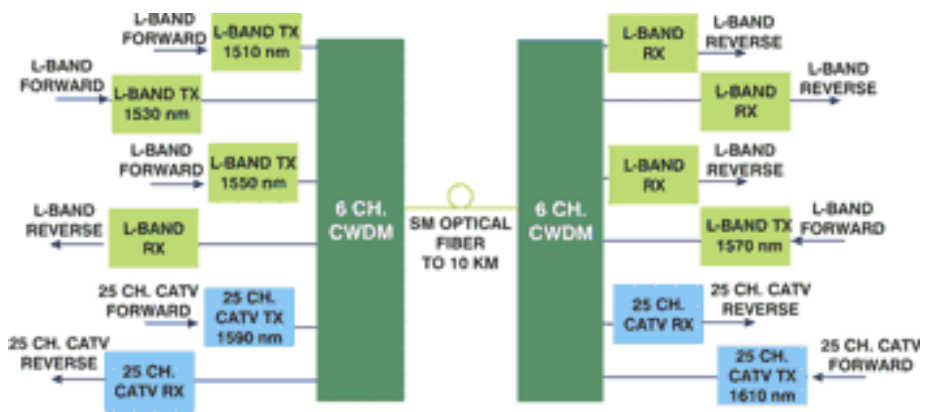

Figure 2.13 Aplicação biderecional do CWDM. 


\section{3 - TIPOS DE REDES ÓPTICAS:}

\section{1 - REDE ÓPTICA PASSIVA}

Uma rede PON (Passive Optical Network) apresenta topologia ponto-multiponto. É formada por equipamentos OLT (Optical Line Terminal), localizados nas bordas dos anéis ópticos das redes de transporte SDH, e também por equipamentos ONU (Optical Network Units) ou ONT (Optical Network Terminal), figura 3.1.

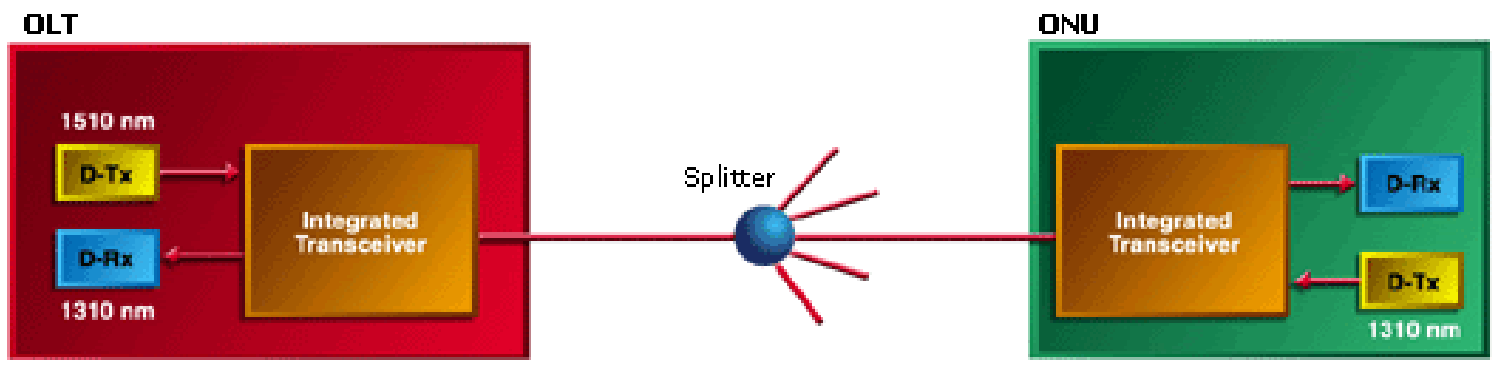

Figura 3.1 Estrutura básica de uma rede PON.

O OLT é o equipamento que viabiliza os serviços para o usuário, controla a qualidade do serviço (Qos) e o SLA (Service-level Agreement). SLA é um contrato informal entre um provedor e um cliente em que são definidos os termos de responsabilidade do portador ao cliente e o tipo e de extensão da remuneração se aquelas responsabilidades não forem cumpridas. O OLT também realiza a multiplexação dos diferentes usuários. A alocação de banda, que antigamente era realizada de forma semelhante ao TDM, atualmente ocorre de forma dinâmica e a reutilização da banda considera os perfis de tráfego, as políticas de QoS e SLAs, figura 3.2. 


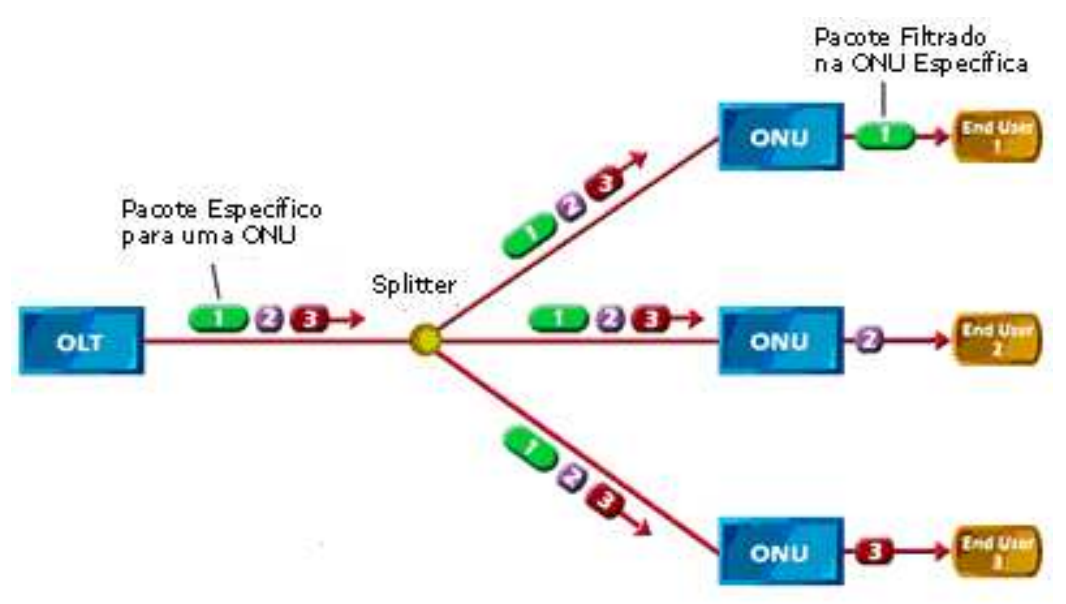

Figura 3.2 Funções do OLT.

O ONU é um equipamento utilizado para converter o sinal óptico em sinal elétrico, que será encaminhado para as portas padrões dos equipamentos de aplicação do usuário final, como: ATM, Ethernet, IP etc, Figura 3.3:

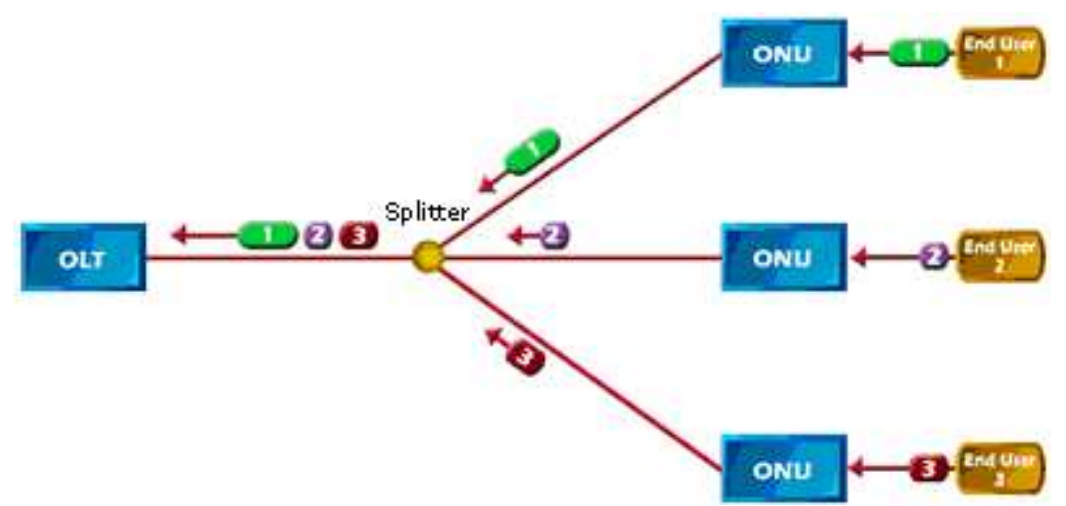

Figura 3.3 Funções do ONU.

O sinal óptico de uma fibra é enviado para um ou mais divisores passivos, denominados splitters, e retransmitida para vários equipamentos ONU's. Cada ONU irá então receber e transmitir sinais em um canal próprio com a banda dinamicamente alocada e QoS e SLAs individuais. Os sinais transmitido e recebido operam com comprimentos de onda diferentes, permitindo, dessa forma, que a operação ocorra sobre uma única fibra. A OLT irá avaliar esses QoS e SLAs e a disponibilidade do segmento PON que ele opera. Após isso, a alocação dinâmica é aplicada. Esse processo pode prover banda entre $1 \mathrm{Mbps}$ e $10 \mathrm{Gbps}$ aos usuários. 
Algumas vantagens da tecnologia PON são apresentadas a seguir.

- Baixo custo: por não existir elementos ativos ocorre economia de energia, de espaço entre os sites e de manutenção;

- É feita por compartilhamento da capacidade da fibra óptica;

- Tem grande ganho de escala no atendimento à demanda dos usuários;

- Flexibilidade e otimização do uso da fibra que é conseguido pela alocação dinâmica da banda;

- Diversificação dos serviços;

- Viabilidade de criação de uma maior variedade de portifólio que faz o balanceamento das várias opções ofertadas.

A PON trabalha, basicamente, em duas formas diferentes: upstream e downstream. Considera-se upstream todos os pacotes que se originam no cliente e se dirigem à operadora e downstream todos os pacotes que se originam na rede e se dirigem para o cliente. Quando o splitter faz upstream, a distribuição pode ser feita usando-se vários métodos, como TDMA (Time Division Multiple Access), WDMA (Wave Division Multiple Access), CDMA (Code Division Multiple Access) ou SCMA (Subcarrier Multiple Access). Geralmente é utilizado o TDMA para upstream devido à sua simplicidade e menor custo. No caso do downstream, as recomendações do ITU-T utilizam o TDM, que associa cada cliente com seus respectivos time slots.

$\mathrm{Na}$ arquitetura ponto-multiponto, uma única fibra é compartilhada por vários pontos finais e não existem elementos ativos. Entre as opções de topologias, têm-se em anel, árvore e barramento. [32]

A topologia em anel é aquela onde duas ONUs são conectadas a uma OLT, o que gera dois segmentos PONs que podem ser chamados de PON A e PON B. As outras ONUs são conectadas de forma serial a partir da primeira ONU do segmento, o que forma um barramento óptico. Dessa forma, cada ONU de cada barramento funcionará como um derivador óptico ativo. As últimas ONUs são, então, conectadas entre si fechando o anel lógico, figura 3.4. Essa topologia possui vantagens como redundância da rede e possibilidade de configuração do custo métrico de tráfego. 


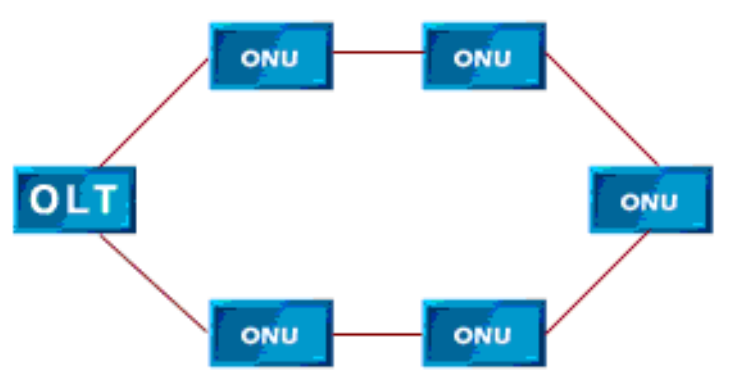

Figura 3.4 Topologia em anel.

Na topologia em árvore, as ONUs são conectadas a uma OLT por um único segmento PON. A partir dessa OLT conecta-se um segmento de fibra óptica (Deep Fiber). Esse segmento recebe um derivador passivo (splitter), figura 3.6. O primeiro derivador deve ter, no mínimo, um fator de derivação de 1:2 pois, dessa forma, um splitter criará dois sub-segmentos de fibra. A maior vantagem dessa topologia é que, mesmo que as ONUs estejam relativamente distantes da OLT e/ou concentradas a partir de uma certa distância onde não existam ONUs intermediárias, pode-se lançar alguns quilômetros de segmento de fibra e somente começar a derivação deste segmento a partir desta distância.

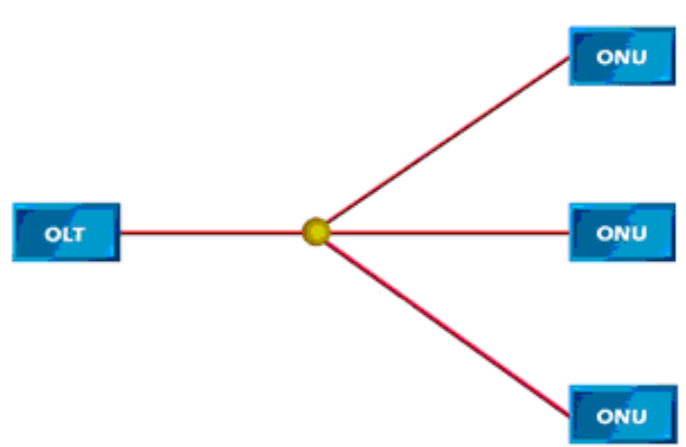

Figura 3.5 Topologia em árvore.

$\mathrm{Na}$ topologia em barramento, as ONUs são conectadas a uma OLT através de um segmento de fibra óptica, que recebe vários derivadores passivos com o fator de derivação de 1:2, ou seja, um splitter cria dois outros segmentos de fibra, figura 3.6. Um dos segmentos servirá de conexão para a ONU e o outro servirá como caminho passante para o próximo spliter. Essa topologia é útil para aplicações de abordagem nas ruas (Fiber To The Curb), no 
qual cria-se um segmento de fibra e instala-se pequenos gabinetes de distribuição nas calçadas ou postes onde estarão os derivadores e/ou ONUs, que farão a conectividade via fibra óptica, cabo coaxial ou wireless para os usuários finais.

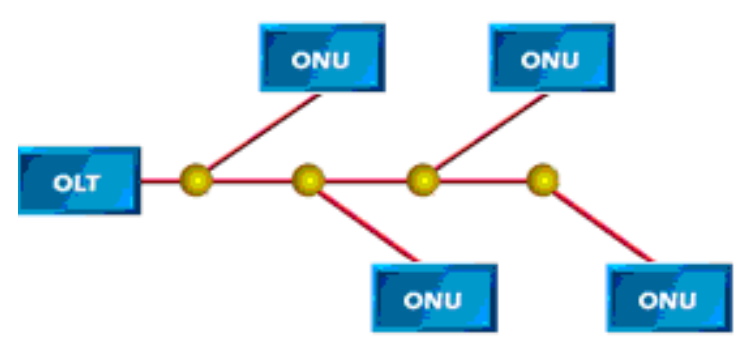

Figura 3.6 Topologia em barramento.

Uma típica rede PON é composta por um misto de topologias vislumbradas de acordo com a estratégia de implementação e com a grande flexibilidade de arquitetura. A figura 3.7 ilustra uma aplicação típica de ganho de escala no atendimento e mix de portifólio com topologia flexível em redes PONs.

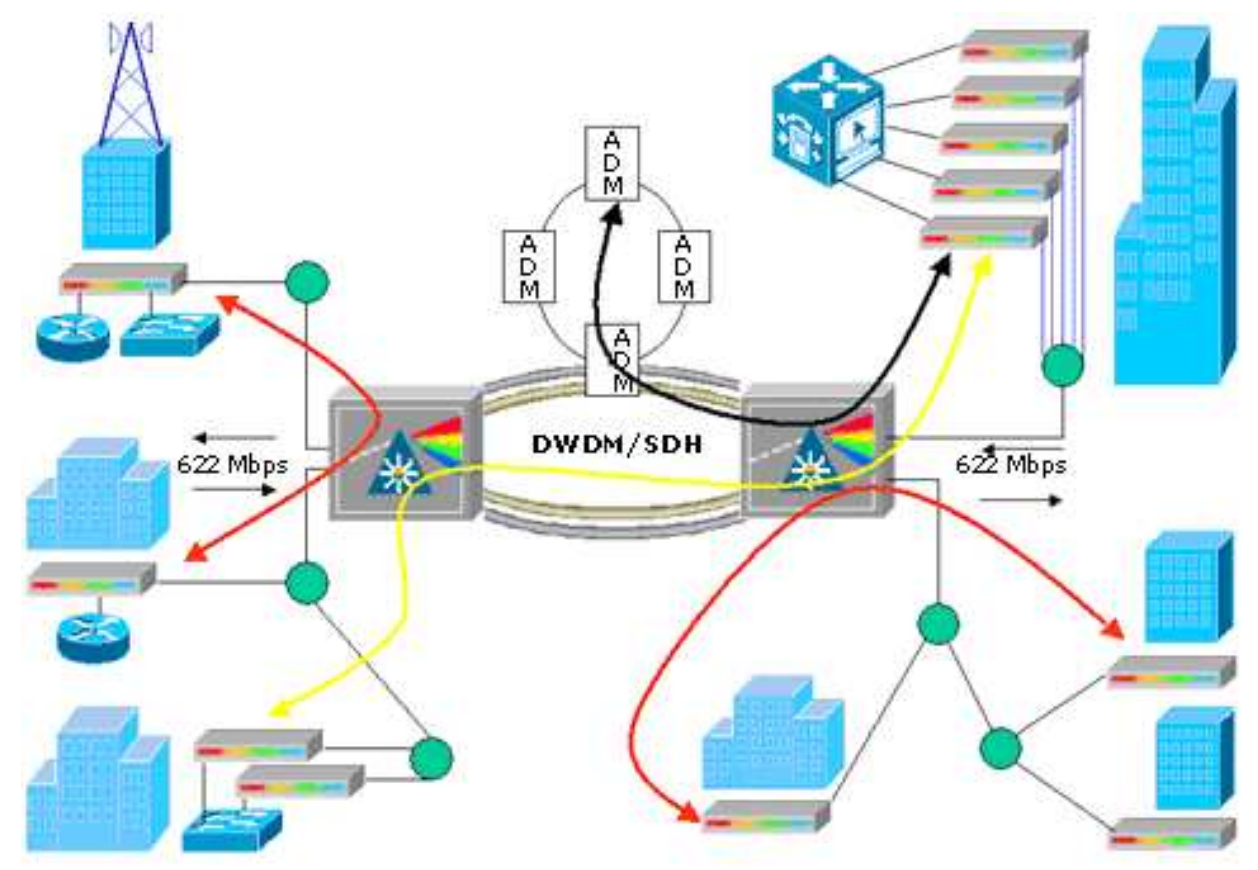

Figura 3.7 Visão geral de uma rede PON completa. 
Existem vários tipos de PON, mas a tecnologia geral é a mesma. As diferenças estão nas especificações e nas camadas altas dos protocolos: APON (ATM PON - 155 Mbps a 622 Mbps), BPON (Broadband PON - 155 Mbps a 1,25 Gbps), EPON ou GE-PON (Ethernet based PON - 1,25 Gbps) e GPON (Gigabit PON - 622 Mbps a 2,5 Gbps).

\section{2 - APON:}

A rede APON foi desenvolvida em 1990, quando havia duas escolhas lógicas para protocolos e planta física: ATM e PON. A primeira porque poderia servir múltiplos protocolos e a segunda porque é a solução óptica mais econômica. Tecnologias que possuem fibra óptica em arquiteturas de rede de acesso como FTTH (fiber-to-the-home), FTTB (fiber-to-thebuilding), FTTCab (fiber-to-the-cabinet) e FTTC (fiber-to-the-curb) oferecem um mecanismo que habilita banda suficiente para oferecer novos serviços e aplicações. ATM-PON pode ser incluída em todas essas tecnologias, figura 3.8.

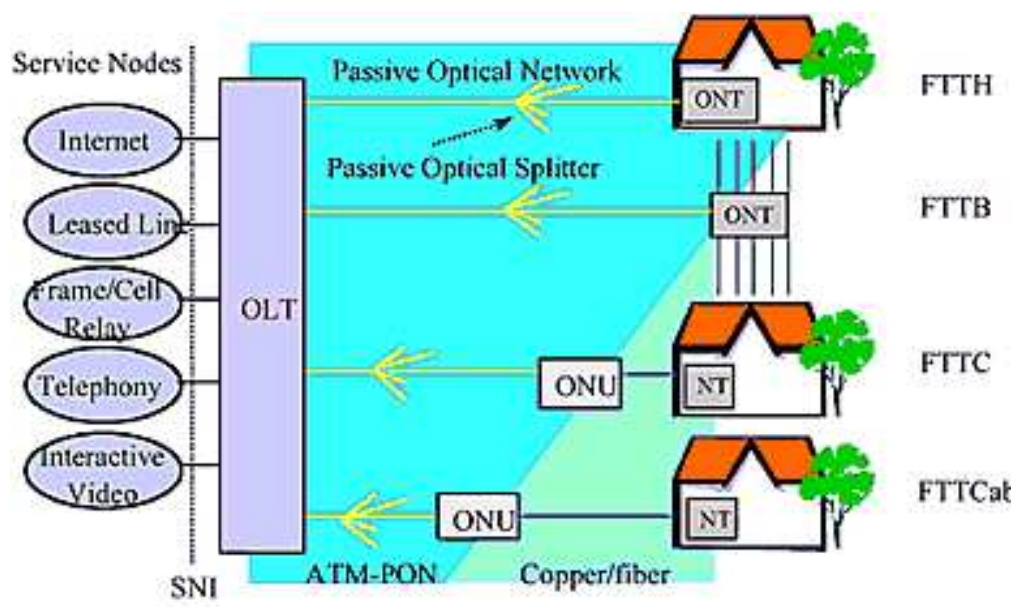

Figura 3.8 ATM-PON arquitetura.

A PON pode ser utilizada nessas arquiteturas, porém, somente nas configurações FTTH e FTTB todos elementos ativos podem ser eliminados da planta externa. As arquiteturas FTTCab e FTTC necessitam de elementos ativos na vizinhança da planta externa. Uma visão geral da função de uma arquitetura ATM-PON é representada na figura 3.9: 

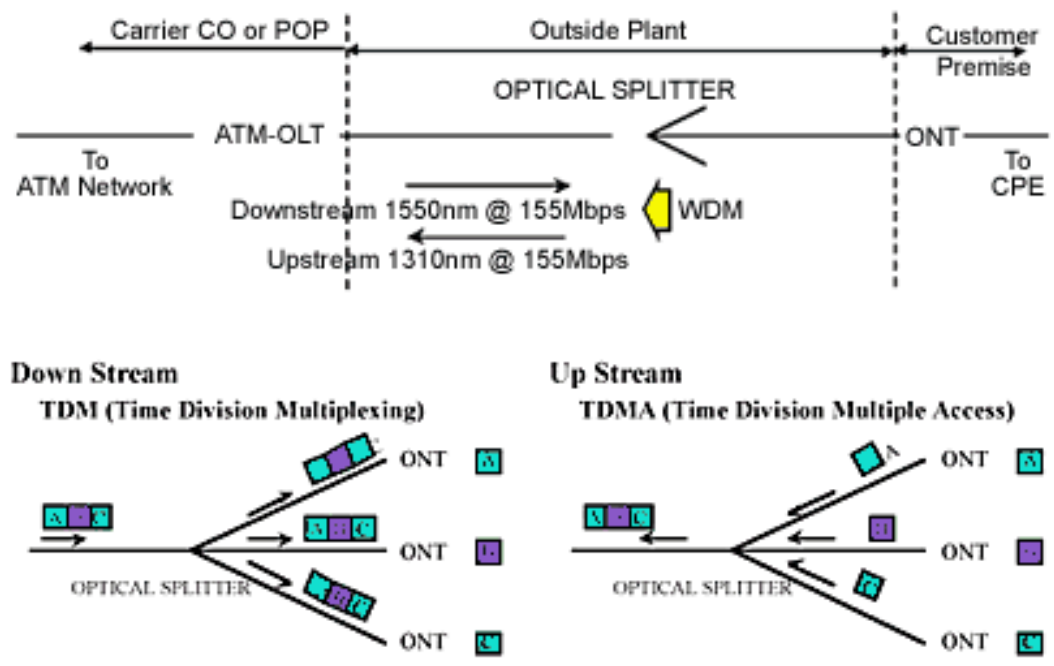

Figura 3.9 Visão geral da funcionalidade da ATM-PON.

Na Figura 3.10, observa-se que o ONT é posicionado próximo ao cliente o que sugere a arquitetura FTTH/B. O ponto de demarcação do provedor seria ao lado do subscritor ONT tipicamente de um formulário T1, Ethernet, RDSI etc.

$\mathrm{O}$ acesso à banda em uma rede PON pode ser obtido por vários métodos, incluindo TDMA, WDMA, CDMA e SCMA. Como mostrado na Figura 3.10, a rede de componentes ATM-PON consiste de OLT, ONT e splitters ópticos passivos. O sinal de uma fibra é dividido entre múltiplos ONTs. Essa divisão passiva requer ações especiais de privacidade e de segurança e um protocolo TDMA se faz necessário no upstream. $\mathrm{O}$ uso de um divisor óptico na arquitetura PON permite que vários usuários compartilhem da mesma banda e dividam custos.

O sistema ATM-PON utiliza uma arquitetura denominada de "dupla estrela". A primeira estrela está localizada na OLT, onde a interface WAN é logicamente compartilhada e comutada para a interface ATM-PON. A segunda estrela está localizada no splitter onde a informação, passivamente compartilhada, é entregue para cada ONT. O OLT é geralmente localizado no $\mathrm{CO}$ (central office) e é o ponto de interface entre o sistema de acesso e os pontos de serviços dentro da rede do provedor. Quando o conteúdo dos dados da rede encontra o OLT, ele é comutado diretamente para o splitter passivo usando TDM no downstream. 
O ONT filtra as células e recupera somente aquelas que são endereçadas a ele. Cada célula ATM tem 28 bits de endereço associado com o VPI/VCI. Dessa forma, primeiramente o OLT enviará uma mensagem para o ONT avisando que este deve a aceitar as células contendo determinados VPI/VCI.

Como o TDMA é usado no upstream, cada ONT é sincronizado em tempo com outro ONT em um processo denominado ranging. Basicamente, o OLT deve determinar a distância entre os ONT para que possa ser assumido um time slot ótimo no qual ocorra uma transmissão sem interferência por parte dos outros ONTs. O OLT mandará, então, mensagens via células de operação, administração e manutenção de camada física (PLOAM) para avisar ao TDMA sobre os time slots pertencentes aquele ONT. Dessa forma, o ONT adaptará o serviço de interface para o ATM e enviará para a rede PON usando o protocolo TDMA. Como ATMPON é um serviço independente, todos os serviços legados e futuros podem ser facilmente transportados.

O formato básico do frame entre o OLT e ONT para uma taxa de transmissão simétrica $155 \mathrm{Mbps}$ é mostrado na figura 3.10.

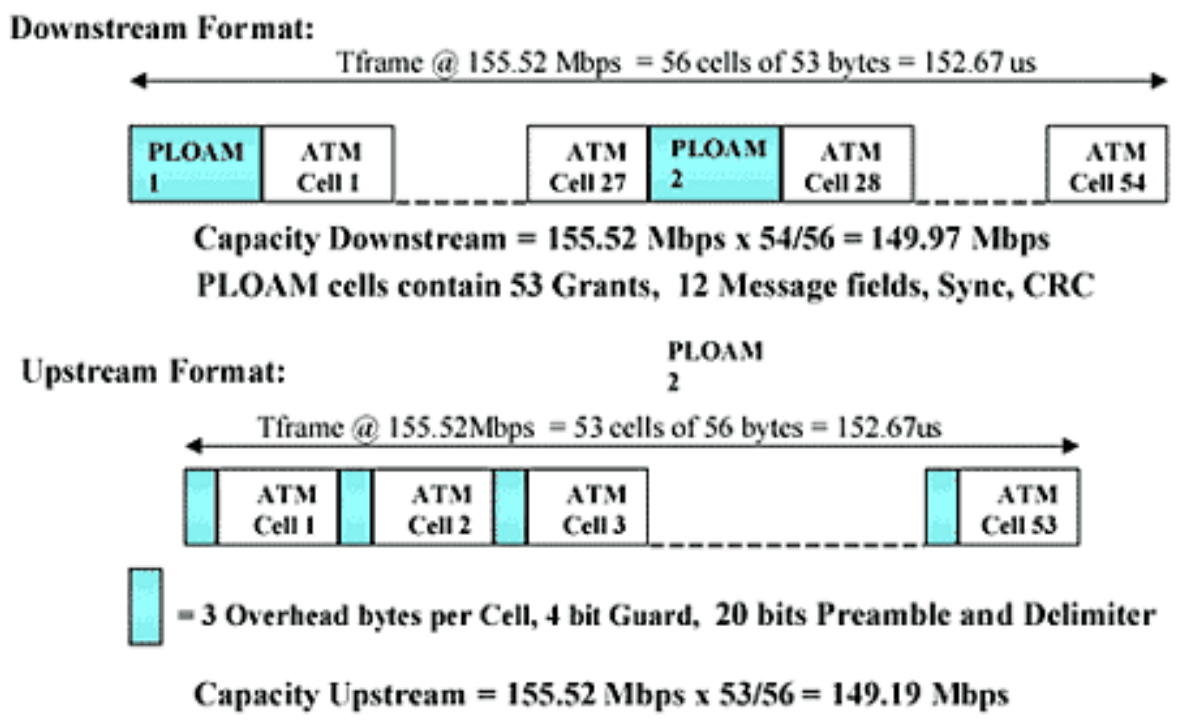

Figura 3.10 Formato básico do frame entre OLT e ONT.

Pode-se observar, pela figura 3.11, que a capacidade de payload no downstream é reduzida para 149,97 Mbps devido às células PLOAM. Estas células são responsáveis pela alocação de banda, sincronização, controle de erro, segurança, ranging e manutenção. 
No upstream a capacidade é reduzida para 149,19 Mbps porque há 3 bytes de redundância por célula ATM, além disso, há células PLOAM no upstream. Aquela taxa é definida pelo OLT para cada ONT, dependendo da funcionalidade requerida. A taxa mínima de PLOAM no upstream é de um PLOAM a cada $100 \mathrm{~ms}$. Isso iguala para 1 PLOAM a cada 655 frames, que se torna irrisório. Os 3 bytes de overhead contêm um mínimo de 4 bits de tempo de guarda para ter distância, em tempo, suficiente para que não haja colisões entre células de ONTs diferentes. Este tamanho de campo é programável pelo OLT e existem dois tipos: preâmbulo e delimitação. O primeiro é usado para adquirir sincronização de bit e recuperação de amplitude. O segundo usado para indicar o começo da célula que está chegando.

Dado que uma única fibra é usada tanto para upstream como para downstream, dois comprimentos de ondas de luz são usados $-1.550 \mathrm{~nm}$ para o downstream e $1.310 \mathrm{~nm}$ para o upstream. Embora um único comprimento de onda também pudesse ser usado, dois proporciona um melhor isolamento óptico entre transmissores e receptores. A conversão eletro-óptica das células ATM ocorre de forma direta, sendo, a seguir, enviadas para a rede PON. Devido ao broadcast natural da rede PON, técnicas de criptografia foram desenvolvidas para prevenir brechas de segurança. No upstream, o ONT utiliza o TDMA e, novamente, ocorre a conversão eletro-óptica das células ATM para transporte através de PON. Um típico sistema ATM-PON pode ter até 64 usuários numa única fibra compartilhando 155 Mbps.

\section{3 - BPON:}

É uma configuração de rede baseada na ATM-PON. As especificações iniciais da PON utilizadas pela FSAN (Full Service Access Network) utilizam-se de ATM como a segunda camada de sinalização. O uso do termo APON faz que os usuários acreditem que apenas os serviços ATM podem ser providos para os usuários finais. Em função desse fato, FSAN decidiu modificar o nome para Broadband PON ou BPON. O sistema BPON oferece inúmeros serviços incluindo acesso a Ethernet e distribuição de vídeo. Acrescenta suporte para WDM, banda em upstream é alocada de forma mais rápida, dinâmica e durável. A figura 3.11 representa a rede $\mathrm{BPON}$. 


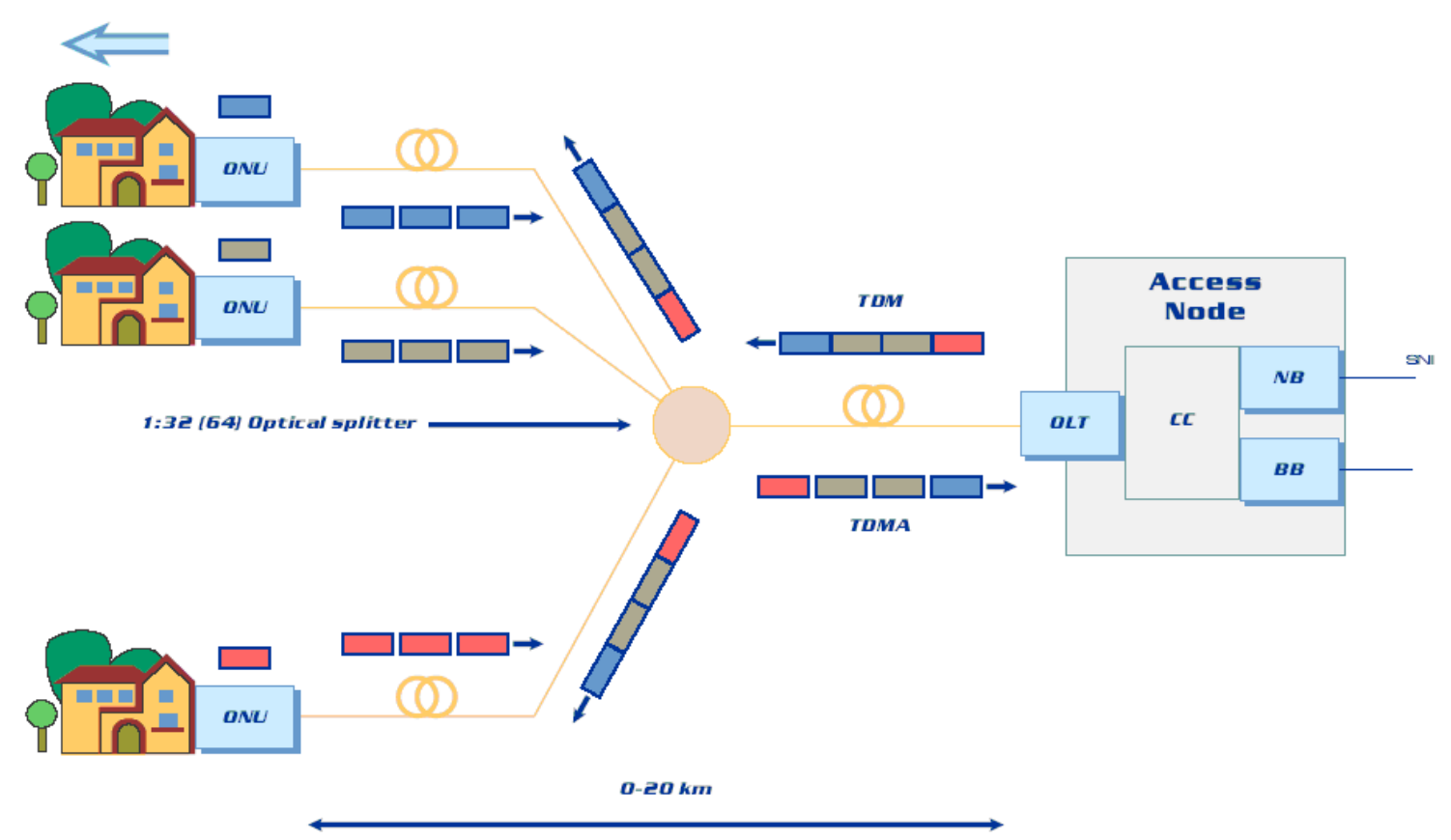

Figura 3.11 Representação de uma rede BPON.

\section{4 - EPON}

Os elementos passivos de uma EPON estão alocados em uma rede de distribuição óptica (também conhecida como outside plant) e incluem fibra monomodo, splitters, conectores e splices, figura 3.12. Os OLTs e as múltiplas ONUs estão alocados nos pontos finais da PON. Os sinais ópticos podem passar por várias fibras ou serem combinados em uma única fibra através dos splitters, dependendo da posição na qual a luz está viajando dentro da PON. [19] 


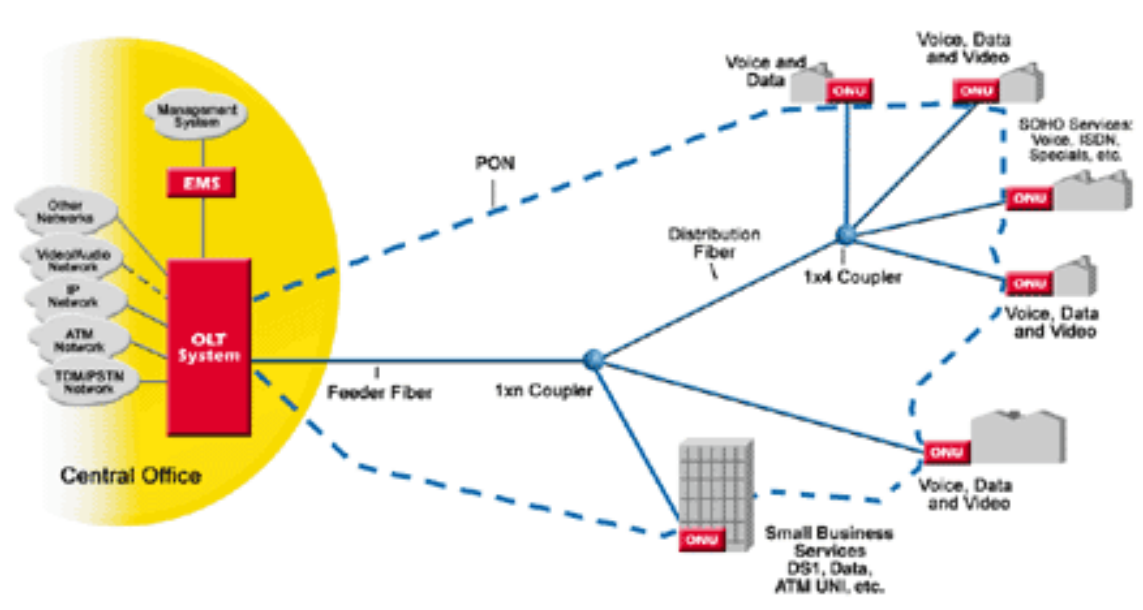

Figura 3.12 Representação de uma rede EPON.

As EPONs são mais simples, mais eficientes e mais baratas que as demais soluções para multiserviços de acesso. As principais vantagens são apresentadas a seguir:

- Banda maior que 1,25 Gbps, o que gera outras vantagens como maior número de usuários por PON, maior largura de banda por usuário, contagens mais elevadas do split, potencial para distribuição de vídeo e melhor QoS;

- Custos mais baixos conseguidos através da arquitetura simples, da operação mais eficiente e menor custo de manutenção necessário;

- Maior rendimento podendo suportar dados, vídeo e voz.

A grande diferença entre EPON e APON reside no fato de que, no primeiro caso, os dados são transmitidos em pacotes de tamanho variáveis de até 1.518 bytes dependendo do protocolo 802.3 do IEEE, enquanto, no segundo caso, há transmissão de pacotes de tamanhos fixos de 53 bytes por pacote. Este formato representa uma dificuldade e ineficiência para APONs no que diz respeito ao transporte de tráfegos formatados de acordo com o IP. As chamadas IPs para dados devem ser segmentadas em pacotes de tamanhos variáveis de até 65.535 bytes. Para um APON carregar tráfego IP, os pacotes devem ser quebrados em segmentos de 48 bytes com 5 bytes de cabeçalho cada um. Este processo consome tempo e gera custos para o OLT e ONU. Além disso, 5 bytes de banda são consumidos para cada segmento de 48 bytes, gerando um oneroso overhead que é geralmente referido a taxa de 
células ATM. Em contraste, Ethernet foi desenvolvido para carregar tráfego IP, o que reduz drasticamente o overhead relativo ao ATM.

No EPON, o processo de downstream do OLT para vários ONUs é fundamentalmente diferente da transmissão upstream de vários ONUs para o OLT. No downstream, os dados são enviados via broadcast do OLT para múltiplos ONUs em pacotes de tamanho variáveis de até 1.518 bytes. Cada pacote carrega um cabeçalho que o identifica. Além disso, alguns pacotes podem ser endereçados para todos os clientes na forma de broadcast ou a um particular grupo de clientes na forma de multicast. No splitter, o tráfego é dividido em 3 sinais separados, cada um carregando todos os pacotes de determinado ONU. Quando os dados encontram o ONU apropriado, os pacotes endereçados corretamente são aceitos e os demais descartados.

No upstream, o tráfego é feito utilizando a tecnologia TDM, na qual cada time slot de transmissão é dedicado a um cliente. Os times slots são sincronizados para que os pacotes upstrem do ONU não interfiram nos dados pertinentes ao fluxo da outra ONU que compartilham a mesma fibra. Ou seja, ONU-1 transmite pacote no primeiro time slot, ONU-2 transmite no segundo time-slot e assim por diante.

O tráfego downstream é segmentado em frames de intervalos fixos (time slots), cada um deles contendo múltiplos pacotes de tamanhos variados. Informações de clock, na forma de marca de sincronização são incluídas no começo de cada frame. $O$ marcador de sincronização é feito através de um byte transmitido a cada 2 segundos para sincronização entre a ONU e as OLTs, figura 3.13.

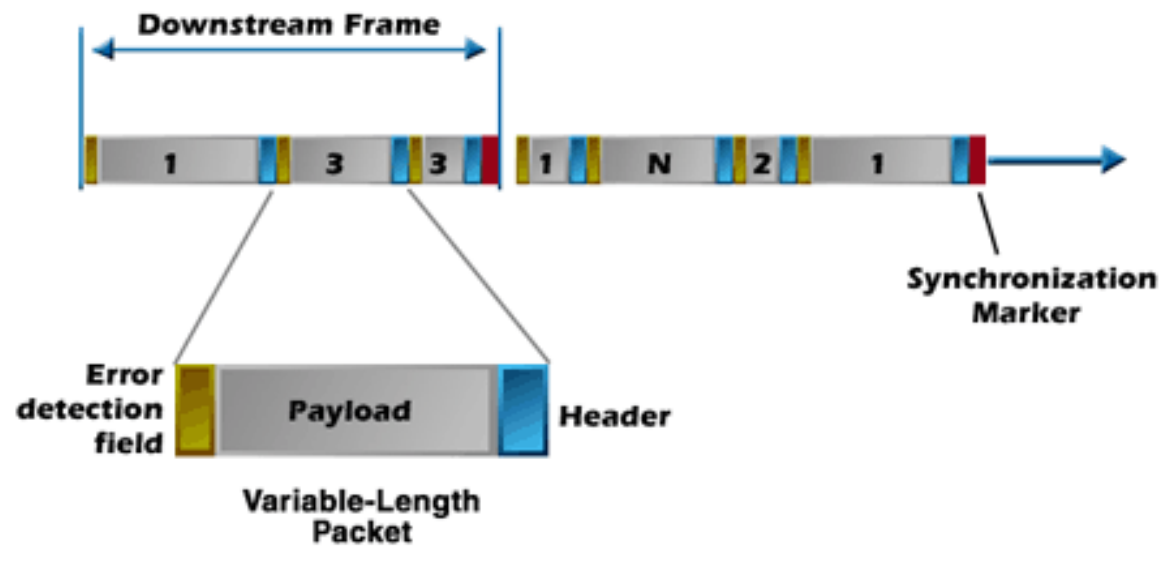

Figura 3.13 Formato do frame do tráfego downstream. 
O tráfego upstream, assim como o downstream, também é segmentado em frame, e cada frame é novamente segmentado em time slots específicos de cada ONU. Os frames upstream são formados por um intervalo de transmissão contínua de $2 \mathrm{~ms}$. Um cabeçalho de frame identifica o começo de cada frame upstream, figura 3.14.

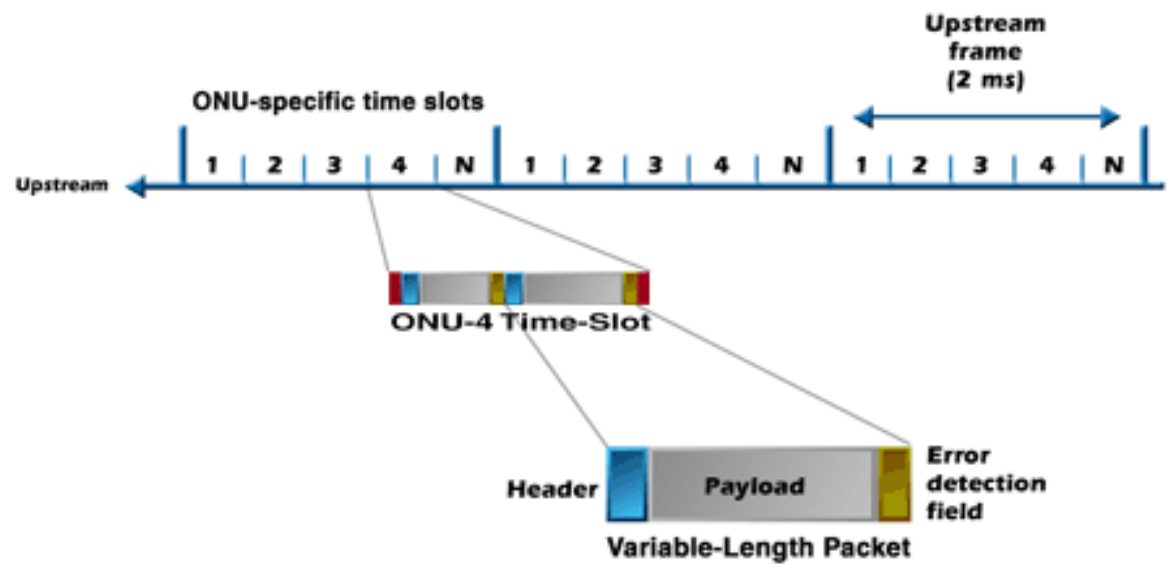

Figura 3.14 Formato do frame do tráfego downstream.

As redes EPONS podem ser implementadas utilizando-se tanto dois quanto três comprimentos de ondas. Utilizam-se dois comprimentos de onda quando o objetivo é a entrega de dados, voz e comutação de vídeo digital sobre IP. Três comprimentos de onda são exigidos para proporcionar radiofreqüência, serviços de vídeo ou DWDM.

$\mathrm{Na}$ arquitetura de dois comprimentos de onda, o comprimento de $1.510 \mathrm{~nm}$ transporta dados, vídeo e voz, enquanto um comprimento de onda de $1.310 \mathrm{~nm}$ é usado para transportar video-on-demand (VOD), figura 3.15.

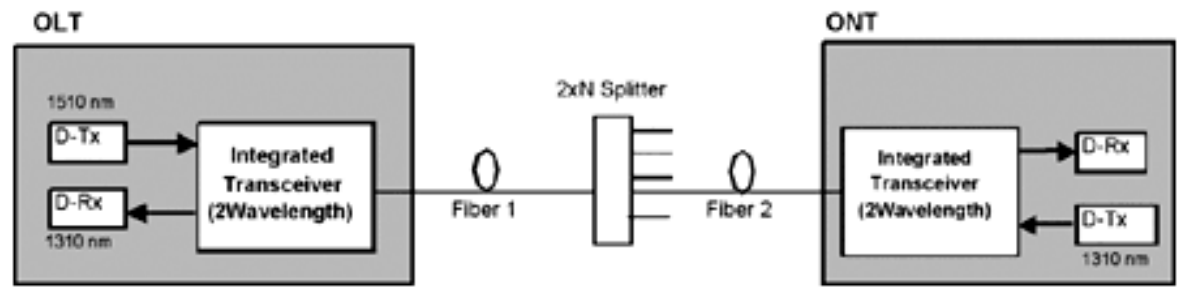

Figura 3.15 Rede EPON com dois comprimentos de onda.

$\mathrm{Na}$ arquitetura de três comprimentos de onda, $1.510 \mathrm{~nm}$ e $1.310 \mathrm{~nm}$ são os comprimentos de onda usados no downstream e no upstream, respectivamente, enquanto 
$1.550 \mathrm{~nm}$ é reservado para o downstream em vídeo. O vídeo é codificado como MPEG-2 e é transportado através de uma modulação de quadratura de amplitude (QAM). Usando esta configuração, o PON proporciona uma distância efetiva de até $18 \mathrm{~km}$ para 32 divisões (ou clientes em localidades diferentes), como ilustra a figura 3.16.

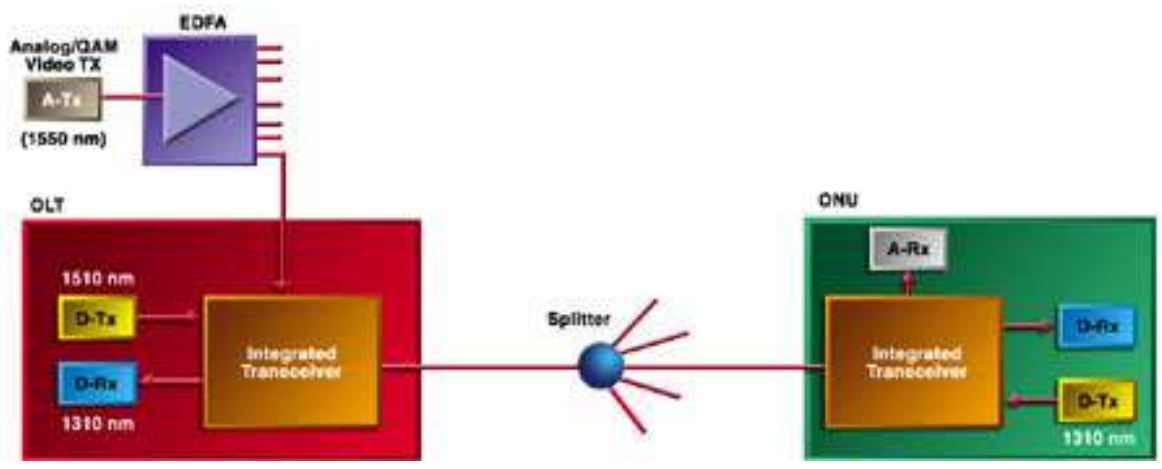

Figura 3.16 Rede EPON com três comprimentos de onda.

As redes EPONs podem oferecer vantagens de custo e de performance que permitem o provedor entregar serviços de nova geração sobre uma plataforma econômica. Porém, um grande desafio técnico para os vendedores encontra-se em aumentar as capacidades da Ethernet para garantir que o serviço de voz em tempo real e o serviço de vídeo sobre IP possam ser entregues sobre uma única plataforma com o mesmo QoS e com a facilidade da gerência do ATM ou do SDH. Para solucionar esse problema, os vendedores estão abordando o problema de vários e diferentes ângulos. Estão, por exemplo, implementando métodos como o DiffServ (differentiated Services) e 802.1p, que provêm tráfico para diferentes níveis de serviço.

\section{5 - GPON}

A GPON emergiu como uma solução nova no mercado de acesso óptico, oferecendo uma elevada taxa de bit ao permitir o transporte de múltiplos serviços, especificamente dados e TDM em formatos originais, e em uma eficiência extremamente elevada, figura 3.17. 


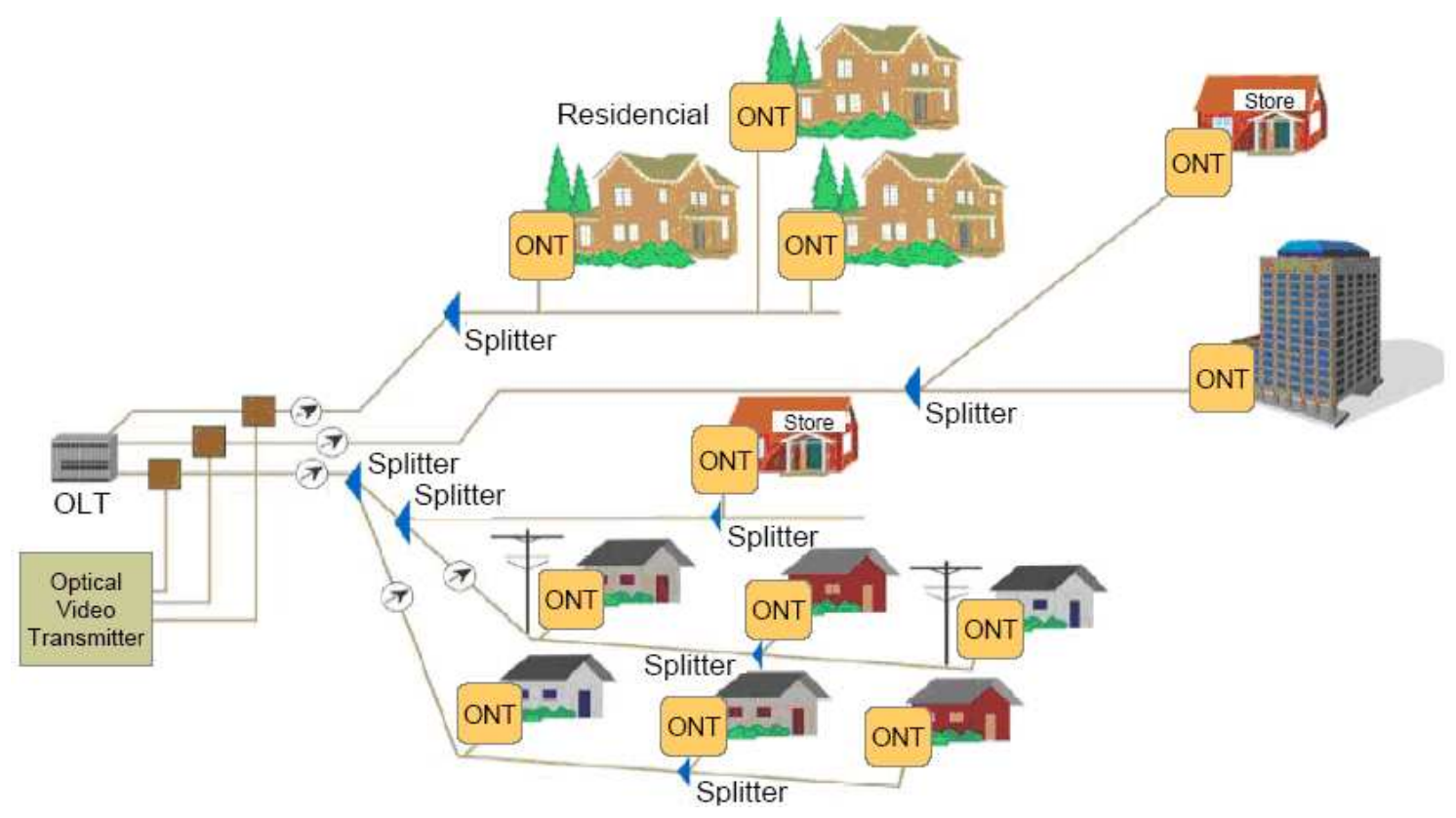

Figura 3.17 Exemplo de uma rede GPON.

GPON ou Gigabit PON é a segunda geração de protocolo publicado pelo ITU-T como uma série de recomendação G.984. O protocolo suporta diversas velocidades de downstream e de upstream, sendo as mais típicas de 1,24 Gbps downstream e $622 \mathrm{Mbps}$ upstream. GPON é baseado em um protocolo denominado de GFP (Generic Framing Protocol). O objetivo é eliminar ou, pelo menos, reduzir significativamente as edições em torno do ATM. Onde o ATM introduziu ineficiências, segmentando tudo em pilhas de 48/53 de byte, o GFP emite frames ou células de comprimento variável com até 65.535 bytes em um frame. Isto permite que a GPON carregue frames de Ethernet com muito mais eficiência do que APON ou BPON e quase tão eficiente quanto EPON. Mas nada é realmente novo: o GFP usa uma técnica da época dos modens de 300 baud desenvolvidos pela Digital Equipment Corporation (DEC). Um protocolo chamado DECNet precede cada pacote com uma contagem dos bytes restantes no pacote. Com isso, o problema era indicar onde o pacote começou e onde a contagem de byte estava. Caracteres especiais eram necessários para endereçar este problema, o que dificultou o sistema.

A IBM foi procurada para corrigir esse problema e criou o código do SDLC e do NRZ/NRZI com seus caracteres especiais encaixados na transmissão. Estes caracteres especiais delinearam o começo e a extremidade de cada mensagem e, dessa forma, uma contagem de byte não era mais necessária. Esse paradigma durou até hoje. 
A GFP resolve a exigência se encontrar, de forma impressionantemente correta, o começo de um pacote (e da contagem de byte). Emitem simplesmente a contagem de byte de 16 bits e um 16 bit CRC. O frame de GFP procura dois bytes e então calcula o CRC depois, compara-o aos dois bytes seguintes. Se forem iguais significa que a contagem de byte foi encontrada e pode-se continuar a ler o pacote. Caso contrário, move-se para o byte seguinte e inicia-se o processo outra vez. Isso pode ser mais simples e mais eficiente do que o ATM. Naturalmente, esta é uma simplificação de um protocolo complicado, que também oferece muitas outras características interessantes que se dirigem aos desafios do ATM hoje. O protocolo é definido pelo ITU-T G.7041. ITU G.984.x é o padrão em desenvolvimento.

Para o ano 2008, GPON é vista como a tecnologia mais relevante de PON pelo EMEA (Europa Mideast e África) com a EPON e a BPON representando um papel menor. GPON surgirá como a principal tecnologia na América do Norte, no momento em que BPON ainda tiver a maior parte do mercado. APAC continuará a ser o maior mercado regional para EPON, mas espera-se que a GPON emirja por lá também, conseguindo cerca de $25 \%$ do mercado até 2008.

A GPON apresenta diversas vantagens quando comparada às outras tecnologias de PON:

- GPON comparado a EPON: A tecnologia de GPON segura o tráfego de TDM naturalmente sem nenhuma necessidade de algum mecanismo encapsulador que utiliza o protocolo GFP. Além disso, a GPON é sincronizada por sua natureza. Isto conduz a uma eficiência de banda maior que $90 \%$ com uma largura de banda de até 2,5 Gbps na PON. EPON fornece a eficiência de banda menor que 50\% por um máximo da largura de banda de 1,25Gbps na PON.

- GPON comparado a APON ou a BPON: A tecnologia GPON permite maiores taxas de divisão e, outra vez, maior largura de banda na PON. Além disso, o uso da largura de banda nas redes GPON tem uma eficiência $20 \%$ maior do que nesses outros casos. 


\section{6 - ETHERNET}

A tecnologia Ethernet tem aproximadamente 30 anos e, nas últimas décadas, tem se tornado uma das tecnologias mais utilizadas, devido a sua velocidade, facilidade de instalação e custo relativamente baixo. [10]

Em 1985, o IEEE publicou a recomendação IEEE 802.3, que define o padrão Ethernet. Após isso, várias outras recomendações foram divulgadas, apresentando melhorias e outras definições do padrão, tabela 3.1:

Tabela 3.1 Recomendações IEEE para o padrão Ethernet.

\begin{tabular}{|l|l|l|}
\hline \multicolumn{1}{|c|}{ Supplement } & \multicolumn{1}{|c|}{ Year } & \multicolumn{1}{c|}{ Description } \\
\hline \hline $802.3 a$ & 1985 & 10 Base-2 (thin Ethernet) \\
\hline $802.3 \mathrm{c}$ & 1986 & $10 \mathrm{Mb} / \mathrm{s}$ repeater specifications (clause 9) \\
\hline $802.3 \mathrm{~d}$ & 1987 & FOIRL (fiber link) \\
\hline $802.3 \mathrm{i}$ & 1990 & 10 Base-T (twisted pair) \\
\hline $802.3 \mathrm{j}$ & 1993 & 10 Base-F (fiber optic) \\
\hline $802.3 \mathrm{u}$ & 1995 & 100 Base-T (Fast Ethernet and autonegotiation) \\
\hline $802.3 \mathrm{x}$ & 1997 & Full duplex \\
\hline $802.3 \mathrm{z}$ & 1998 & 1000 Base-X (Gigabit Ethernet) \\
\hline $802.3 \mathrm{ab}$ & 1999 & 1000 Base-T (Gigabit Ethernet over twisted pair) \\
\hline $802.3 \mathrm{ac}$ & 1998 & VLAN tag (frame size extension to 1522 bytes) \\
\hline $802.3 \mathrm{ad}$ & 2000 & Parallel links (link aggregation) \\
\hline $802.3 \mathrm{ae}$ & 2002 & $10-$ Gigabit Ethernet \\
\hline $802.3 \mathrm{ah}$ & 2004 & Ethernet in the first mile \\
\hline $802.3 a s$ & 2005 & Frame expansion \\
\hline 802.3 at & 2005 & Power over Ethernet Plus \\
\hline
\end{tabular}

Inicialmente, a taxa de transmissão do Ethernet era de 2,94 Mbit/s, mas foi modificada para 10 Mbits. Essa taxa era considerada bastante rápida nos anos 80, mas nos anos 90 houve uma demanda por mais banda. Para suprir essa demanda, foram definidos padrões mais rápidos:

- Fast Ethernet (FE): Possui uma taxa de $100 \mathrm{Mbit} / \mathrm{s}$. Devido à existência de redes que podiam demandar $10 \mathrm{Mbit} / \mathrm{s}$ ou $100 \mathrm{Mbit} / \mathrm{s}$, definiu-se que os equipamentos Ethernet deveriam ser capazes de suportar tais redes, mudando automaticamente a taxa de transmissão. 
- Gigabit Ethernet (GbE): Possui uma taxa de $1 \mathrm{Gbit} / \mathrm{s}$. Sua estrutura é semelhante a de Ethernet e Fast Ethernet, mas utiliza quadros maiores, os chamados jumbo frames, para a transmissão. Ao invés de quadros de 64 a 1.518 bytes, o GbE utiliza quadros com 64 a 9.215 bytes, reduzindo consideravelmente o número de pacotes recebidos e processados pelo host final.

- 10 Gigabit Ehternet (10GbE): Opera de forma semelhante aos Ethernets de taxas menores, mantendo o tamanho dos frames e os protocolos. No entanto, só opera em links ponto-a-ponto em modo full-duplex. Além disso, utiliza apenas fibras ópticas multimodo ou monomodo.

Uma rede Ethernet pode ter dois modos de controle de tráfego: compartilhado (shared) e comutado (switched).

No modo compartilhado, utiliza-se um $H u b$ com um número especificado de portas. Cada porta estará conectada a um único servidor. Forma-se, então, um meio com acesso de apenas um servidor a cada instante. O Hub formará através de suas portas um domínio de colisão. Cada servidor, para acessar o meio, deverá escutá-lo até que um intervalo de silêncio seja verificado. O protocolo que gerencia este acesso é denominado de CSMA/CD (Carrier Sense Multiple Access/Colision Detection).

No modo comutado (switched), utiliza-se um switch. Cada porta do switch possui um domínio de colisão dedicado, isto é, cada servidor conectado a qualquer uma das portas poderá enviar e receber mensagens simultaneamente, sem necessidade de escutar e/ou negociar acesso ao meio.

Nesta configuração, utiliza-se um único domínio de broadcast frames para todas as portas. Este domínio dedica-se a formação de sua tabela de chaveamento através dos endereços das placas de redes dos servidores.

Em conexões metropolitanas e de longa distância e nas taxas de 1 Gbps e 10 Gbps, a tecnologia Ethernet utiliza quase sempre o modo comutado.

O sistema Ethernet consiste de três elementos básicos: 
- Canal Físico : O meio físico é o recurso por onde os sinais elétricos ou ópticos trafegam na rede. A Ethernet define quatro tipos básicos de meio físico: o cabo coaxial fino, cabo coaxial grosso, o par trançado e a fibra óptica.

- Regras de Controle: Um conjunto de regras embarcadas em cada interface de rede que permite, de forma compartilhada, o acesso ao meio físico pelas estações conectadas na rede.

- Quadro Ethernet (frame): O quadro ethernet é formado por campos de endereçamento, um campo de tamanho variável de dados úteis e um campo para verificação de erros de bits. As seções do quadro Ethernet são mostrados na figura 3.18 .

\section{ETHERNET FRAME FORMAT}

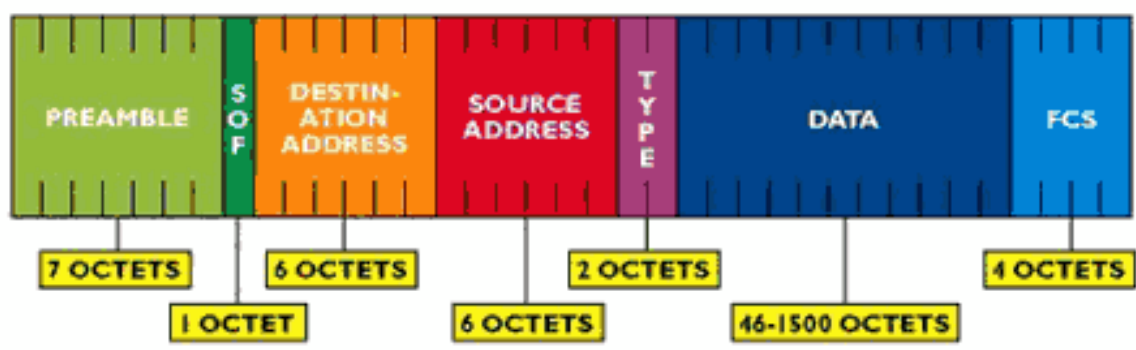

IEEE 802.3 frame format replaces the TYPE field with a LENGTH field for values up to 1500 IEEE 802 . IQ inserts 4 octets - a type code and VLAN tag

Figura 3.18 Estrutura do quadro Ethernet.

Em 1998, o IEEE aprovou o padrão 802.3ac que define o formato das extensões do frame, para suportar a marcação (tagging) de Virtual Local Area Network (VLAN) sob redes Ethernet. O protocolo de VLAN permite inserção de um identificador, ou uma "tag", no formato do frame Ethernet, para identificar a VLAN à qual o frame pertence. Isso permite a frames de estações serem alocados como grupos lógicos. Esse arranjo traz vários benefícios, como facilidade na administração da rede, permite a formação de grupos de trabalho, aumenta a segurança da rede e provê limite do domínio de broadcast. [30]

O Ethernet pode ser transmitido em vários tipos de meios e cada tipo possui uma nomeação que tem três partes: 
- 10, 100, 1000: especificam a velocidade de transmissão;

- Base: vem de baseband, que é o tipo de transmissão feita no Ethernet;

- 5, 2, T etc: especifica o meio físico;

Alguns tipos de meios de transmissão de Ethernet sã apresentados a seguir.

- 10Base5: o 10Base5 é o sistema original Ethernet suporta taxa de transmissão a $10 \mathrm{Mb} / \mathrm{s}$ sobre cabo coaxial grano $(10 \mathrm{~mm})$;

- 10Base2: suporta a taxa de transmissão de $10 \mathrm{Mbps}$ sobre fino (5 mm) cabo coaxial fino. Ele é também conhecido como "thin Ethernet", ou "cheapernet" (Ethernet barata). Foi a primeira variação física no tipo de mídia a ser adotada após o padrão original thick Ethernet.

- 10Base-T: suporta uma taxa transmissão de $10 \mathrm{Mbps}$ sobre dois pares telefônicos de par trançado de categoria 3 ou melhores, também conhecidos como par trançado graduado para voz. O largo uso dos cabos de par trançado fez do 10Base-T a versão mais popular da Ethernet. O 10Base-T usa um par de cabos para transmitir dados, e outro par para receber dados.

- 10Broad36: o 10Broad36 suporta uma taxa de transmissão da ordem de 10 Mbps sobre um sistema de cabo banda larga. O "36" do nome refere-se a expansão total de 3.600 metros suportada entre duas estações.

- 10Base-F: o padrão 10Base-F define operações sobre fibra óptica com a taxa de 10 Mbps. A identificação "10Base-F" refere-se coletivamente a três tipos de segmentos de fibra óptica: 10Base-FL, 10Base-FB e 10Base-FP. As três implementações de 10Base-F não são compatíveis com outras interfaces de fibra.

- 100Base-TX: suporta transmissão taxa da ordem de $100 \mathrm{Mbps}$ sobre dois cabos de par trançado. Ele usa um par de cabos para transmitir dados e o outro par para receber os dados. Os dois pares de cabos são embutidos dentro de um único cabo, onde freqüentemente constam mais dois pares de cabos. Se presentes, os dois pares adicionais de cabos devem permanecer sem uso, pois o 100Base-TX não foi projetado para tolerar anomalias do tipo "cross talk" que pode ocorrer quando o cabo é compartilhado com outros sinais. 
- 100Base-FX: suporta taxa transmissão a $100 \mathrm{Mbps}$ sobre dois cabos de fibra óptica. Ele aceita um tamanho máximo de segmento da ordem de 412 metros para links half-duplex, e 2.000 metros ou mais para links de full-duplex. O 100Base-FX é essencialmente a versão em fibra do padrão 100Base-TX. O cabeamento de par trançado e os conectores usados no 100Base-TX são substituídos com cabeamento em fibra óptica e conectores 100Base-FX.

- 100Base-T4: suporta taxa transmissão de 100 Mbps sobre cabeamento de quatro pares de par trançado de categoria 3 ou melhor. Ele permite que a Ethernet de 100 Mbps possa ser levada para o cabeamento barato de categoria 3 em oposto ao cabeamento de categoria 5 requerido pelo 100Base-TX

- 100Base-T2: é o único padrão Ethernet que suporta taxa de transmissão a 100 Mbps sobre cabeamento de dois pares de par trançado, categoria 3. Se o cabo tem mais do que dois pares, ele também permite que os pares adicionais possam ser usados em outros serviços como telefone digital, conexões 10Base-T, ou mais conexões 100Base-T2.

- 1000Base-LX: o "L" no 1000Base-LX é o indicativo para "long", como ele usa lasers com longo comprimento de onda para transmitir dados sobre cabos de fibra óptica. Os lasers de tamanho de onda longos especificados pelo padrão operamem comprimento de onda da ordem de 1.270 a 1.355 nanômetros. Ambos, fibras de multimodo e monomodo são suportadas. Os lasers de comprimento de ondas longos são mais caros que os lasers de comprimento de ondas curtos, mas trazem a vantagem de poderem atingir distâncias maiores.

- 1000Base-SX: O "S" no 1000Base-SX significa "short" como ele usa lasers com comprimento curto de onda para transmitir dados sobre cabo de fibra óptica. Os lasers especificados pelo padrão operam em comprimento de onda na faixa de 770 a 860 nanômetros. Somente fibra óptica multimodo é suportada. Lasers de comprimento de onda curto têm a vantagem de serem mais baratos do que os lasers de comprimento de ondas longos.

- 1000Base-CX: O "C" no 1000Base-CX é de cobre. Usa cabos especialmente protegidos, balanceados com jumper de cobre também chamados de "twinax" ou "short haul cobre ". O tamanho do segmento está limitado a somente 25 metros 
com restrições com o 1000Base-CX para conectar equipamento em pequenas áreas como cabines de cabos.

- 1000Base-T: O padrão 1000Base-T foi definido pelo grupo de trabalho IEEE 802.3ab e formalmente liberado em junho de 1999. O padrão suporta Gigabit Ethernet sobre cabeamento até 100 metros de categoria 5 cobre balanceado.

Como visto, o padrão Ethernet pode ser transmitido em vários meios. No entanto, há o padrão Ethernet óptico, que representa a combinação e a extensão de duas tecnologias existentes, Ethernet e sistemas ópticos. Esta união usa o melhor de ambos, Ethernet e sistemas ópticos e amplia suas potencialidades para criar um novo paradigma que fundamentalmente muda a maneira que os provedores de serviços e as corporações planejam, controlam e operam suas redes. É uma tecnologia que combina a onipresença, a flexibilidade e a simplicidade do Ethernet com a confiabilidade e a velocidade dos sistemas ópticos.

O Ethernet óptico, entretanto, é mais do que apenas o Ethernet mais os sistemas ópticos. Os participantes dos padrões da indústria, assim como os fabricantes, têm desenvolvido soluções de Ethernet óptico específicas que são mais do que meramente transportar Ethernet sobre sistemas ópticos. Em conseqüência, o Ethernet Óptico redefine o desempenho e a economia de ambos, o provedor de serviços e as redes corporativas em diversas maneiras.

Primeiro, o Ethernet óptico simplifica a rede, removendo as complexidades de endereçamento da rede e outros problemas de complexidade da rede, tais como os existentes com as redes baseadas em Frame Relay (FR) e em Asynchronous Transfer Mode (ATM).

Também, o Ethernet óptico remove a necessidade de múltiplas conversões de protocolos que criam grandes dores de cabeça aos operadores da rede com respeito à gerência - porque é Ethernet fim-a-fim. As múltiplas conversões de protocolos também impedem o bom desempenho da rede introduzindo latência e jitter na rede. A latência e o jitter são dois atributos importantes que descrevem o prognóstico e o atraso em uma rede e determinam quais serviços e aplicações podem ser oferecidas eficazmente.

A simplicidade da rede Ethernet óptica também se estende para o provisionamento e a reconfiguração da rede. A largura de faixa do Ethernet óptico pode ser aumentada ou diminuída sem um atendimento técnico e permite mudanças da rede sem reconfigurar cada elemento da rede. 
Além da simplicidade, a velocidade é um atributo chave do Ethernet óptico. Com o Ethernet óptico, o estrangulamento da largura de faixa é eliminado. A conectividade do Ethernet óptico permite velocidades de acesso de até 10 Gbips (gigabits-por-segundo). A largura de faixa também está disponível em fatias mais granulares. Os enlaces de acesso podem ser aumentados/ diminuídos em incrementos/ decrementos de $2 \mathrm{Mbps}$ para fornecer a largura de faixa de $2 \mathrm{Mbps}$ até $10 \mathrm{Gbps}$ ou qualquer valor intermediário.

Além disso, as topologias do Ethernet óptico permitem uma maior confiabilidade do que as redes de acesso atuais podem fornecer. Por exemplo, os seguintes tipos de soluções de Ethernet Óptica: Ethernet sobre SDH (Synchronous Digital Hierarchy), Ethernet sobre DWDM (Dense Wave Division Multiplex) e Ethernet sobre RPR (Resilient Packet Ring) fornecem a recuperação do tráfego em menos de 50 mili-segundos no evento de uma falha, tal como uma interrupção do enlace óptico. Esta disponibilidade elevada garante um tempo superior nas redes que fornecem aplicações de missão crítica.

Finalmente, a Ethernet Óptica é significativamente mais barata do que as redes atuais. As economias de custos podem ser vistas em ambos, as economias de custos operacionais e investimentos. Para o acesso, foi realizada uma pesquisa pelo Metro Ethernet Fórum, que pode ser vista na figura 3.19 .

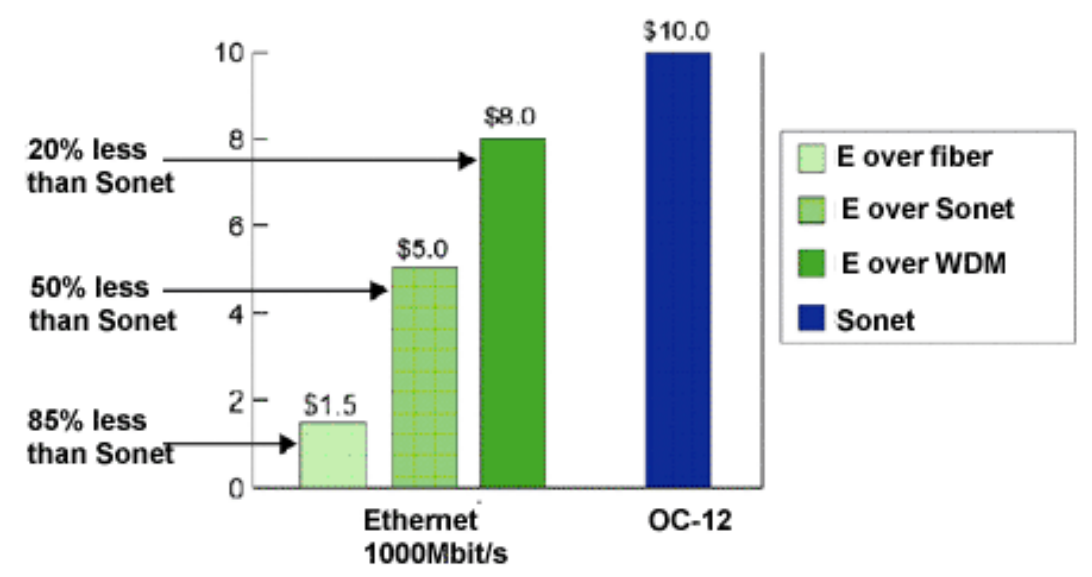

Figura 3.19 Análise econômica do Metro Ethernet Fórum para a tecnologia Ethernet no acesso.

O Ethernet óptico fornece um trajeto de transmissão transparente permitindo que os provedores de serviços aumentem seu faturamento e diminuam os custos enquanto continuam a suportar os serviços legados. 
O Ethernet óptico permite que as corporações ganhem a vantagem competitiva de suas redes reduzindo seus custos, fornecendo informação mais rápida, aumentando a produtividade dos empregados e melhorando a utilização dos recursos.

A utilização do Ethernet na rede de acesso é devido à demanda por serviços que necessitam de altas taxas de transmissão. O padrão IEEE 802.3ah, finalizado em Junho de 2004, provê uma resposta a esses requisitos. A figura 3.20 mostra o posicionamento das novas definições do Ethernet com relação aos padrões anteriores.

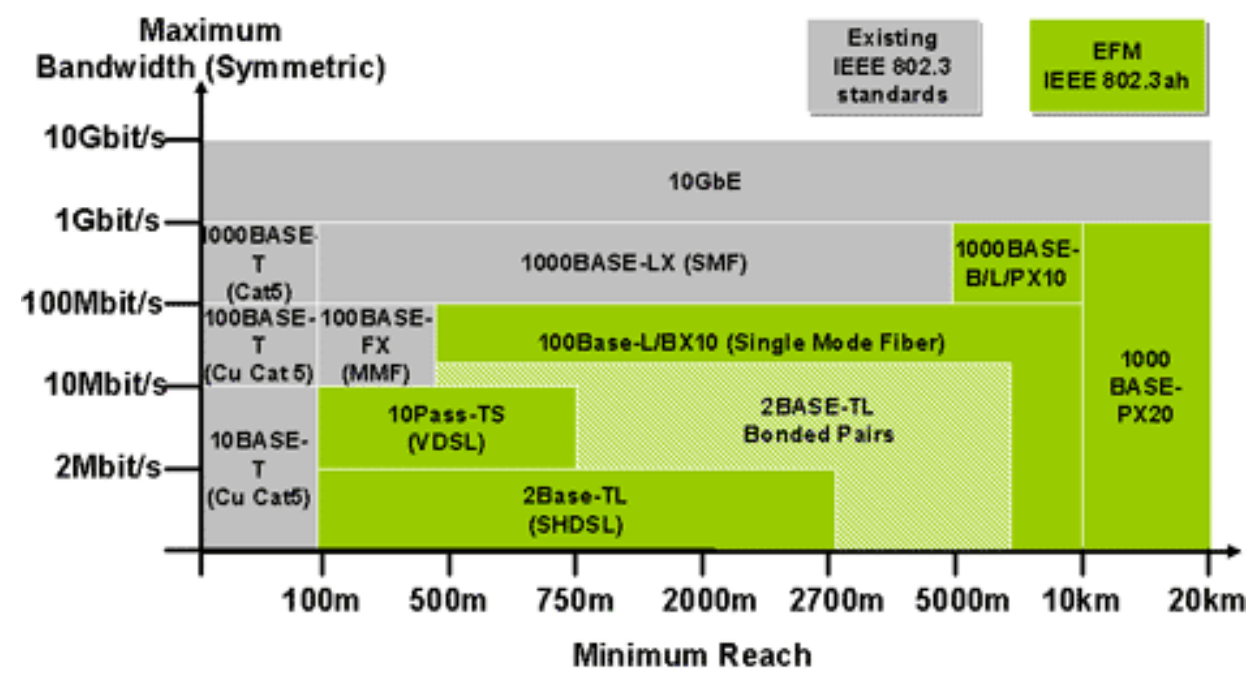

Figura 3.20 Comparação entre o padrão 802.3ah e os outros padrões 802.3.

O padrão define os meios que permitem a transmissão, alcançando de $100 \mathrm{~m}$ a $20 \mathrm{~km}$, provendo bandas de $2 \mathrm{Mbit} / \mathrm{s}$ a $1 \mathrm{Gbit} / \mathrm{s}$. O padrão 802.3ah especifica:

- Ethernet in the First Mile PON (EFMP), também conhecida como EPON: Provê transmissão simétrica ponto-multiponto de $1 \mathrm{Gbit} / \mathrm{s}$ sobre fibra monomodo, com alcance de 10 a $20 \mathrm{~km}$.

- Ethernet in the First Mile Fiber (EFMF): Provê 100 a 1000 Gbit/s em uma conexão ponto-a-ponto sobre fibra monomodo, com alcance de até $10 \mathrm{~km}$.

- Ethernet in the First Mile Copper (EFMC): Utiliza par-trançado de cobre em conexão ponto-a-ponto, para prover $10 \mathrm{Mbit} / \mathrm{s}$ numa distância de $750 \mathrm{~m}$ (com tecnologia VDSL) ou $2 \mathrm{Mbit} / \mathrm{s}$ numa distância de $2.700 \mathrm{~m}$ (com tecnologia SHDSL). 
O padrão 802.3ah também define soluções híbridas e especifica um sistema de operação e manutenção que torna o acesso Ethernet uma tecnologia de padrão de operadoras (carrier-grade). 


\section{4 - TIPOS ACESSOS COM FIBRA ÓPTICA:}

\section{1 - REDE DE ACESSO}

A rede de acesso é a parte da rede de comunicação que conecta o usuário final a um ponto de terminação na planta ligado ao nó de acesso. A rede de acesso é definida de forma a fornecer ao usuário as diferentes aplicações que ele deseja e que seja economicamente viável para a operadora de telecomunicações. $\mathrm{O}$ investimento principal das telecomunicações é feito na rede de acesso e pode até mesmo exceder $50 \%$ do capital total investido em determinada área. Os elementos da rede de acesso são mostrados na figura 4.1.

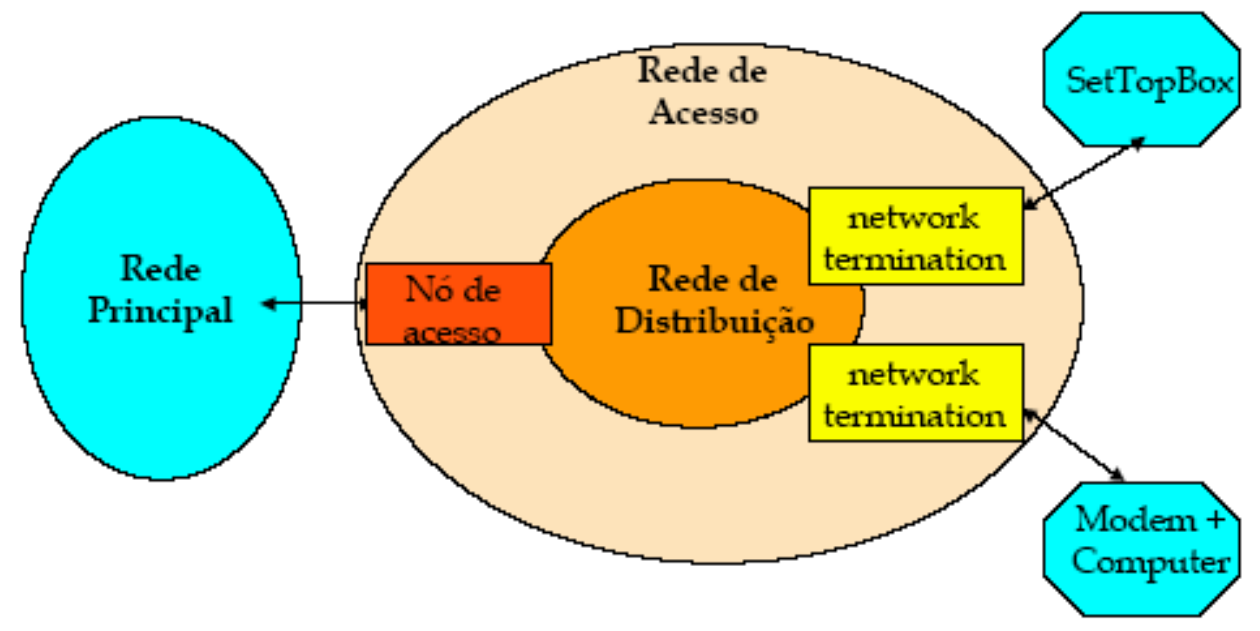

Figura 4.1 Elementos da rede de acesso.

O Nó de Acesso é o ponto de conexão à rede principal. Suas funções principais são de conversão de velocidade de transmissão e conversão de protocolo.

A rede de distribuição possui tipos diferenciados como: wireless, fibra óptica, cabo de par trançado, cabo coaxial ou até mesmo a combinação desses. Além disso, possui diferentes topologias, como em estrela e barramento.

O network termination é o ponto de demarcação entre o domínio público e o privado e pode ser passivo, apresentando somente a função de conexão, ou ativo, apresentando as funções de conversão de sinais e conversão de protocolos. 
Nunca antes na história uma rede de acesso foi tão importante a ponto de fazer com que os fornecedores procurassem novas maneiras para entregar serviços de banda larga a seus usuários finais. Serviços esses que geram novos rendimentos ajudam-lhes a reter e a atrair novos clientes além de aumentar os lucros. A fibra é vista como a melhor alternativa, em longo prazo, de acesso às tecnologias broadband, seria uma tecnologia que permite não somente que se gere novos serviços, mas também permite que os se obtenha significantes e duradouras reduções em despesas de operação além de se deslocar as despesas de tecnologias mais velhas para tecnologias que, apesar de serem mais novas, são mais baratas.

O maior fator de excitação em torno da rede de acesso por fibra é o que se chama de Triple Play, a oportunidade de oferecer de uma só vez aos clientes finais serviços de alta velocidade de dados, de voz e de vídeo. O mercado para o Triple Play é grande e crescente e inclui não só residências como também negócios em prédios comerciais. Os centros comerciais dados e os serviços de vídeo, de um único vendedor e em uma única conta, direto no seu próprio escritório. Tendo o Triple Play como principal objetivo, os fornecedores estão explorando a melhor maneira de mover a fibra cada vez mais para perto do usuário.

Todos vêem o Triple Play como um serviço forte e competitivo de se oferecer, agora e no futuro. Vislumbra-se a fibra como a maneira de levar ao usuário não só o Triple Play, mas também outros serviços novos tais como o ensino à distância, jogos interativos e telemedicina. Hoje, as redes de fibra óptica vêm em muitas variedades, dependendo do ponto de terminação: Premise (FTTP), Home (FTTH), Curb (necessitam de mais largura de banda e de muitos outros serviços avançados que somente a fibra poderá entregar quando o Triple Play oferecer a conveniência de receber a voz, os FTTC) ou Node (FTTN). Para simplificar, denominou-se a rede via fibra como FTTx, em que x está para o ponto de terminação. Existe, porém, uma enorme variedade de arquiteturas de FTTx a se considerar. Não existe, hoje em dia, uma arquitetura única que serve para qualquer aplicação. Assim, tem que se tomar uma série de decisões quanto à tecnologia baseadas em seus objetivos finais. Uma consideração preliminar é quando se empregar uma rede ativa (ponto-a-ponto) ou passiva (pontomultiponto). A figura 4.2 mostra as diferentes arquiteturas utilizadas. 


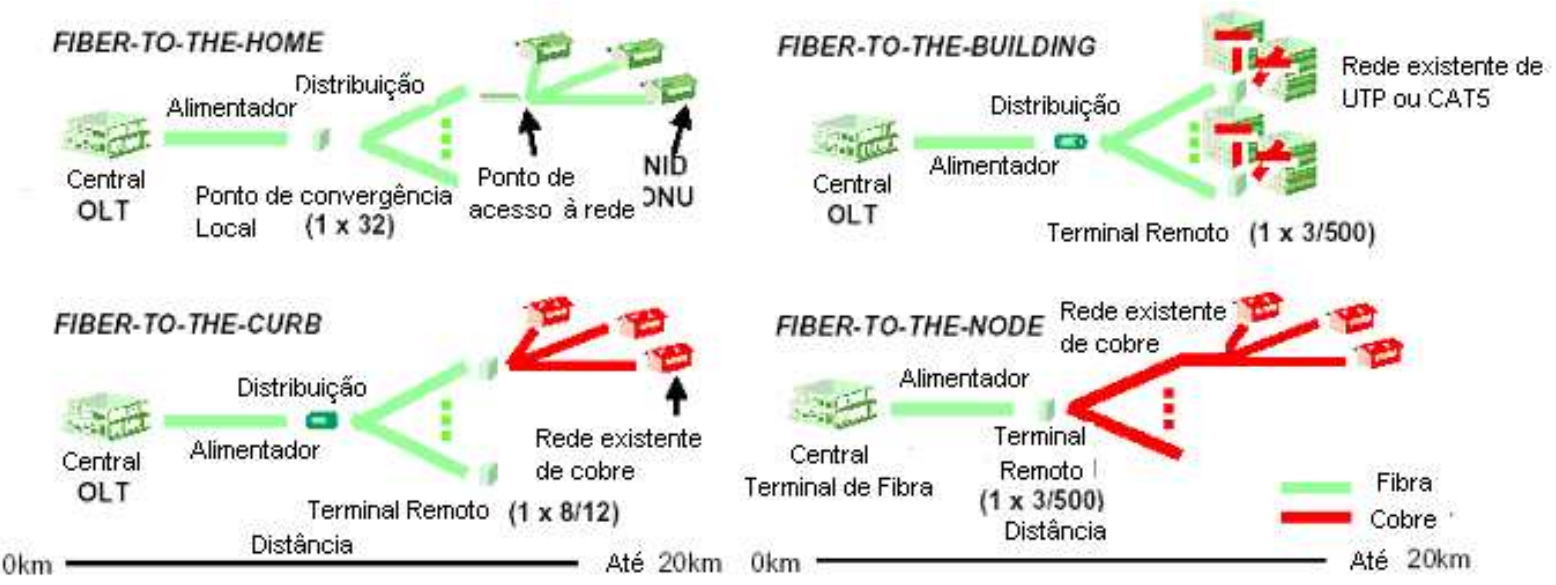

Figura 4.2 Diferentes arquiteturas do FTTX.

A penetração da fibra está fortemente correlacionada ao throughput da largura de banda de cada arquitetura definida e, conseqüentemente, à potencialidade do serviço para o operador. As exigências da largura de banda de cada usuário diferem, mas todos estão crescendo. $\mathrm{O}$ operador deve levar isso em conta quando decide qual arquitetura deve ser utilizada para cada cliente. A penetração da fibra é também um indicador de CAPEX (despesas em investimento) e de OPEX (despesas de operação esperadas). Arquiteturas com alto grau de riqueza de fibra resultarão em um CAPEX mais elevado, mas está praticamente igual ao custo com todas as novas configurações de arquitetura. A alta riqueza de fibra entregará a quantidade máxima de economias de OPEX comparável. As redes FTTH permitem que sejam feitas economias já que ocorrem reduções no custo da rede, da sede e das operações de planta externa assim como o serviço de cliente. A confiabilidade da rede aumenta dramaticamente também, com FTTH assegurando um fluxo constante do rendimento e de satisfação do cliente. [7]

\section{2 - FTTH:}

FTTH é simplesmente os $100 \%$ da distribuição da fibra óptica na rede de acesso. É geralmente desdobrado em duas configurações específicas. Na primeira, a fibra é dedicada a cada usuário na rede de acesso. Isto é chamado de rede ponto-a-ponto (PTP). Na segunda, uma fibra é compartilhada (através de um divisor de potência - splitter) entre um número especifico 
de usuários, tipicamente entre dezesseis e trinta e dois. Isto é denominado de rede óptica passiva (PON), como já mostrado anteriormente. Há vantagens e desvantagens quanto à distribuição das redes em PTP e PON baseadas em custos, na largura de banda e considerações de componentes. As redes de PTP são caracterizadas pelo uso de uma única fibra e um único laser por usuário. São as redes mais simples de FTTH para se projetar. As redes de PTP são às vezes chamadas como as redes all-optical Ethernet (AOEN). A figura 4.35 ilustra diversos exemplos de como as arquiteturas PTP puderam ser desdobradas: uma fibra dedicada tem suas terminações no usuário final e em dispositivos na sede, ou Central Office (CO), para um fornecedor, ou extremidade no caso de um operador da tevê de cabo (CATV) ou de um dispositivo remoto no campo. O dispositivo ou o interruptor remoto no campo são sempre dispositivos ativos e devem ser potencializados. Tanto fibras monomodo quanto multimodo podem ser usadas ao longo de toda a rede. As redes de PTP têm dispositivos eletrônicos ativos no campo, são inerentemente simples, são "fibras-ricas" e não requerem nenhum compartilhamento de fibra ou de largura de banda para o usuário final.

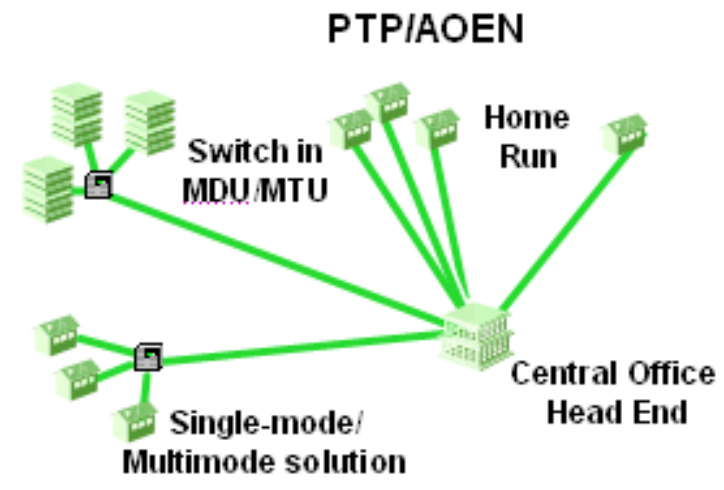

Figura 4.3 Arquitetura PTP em FTTH.

As PONs são caracterizadas pela divisão da fibra óptica uma ou mais vezes no campo, tendo por resultado o compartilhamento da fibra óptica entre usuários múltiplos. A divisão da rede é realizada por um divisor óptico (splitter), que devido a sua natureza, podem introduzir elevadas perdas inerentes na rede. Conseqüentemente, seu uso é limitado por causa das considerações orçamentárias de potência da rede. Uma rede PON terá menos "riqueza óptica" do que uma rede PTP, que não usa splitters. Tipicamente, uma rede PON é capaz de alcançar usuários que estão a 20 quilômetros do transmissor original, que cobrirá 98 por cento da 
população. Uma rede PON não usa nenhum dispositivo eletrônico no campo, é suportada por padrões maduros e é a arquitetura mais extensamente desdobrada de FTTH nos Estados Unidos. A figura 4.4 ilustra as configurações múltiplas de uma rede PON.

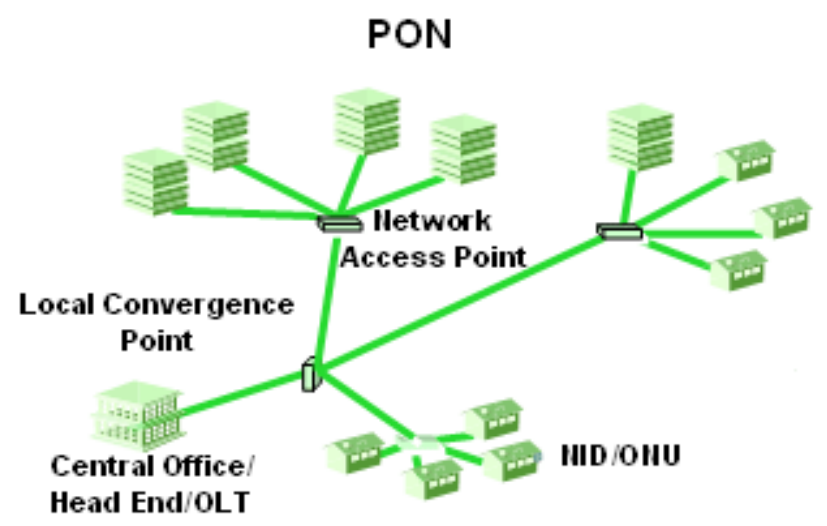

Figura 4.4 arquitetura PON em FTTH.

As operadoras que exploram uma rede PON têm escolhas adicionais de arquitetura a fazer decidindo-se entre um divisor centralizado e um arranjo de divisor distribuído ou cascateado. Ambos são utilizados com intuitos diferentes dependendo dos tradeoffs de suas características específicas.

Primeiramente, todos os splitters podem ter uma posição "central" como pode ser visto na figura 4.4. Nesse caso, os provedores procuram a máxima eficiência no CO/HE e utilizam splitter de 1x32 para maximizar a capacidade compartilhada da rede. Isto resulta em minimizar o número de transmissores usados no CO/HE e nos splitters. Nesse caso, os splitters se situam tipicamente em um armário chamado de LCP, que é o lugar onde as extremidades do cabo de alimentador e o cabo de distribuição começam (daqui cada cliente tem uma fibra dedicada). Quando um cabo da distribuição aproxima-se de um usuário, um ponto de rede (NAP) será usado para alcançar um número pequeno de fibras ópticas no cabo. Deste ponto, os cabos pendentes, contendo geralmente uma a quatro fibras, são usados para conectar ao ONT. A arquitetura com splitters centralizados fornece uma medida melhor da perda total para a PON, aumentando dessa maneira a confiabilidade da rede. Um único divisor 1x32 tem menos perda do que vários outros conectados em cascata, o que melhora o alcance óptico e reduz o número de componentes ópticos. essa forma, é diretamente proporcional ao aumento da confiabilidade da rede através da redução nos pontos da falha. Além disso, o 
splitter centralizado minimiza as despesas em investimento (CAPEX) dos divisores inicialmente na rede. Outra vantagem é a simplicidade da pesquisa na busca de defeitos na rede e da posição de falha que traduzem diretamente em economias de trabalho e tempo.

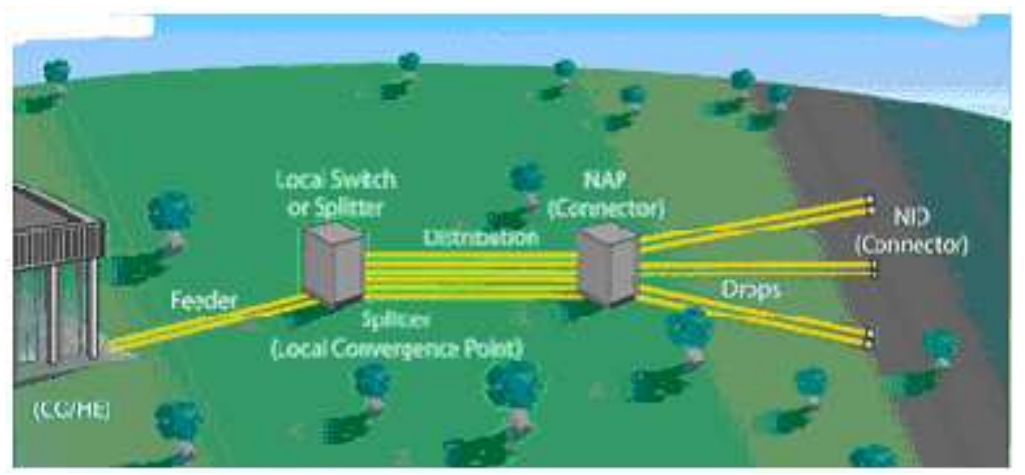

Figura 4.5 Rede PON com splitter central.

Uma configuração de splitters distribuídos ou em cascata introduz os divisores de forma mais profunda na rede, figura 4.6. Como os splitters não são centralizados, a exigência de LCPs fica reduzida ou removida, pois os divisores são incorporados geralmente em cercos modificados ou na parte traseira uniforme no $\mathrm{CO} / \mathrm{HE}$. O compartilhamento de um transmissor entre 32 usuários ainda é conseguido com a distribuição de divisores múltiplos ao longo da rede. Posicionar mais profundamente os divisores pode resultar no "stranding" de recursos enquanto o operador espera por usuários novos na rede ou taxas da tomada é baixa. busca por falhas na rede pode ser mais difícil porque o equipamento de teste deve analisar a disposição dos splitters ao longo do laço óptico. A confiabilidade da rede pode ser afetada pelo maior número de componentes ópticos.

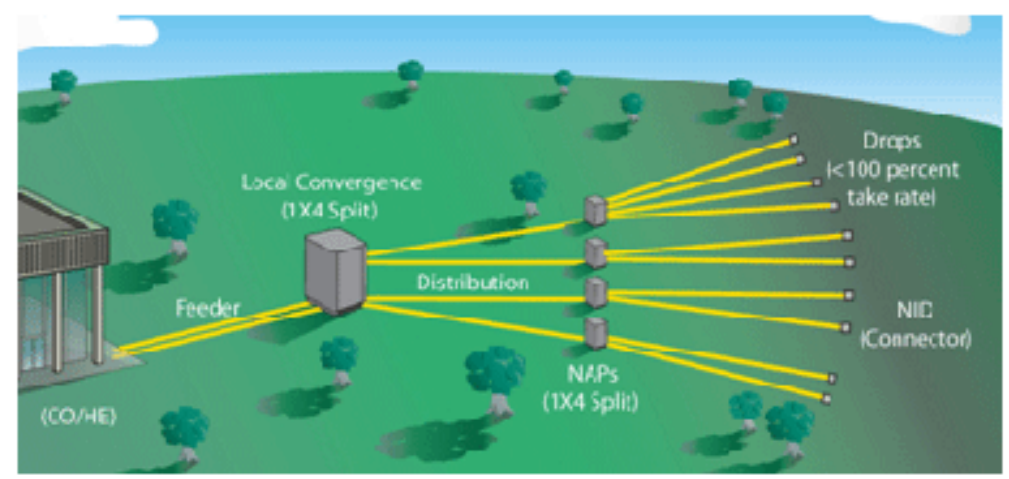

Figura 4.6 Rede PON com splitter distribuído ou cascateado. 
Os padrões de transmissão utilizados em redes FTTH são baseados no ATM e nas tecnologias da Ethernet. Os provedores são extremamente familiarizados com ambas as tecnologias, que suportam uma ampla variedade de serviços. Hoje, a maioria das redes PTP usa a tecnologia da Ethernet e são governadas pelo IEEE 803.2ah. As redes de PTP são simplesmente uma extensão Ethernet usada em espaços metropolitanos e empresariais e estendida na rede de acesso. As taxas de transmissão são limitadas somente ao tipo do transmissor no $\mathrm{CO} / \mathrm{HE}$ e na residência. Como já foi visto, as redes PON oferecem diferentes protocolos com diferentes capacidades: APON, BPON, GPON e EPON.

Então, resumindo, FTTH leva a fibra diretamente nas moradias residenciais individuais. Está completamente livre do cobre na planta exterior e fornece tipicamente um serviço que vai de $30 \mathrm{Mbps}$ até $100 \mathrm{Mbps}$, mas, por causa das características inerentes da fibra óptica, pode fornecer literalmente uma largura de banda infinita.

\section{3 - FTTB}

O FTTB usa tipicamente a arquitetura de PTP na planta exterior, fornecendo uma fibra dedicada a cada edifício ou bloco de edifícios. A fibra é finalizada em um terminal remoto (RT), que é um dispositivo ativo que requer potência e segurança no armário de utilidade. Se o edifício for equipado com cabo CAT5 a cada unidade da moradia, uma rede local do Ethernet (ELAN) está instalada para fornecer uma largura de banda compartilhada de $10 \mathrm{Mbps}$ ou de 100 Mbps. Se somente o par trançado estiver disponível, o RT é uma linha digital multiplexada do usuário final do acesso (DSLAM) e está instalado para fornecer os serviços da largura de banda exigida que oferecem até $50 \mathrm{Mbps}$; as aplicações de hoje de FTTB estão fornecendo aproximadamente $10 \mathrm{Mbps}$. 


\section{4 - FTTC e FTTN:}

As redes FTTC empurram, tipicamente, a fibra para aproximadamente 500 a 1.000 pés $(152,4 \mathrm{~m}$ a $304,8 \mathrm{~m})$ do usuário final, terminando em um RT e servindo entre oito e doze usuários.

As redes FTTN são similares as FTTC quanto a arquitetura. Mas, nas redes FTTN, o RT é posicionado bem mais distante dos usuários, acima a 5.000 pés (1.524 m). Além disso, o mesmo RT serve de três a 500 usuários. Ambos utilizam um par trançado existente fora da planta para se conectar ao cliente. A largura de banda é ditada pela tecnologia de DSL e pelo comprimento do par trançado de cobre. Tanto o DSL (VDSL) quanto o VDSL2 trabalham melhor com maiores comprimentos de par trançado e são predominantemente utilizados nas redes FTTN. No caso das redes FTTC, são mais utilizados DSL2 symmetric (ADSL2), 2+e 2++. Os sinais sobre o cobre degradam significativamente a longas distâncias, afetando diretamente a potencialidade da largura de faixa. Nas circunstâncias mais extremas (quatro a cinco quilômetros), alguns clientes não poderão ser servidos por DSL. Se as condições permitirem, em alguns casos, o portador usará ambos os pares trançados para aumentar o throughput da largura de banda. Ambas as arquiteturas tiveram recursos para o serviço de aproximadamente $20 \mathrm{Mbps}$ no laboratório. Devido a comprimentos de cobre mais curtos em uma rede FTTC, o operador melhorou o excalassilidade da perspectiva da largura de banda. As distribuições em grande escala de FTTC e de FTTN estão sendo planejadas para o futuro. 


\section{5 - ESTUDO DE CASO}

Este capítulo apresenta e discute algumas situações práticas na aplicação de uma rede de acesso de fibra óptica. $\mathrm{O}$ estudo considerado baseia-se em uma análise da situação atual de mercado e das aspirações da população. Leva-se em consideração a concorrência entre tecnologias de acesso e crescimento na demanda por serviços de banda-larga.

Pode-se verificar a penetração do acesso banda larga em diferentes países, em números de acessos por 100 habitantes na figura 5.1:

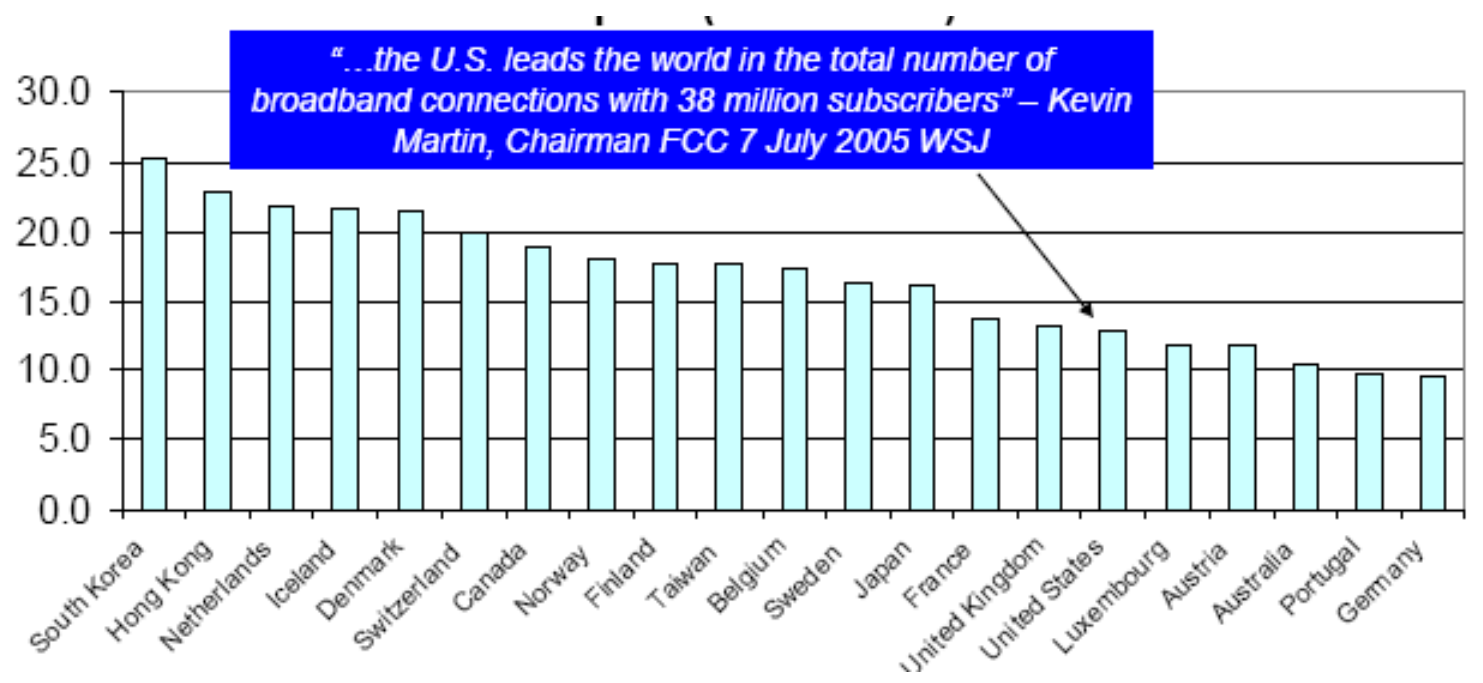

Figura 5.1 Penetração do acesso banda larga

A previsão de utilização de FTTH é bastante promissora, estando ainda em um estágio inicial do crescimento, figura 5.2:

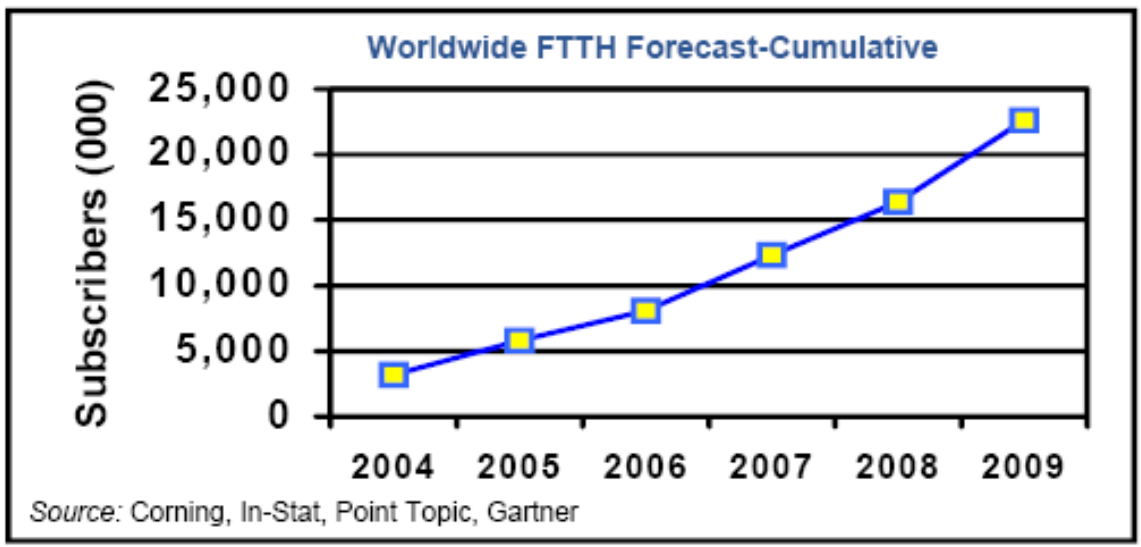

Figura 5.2: Estimativa de usuários de FTTH 
Na Europa, há alguns exemplos de implementação de FTTH:

- Suécia: Na área nordeste foi implementado na região de Västerbottena, com uma população de 260 mil habitantes;

- Finlândia: Há FTTH em aproximadamente 10 mil residências e 2000 estabelecimentos comerciais;

- Países Baixos: Possui vários projetos em Amsterdam, Rotterdam e Kenniswijk.

- França: A France Telecom implementou GPON em aproximadamente 10 mil residências.

A expectativa de implementação de FTTH na Europa é mostrada na figura 5.3:

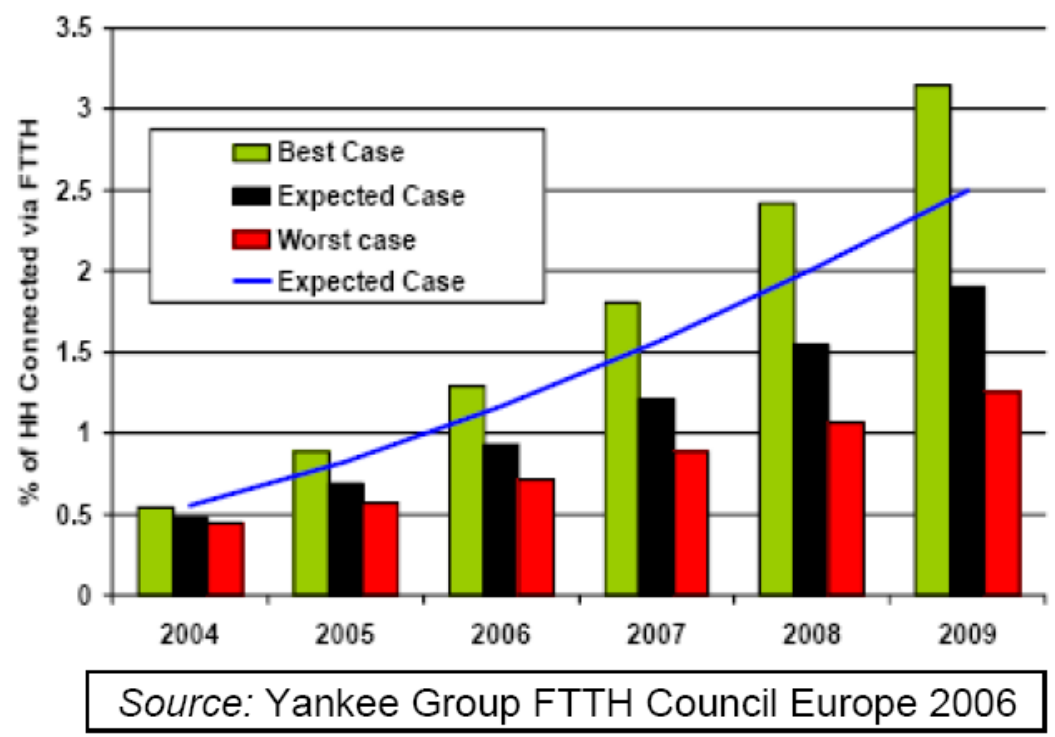

Figura 5.3: Previsão de implementação de FTTH na Europa

A situação de FTTH na Ásia é bastante avançada e o Japão é o líder mundial nesta tecnologia, tendo a quantidade de usuários FTTH ultrapassado a de usuários de modens e ADSL no ano de 2005. Espera-se que os novos usuários de FTTH continuem a uma taxa de 160 mil por mês, Figura 5.4 . 


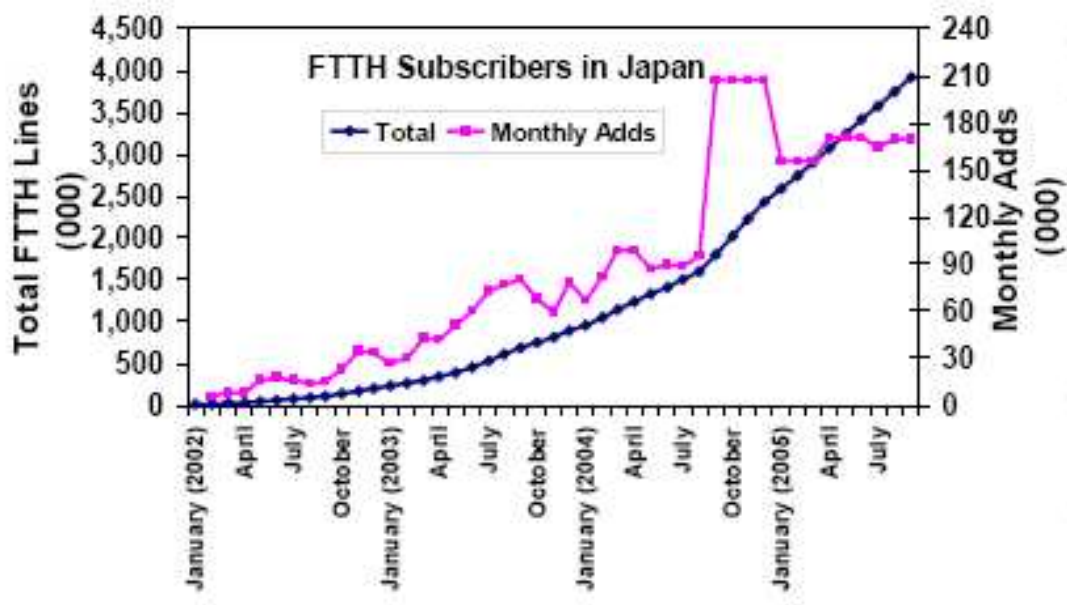

Figura 5.4 Situação de FTTH no Japão.

Além do Japão, tem-se a situação da Korea, que é um país que chegou à saturação do DSL e do cabo, tendo que promover a utilização dos serviços banda larga para utilizar sua banda disponível.

Nos Estados Unidos, o crescimento da utilização da fibra diretamente no acesso foi bastante significativo no ano de 2005, como pode ser visto na figura 5.5.

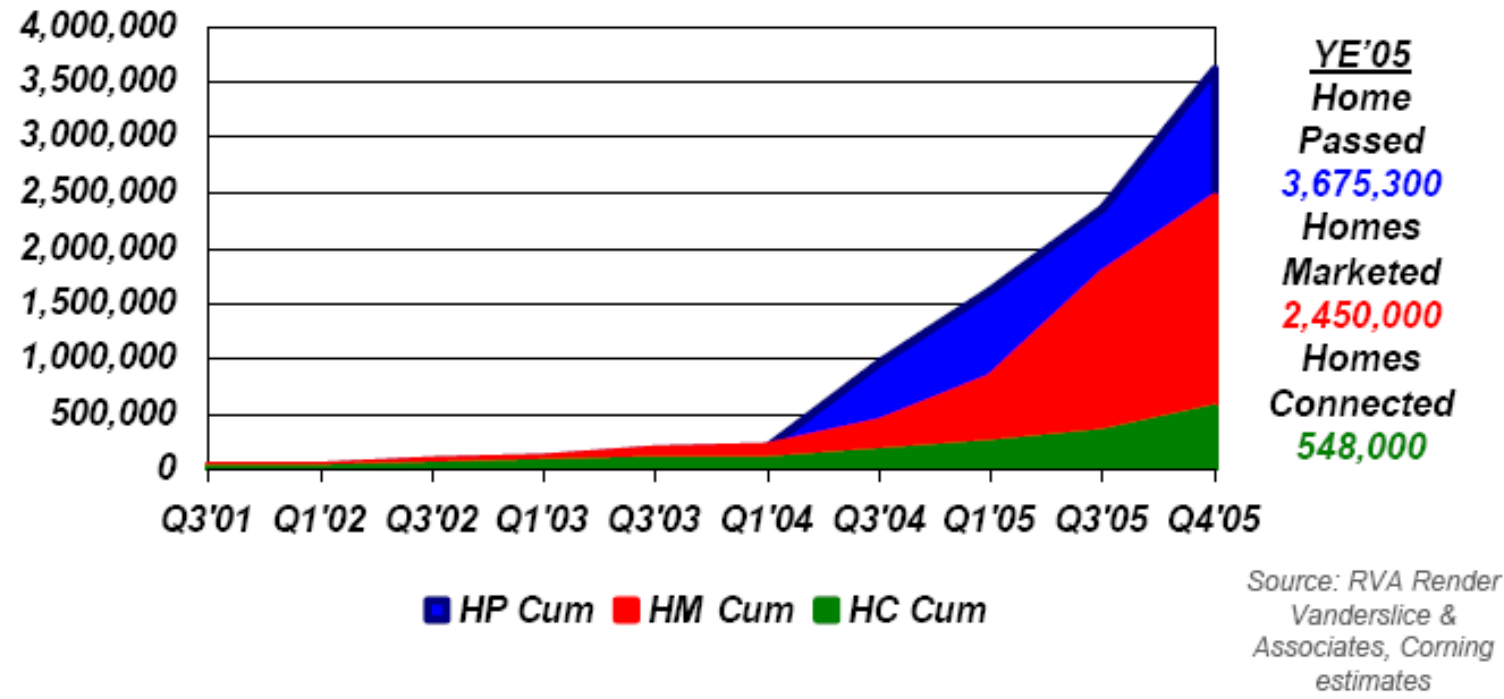

Figura 5.5 Número de usuários FTTx nos EUA.

Na América Latina, há alguns projetos em fase inicial. 
- A Telefônica pretende fazer testes de FTTH, utilizando preferencialmente a tecnologia GPON;

- Há também um projeto em Santa Catarina, financiado pelo BNDES para conectar os usuários de 48 cidades em FTTC;

- A Embratel está realizando um estudo com EPON para conectar 130 mil residências nas maiores cidades brasileiras;

- Em Monterrey, no México, a Interfibra conectou 1200 residências na primeira fase de implementação e pretende chegar a 30 mil residências em uma segunda fase.

Por esses dados, percebe-se que a tecnologia FTTH é uma realidade e está sendo testada e implementada em vários países do mundo.

\section{1 - ESTRATÉGIAS DE PLANEJAMENTO}

A elaboração de estratégias de planejamento envolve a definição de alguns itens importantes. O setor de telecomunicações é hoje extremamente dinâmico e, devido a esse dinamismo, o horizonte para planejamentos de redes de acesso não deve ser longo para que não se comprometam os dados de entrada, como previsões de demandas e serviços, preços, custos e escolha de tecnologias.

A definição dos serviços deve considerar alguns importantes fatores como a Qualidade do Serviço (QoS) exigida, a aceitação do serviço (taxa de penetração) na área em estudo e a sua receita (anual ou mensal) estimada. Essas informações variam ao longo do tempo e devem ser acompanhadas pelo processo de planejamento. No caso das projeções de demanda, por exemplo, há ainda algumas regiões com altos índices de demanda reprimida para o serviço de voz, tanto na telefonia fixa quanto na móvel; quanto às projeções de tarifa, existe uma tendência de queda destes valores em função de um ambiente de maior concorrência e maturidade tecnológica.

A área de atendimento que define uma rede de acesso é aquela delineada por uma central de comutação (CC). A rede pode ser representada por um grafo, composto por arcos e 
nós. Cada trecho da rede (arco do grafo) representa as conexões físicas entre os nós e possui como atributos, por exemplo, quantidade de pares metálicos e dutos disponíveis. Os nós de rede podem ser:

- Nó de CC: corresponde ao prédio onde está localizada a central (ou centrais) de comutação. CT no STFC, CCC no SMC ou POP (provedores de Internet/ comunicação multimídia);

- Nó de Acesso: é um ponto intermediário entre a CC e o usuário (por exemplo, armário de distribuição no STFC e ERB no SMC), onde estão localizados alguns equipamentos ativos da rede;

- Nó de Usuário: é um ponto terminal no sistema, onde se localiza (ou se encontra) o assinante.

Para simplificar o planejamento, pode-se considerar o nó de acesso como ponto de concentração de demanda, ou seja, em cada nó de acesso deve ser conhecida a demanda de todos os serviços considerados, para cada período do planejamento.

A escolha das soluções tecnológicas de acesso só é possível após a definição da variedade de serviços a ser oferecida e do tipo de rede a ser dimensionada. Eleger soluções tecnológicas implica, entre outras coisas, em saber quais são os dispositivos de rede (equipamentos, cabos, infra-estrutura etc.) a serem considerados para efeito de planejamento e como eles são dimensionados nos nós da rede (nós de controle, de acesso e de usuário); é preciso, também, estimar o custo de cada dispositivo considerado, para todos os períodos de planejamento. A atualização dos dados é um fator importante para o estudo de casos em planejamento de redes. Os dados necessários para realização de um estudo de caso são divididos em duas classes: os dados gerais de planejamento, que não possuem relação com a rede a ser estudada, e os dados de rede propriamente ditos. Os dados gerais de planejamento mais relevantes são:

- Dados de custo e dimensionamento dos equipamentos;

- Dados de custo (por unidade de comprimento) dos cabos, tanto metálicos como de fibras ópticas; 
- Dados de infra-estrutura como canalização de dutos (por unidade de comprimento) e sub-dutos e ampliação no centro de fios (obras civis).

Os principais dados de rede a serem levantados pelo planejador são:

- Rede de dutos da área considerada, informando a quantidade de dutos disponíveis em cada arco. A rede de dutos é formada pelos arcos (canalização subterrânea) e os nós de controle

- Quantidade de pares metálicos disponíveis em cada arco;

- Quantidade de fibras disponíveis em cada arco;

- Demanda concentrada em cada nó de acesso, para cada serviço considerado e para cada período de planejamento;

- Localização da CC e dos nós de acesso.

No panorama atual, onde as empresas enfrentam grandes concorrências, é esperado que os objetivos frisados pelos planejadores sejam conflitantes. Por isso, é de extrema importância que o planejamento da rede seja realizado de forma otimizada, utilizando-se modelos matemáticos. Os critérios de otimização mais significativos e prováveis de serem adotados pela empresas operadoras são: maximizar a receita respeitando um limite orçamentário, maximizar a receita a um custo mínimo, maximizar o lucro, atender toda a demanda prevista a um custo mínimo etc.

Um estudo de caso pode ser composto por vários cenários. Um cenário pode planejar a expansão de determinada área de atendimento, já em funcionamento, ou pode planejar a implantação de uma área totalmente nova, chamada situação "green field". Além disso, o cenário pode utilizar uma ou mais soluções tecnológicas, que irão concorrer entre si para a implantação e expansão da rede de acesso. A diversidade de simulações ajuda os planejadores a visualizarem melhor a situação da rede. 


\section{2 - PRIMEIRO CASO: FTTH COMMUNICATION}

O seguinte exemplo foi todo idealizado pela FTTH Communications, que é um fornecedor integrado de voz, de vídeo e de serviços de Internet em Minneapolis. Provendo serviços aos clientes residenciais e comerciais (de negócio) em uma rede toda constituída de fibra, a planta de negócio da FTTH Communications se baseia em uma combinação de baixos custos, de serviços de altíssima qualidade, e de tecnologia de ponta para aumentar o número de usuários finais e a satisfação total dos mesmos.

Os gerentes da organização tinham visto, de outros projetos de FTTH em torno do país, que variar as taxas previamente estabelecidas podem impactar no lucro e drenar o capital de usos mais produtivos, tais como a criação de serviços avançados. O desafio era criar uma infra-estrutura que mantivesse o investimento tão perto quanto possível da receita e, ao mesmo tempo, oferecer custos de operação reduzidos, de modo que o investimento em novos serviços fosse possível.

\subsection{1 - Solução}

A FTTH Communications achou que a melhor arquitetura para prover o serviço era uma rede óptica passiva (PON) com os splitters passivos centralizados nos hubs de distribuição da fibra (FDH - Fiber Distribution Hubs). Os splitters eram 1x32 especificados para espelhar a capacidade portuária nos OLTs. Com nenhum splitter nos terminais de acesso (AT) mais perto das casas, a FTTH Communication pode maximizar o uso das portas em cartões caros de OLT.

Para ilustrar, a companhia usa cartões OLT de quatro portas no centro de dados. Cada porta suporta 32 casas, cada cartão de OLT suporta, então, um total de 128 casas. Cada vizinhança é suportada por seu próprio FDH, até 1.152 casas. Os primeiros 32 usuários da vizinhança são conectados ao mesmo splitter 1x32 no FDH. Este splitter é suportado pelo cartão número 1 de OLT no centro de dados. Quando o $33^{\circ}$ usuário é adicionado, o splitter seguinte no FDH é posto em uso, que utiliza então a porta de número dois no cartão de OLT número 1 . Somente quando o $129^{\circ}$ usuário assina o serviço aparece uma exigência de comprar e transferir o serviço para o cartão número 2 de OLT no centro de dados. 
Esta arquitetura de splitters centralizados adia eficazmente a despesa para mais perto da geração de rendimento. A arquitetura alternativa, splitters tanto nos FDHs quanto nos ATs, é uma proposta relativamente cara. Na proposta anterior, 128 usuários finais de 1.152 casas podem ser servidos com um único cartão OLT quando os splitters são centralizados no FDH. Contudo com os splitters estão tanto nos FDHs quanto nos ATs, serão necessários cartões adicionais de OLT no centro de dados, o que resultará em usuários sendo espalhados através de mais cartões OLT do que seja necessário para a contagem do cliente. De fato, com qualquer taxa abaixo de 100\%, quando os splitters são colocados em FDHs e em Ats, haveria sempre portas inutilizadas e encalhadas em cartões, caros, de OLT.

O FDH oferece também o benefício adicional de custos mais baixos caso seja necessário fazer um up-grade nos serviços, isso porque são utilizados conectores, não talas, para adicionar usuários e serviços. Caso o negócio cresça, a FTTH Communications fará economias operacionais porque o up-grade do serviço pode ser feito mais rapidamente e com os técnicos menos-hábeis e mais baratos.

Analisando o FDH utilizado, observa-se a possibilidade de utilizar mais sete splitters 1x32. O cabo de distribuição está finalizado com segurança em uma espécie de estacionamento até que um usuário esteja ativado, figura 5.6. Neste FDH novo, um usuário é ativado, mostrado pelo ponto vago no "estacionamento" e no cabo de distribuição etiquetado.

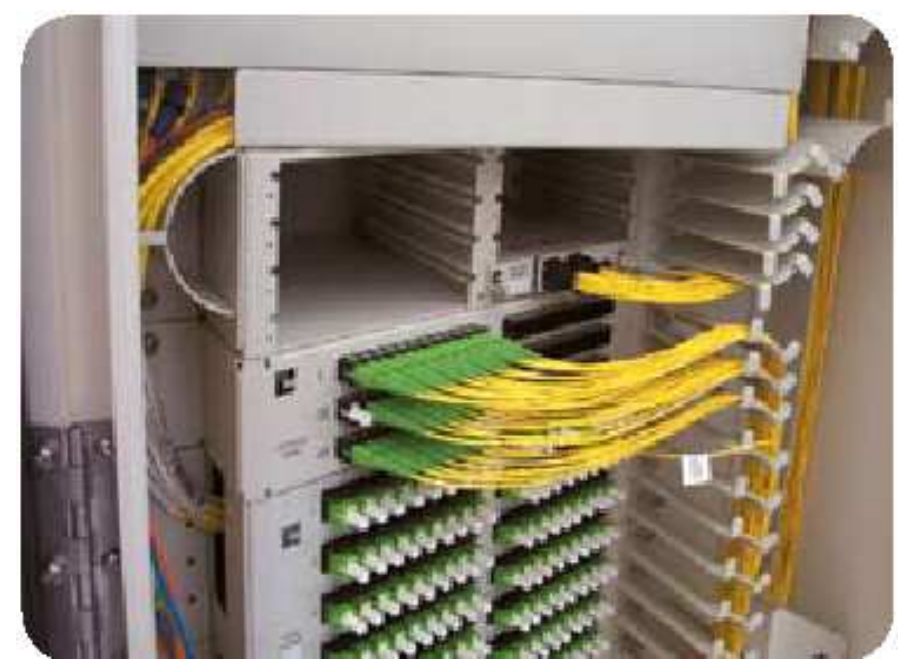

Figura 5.6 Detalhe no FDH. 
Então, o principal benefício da solução encontrada pela ADC é a possibilidade de espelhamento da capacidade das portas de OLT com os splitters 1x32 centralizados, a alta densidade e FDHs fáceis de manejar. Esta arquitetura centralizada do splitter 1x32, permitida pelo projeto do $\mathrm{FDH}$, atrasa investimentos importantes na planta externa e reserva mais investimento em serviços principais de borda para os usuários.

\subsection{2 - Implementação}

John Schultz, gerente geral da FTTH Communications disse que havia um problema com o tipo de arquitetura na qual o splitter ficava de forma distribuída nos ATs. Muito dinheiro é gasto enterrando e há uma enorme subutilização de equipamentos eletrônicos nos pontos finais. Como configurações iniciais, a FTTH Communications tinha colocado splitters nos ATs e nos FDHs e o serviço de up-grade com talas, uma estratégia de distribuição que provou ter uma cara implementação. "A aquisição por parte do cliente nunca é lógica. Colocar splitters no ATs era um desperdício de dinheiro e ainda encarecia um eventual processo de upgrade" disse Schultz.

Dessas lições anteriores, FTTH Communications chegou à conclusão que splitters centralizados nos FDHs eram melhores tanto no sentido operacional como no custo de implementação. Contudo, quando diversos vendedores ofereceram um $\mathrm{Hub}$ centralizado para a distribuição da fibra com os splitters 1x32, as características originais do FDH balançaram a decisão de compra do ADC.

"Se você construir a planta externa corretamente, você pode realmente abaixar os custos. Isso está nos permitindo a gastar o dinheiro com novas tecnologias para os usuários”.

De fato, a FTTH Communications está no processo de substituir um cabinet mais velho que foi configurado com os splitters que não possuem nenhuma gerência para o cabo de fibra. "Nós quisemos eliminar os pontos de falha na rede. Abrigando os splitters, o cabo de distribuição e o cabo de alimentação em um cabinet sem gerência de fibra era realmente um péssimo projeto. Nós sabemos que a gerência apropriada da fibra significa menos problemas para serem tratados" disse Schultz.

Com este projeto do cabinet, o serviço de up-grade requer agora conectores de acoplamento, o que se torna melhor do que se fazer emendas. $\mathrm{O}$ uso dos conectores no FDH 
dá a FTTH Communications uma rede que pode ser construída à medida que precisa crescer. Essa é uma solução que permite a adição fácil de usuários e a instalação da eletrônica de headend paralelamente ao crescimento.

"É realmente ruim investir muito dinheiro logo no começo sem saber se haverá rendimento para cobri-lo. Este é a arquitetura certa e o produto certo para suportá-la. Financeiramente falando, dentro de um ponto de vista operacional e de projeto, nós temos a melhor solução disponível" disse Schultz.

Schultz achava que o projeto prático e lógico do FDH mostraria retornos, dentro de alguns anos, em termos de velocidade no serviço de up-grade, custos reduzidos para o serviço de up-grade e uma confiabilidade mais elevada na rede PON. Contudo o valor do FDH tornou-se aparente antes mesmo que o primeiro usuário fosse inserido no serviço.

"Nossa distribuição inicial era uma instalação muito simples" disse Schultz. "Emendar era um tipo de exploração pessoal, assim como eram o roteamento e o armazenamento da fibra. Esta foi uma das razões pela qual optamos pela ADC - eles são líderes na gerência de cabo de fibra" disse. Até mesmo a documentação que faltou do primeiro FDH enviado a FTTH Communications não causou nenhum problema, que necessitasse de edição, com a instalação. "Os caras realmente entenderam. Este era um produto totalmente novo para eles contudo, a instalação inteira ocorreu sem qualquer tipo de problema" disse Schultz.

\subsection{3 - Conclusão}

A FTTH Communications encontrou na ADC um sócio com o mesmo objetivo: abaixar os custos empurrando as despesas em investimento para o mais distante possível. Estes eram os objetivos de projeto do FDH. Contudo, o principal benefício obtido, de acordo com Schultz, foi conseguir que os usuários ficassem satisfeitos. "Se você constrói a planta externa de maneira correta, você pode realmente abaixar os custos. Isto está permitindo que nós gastemos o capital com novas tecnologias para os usuários, tais como o VDO (vídeo on demand) e a TV interativa. Nós gastamos menos com planta externa e, assim, nós podemos gastar mais em serviços" disse Schultz. 


\section{3 - SEGUNDO CASO: KUTZTOWN - FTTH}

Os Borough of Kutztown, Pensilvânia, é uma comunidade avançada - casa de mais de 5.000 residentes e posicionada estrategicamente entre Allentown e Reading. A comunidade de Kutztown é também uma cidade universitária, com a universidade de Kutztown - uma das principais escolas de negócio do nordeste - nas proximidades.

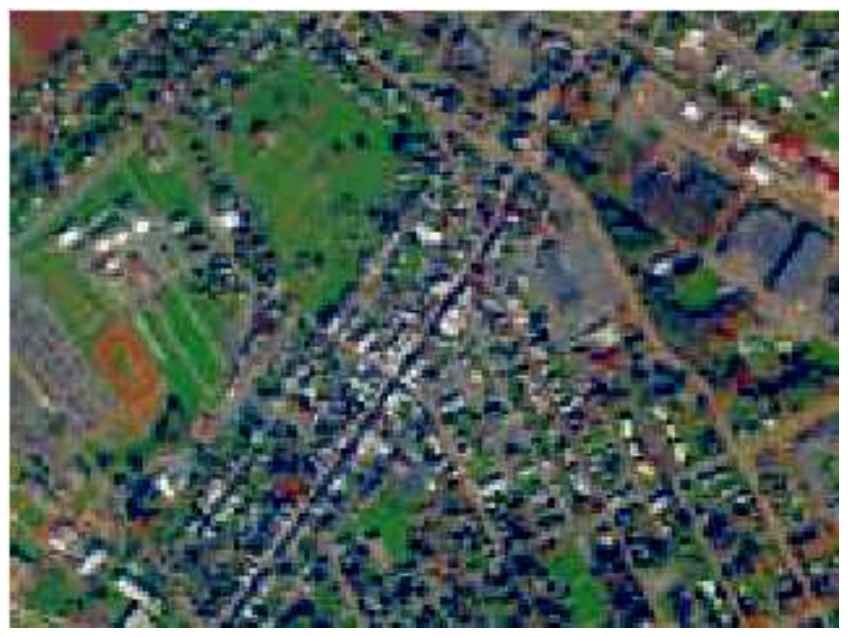

Figura 5.7 Kutztown

Quando os Borough of Kutztown e as autoridades municipais de Kutztown olharam para o futuro, eles perceberam a necessidade expandir os serviços públicos atuais para fornecer serviços mais avançados de voz, de vídeo e de dados aos cidadãos que moravam ou tinham negócios dentro de sua comunidade. Estes serviços incluem serviços de voz e conectividade à tradicional Internet de 10-100 Mbps, com um objetivo de fornecer também os serviços mais avançados que existem em termos de vídeo e de música (incluindo vídeo-ondemand e a televisão interativa) e a rede virtual confidencial (VPN). Os serviços novos tais como uma Intranet de banda larga para a comunidade, a leitura automatizada de medidor e outros serviços de gerência de energia estão sendo executados atualmente. 


\subsection{1 - Objetivos}

Os Borough ficaram tão convencidos do valor que estes serviços poderiam fornecer a seus cidadãos que criaram um programa chamado Hometown Utilicom que tinha os seguintes objetivos:

- Construir uma loja que funcionasse durante as $24 \mathrm{~h}$ do dia, assim como consolidar o faturamento e a manutenção para todos os serviços municipais e de telecomunicações;

- Oferecer serviços de valor agregado próximos ao cliente, incluindo um menu completo de serviços e de opções diversas de faturamento e de pagamento;

- Permitir a oferta de serviços avançados, tais como serviços de Internet wireless, monitoração de dispositivos, serviços de segurança tanto para a casa quanto para os negócios e avançadas formas de modelamento e armazenamento de dados.

\subsection{2 - Fibra - A Melhor Escolha}

Os Borough of Kutztown decidiram que uma rede de acesso via fibra direto na casa, FTTH, era a melhor solução de infra-estrutura para atender as necessidades de seus cidadãos agora e no futuro. De frente com tecnologias alternativas que poderiam tirar vantagem da tradicional infra-estrutura de cobre, os Borough sentiram que as soluções baseadas na tecnologia do cobre não eram a melhor solução para as demandas de serviços de hoje, e que uma solução baseada em cobre restringiria um up-grade futuro da rede para os cidadãos de Kutztown. Além disso, as soluções baseadas em cobre limitariam também a habilidade dos Borough de entregar os serviços avançados à comunidade, que aumentariam finalmente o valor de propriedade e diferenciariam os Borough of Kutztown das comunidades vizinhas.

Além disso, Kutztown descobriu que uma solução de FTTH complementaria o seu sistema elétrico municipal já existente, permitindo que eles fizessem uso do seu útil serviço público de pólo, dos serviços de atribuição e de equipamentos de construção, assim como sua competente equipe técnica de funcionários de campo para a construção, do serviço e a 
manutenção, de sua equipe de funcionários de escritório a serviço do cliente e dos serviços de marketing e de faturamento. Com estes serviços, o Hometown Utilicom podia transformar-se um enorme sucesso.

\subsection{3 - Solução}

Após terem conduzido uma avançada pesquisa de negócio tecnológica e uma análise de caso completa, os Borough of Kutztown e a autoridade municipal de Kutztown procuraram uma firma para fornecer um retorno contendo a solução, de FTTH, com o melhor custobenefício. Tirando vantagem das suas experiências e da sua perícia industrial na área de telecomunicações, o grupo Atlantic Engenharia podia oferecer aos Borough a solução pontoa-ponto que eles procuravam - combinando os equipamentos eletrônicos de FTTH da Optical Solutions com toda a infra-estrutura de planta externa da Corning Cable Systems.

Trabalhando junto com a Atlantic engenharia, a Corning Cable Systems forneceu aos Borough of Kutztown uma solução de infra-estrutura passiva completa para sua distribuição de FTTH, incluindo o cabo óptico, os fechamentos da tala e os acopladores e os splitters.

"Parte de nossa estratégia em construir uma rede FTTH reside em se construir um recurso físico chave que seja uma fonte de geração contínua de rendimento" diz Caruso frank, diretor de tecnologia de informação, para os Borough of Kutztown. "Esta aproximação nos permitirá manter os rendimentos de telecomunicações dentro dos Borough, também poderemos controlar as taxas que nossos cidadãos têm que pagar. Além disso, nós acreditamos que a construção de uma rede com um melhor custo benefício, mas de elevado grau de confiança, melhorará a avaliação e a habilidade de crédito dos Borough para solicitar maiores quantidades de dinheiro para projetos futuros".

\subsection{4 - Conclusão}

Com programação agressiva de distribuição do FTTH de Kutztown, os benefícios de se trabalhar com a Corning Cable Systems e com o grupo Atlantic Engenharia em uma solução 
de FTTH tornaram-se evidentes. O próximo relacionamento de trabalho entre as duas companhias assegurou que a rede de FTTH estivesse projetada para um desempenho livre de problemas e de altíssima confiabilidade, dessa forma, não haveria a necessidade de possíveis modificações na integração ou na qualidade de campo o que poderia resultar em uma distribuição atrasada ou em perda de desempenho.

"Trabalhando com uma indústria que é líder de mercado na infra-estrutura óptica passiva, assim com a Corning Cable Systems, nós sabíamos que estávamos abastecendo a cidade de Kutztown com uma solução de altíssima confiança - sustentada por mais de 150 anos de qualidade e reputação da marca Corning" disse James Salter, principal executivo oficial do grupo Atlantic Engenharia.

Juntas, a Corning Cable Systems e a Atlantic Engenharia estão fazendo do sonho da cidade de Kutztown uma realidade, fornecendo a seus cidadãos uma rede com um alto custo benefício que suprirá as suas necessidades de agora e do futuro e que permitirá que os mesmos se beneficiem dos serviços de melhoria de qualidade vida enquanto emergem. 


\section{6 - CONCLUSÕES}

No início, as redes de acesso banda larga eram baseadas em DSLAMs ATM, principalmente devido à ampla implantação de redes de agregação ATM e à visão que havia, durante os anos 90, sobre o importante papel que cumpriria a tecnologia ATM nas redes do futuro. Hoje em dia, o ATM é uma tecnologia madura, robusta e estável que fornece variadas ferramentas para a gerência de tráfego e controle da qualidade de serviço, mas, devido a seu elevado custo, complexidade e rigidez para transportar serviços de dados, têm motivado a busca por uma tecnologia alternativa. Como resultado desta busca, tem-se o processo atual de adoção da Ethernet como tecnologia de fato para os equipamentos de agregação das linhas DSL e, inclusive, para as redes de transporte metropolitano (Carrier Ethernet). Entra-se, então, em um segundo estágio em que, as redes de acesso de banda larga deixaram de crescer com DSLAMs ATM e têm continuado sua expansão com a tecnologia Ethernet (ou IP-DSLAMs).

A Ethernet apresenta algumas vantagens importantes como preço baixo, simplicidade e a alta capacidade, mas, a principal delas, é a naturalidade com que as aplicações de dados (IP) podem ser transportadas, o que faz dela uma excelente opção para as redes de acesso e de transporte.

Há apenas alguns anos, o serviço de Internet de alta velocidade era visto como um serviço de valor agregado e representava um fator diferenciador para as operadoras. Hoje, oferecer somente o acesso de Internet de alta velocidade não é suficiente para competir com operadoras de TV a cabo, as quais estão oferecendo ao cliente final "pacotes" de serviço (voz, Internet e TV) a preços muito competitivos. O "Triple-Play" transformou-se no objetivo de curto prazo das operadoras tradicionais de telecomunicações, que precisam atualizar suas redes (de acesso, transporte e core) para suportar as larguras de banda requeridas pelas novas aplicações. A fim de oferecer um pacote atrativo de serviços "Triple-Play" (Internet, IPTV e voz - seja VoIP ou TDM), é requerida uma largura de banda de pelo menos 8 a $10 \mathrm{Mbps}$. Cada canal de IPTV consome hoje entre 4 e 6 Mbps com codificação MPEG-2 e entre 2,5 e 3,5 Mbps com MPEG 4. Para competir com o serviço oferecido pelas operadoras de CATV, devese poder oferecer a cada usuário pelo menos 2 ou 3 canais de IPTV simultâneos. Se considerar-se, além disso, acesso a Internet (HSI) a 2 Mbps, será necessária uma largura de 
banda de downstream de aproximadamente 8 a 10 Mbps por usuário no acesso (2 canais IPTV MPEG-4 + Internet + voz).

A tecnologia ADSL2+ pode suportar larguras de banda maiores do que o ADSL tradicional, mas esta capacidade depende fortemente de fatores tais como a distância que se encontra o usuário final, a qualidade do par do cobre, a quantidade das linhas ADSL dentro de um cabo multipar (crosstalk) etc. Estimativas feitas por diversas operadoras na Europa e América Latina falam de velocidades de $10 \mathrm{Mbps}$ a distâncias de até 2 quilômetros atingíveis com o ADSL2+. Isto implica que para implantações massivas de IPTV, é necessária uma tecnologia alternativa que suporte estes níveis de largura de banda a distâncias maiores que 2 quilômetros.

A evolução do mercado e das aplicações indica que, no futuro, a tendência será chegar com fibra até a casa de cada usuário (FTTH), permitindo assim suportar aplicações que irão requer grandes larguras de banda como, por exemplo, televisão de alta resolução (HDTV, 8-12 Mbps por canal). Os sistemas de PON já foram disponibilizados, por diversos fabricantes. Esses oferecem, a um bom custo-benefício, uma escala variada de serviços de vídeo, de voz e de dados. Funcionam e são confiáveis. As redes ponto-multiponto já se tornaram uma tecnologia madura, enquanto as redes PONs são apenas uma aplicação mais nova desta tecnologia. O vídeo pode ser carregado da mesma forma que em sistemas de HFC, como transmissão analógica e como sinais digitais modulados. Pode, também, ser carregado como pacotes de IP (IPTV). O serviço de voz pode ser TDM ou baseado em padrões de VoIP. Os dados podem ser armazenados com muita eficiência e a habilidade de oferecer centenas de Megabits/segundo de velocidades de throughput permitirá que mais aplicações sejam desenvolvidas. É importante lembrar que uma vez que a fibra está enterrada e os serviços em andamento, outros serviços podem ser adicionados relativamente sem custo. O cobre é a tecnologia de hoje, fibra será pelos 50 anos seguintes.

Falando de Brasil, tem-se um cenário que sofreu diversas modificações desde a privatização do setor de telecomunicações. A concorrência entre as empresas operadoras do sistema é o ponto alto desse processo, que pode beneficiar os usuários, tanto aqueles que já assinavam algum serviço quanto os novos compradores de serviços de telecomunicações. A ANATEL tem um papel importante nesta nova condição de prestação privada de serviços de telecomunicações. Como o objetivo das operadoras do sistema é obter lucro, a qualidade do 
serviço prestado nem sempre é o esperado. É o que vem acontecendo no Brasil: a gama de serviços modernos de telecomunicações aumentou, mas a qualidade e o custo dos serviços oferecidos ainda deixam a desejar. Por isso, a agência reguladora deve estar em constante alerta para fiscalizar e garantir os direitos dos assinantes.

O crescimento intenso e incessante das demandas e a necessidade de tomar decisões importantes em espaços curtos de tempo exigem agilidade por parte das operadoras. Visando aumentar a receita e a participação no mercado, as operadoras vêm apostando em novas tecnologias, capazes de oferecer serviços inovadores e competitivos, mas o mercado latino americano ainda não está preparado para implantações massivas de FTTH, devido a seu elevado custo em infra-estrutura e equipamentos. Entretanto, em curto prazo, algumas operadoras já planejaram implantações iniciais de fibra com tecnologia GPON, mas na modalidade FTTB (Fiber to the Building) e FTTC (Fiber to the Curb).

É nessa linha de pensamento que o trabalho foi realizado e os objetivos principais cumpridos: enumerar as tecnologias existentes e mostrar, com isso, as vantagens de uma rede de acesso via fibra e sua importância na evolução das telecomunicações.

No trabalho exposto, foram apresentados exemplos de redes FTTH desenvolvidas e já implementadas ao redor do mundo, assim como considerações econômicas a respeito dessas implementações. Uma interessante continuação desse trabalho seria um estudo para uma possível implementação desse cenário no Brasil visto que diversas operadoras já solicitaram estudos semelhantes para fornecedores. 


\section{REFERÊNCIAS BIBLIOGRÁFICAS}

[1] http://en.wikipedia.org/wiki/MMDS

[2] http://inventabrasilnet.t5.com.br/ripper.htm

[3] http://kb.iu.edu/data/aesi.html

[4] http://lw.pennnet.com/articles/lw_onlinearticles.cfm

[5] http://magda.elibel.tm.fr/refs/telecom/sdh.pdf

[6] http://pt.wikipedia.org/wiki/Fibra \%C3\%B3ptica

[7] http://www.americasnetwork.com/americasnetwork/article/articleDetail.jsp?id=143906

[8] http://www.ampnetconnect.com/Portugal/fibraoptica.htm

[9] http://www.anatel.gov.br/INDEX.ASP?LINK=/AJUDA/DUVIDAS/TVC_MMDS/MMD $\underline{\text { S.HTM?COD }=79}$

[10] http://www.cisco.com/univercd/cc/td/doc/cisintwk/ito_doc/ethernet.htm

[11] http://www.clubedohardware.com.br/artigos/371

[12] http://www.corningcablesystems.com/web/pubnet/ftppub.nsf/download/migration.pdf/\$FI

LE/migration.pdf

[13] http://www.erg.abdn.ac.uk/.../digital-video/dsm-cc.html

[14] http://www.ericsson.com/technology/tech_articles/SDH.shtml 
[15] http://www.espacoacademico.com.br/007/07mendes.htm

[16] http://www.fiber-optics.info

[17] http://www.flexlight-networks.com/

[18] http://www.ftthcouncil.org/?t=84\&category=2

[19] http://www.iec.org/online/tutorials/epon/topic03.html

[20] http://www.iec.org/online/tutorials/lmds/

[21] http://www.iec.org/online/tutorials/sdh/

[22] http://www.imec.be/wwwinter/mediacenter/en/SR2005/html/142453.html

[23] http://www.lightreading.com/document.asp?doc id=86747

[24] http://www.maxarte.com.br/eduardocustodiohp/Redes/FibrasOpticas.htm

[25] http://www.maxarte.com.br/eduardocustodiohp/Redes/RDSI.htm

[26] http://www.mscmc.org/Docs/Slides/050223/050223Nulty-paper.pdf

[27] http://www.rnp.br/ arquivo/sci/2005/nakamura-roberto novastecnologias.pdf\#search = \%22GPON\%20gigabit\%20passive\%20optical\%20network\%22

[28] http://www.rnp.br/newsgen/0203/fibras_opticas.html\#ng-3-5

[29] http://www.tcil-india.com/new/new site/white\%20paper/FTTH\%20revised\%20prsntation 
$\mathrm{ppt \# 301,41}$

[30] http://www.tech-faq.com/lang/pt/ethernet.shtml

[31] http://www.tech-faq.com/lang/pt/mmds-multichannel-multipoint-distribution$\underline{\text { service.shtml }}$

[32] http://www.teleco.com.br

[33] http://www.uem.mz/ictproj/emunet/slide18.htm

[34] http://www.unicamp.br/unicamp/unicamp_hoje/ju/agosto2003/ju224pg03.html

[35] http://www.usenix.org/publications/library/proceedings/als00/2000papers/papers/full_ papers/ong/ong html/node5.html

[36] http://www.vitesse.com/technologies/index.php?id=11

[37] http://www.wcai.com/lmds.htm

[38] http://www.wcai.com/mmds.htm

[39] http://www.wcai.com/pt/especial.htm

[40] http://www.webopedia.com/TERM/M/MMDS.html

[41] http://www.xilinx.com/esp/wired/optical/collateral/PON_LRE.pdf 


\section{APÊNDICES}




\section{APÊNDICE A - TECNOLOGIAS DE ACESSO}

As tecnologias de acesso podem ser classificadas em acesso por fio ou acesso sem fio. Cada um desses dois grupos possui subdivisões como mostrado na figura A.1.

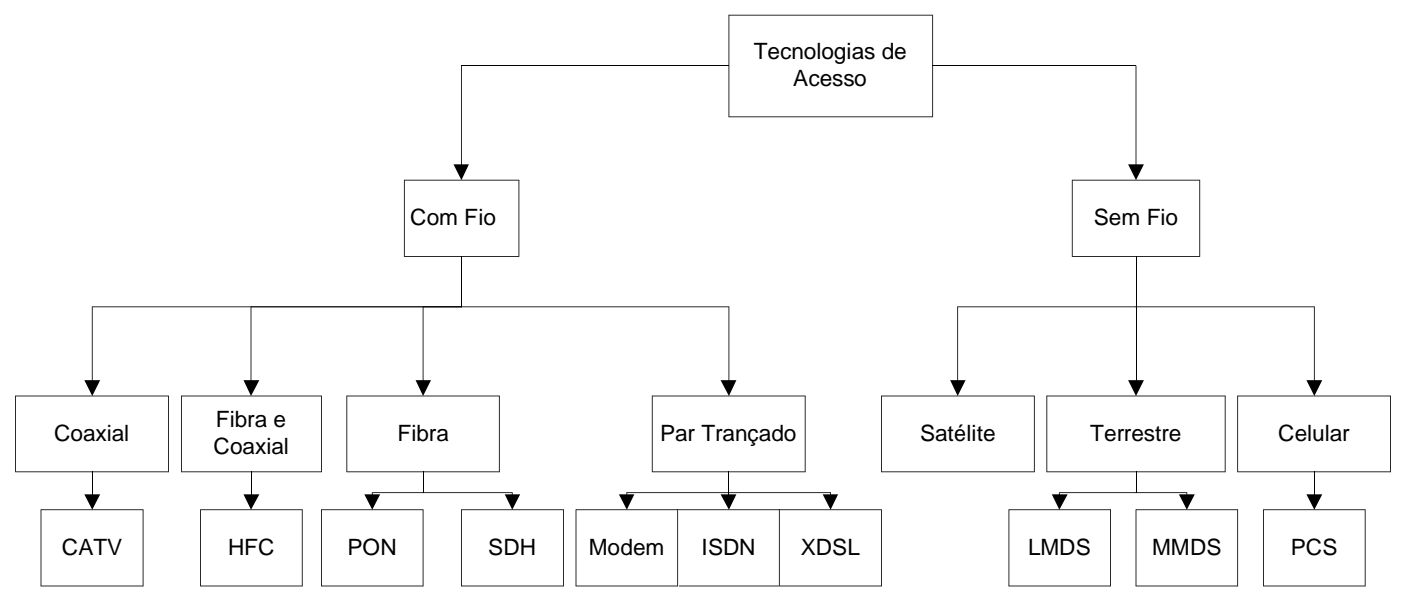

Figura A.1 Tecnologias de acesso à rede de comunicação.

No início do desenvolvimento dos sistemas de comunicação utilizou-se o acesso com fío via par trançado, no sistema telefônico.Esse é, até hoje, o meio de transmissão mais utilizado. Em seguida, começou-se a empregar os cabos coaxiais e as fibras ópticas, principalmente para a difusão de imagens. Atualmente, esses sistemas estão sendo adaptados para suportarem plenamente as redes de dados.

Os sistemas wireless (sem fio) utilizam ondas eletromagnéticas para comunicação e têm provocado verdadeira revolução na sociedade, permitindo serviços como Rádio, Televisão, Comunicações via Satélite e, mais recentemente, com os sistemas celulares que propiciam mobilidade às comunicações.

\section{A.1 - PAR TRANÇADO DE COBRE}

Em sua forma mais simples, o cabo de par trançado é constituído por filamentos isolados de cobre torcidos. Esses fios são enrolados em espiral para que haja uma redução do 
ruído, através do efeito de cancelamento, no ruído além de manter constantes as propriedades elétricas do meio. $\mathrm{O}$ efeito de cancelamento reduz a diafonia entre os pares de fios e diminui o nível de interferência eletromagnética/ radiofreqüência. $\mathrm{O}$ número de tranças nos fios pode ser variado a fim de reduzir o acoplamento elétrico.

Há dois tipos de cabos de par trançado: par trançado não-blindado (UTP, Unshielded Twisted-Pair) e par trançado blindado (STP, Shielded Twisted-Pair).

O cabo STP, além de possuir uma malha blindada global que para aumentar a imunidade às interferências eletromagnética/ radiofrequência externas, possui uma blindagem interna que envolve cada par trançado cujo objetivo é reduzir a diafonia, figura A.2. Um cabo STP geralmente possui dois pares trançados blindados, impedância característica de 150 Ohms e pode alcançar uma largura de banda de $300 \mathrm{MHz}$ em 100 metros de cabo.

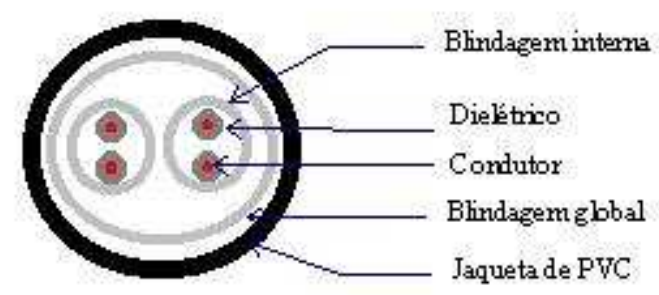

Figura A.2 Cabo STP.

Os pares trançados não-blindados (UTP) possuem um alto desempenho em termos de qualidade e baixo custo de aquisição e instalação. A figura A.3 mostra um exemplo de cabos UTP.

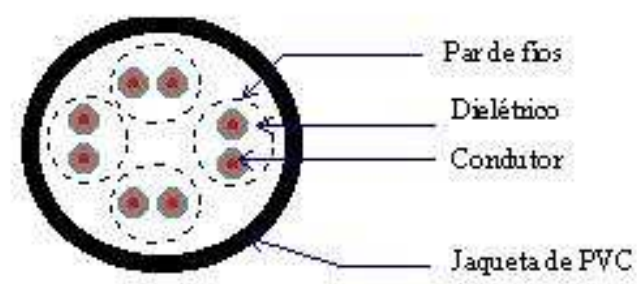

Figura A.3 cabo UTP. 
Para que um cabo UTP transporte de forma confiável sinal a $10 \mathrm{Mbps}$, se faz necessário muito cuidado e muita habilidade para a instalação do sistema. Também os cabos UTP a 100 Mbps (UTP cat.5), têm que ser cuidadosamente planejados e instalados. Mesmo custando mais barato do que qualquer outro tipo de cabo de rede local, as despesas com mão de obra ainda são altas nesse tipo de sistema.

A desvantagem do par trançado é a sua susceptibilidade à interferência e ruído, incluindo "cross-talk" de fiação adjacente. Em sistemas de baixa freqüência, a imunidade a ruído é tão boa quanto no cabo coaxial.

Pode-se utilizar o par trançado para transmitir tanto sinais analógicos quanto sinais digitais. A taxa de transmissão varia de acordo com as condições dos cabos e a tecnologia utilizada.

Os três tipos de acesso que fazem uso do par trançado são os Modems, RDSI e o xDSL.

\section{A.1.1 - Modems}

Modem, de modulador e demodulador, são dispositivos eletrônicos que modulam um sinal digital em uma onda analógica, pronta a ser transmitida pela linha telefônica, e que demodulam o sinal analógico e o reconverte para o formato digital original. De modo geral, o Modem nada mais é do que o aparelho que converte os dados que chegam da Internet para o computador.

A grande vantagem oferecida pelo modem é permitir acesso a Internet e ao mesmo tempo liberar a linha telefônica.

Quase todos os modems para uso pessoal utilizam a técnica de transmissão assíncrona. É um método de intercâmbio de informações entre dois computadores diferentes, que operam de maneira independente e não compartilham nenhuma informação de sincronia. Geralmente, os sinais dos modems que utilizam a rede telefônica são assíncronos, porque seria mais caro e mais difícil sincronizar sinais através do sistema telefônico, onde os sinais podem ser redirecionados a qualquer momento, sem aviso. Assim, também são utilizadas técnicas de compressão e correção de erro. 


\section{A.1.2 - RDSI}

A Rede Digital de Serviços Integrados (RDSI) é uma tecnologia que permite o tráfego simultâneo de dados e de voz em velocidades de até $128 \mathrm{kbps}$. Trata-se de um serviço disponível em centrais telefônicas digitais, que permite acesso à Internet e baseia-se na troca digital de dados, onde são transmitidos pacotes por multiplexagem (possibilidade de estabelecer várias ligações lógicas numa ligação física existente) sobre par trançado. [25]

Fisicamente, é formado por um par de fio de cobre de forma semelhante às linhas analógicas mas, nesse caso, não é usada a mesma fiação, já que as linhas analógicas possuem bobinas de carga que impedem a transmissão dos sinais digitais, além de os cabos da linha RDSI não poderem possuir mais que $16 \mathrm{~km}$ da central telefônica por causa do nível de ruído.

A estrutura de transmissão RDSI utiliza três tipos de canais:

- canais B duplex, de $64 \mathrm{kbps}$

- canais D duplex, de 16 ou 64 kbps;

- canais H duplex, de 384 kbps (H0), 1.536 kbps (H11) e 1.920 kbps (H12).

Em linhas RDSI só podem ser instalados diretamente aparelhos telefônicos, fax e modems que tenham a tecnologia RDSI. É possível instalar aparelhos convencionais (analógicos) à linha RDSI através de adaptador (normalmente a companhia telefônica instala este adaptador em locais dotados de linhas RDSI). O RDSI não deixa de ser uma modalidade de conexão discada. A diferença é que a taxa de transmissão pode chegar até $128 \mathrm{kbps}$. Essa tecnologia divide a linha telefônica em dois canais independentes de 64 kbps cada. Por meio deles, é possível ter acesso à Internet e receber ligações telefônicas simultaneamente. Mas, quando isso ocorre, a velocidade de navegação cai pela metade.

Por meio do uso de um equipamento adequado, uma linha telefônica convencional é transformada em dois canais de $64 \mathrm{kbps}$, onde é possível usar voz e dados ao mesmo tempo, sendo que cada um ocupa um canal. Também é possível usar os dois canais para voz ou para dados. 
É possível usar duas formas de comunicação na RDSI: acesso básico e acesso primário. O acesso básico utiliza dois canais de dados (B channels) de $64 \mathrm{kbps}$ e um canal de sinalização de 16 kbps (D channel), figura A.4.

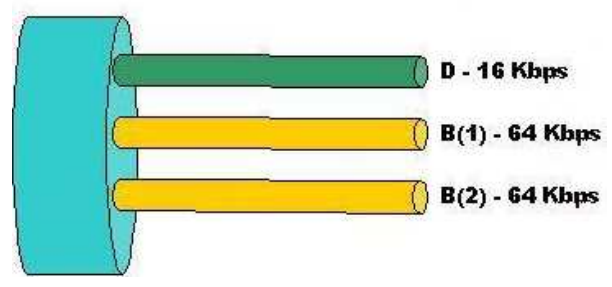

Figura A.4 Acesso básico.

No acesso primário, são utilizados 30 canais de dados, com taxa de transmissão total de 2.048 kbits e 1 canal de sinalização de 64 kbps, figura A.5.

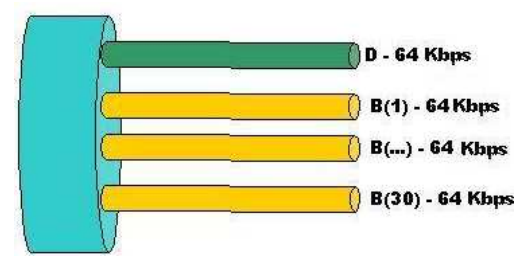

Figura A.5 Acesso primário.

A vantagem desse sistema é que se trata da modalidade de acesso por banda larga mais barata do mercado. A desvantagem é o fato do serviço ainda ser cotado pela companhia telefônica, ou seja, não deixa de ser um acesso discado no qual o usuário continua pagando pelos pulsos. Outra desvantagem é que a velocidade está limitada a $128 \mathrm{kbps}$, o que é equivalente aos planos mais básicos oferecidos nas demais modalidades de acesso por banda larga. Além disso, o provedor não cobra somente a mensalidade de acesso RDSI ele ainda oferece a infra-estrutura de servidores de correio eletrônico (com suporte), conteúdo para banda larga e outros serviços.

A tecnologia RDSI perdeu força nos últimos anos principalmente por conta da adoção dos padrões xDSL, em especial o ADSL, que oferecem taxas de transmissão superiores. 


\section{A.1.3 - xDSL}

Digital Subscriber Line, ou simplesmente DSL, é uma família de tecnologias que fornecem um meio de transmissão digital de dados, aproveitando a rede de telefonia que chega na maioria das residências.

As tecnologias DSL oferecem várias vantagens na comunicação de banda larga. A vantagem mais importante é o preço, que se torna muito mais barato pelo fato de que DSL é oferecida através da rede legada de cobre. Uma outra vantagem é que o tráfego de dados é transmitido simultaneamente com o tráfego de voz. O tráfego de dados é direcionado a uma rede de pacotes e a voz é direcionada à rede PSTN.

Há alguns tipos de xDSL, que diferem principalmente nos seguintes aspectos: velocidade (taxa de bits); Line Coding (codificação); número de linhas (1 par trançado ou 2 pares trançados) e Alcance.

Os tipos de DSL são classificados em assimétricos, quando as taxas de download e upload são diferentes, e simétricos, quando as taxas são iguais.

\section{A.1.3.1 - DSL Assimétricos}

- ADSL (Full Rate asymmetrical DSL): oferece diferentes taxas de upload e download e podem ser configuradas até $6 \mathrm{Mbps}$ da rede para o usuário. Esse tipo de DSL é o predominante no uso comercial e residencial. É conviniente para Internet e para aplicações que necessitam de maiores taxas no downstream, como video-on-demand. Há, também, uma recomendação do ITU (Recommendation G.992.5) que especifica o ADSL2Plus, com banda duas vezes maior que o ADSL, chegando a 20 Mbps downstream em distâncias pequenas.

- G.lite ADSL (ou simplesmente G.lite): O padrão G.lite foi desenvolvido para atender às necessidades de plug-and-play do mercado. G.lite é uma versão de banda intermediária do ADSL, que permite uma velocidade de 1,5 Mbps downstream e 500 kbps upstream. Essa tecnologia tem pouca utilização comercial. 
- RADSL (rate adaptive DSL): É uma tecnologia não-padronizada. É importante notar que o padrão ADSL também permite que o modem seja flexível quanto às taxas de transmissão.

- VDSL (very high bit rate DSL): Transmite até $26 \mathrm{Mbps}$, a distâncias de até 50 metros. Na maioria dos casos, as linhas VDSL serão a parte final de um acesso com fibra até um cabinet. Estão sendo realizados testes para utilizar o VDSL para a transmissão de vídeo. VDSL pode também ser configurado no modo simétrico.

- VDSL2 (VDSL 2 $2^{\mathrm{a}}$ geração): A recomendação do ITU (Recommendation G.993.2) especifica 8 perfis de VDSL2 para diferentes tipos de aplicações, como transmissão simétrica de até $100 \mathrm{Mbps}$ em loops de até $100 \mathrm{~m}$ (utilizando uma banda de $30 \mathrm{MHz}$ ), transmissão simétrica de 10-30 Mbps em loops com uma distância intermediária (utilizando banda de $12 \mathrm{MHz}$ ) e operação assimétrica com taxa de downstream de 10-30Mbps em loops de 1 a $3 \mathrm{~km}$ (utilizando uma banda de 8,5 MHz). VDSL2 inclui a maioria das facilidades do ADSL2. Sua performance é melhor do que VDSL.

\section{A.1.3.2 - DSL Simétricos:}

- SDSL (symmetric DSL): SDSL é uma versão proprietária de DSL, cujas taxas podem variar de $128 \mathrm{kbps}$ a 2,32 Mbps. SDSL é um termo utilizado para designar várias implementações específicas de empresas sobre o par trançado e que provém taxas simétricas de transmissão.

- SHDSL (ou G.shdl) é o estado-da-arte em termos de transmissão DSL com taxas simétricas. SHDSL tem um alcance $20 \%$ melhor que versões anteriores de DSL, causa bem menos crosstalk em sistemas de transmissão que estão no mesmo cabo e a interoperabilidade é facilitada, por ser uma tecnologia padronizada SHDSL pode ter taxas de $192 \mathrm{kbps}$ a 5,7 Mbps, maximizando as taxas para cada usuário. G.shdsl especifica operação via 1 par trançado ou 2 pares trançados para operar em loops longos. SHDSL é utilizado para aplicações de dados nas quais é necessária uma alta taxa de upstream. Essa tecnologia está sendo utilizada principalmente por usuários empresariais. 
- HDSL (high data rate DSL): Essa tecnologia permite taxas de até 2,3 Mbps nas duas direções. Essa tecnologia não permite o service telefônico na mesma linha e pode usar 1, 2 ou 3 pares trançados.

- HDSL2 (HDSL 2a geração): Essa tecnologia permite taxa de 1,5 Mbps para cada lado, suportando voz, dados e video usando ATM ou linha privada de services sobre o cobre. HSDL2 difere do HDSL, pois HDSL2 usa um par trançado enquanto o HDSL usa dois.

- HDSL4: HDSL4 é basicamente o mesmo que HDSL2, mas alcança aproximadamente $30 \%$ mais do que HDS ou HDSL 2, utilizando dois pares trançados, ao invés de 1 par no HDSL.

- IDSL (integrated services digital network DSL): Essa é uma forma de DSL que suporta taxas de transmissão de $144 \mathrm{kbps}$, simétrica. Ela difere pelo fato de transmitir através do DLC (Digital Loop Carrier): um dispositivo remoto geralmente colocado próximo ao usuário, para simplificar a distribuição de cabos e fios da empresa de telefonia. IDSL difere da RDSI pelo fato de que está sempre disponível, mas utiliza o mesmo modem utilizado para a RDSI.

A relação entre as capacidades de cada tecnologia DSL e as distâncias é apresentada na figura A.6:

xDSL Capacity vs. Distance

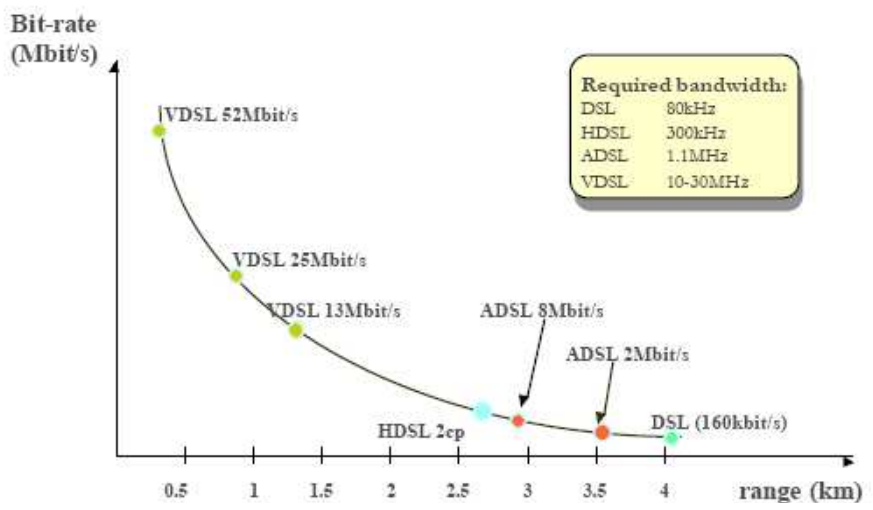

Figura A.6 Gráfico capacidade Vs diatância (xDSL). 
As velocidades típicas de download de uma linha DSL variam de $128 \mathrm{kbps}$ até 52 Mbps dependendo da tecnologia implementada, conforme os dados da tabela A.1.

Tabela A.1 Tecnologias xDSL

\begin{tabular}{|c|c|c|c|c|}
\hline Tecnologia & Taxa Upstream & Taxa Downstream & Distância Max. & No. pares \\
\hline ADSL-1 & 16-64 kbps & 1.5-2.0 Mbps & $6 \mathrm{~km}$ & 1 \\
\hline ADSL-2 & $640 \mathrm{kbps}$ & 6.144 Mbps & $4 \mathrm{~km}$ & 1 \\
\hline $\begin{array}{ll}\text { VDSL } & \text { (Very } \\
\text { High } & \text { Speed } \\
\text { DSL) } & \end{array}$ & 13 a $52 \mathrm{Mbps}$ & Em padronização & $\begin{array}{l}\text { Mais curta que } \\
\text { ADSL }\end{array}$ & \\
\hline $\begin{array}{l}\text { RADSL (Rate } \\
\text { Adaptive DSL) }\end{array}$ & $\begin{array}{l}\text { Ajustável em função } \\
\text { da qualidade do par } \\
\text { trançado }\end{array}$ & $\begin{array}{l}\text { Ajustável em função } \\
\text { da qualidade do par } \\
\text { trançado }\end{array}$ & & \\
\hline $\begin{array}{l}\text { HDSL (High } \\
\text { Data Rate DSL) }\end{array}$ & $1.5 \mathrm{Mbps}$ & $1.5 \mathrm{Mbps}$ & $4 \mathrm{~km}$ & 2 \\
\hline $\begin{array}{l}\text { SDSL } \\
\text { (Symmetrical } \\
\text { DSL) }\end{array}$ & 64 kbps - 2 Mbps & 64 kbps - 2 Mbps & $4 \mathrm{~km}$ & 1 ou 2 \\
\hline
\end{tabular}

\section{A.2 - CABO COAXIAL:}

Criado com a finalidade de transportar fluxo de bits de uma máquina à outra, o cabo coaxial pode ser utilizado tanto em redes locais quanto em transmissões de longa distância. O cabo coaxial também é geralmente utilizado para ligar o televisor aos serviços do operador de televisão por cabo. [2]

Consiste num pequeno tubo de cobre coberto por um material isolante, que é envolto por um condutor cilíndrico com um diâmetro superior sob a forma de bainha. O núcleo é formado por um fio de cobre rígido ou flexível e o condutor externo é coberto por uma capa plástica protetora, veja a figura A.7: 


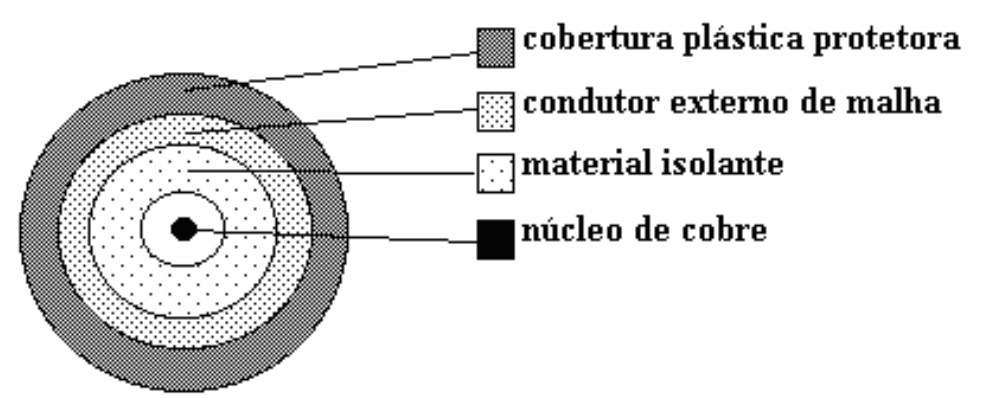

Figura A.7 Corte em um cabo coaxial.

Essa forma de construção do cabo coaxial lhe garante uma boa combinação de alta banda passante e boa imunidade a ruídos. A banda passante depende do tamanho do cabo. Para altas taxas de transmissão, deve-se utilizar cabos mais curtos, mas, se o importante é a distância, utiliza-se cabos mais longos com menores taxas. Para um cabo de 1 km, tem-se uma taxa de mais ou menos $10 \mathrm{Mbps}$.

Os tipos de cabos coaxiais são: Cabo em Banda Base e Cabo em Banda Larga.

\section{A.2.1 - Cabo Coaxial Banda Base}

Também chamado de Cabo Coaxial Fino tem impedância de 50 ohms e é amplamente utilizado em redes locais. O método de acesso a redes locais é o de detecção de portadora, com detecção de colisão. O tamanho de cada segmento pode variar entre $45 \mathrm{~cm}$ e $185 \mathrm{~m}$ chegando a um número máximo de 5 segmentos, ou seja, o comprimento do cabo pode chegar a $925 \mathrm{~m}$. Quando a rede não tem repetidores, o tamanho máximo se reduz a $300 \mathrm{~m}$. A taxa de transmissão depende do tamanho do cabo, mas geralmente varia de 1 a 50 Mbps. O modo de transmissão é Half-Duplex, e utiliza o Código Manchester por pulsos de corrente contínua. A instalação é facilitada por ser um cabo fino e flexível. Usa-se conectores do tipo $\mathrm{T}$ e sua imunidade a EMI/RFI é de $50 \mathrm{~dB}$. A figura A.8 ilustra esse tipo de cabo. 


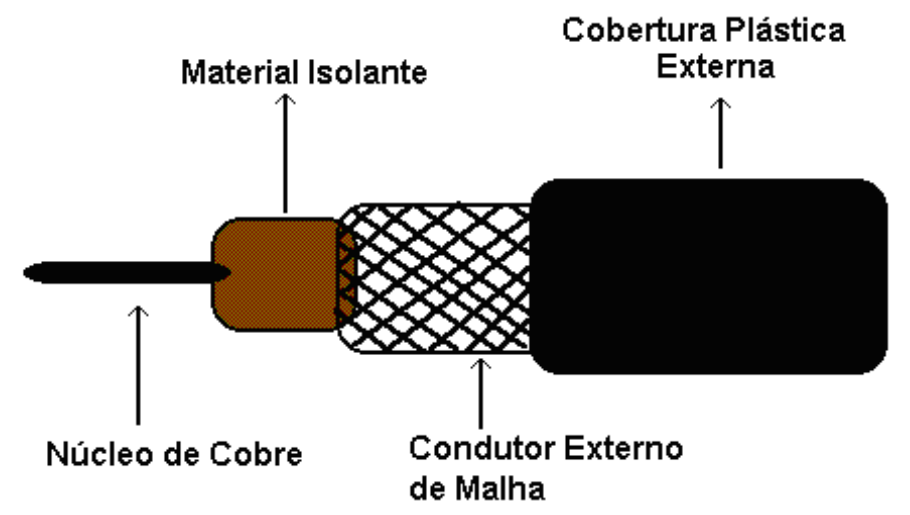

Figura A.8 Cabo Coaxial Banda Base.

\section{A.2.2 - Cabo Coaxial Banda Larga}

Também chamado de Cabo Coaxial Grosso tem impedância de 75 ohms e pode ser utilizado tanto em redes locais como em redes de longa distância, com método de acesso FDM (Frequency-division multiplexing). $\mathrm{O}$ tamanho de cada segmento pode variar entre 2,5 $\mathrm{m}$ e $500 \mathrm{~m}$ chegando a um número máximo de 5 segmentos, ou seja, o comprimento do cabo pode chegar a $2.500 \mathrm{~m}$, mas os tamanhos geralmente recomendados são múltiplos de 23,4 - 70,2 ou 117 metros. A taxa de transmissão depende do tamanho do cabo, mas geralmente varia de 100 a 150 Mbps. O modo de transmissão é Full-Duplex, feito por variação em sinal de frequência de rádio. Possui uma capacidade de 1.500 canais com 1 ou mais equipamentos por canal. A velocidade de propagação é de 0,77 vezes a velocidade da luz no vácuo. Sua imunidade a EMI/RFI é de $85 \mathrm{~dB}$, mas, para $500 \mathrm{~m}$ de cabo, a atenuação não pode exceder 8,5 dB medido a $10 \mathrm{MHz}$ ou 6,0 dB medido a $5 \mathrm{MHz}$. Sua instalação é mais complicada pelo fato do cabo ser grosso e não flexível, por isso, requer prática e pessoal especializado. O conector pode ser do tipo Derivador Vampiro ou pode-se utilizar transceptores (detecta porta elétrica do cabo). A figura A.9 ilustra esse tipo de cabo. 


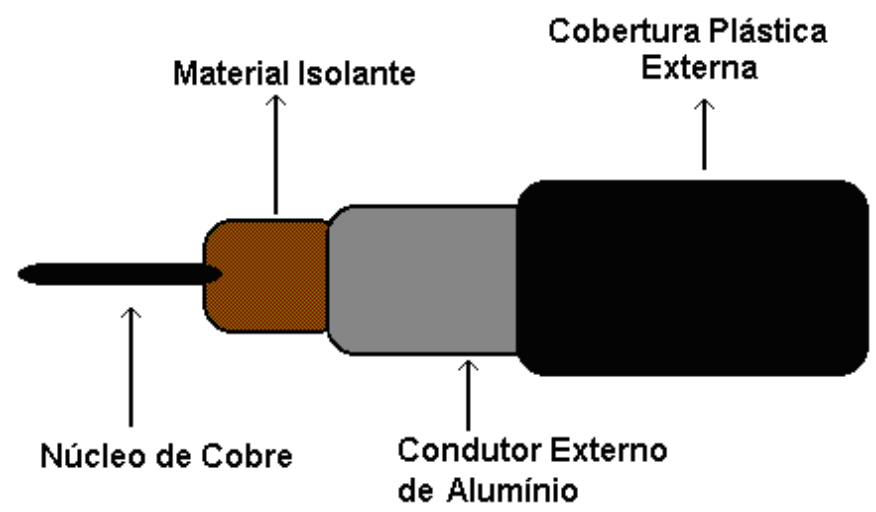

Figura A.9 Cabo Coaxial Banda Larga.

\section{A.3 - ACESSO TERRESTRE SEM FIO}

\section{A.3.1 - Sistema MMDS}

O MMDS (Multipoint Multichannel Distribution System ou Serviço de Distribuição Multiponto Multicanal), também chamado de Wireless Cable, pode ser descrito como uma das modalidades de serviço especial de TV por assinatura, que utiliza uma faixa de microondas (2.500 a $2.680 \mathrm{MHz}$ ) para transmitir sinais aos clientes que se encontram dentro da área de prestação de serviço. O sistema é formado por um equipamento head-end (equipamento de recepção de sinal de satélite, transmissor de rádio, antena transmissora e outros equipamentos de transmissão) e um equipamento receptor para cada assinante (antena, conversor de freqüência e dispositivo de ajuste alto), figura A.10. [1]

Uma das vantagens proporcionadas é que os sinais do MMDS cobrem uma área com raio de até 50 quilômetros, levando a programação tanto às áreas urbanas quanto às periféricas. Além disso, permite transmissão de programação local, pois o head-end está situado no local da prestação do serviço. Sua capacidade é de até 31 canais analógicos ou de cerca de 180 canais digitais. O número de canais digitais transmitidos pode aumentar com as novas tecnologias que vem surgindo. Outra vantagem é a portabilidade proporcionada pelo sinal de microondas, que permite a recepção do sinal em qualquer ponto da área de cobertura, em geral toda a cidade, o assinante podendo mudar de endereço sem ter problemas em transferir o serviço. 
Como desvantagem tem-se o fato da capacidade de canais do MMDS ser menor que a do cabo, porque o sistema dispõe de uma faixa limitada do espectro de radiofrequiências. Porém, essa capacidade pode ser aumentada com a digitalização dos sinais. Por outro lado, a instalação de um novo sistema de MMDS em uma cidade tem custo menor que o sistema de cabo porque não há o custo relativo a cabos e as antenas e receptores são colocados nas residências apenas na medida em que surgem novos assinantes.

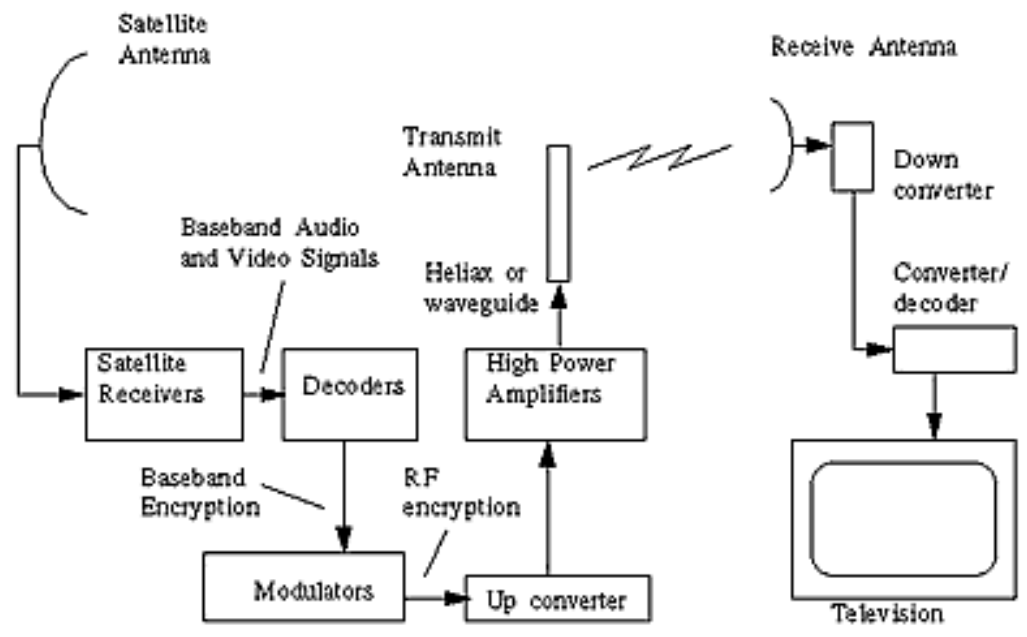

Figura A.10 Arquitetura típica de uma rede MMDS.

\section{A.3.2 - Sistema LMDS}

O LMDS (Local Multipoint Distribution System) foi desenvolvido em 1986 e é um sistema de comunicação de ponto a multiponto que utiliza ondas eletromagnéticas em freqüências em torno de 28 ou $40 \mathrm{GHz}$. Essa configuração ponto multiponto forma células com o objetivo de se otimizar a cobertura de uma determinada localidade. Dada a banda larga disponível, o LMDS pode dar suporte a uma grande variedade de serviços simultâneos: televisão multicanal (difusão, PPV, vídeo on demand), telefonia, dados, serviços interativos multimídia (tele-educação, telemedicina, acesso à Internet em banda larga etc.). [20]

Cada célula LMDS é composta por uma ERB (Estação Rádio Base) e por diversas ER (Estações Remotas). Existem dois tipos de ERBS: ominidirecionais e setorizadas. No primeiro caso, utiliza-se uma única antena para prover uma cobertura de $360^{\circ}$, no segundo caso, cada 
setor possui uma antena específica. As células setorizadas são vantajosas, pois podem oferecer a banda total de cada rádio para determinado setor, o que gera aumento na banda total da célula. Outra vantagem é que a potência dos transmissores das células setorizadas podem ser menor já que as antenas possuem alto ganho. Para que não haja interferência entre células ou setores adjacentes usa-se o recurso da inversão de polarização como mostrado na figura A.11.

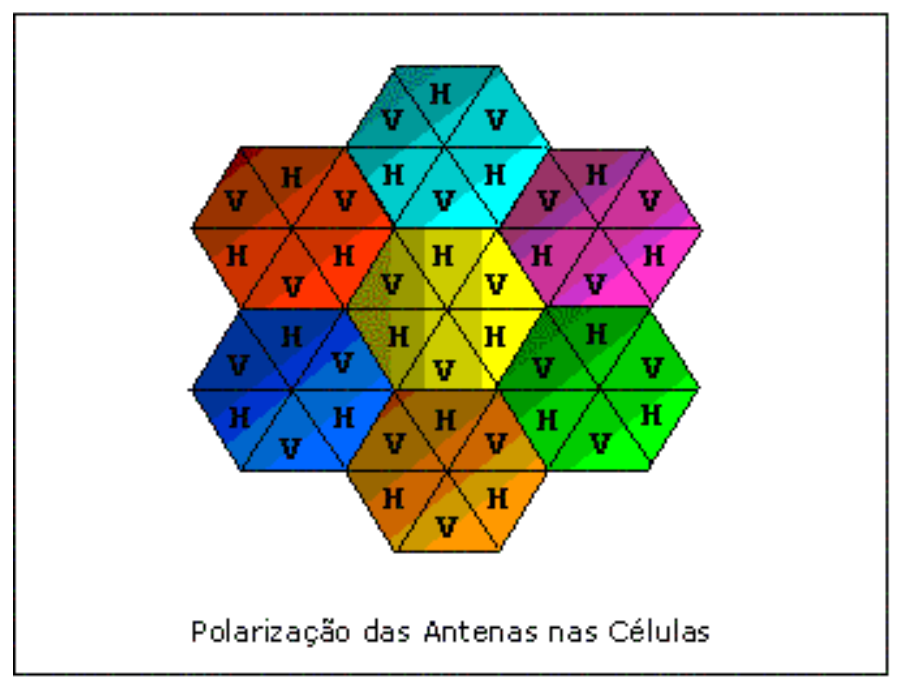

Figura A.11 Polarização das antenas em uma células LMDS. H (polarização horizontal, V (polarização vertical).

Algumas vantagens do sistema LMDS quando comparado aos sistemas a cabo e também ao MMDS, são representadas a seguir.

- O sistema LMDS permite oferecer, com grande confiabilidade e qualidade de sinal, praticamente os mesmos serviços que as redes de fibra óptica e cabo coaxial. É através desse que se pode denominar a esta tecnologia como "vias aéreas da informação (ou sistema de informações via ar)".

- Como no LMDS não é necessário cabear, as grandes vantagens potenciais do sistema são:

- Pode-se oferecer o serviço e gerar receitas muito antes em toda a área de cobertura (de 6 a 18 meses, frente a 5-7 anos para completar uma rede de cabo); 
- Pode-se oferecer o serviço de forma economicamente viável, se não a $100 \%$ da população, mas a grande parte da mesma (principalmente aquela que está dispersa e que em nenhum caso se pode oferecer serviço via cabo de forma rentável);

- Por último, não menos importante, o operador com LMDS teria custos reduzidos para manter e operar a planta, já que não há uma rede a ser mantida (somente uns poucos repetidores por célula).

- Outra possibilidade menos radical que a de substituir o cabo por LMDS, consistiria em utilizar esta tecnologia desde o princípio, enquanto se vai cabeando, de forma que se daria serviço muito antes à população e se geraria recursos que permitiriam auto financiar a construção da rede de cabo. À medida que se fosse completando a mesma, poder-se ir substituindo a conexão de LMDS pela rede de cabo.

- Por último, comparando o LMDS com o MMDS, sendo que com esse último tem um maior alcance e o mesmo não sofre com a interferência da chuva, mesmo tendo uma largura de banda menor (somente $200 \mathrm{MHz}$ frente a $1 \mathrm{GHz}$ do LMDS), a necessidade de visibilidade direta entre emissor e receptor com MMDS (o que no LMDS não é em muitos casos necessário por causa das reflexões de sinal de microondas em obstáculos naturais), e a dificuldade no MMDS para reutilizar frequências entre células adjacentes - que é possível com o LMDS - tornam o LMDS tecnologia muito mais atrativa para a provisão de serviços de telecomunicações interativos e de banda larga.

A figura A.12 mostra a arquitetura de um sistema LDMS. 


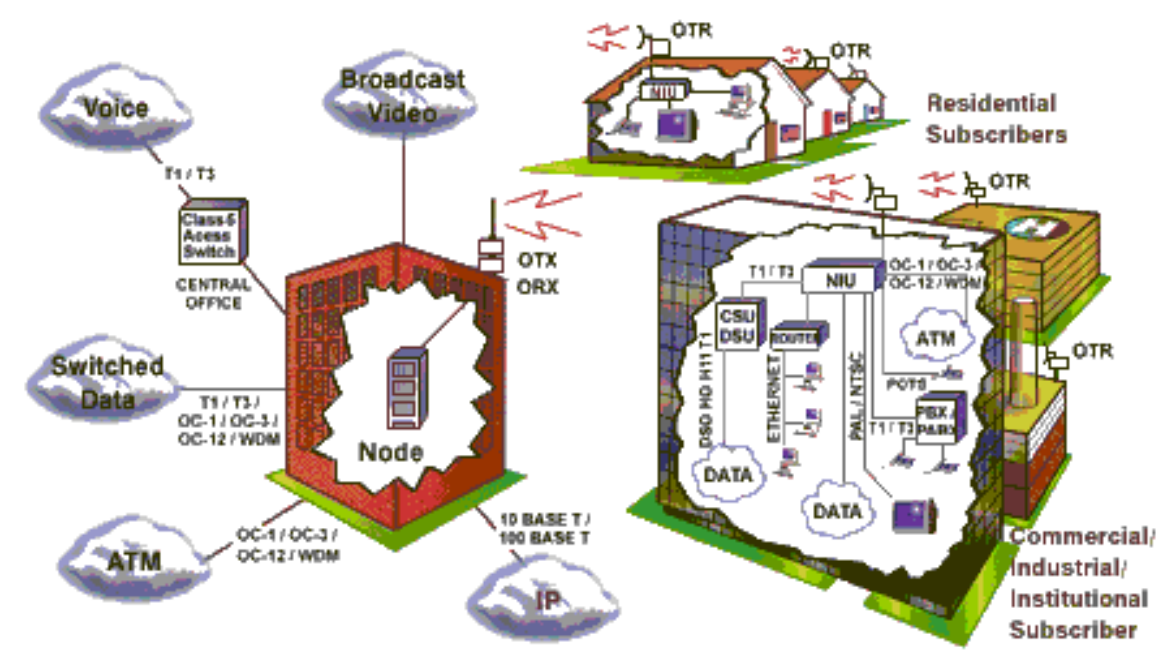

Figura A.12 Arquitetura do sistema LMDS.

\section{A.4 - ACESSO VIA SATÉLITE}

O DTH (Direct to Home) ou Sistema de Distribuição de Sinais de Televisão e de Áudio por Assinatura via Satélite tem como objetivo a distribuição de sinais de televisão ou de áudio, ou dos dois, através de satélites, a assinantes localizados na área de prestação de serviço. Como é um sistema de TV paga, o assinante tem que instalar em sua casa uma antena parabólica e um receptor/decodificador, chamado IRD (Integrated Receiver/Decoder), para receber os canais diretamente de um satélite geoestacionário, figura A.13.

O DTH é uma tecnologia unidirecional, ou seja, só permite receber dados (downloads), necessitando de uma linha telefônica convencional para fazer a transmissão de dados (upload). Possui taxa de recepção máxima de 400 kbps e necessita de hardware específico.

Entre suas vantagens está a cobertura nacional ou mesmo continental, com mais de 180 canais digitais, e a rápida implantação. Uma outra grande vantagem está na excelente qualidade de som e de imagem, melhor aproveitamento do caro espaço que ocupam nos satélites. Isso se deve ao fato de todos os serviços de DTH no Brasil - DirecTV, Sky e Tecsat na banda $\mathrm{KU}$, e Digisat na banda $\mathrm{C}$ - usarem sinais digitais.

Como desvantagens, tem-se o fato de que, contrariamente às tecnologias de cabo e MMDS, o DTH não viabiliza a inserção de programas de conteúdo local, pois a programação é a mesma para todos os assinantes, em toda a área de cobertura. O custo inicial do sistema é 
elevado, pois envolve o aluguel de espaço em satélites e montagem de uma rede nacional de distribuição e de venda. Além disso, em dias de chuvas fortes não é possível utilizar o serviço no caso do satélite ficar encoberto.

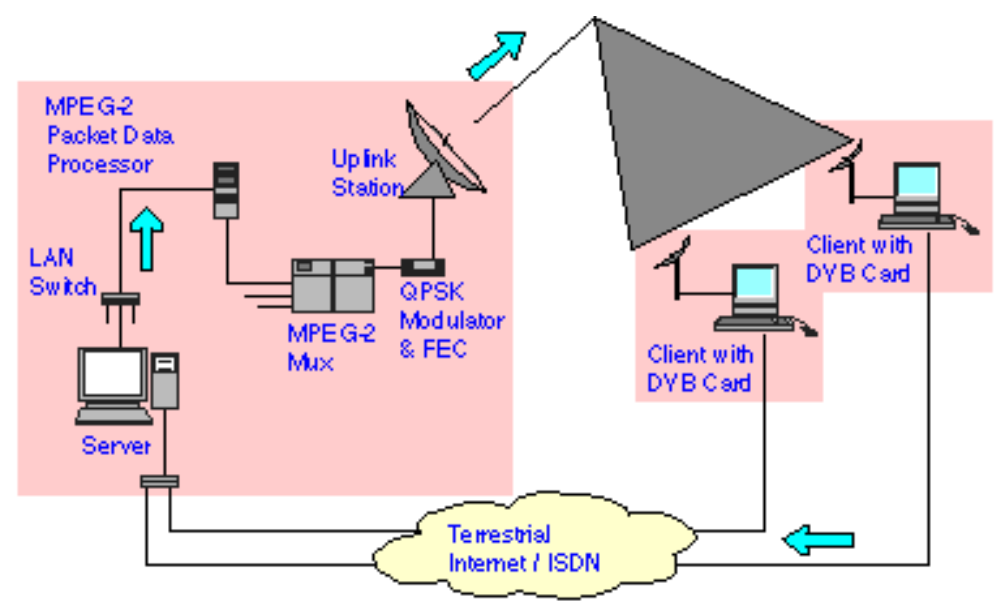

Figura A.13 Configuração típica para se prover DTH Internet delivery utilizando-se DVB.

\section{A.5 - SISTEMA PCS (PERSONAL CELLULAR SYSTEM)}

O sistema de comunicações móvel trabalha com o conceito de células que seriam o resultado da divisão de uma área geográfica em pequenas áreas.

O compartilhamento de recursos é uma forma muito eficiente de se obter alta capacidade em uma rede de comunicações. No que diz respeito a comunicações móveis, os recursos são os canais disponíveis ou, de forma mais ampla, a banda de frequiências. $\mathrm{O}$ mecanismo de acesso deve permitir que qualquer terminal acesse o sistema, provendo um sistema de acesso troncalizado. Se canais são designados a usuários por demanda, o esquema é chamado de Acesso Múltiplo com Alocação por Demanda (DAMA, Demand-Assigned Multiple Access), ou simplesmente Múltiplo Acesso.

De acordo com a forma com que o espectro é disponibilizado aos usuários, tem-se a classificação geral de sistemas em faixa estreita e faixa larga. Em um sistema faixa estreita, a faixa de freqüências é subdividida em várias faixas menores, os canais, que são alocadas sob demanda aos usuários. Em sistemas faixa larga, toda ou grande parte da banda de freqüências é disponibilizada aos usuários, como um único bloco. 
Há três formas básicas de se realizar múltiplo acesso, nomeadas de acordo com o mecanismo chave usado para implementá-las.

- Múltiplo Acesso por Divisão de Freqüiência (FDMA): Sendo a mais antiga das técnicas de acesso, baseia sua ortogonalidade na separação de freqüências, colocando cada usuário em uma portadora distinta durante todo o tempo. Transmissor e receptor devem estar sintonizados na mesma freqüência e o canal estará disponível $100 \%$ do tempo de uso para aquele usuário/serviço. É utilizada em radiodifusão, telefonia celular analógica e em outros sistemas mais antigos. As desvantagens são desperdício de energia, pois o canal fica alocado durante todo o tempo mesmo que não haja informação para se transmitir.

- Múltiplo Acesso por Divisão de Tempo (TDMA): temos na maioria dos sistemas tem-se a mesma estrutura de divisão de freqüências dos sistemas FDMA. A ortogonalidade das informações é garantida, além da separação em frequiência, pelo fato de que o tempo é dividido em time slots, e cada time slot é atribuído a somente um usuário por acesso. Visto que a transmissão é feita de forma interrompida, transmitindo-se num instante e ficando mudo no tempo restante, são utilizada técnicas de codificação e compressão de voz ou dados para que a informação seja adequadamente transmitida utilizando-se as taxas disponíveis. A vantagem de um sistema como este é que, para se aumentar a taxa de transmissão por usuário, basta que este utilize mais de uma janela simultaneamente. Isto limitaria a quantidade global de acessos ao sistema, mas é capaz de oferecer taxas mais elevadas para aqueles que as necessitem;

- Múltiplo Acesso por Divisão de Código (CDMA): baseiam a ortogonalidade entre os acessos nos diferentes códigos empregados para espalhamento. O sinal de espalhamento é composto de símbolos chamados chips. A sequiência de chips deve ser o mais aleatória possível, e em sistemas comerciais por ser gerada através de um algoritmo, é chamada de pseudo-aleatória ou pseudo-randômica. Além disso, as sequiências utilizadas deverão ser ortogonais entre si. 
Enquanto o FDMA e o CDMA são, respectivamente, técnicas faixa estreita e faixa larga por natureza, o TDMA permite ambas as formas de implementação.

Para a implementação de comunicação bidirecional full-duplex, pode-se utilizar divisão no tempo (TDD - Time Division Duplex) ou na freqüência (FDD - Frequency Division Duplex). No TDD, as duas direções de comunicação utilizam uma mesma faixa de freqüências comum, mas instantes de tempo distintos. Por outro lado, no FDD, cada sentido utiliza faixas distintas de frequiências, separadas convenientemente para evitar interferências, permitindo um full duplex real, pois a informação pode trafegar nos dois sentidos simultaneamente. O TDD requer sincronização e tempo de guarda entre slots de ambos os sentidos, também para evitar interferência. Observa-se que o TDD, por utilizar a mesma faixa de freqüências, permite que a comunicação mantenha a mesma qualidade em ambos os sentidos.

\section{A.5.1 - Arquitetura do sistema faixa estreita}

Em geral, a arquitetura faixa estreita está associada a sistemas com alta capacidade - o número de canais em que a banda é dividida dá uma dimensão da capacidade do sistema quanto ao número de usuários - mas, muitas vezes, baixa qualidade de transmissão - muitos canais significa banda pequena para cada canal. Nesse sentido, há um esforço para que se utilize técnicas de modulação que permitam qualidade de voz aceitável sem que se aumente a banda ocupada pelos canais, ou até, que se reduza a banda ocupada. Outro aspecto é a necessidade de se utilizar filtros estreitos para minimizar a interferência de canal adjacente, o que contribui para o aumento no custo de equipamento. E ainda, em sistemas faixa estreita, o sinal propagante sofre o chamado desvanecimento não seletivo em freqüência, ou seja, quando ocorre um desvanecimento toda a informação contida no canal é afetada, pois o canal é, em geral, muito estreito. 


\section{A.5.2 - Arquitetura do sistema faixa larga}

As técnicas de acesso que se utilizam dessa arquitetura são o TDMA faixa larga e o CDMA, sendo que este último freqüentemente usa toda a faixa disponível. Como grande vantagem dessa abordagem, pode-se citar o fato de que a banda utilizada é maior que a banda dentro da qual ocorre desvanecimento não seletivo. Ou seja, o sinal faixa larga experimenta desvanecimento seletivo em freqüência e, então, apenas uma fração das freqüências que o compõem é afetada pelo desvanecimento. Da mesma forma, interferências também podem ser minimizadas com o uso dessa arquitetura.

\section{A.6 - WIMAX}

O WiMax (Worldwide Interoperability for microwave access) é uma organização formada por empresas fornecedoras de equipamentos de telecomunicações e operadoras para promover e certificar a compatibilidade e a interoperabilidade dos equipamentos de acesso wireless com as especificações IEEE 802.16 e ESTSI HIPERMAN. O padrão 802.16 acabou por ser reconhecido pelo nome da organização que o promove, WiMax.

O padrão 802.16 é uma tecnologia wireless de redes metropolitanas (WMAN) que provê um acesso de banda larga alternativo ao cabo, DSL, fibra. O WiMax é uma evolução da tecnologia de comunicação sem fio que promete o ideal de uma plataforma comum padronizada para o transporte de vídeo, voz, imagens e dados com segurança e QoS num ambiente wireless.

O padrão especifíca duas faixas no espectro de frequência: 2 a $11 \mathrm{GHz}$ para situações sem visada direta (NLOS - non line of sight), atingindo até 8 quilômetros, e 10 a $66 \mathrm{GHz}$ para situações com visada direta (LOS - line of sight), atingindo até 50 quilômetros, cabendo aos

fabricantes e órgãos regulamentadores decidir quais serão as frequências utilizadas. As extensões do padrão podem ser vistas na Tabela A.2: 
Tabela A.2 Especificações da recomendação IEEE 802.16.

\begin{tabular}{|c|c|c|c|}
\hline NOME & CLASSIFICAÇÃO & PONTOS PRINCIPAIS & STATUS \\
\hline 802.16 & Interface Aérea & $\begin{array}{c}\text { Padrẫo para WirelessMAN (interface aérea para acesso } \\
\text { banda larga fixo), redes metropolitanas sem fio }\end{array}$ & $\begin{array}{c}\text { Publicada em Abril } \\
\text { de } 2002\end{array}$ \\
\hline $802.16 a$ & Interface Aérea & Expansão do escopo para frequências de 2 a $11 \mathrm{GHz}$. & $\begin{array}{c}\text { Publicada em Abril } \\
\text { de } 2003\end{array}$ \\
\hline $802.16 \mathrm{c}$ & Interface Aérea & $\begin{array}{c}\text { Define os perfis do sistema para } 10 \text { a } 66 \mathrm{GHz} \text { e a } \\
\text { interoperabilidade da interface aérea }\end{array}$ & $\begin{array}{l}\text { Publicada em } \\
\text { Janeiro de } 2003\end{array}$ \\
\hline 802.16REVD & Interface Aérea & Convertido no padrẫo $802.16 \mathrm{~d}$ & $\begin{array}{c}\text { Aprovada como } \\
802.16-2004 \text { em } \\
\text { Junho de } 2004\end{array}$ \\
\hline 802.16 .2 & Coexistência & $\begin{array}{c}\text { Definiçỗes para a coexistência de sistemas de acesso } \\
\text { banda larga de } 10 \text { a } 66 \mathrm{GHz} \text {. }\end{array}$ & $\begin{array}{c}\text { Publicada em } \\
\text { Setembro de 2001; } \\
\text { substituída pela } \\
802.16 .2-2004\end{array}$ \\
\hline $802.16 .2 a$ & Coexistência & $\begin{array}{l}\text { Expansẫo do escopo para frequências de } 2 \text { a } 11 \mathrm{GHz} \text { e } \\
\text { mais recomendaçốes de sistemas ponto-a-ponto }\end{array}$ & $\begin{array}{c}\text { Convertida e } \\
\text { publicada como } \\
802.16 .2-2004 \mathrm{em} \\
\text { Março de } 2004\end{array}$ \\
\hline $802.16 /$ ConfD1 & Conformidade & $\begin{array}{l}\text { Especificaçẫo de protocolos de testes para a } \\
\text { implementaçẫo de } 10 \text { a } 66 \mathrm{GHz}\end{array}$ & $\begin{array}{c}\text { Publicada em } \\
\text { Agosto de } 2003\end{array}$ \\
\hline $802.16 /$ Confl02 & Conformidade & Estrutura e propósito de testes para 10 a $66 \mathrm{GHz}$ & $\begin{array}{c}\text { Publicada em } \\
\text { Fevereiro de } 2004\end{array}$ \\
\hline $802.16 / \operatorname{Confl} 3$ & Conformidade & Testes de conformidade de rádio para 10 a $66 \mathrm{GHz}$ & $\begin{array}{c}\text { Aprovada em Maio } \\
\text { de } 2004\end{array}$ \\
\hline $802.16 /$ ConfD4 & Conformidade & $\begin{array}{l}\text { Especificação de protocolos de testes para a } \\
\text { implementaçẫo a partir de } 11 \mathrm{GHz} \text {. }\end{array}$ & Em aberto \\
\hline
\end{tabular}

O 802.16d (ratificado em Junho de 2004) é o padrão de acesso sem fio de banda larga fixa (também conhecido como WiMax Fixo) e teve os primeiros equipamentos homologados em Janeiro de 2006 pelo laboratório espanhol Cetecom. Este padrão pode ser referido como WiMax fixo, porque utiliza uma antena montada no local do assinante. O padrão IEEE 802.16 utiliza o OFDM para otimização dos serviços de dados wireless. Os sistemas baseados nos padrões 802.16 emergentes são as únicas plataformas padronizadas de redes wireless de áreas metropolitanas (WMAN) baseadas em OFDM.

O 802.16e (ratificado em Dezembro de 2005) é o padrão de acesso sem fio de banda larga móvel - WiMax Móvel (assegurando conectividade em velocidades de até $100 \mathrm{~km} / \mathrm{hora}$ ) e cujos equipamentos estarão disponíveis no mercado em meados de 2007. A grande diferença entre o WiMAX "Nomâde" (ou Fixo) e o Móvel é que o primeiro é apenas portátil (não comuta - não possui handoff - entre estações radio-base em altas velocidades) e o segundo é móvel (comuta - possui handoff - entre estações radio-base em velocidades de até $100 \mathrm{Km} / \mathrm{h}$ ). O padrão 802.16e utiliza o Acesso Múltiplo por Divisão Ortogonal da Freqüência (OFDMA), que é similar ao OFDM pelo fato de que ele divide as portadoras em várias sub-portadoras. No entanto, o OFDMA vai além ao agrupar diversas sub-portadoras em sub-canais. Um único 
cliente ou estação de assinante poderá transmitir utilizando todas as sub-portadoras no espaço da portadora, ou múltiplos clientes poderão transmitir, sendo que cada um utiliza uma parcela do número total de sub-canais simultaneamente.

O padrão possui a camada física adaptativa, ou seja, ele altera a modulação (Ex: 16 QAM, QPSK, 64 QAM) e codificação do equipamento de acordo com as condições do canal. Permite correção de erro e suporte a antenas adaptativas. A taxa de transmissão depende da modulação e dos códigos usados, variando entre 1 Mbps e 75 Mbps.

Os equipamentos WiMAX que operam em faixas de frequiência sem licença utilizarão a duplexação por divisão de tempo (TDD). Os equipamentos operando em faixas de freqüência licenciadas utilizarão o TDD ou a duplexação por divisão da frequiência (FDD).

O WiMax apresenta três modos de operação,todos os três em sua camada física, quais sejam: single carrier, OFDM 256, ou OFDMA 2K. O modo mais comumente utilizado é o OFDM 256.

O WiMax provê o suporte a duas topologias: Ponto-Multiponto (PMP - PointMultipoint) e Malha (Mesh). A topologia ponto-multiponto permite apenas a comunicação entre a estação base e as estações assinantes, ou seja, toda comunicação de uma estação de assinante passa sempre pela estação base. Esta foi a primeira topologia desenvolvida para as redes WiMAX. Na topologia em malha, o tráfego pode ser roteado através das estações assinantes, passando diretamente entre elas sem passar pela estação base. A topologia pontomultiponto é mais barata, pois reduz-se a complexidade e a necessidade de equipamentos mais sofisticados (roteadores e comutadores) nas estações dos assinantes. Em síntese, a topologia PMP é bastante semelhante a uma rede de telefonia celular, com a exceção de que, por enquanto, os assinantes são fixos. Assim, devido as limitações de linha de visada, em grandes cidades, torna-se díficil atender a todos os clientes em potencial. Para aumentar a quantidade de usuários, sem acrescentar novas BSs (de custo elevado), a topologia mesh surge como uma alternativa interessante. $\mathrm{Na}$ arquitetura mesh, cada estação funciona como um "nó repetidor" distribuindo tráfego para os seus vizinhos.

As possibilidades de utilização da tecnologia WiMax podem ser vistas na figura A.14. 


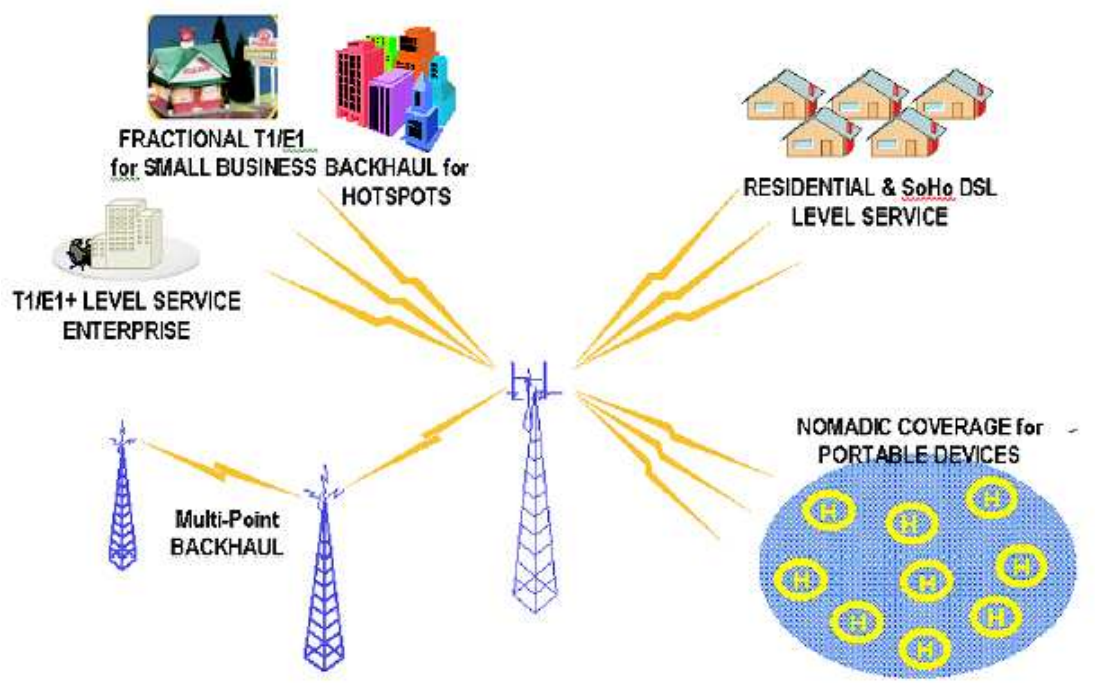

Figura A.14 Modelo de utilização para o Wimax

O que impulsiona a indústria em direção ao WiMax é a combinação entre um custo potencialmente baixo e a flexibilidade da tecnologia.

Um dos principais elementos da tecnologia é a interoperabilidade dos equipamentos, resultando nas facilidades para os provedores de serviço para obter equipamentos de diferentes fornecedores, permitindo uma maior competitividade, tornando os preços dos equipamentos mais baixos.

O fato de possibilitar o acesso quando não há linha de visada é uma vantagem, que possibilita maiores áreas de cobertura, com necessidade de instalar poucas estações-base, com um simples planejamento de freqüências, torres menores e maiores facilidades para a instalação dos CPEs, figura A.15. A grande área de cobertura é possível graças às técnicas utilizadas para permitir a recepção sem visada, como diversidade, codificação no espaço e no tempo e Automatic Retransmission Request (ARQ). 


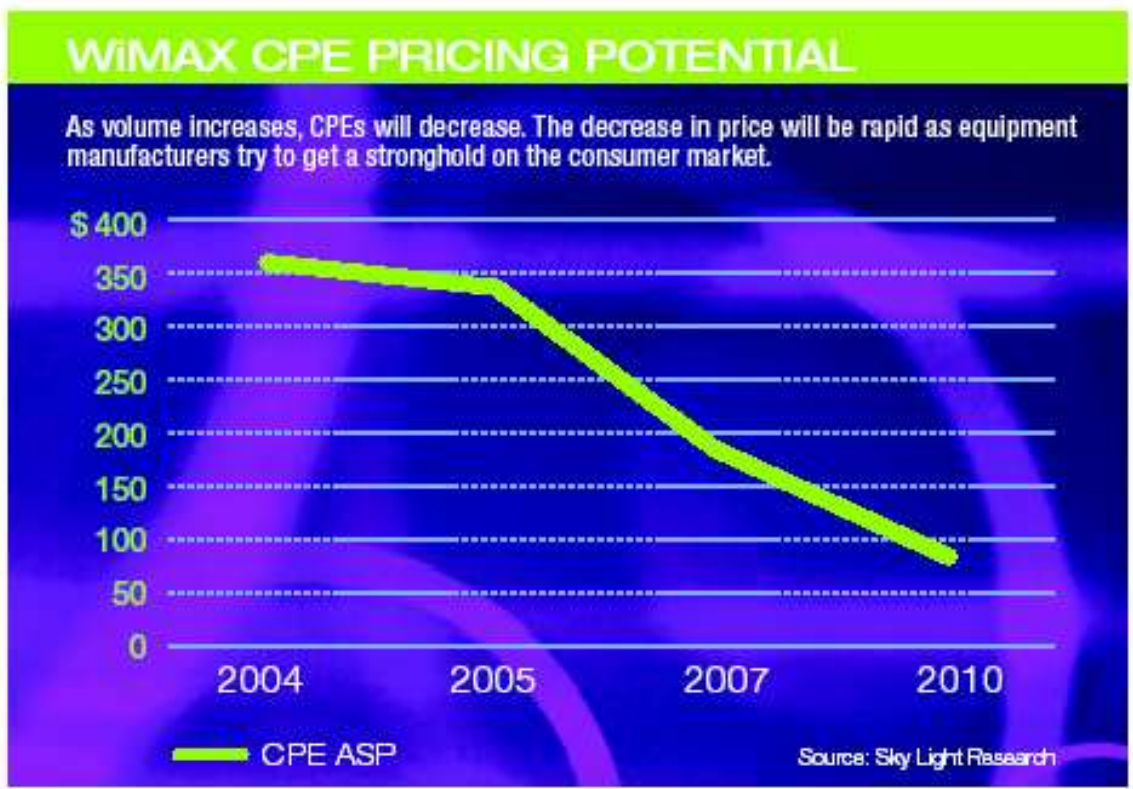

Figura A.15 Estimativa de preço dos CPEs WiMax.

O padrão WiMax utiliza um protocolo de concessão-requisição de acesso que não permite colisão de dados, e, portanto, utiliza a largura de banda disponível com mais eficiência. Nenhuma colisão significa nenhuma perda de largura de banda devido à transmissão de dados. Todas as comunicações são coordenadas pela estação base.

O padrão foi projetado para operação em classe de operadora. Conforme mais usuários são integrados, eles devem compartilhar a largura de banda agregada, e sua capacidade individual diminui linearmente. Além disso, possui larguras de banda de canal flexíveis entre 1,5 e $20 \mathrm{MHz}$ para facilitar a transmissão por longas distâncias e para diferentes tipos de plataformas de assinantes.

$\mathrm{O}$ acesso às áreas muito remotas, ou que sejam muito difíceis ou dispendiosas de alcançar com as infra-estruturas cabeadas tradicionais (como a fibra) tornam o WiMax uma solução bastante viável.

Enquanto os padrões para o WiMax não são completamente definidos, principalmente para o WiMax móvel, as operadoras e fornecedores realizam testes e começam a fazer projetos e implementações comerciais para ganhar experiência nessa nova tecnologia. Apesar de ainda não haver muitos equipamentos certificados e a indústria ainda estar começando a lidar com estes, as operadoras já possuem bastante informações sobre os serviços que seus clientes 
desejam, assim como o quanto eles estão dispostos a pagar por esses serviços. Alguns serviços que poderão ser oferecidos via WiMax são apresentados na Figura A.16.

\begin{tabular}{|c|c|c|c|}
\hline Tipo de Serviço & Tempo Real? & Aplicação & Banda \\
\hline Jogos Interativos & $\operatorname{Sim}$ & Jogos Interativos & 50 a 85 Kbit's \\
\hline \multirow{2}{*}{ VolP, Video Conferência } & \multirow{2}{*}{$\operatorname{Sim}$} & VolP & 4 a $64 \mathrm{Kbit/s}$ \\
\hline & & VideoFone & 32 a $284 \mathrm{Kbit} / \mathrm{s}$ \\
\hline \multirow{3}{*}{ Streaming } & \multirow{3}{*}{ No } & MúsicalFala & 5 a 128 Kbit/s \\
\hline & & Video-clipes & 20 a 384 Kbit/s \\
\hline & & Filmes & $>2 \mathrm{Mbit} / \mathrm{s}$ \\
\hline \multirow{3}{*}{$\begin{array}{l}\text { Tecnologia da } \\
\text { Informação }\end{array}$} & \multirow{3}{*}{ No } & Torpedos & $<250$ bytes \\
\hline & & Navegação Web & $>500 \mathrm{Kbit} / \mathrm{s}$ \\
\hline & & E-mails (com anexos) & $>500 \mathrm{Kbit} / \mathrm{s}$ \\
\hline \multirow{2}{*}{$\begin{array}{l}\text { Downloads de } \\
\text { conteúdo }\end{array}$} & \multirow{2}{*}{ No } & Filmes & $>1 \mathrm{Mbit} / \mathrm{s}$ \\
\hline & & Ponto-a-ponto & $>500$ Kbit/s \\
\hline
\end{tabular}

Figura A.16 Serviços suportados pelo WiMax. 


\section{APÊNDICE B - TECNOLOGIAS DE TRANSPORTE}

\section{B.1 - SDH, Sonet e PDH}

A rede de telefonia desenvolveu-se inicialmente com o intuito de transportar apenas voz. Para isso, eram utilizados fios de cobre e sinais analógicos, utilizando FDM para a transmissão, que permitia que vários sinais pudessem ser transmitidos em um único meio. [21]

A primeira grande mudança na telefonia foi a digitalização do sinal, feita utilizando-se a técnica PCM, no qual é possível representar um sinal de voz na faixa de 300 a $3.400 \mathrm{~Hz}$ por um fluxo digital de $64 \mathrm{kbps}$. Uma taxa de transmissão de $2.048 \mathrm{Kbps}$ é alcançada multiplexando-se, através da técnica TDM, 30 desses canais de voz, juntamente com a sinalização necessária. Essa é a chamada taxa primária, que é utilizada na grande parte do mundo, como o Brasil, excluindo-se Canadá, Estados Unidos e Japão, que utilizam a taxa de $1.544 \mathrm{Kbps}$. Pode-se verificar um processo de digitalização e multiplexação da voz na figura B.1:

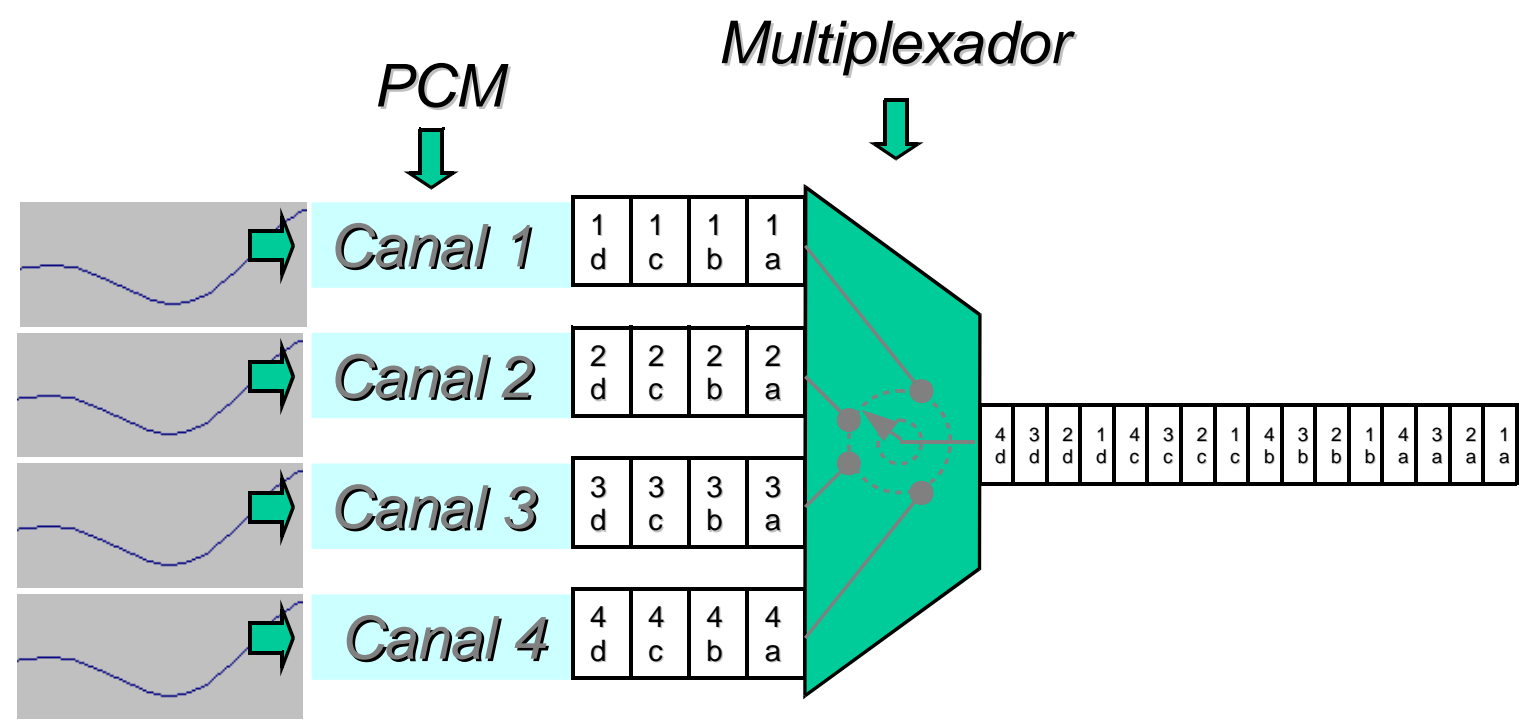

Figura B.1 Multiplexação de vários canais de voz.

Foram modificados os sistemas de transmissão, as centrais e, por fim, o acesso tornouse também digital. Durante os primeiros anos, os sistemas de transmissão utilizaram tecnologias proprietárias, com diferentes formas de multiplexação e manutenção da rede. A digitalização da rede possibilitou a criação de novos serviços, além da voz, como mostrado na figura B.2. 


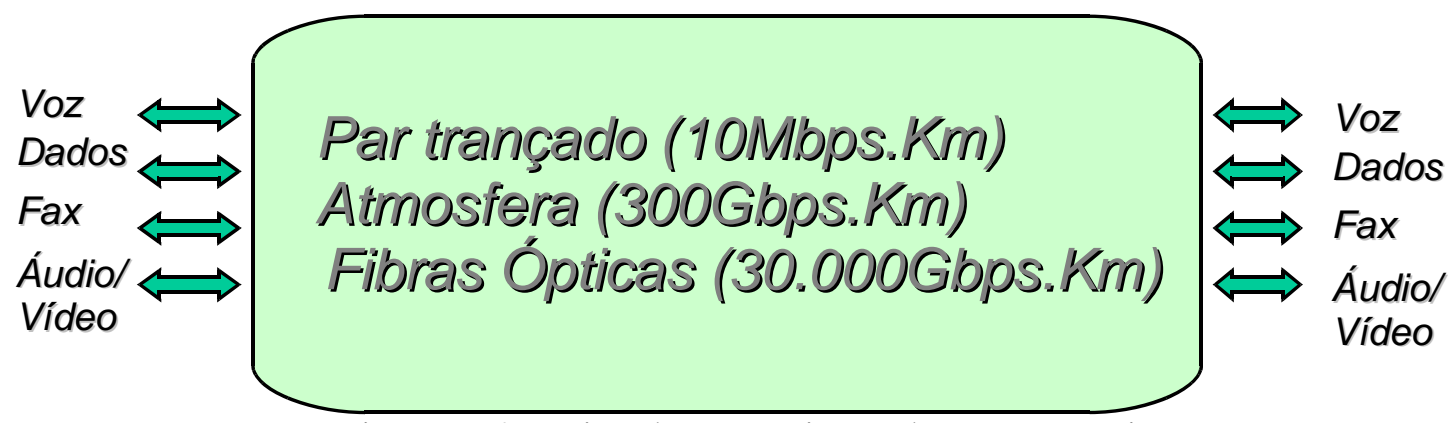

Figura B.2 Meios de transmissão de novos serviços.

À medida que eram criados novos serviços, era requisitada mais banda e novos níveis tiveram de ser definidos, figura B.3.

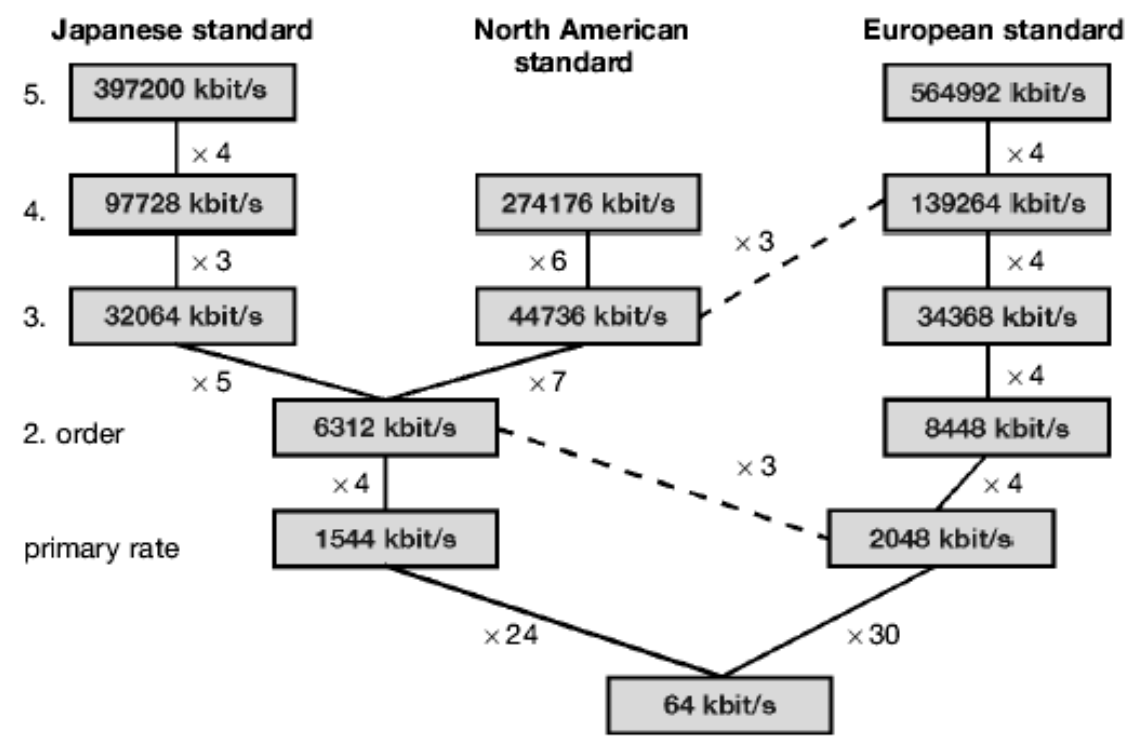

Figura B.3 Estrutura organizacional da PDH.

Criou-se, então, uma rede plesiócrona, a chamada rede PDH (plesiochronous digital hierarchy). Havia, no entanto, a necessidade da introdução de bits "não-significativos" a fim de ajustar as frequiências de relógio que podiam diferir, devido aos diversos caminhos e fontes da informação. Esse processo torna a rede quase síncrona, ou seja, plesiócrona.

O surgimento de novos serviços, que precisavam de uma sincronização em toda a rede, a necessidade da garantia da qualidade de serviço (QoS), o crescente número de diferentes operadores da rede e o grande crescimento da rede demandaram a criação de uma nova hierarquia digital, que eliminasse algumas desvantagens inerentes da rede PDH: 
- A rede PDH não era completamente padronizada;

- A inflexibilidade da rede, que demanda uma demultiplexação complexa para extrair tributários de baixa ordem de uma estrutura de alta ordem;

- Pouco espaço disponível no byte PDH para a administração da rede;

- Falta de possibilidade de monitoramento de performance.

A ECSA - EUA (Exchange Carriers Standards Association) criou, em 1984, o padrão SONET (Synchronous Optical Network), que foi adotado pelos EUA. Após algum tempo, o ITU-T - Europa (antigo CCITT) envolveu-se no trabalho para que um único padrão internacional pudesse ser desenvolvido para criar um sistema que possibilitasse que as redes de telefonia de países distintos pudessem ser interligadas. Foi criado, então, a rede SDH (Synchronous digital hierarchy). Posteriormente, foram realizados alguns ajustes no SONET, de forma a permitir a interconexão entre o SDH e SONET. A correspondência entre SDH e SONET é mostrada na tabela B.1.

Tabela B.1 Comparação entre as taxas da SONET e da SDH.

\begin{tabular}{|l|l|l|l|}
\hline \multicolumn{3}{|c|}{ SONET VS SDH BIT RATES } \\
\hline \multicolumn{3}{|c|}{ SONET } & \multicolumn{1}{c|}{ SDH } \\
\hline SYNCHRONOUS & OPTICAL & BIT RATE & SYNCHRONOUS \\
TRANSPORT SIGNAL & CARRIER & MBPS & TRANSPORT MODULE \\
\hline STS-1 & OC-1 & 51.84 & --- \\
STS-3 & OC-3 & 155.52 & STM-1 \\
STS-9 & OC-9 & 466.56 & -- \\
STS-12 & OC-12 & 622.08 & STM-4 \\
STS-18 & OC-18 & 933.12 & -- \\
STS-24 & OC-24 & 1244.16 & -- \\
STS--36 & OC-36 & 1866.24 & --- \\
STS-48 & OC-48 & 2488.32 & STM-16 \\
STS-192 & OC-192 & 9953.28 & STM-64 \\
\hline
\end{tabular}

*BIT RATES FOR HIGHER ORDER IS N-TIMES THE LOWER ORDER

A rede SDH traz, então, as seguintes vantagens:

- Maiores taxas de transmissão, podendo alcançar até $10 \mathrm{Gbps}$;

- Uma forma simplificada para fazer a inserção ou retirada de tributários de baixa ordem, devido à sincronização da rede; 
- O cabeçalho do frame SDH permite a gerência centralizada da rede, que traz vantagens como o provisionamento de serviços de forma mais rápida e otimização dos recursos da rede;

- Padronização tanto em nível de interfaces como em nível de equipamentos, que leva a um mercado mais competitivo, baixando o custo total da rede;

- Os equipamentos possuem mecanismos de proteção;

- Utilização da banda de forma flexível, dinamicamente.

Apesar dessas vantagens, há algumas desvantagens a serem consideradas:

- O projeto, a instalação e a operação da rede SDH são complexos e devem ser feitos com um planejamento criterioso e detalhado;

- Não há uma padronização dos sistemas de gerência, não possibilitando que equipamentos de fabricantes diferentes sejam monitorados por um único sistema;

$\mathrm{Na}$ rede $\mathrm{SDH}$ há um desacoplamento entre o fluxo de transporte (que define o sincronismo de quadro) e o fluxo dos tributários (que depende de uma série de variáveis aleatórias). Por isso, o início dos quadros dos tributários é definido por ponteiros que são utilizados para as justificações de sincronismo necessárias, podendo ser incrementados ou decrementados. Estes ajustes no sincronismo dos tributários não afetam, entretanto, o sincronismo dos quadros SDH.

O sistema $\mathrm{SDH}$, assim como a maioria dos outros sistemas de telecomunicações, é organizado em camadas. Do ponto de vista de rede, a estrutura é a da figura B.4: 


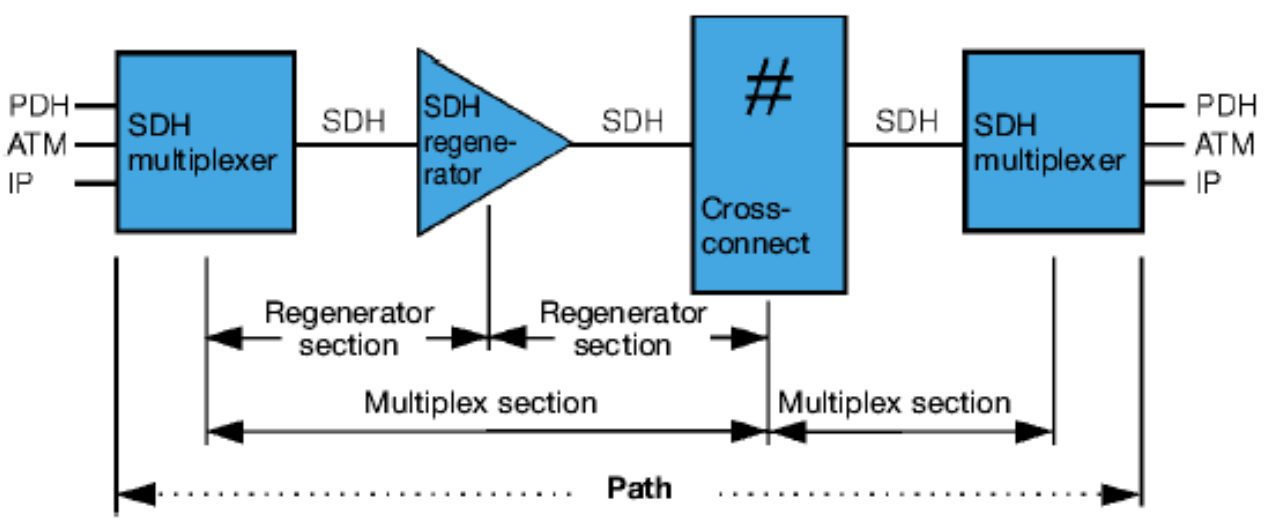

Figura B.4 Estrutura da rede SDH.

A via (path) é o caminho que o sinal percorre entre a origem e o destino. Nesse caminho, é formado o frame $\mathrm{SDH}$, com os sinais da origem, e durante o transporte desse frame, ele é processado pelas camadas adequadas para que possa ser restaurado ou para extrair ou inserir novos serviços. Além disso, cada etapa do processamento inclui informações de administração e supervisão no frame.

O ITU-T subdividiu a rede de transporte SDH em três camadas que são: Camada de Circuito (Circuit Layer Network), Camada de Via (Path Layer Network) e Camada do Meio de Transmissão (Transmission Media Layer Network). Existe uma relação cliente/servidor entre essas camadas, conforme mostrado na figura B.5. Cada camada possui seus próprios procedimentos de operação, manutenção e provisionamento.

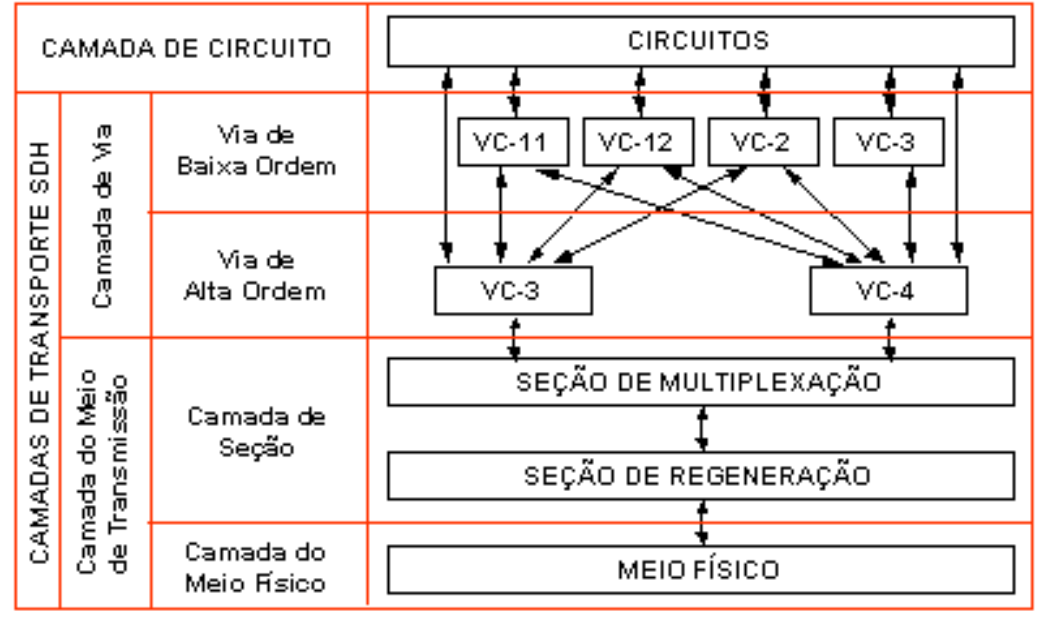

Figura B.5 Camadas da rede SDH. 
- Camada de Circuito - Provê aos usuários serviços de telecomunicações tais como comutação de circuitos e comutação de pacotes. Diferentes camadas de circuito podem ser identificadas de acordo com os serviços fornecidos;

- Camada de Via - É utilizada para dar suporte aos diferentes tipos de camadas de circuito. No caso da SDH, existem dois tipos: a Camada de Via de Ordem Inferior e a Camada de Via de Ordem Superior. A monitoração desta rede de camadas é possível através do POH (Path Overhead) de ordem inferior ou superior; - Camada do Meio de Transmissão - É dividida em camada de seção e camada de meio físico. A camada de seção se ocupa com todas as funções para a transferência de informação entre dois nós na camada de via. A camada de meio físico se ocupa com o meio de transmissão em sí (fibra óptica, rádio ou par metálico), a qual serve à camada de seção.

Na rede SDH a informação é organizada em quadros chamados STM (Synchronous Transport Module), que tem sua estrutura básica representada pela figura B.6.

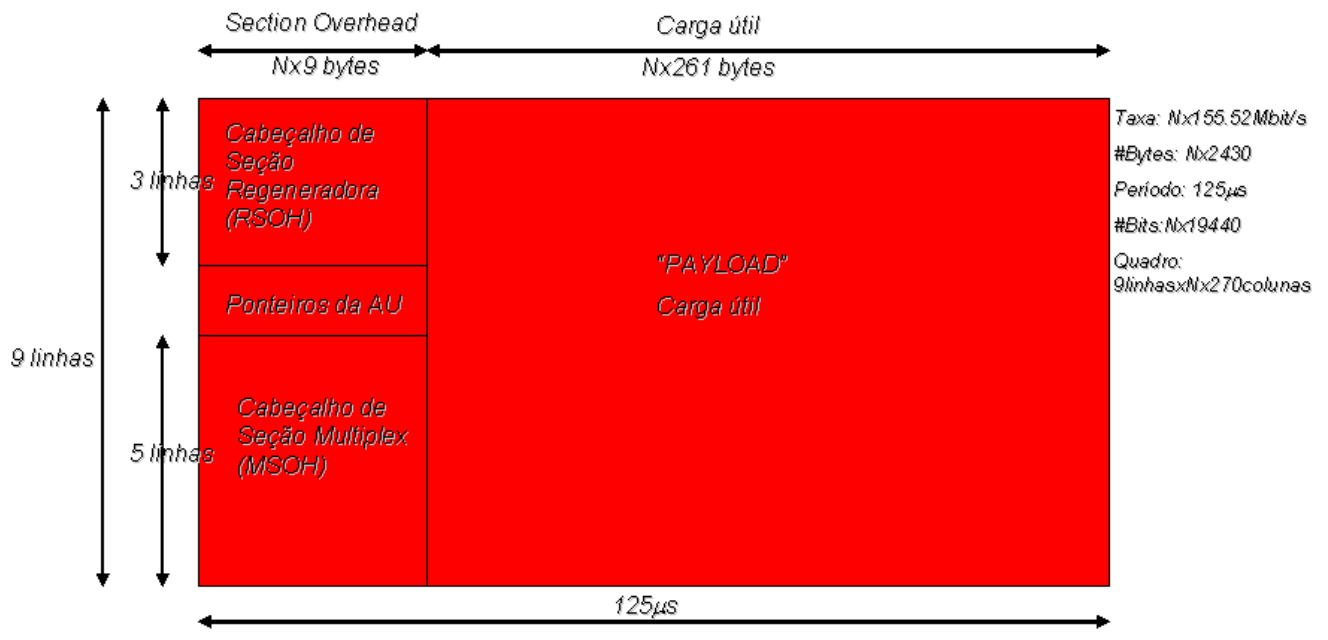

Figura B.6 Estrutura do quadro da rede SDH.

Essa estrutura é formada pela informação (payload), o cabeçalho (overhead ou SOHSession Overhead) e o POH (Path Overhead): 
- $\mathrm{RSOH}$ (Regenerator Section Overhead): é processado em cada equipamento da rede, contém informações de alinhamento de frame, identificação de frame, monitoração de erro de regeneração, alarmes físicos externos ao equipamento, e supervisão de sistema. Contém também um canal de voz, para comunicação de técnicos entre equipamentos.

- MSOH (Multiplex Section Overhead): é processado apenas em equipamentos onde existe inserção (add) ou retirada (drop) de canais multiplexados, contém informações de monitoração e indicação de erros de multiplexação, controle de chaveamento de mecanismos de proteção, monitoração de sincronismo e gerência de sistema.

- POH: processado em cada equipamento, possui os ponteiros que indicam onde se localiza o primeiro byte dos containers virtuais (VCs) dentro da área de informação útil (payload) do frame, e eventuais bytes provenientes de justificação desses VCs.

As topologias de rede geralmente utilizadas são mostradas na figura B.7:

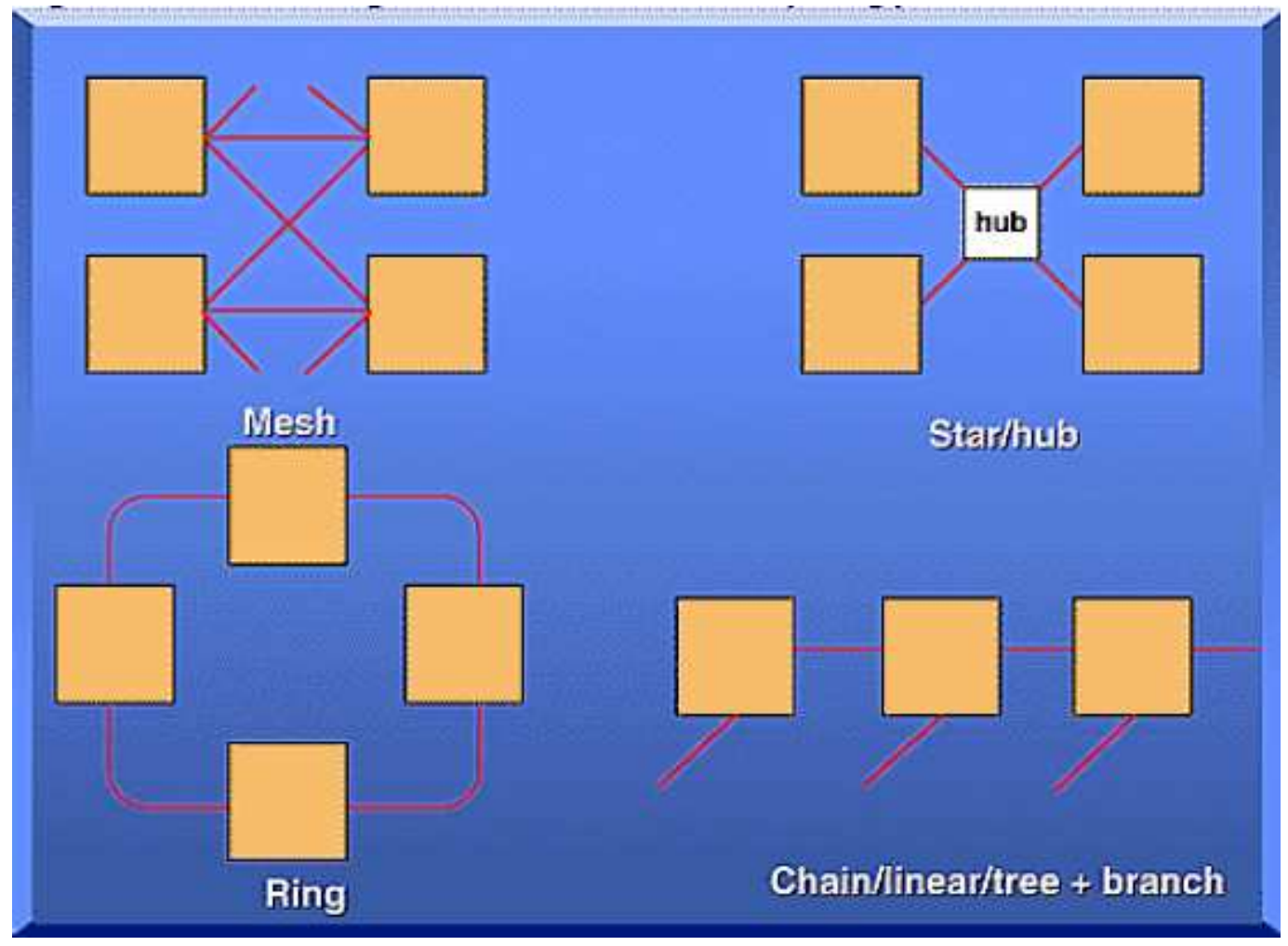


Figura B.7 Topologias de rede.

As atuais redes SDH são construídas basicamente com a utilização de quatro diferentes tipos de elementos de redes:

- Regeneradores: A regeneração é o processo em que o sinal digital degradado tem as características de amplitude, formas de onda e de sincronismo adequadas aos limites especificados para a sua retransmissão. O regenerador (REG) regenera o sinal agregado STM-N e o retransmite.

- Multiplexador Terminal de Linha (Line Terminal Multiplexer - LTM): Multiplexa/ demultiplexa sinais tributários de 2 Mbps, 34 Mbps, 140 Mbps e STM1,formatando/terminando o sinal agregado STM-1.

- Multiplexador Deriva/Insere (Add/Drop Multiplexers - ADM): O ADM (multiplexador insere/deriva) tem a capacidade de acessar qualquer um dos sinais constituintes do sinal agregado STM-N, sem a necessidade de demultiplexar e terminar o sinal completo. Sinais plesiócronos e síncronos de baixa taxa de bits podem ser extraídos ou inseridos em feixes de bits de alta velocidade SDH por meio de ADM's. Esta característica torna possível projetar estruturas em anel, que possuem a vantagem de comutação de caminhos de back-up automáticos dentro de um anel num determinado evento ou falha.

- Cross Conexão Digital (Digital Cross-Connects - DXC): Este elemento de rede possui a maior variedade de funções. Ele permite o mapeamento de tributários de sinais PDH em VC's (virtual containers) tão bem quanto a comutação de vários containers, até VC-4 (inclusive).

\section{B.2 - ATM}

Assynchronous Transfer Mode (ATM) foi concebida para integrar dados, voz e vídeos em uma única rede. Seu desenvolvimento se deu tanto pela necessidade de flexibilidade quanto pelo progresso tecnológico e conceitual de sistemas. Nos últimos anos ela começou a 
ser utilizada para redes locais e corporativas, mas sua concepção inicial tinha sido feita como uma técnica de multiplexação e comutação de alta velocidade para redes públicas.

Para se definir uma rede ATM é preciso introduzir alguns conceitos básicos, são eles: células, endereçamento e circuitos virtuais.

- Células: Nas redes de comutação por pacotes, como os protocolos IP e Ethernet, o encapsulamento de pacotes ocorre de uma forma variável, ou seja, o tamanho dos pacotes é variável; no caso das redes ATM, esses pacotes têm tamanhos fixos, de 53 bytes (sendo 48 de dados e 5 de cabeçalho) e são denominados células. Antes de se definir o tamanho das células, a idéia básica que norteou a decisão foi a de que essas seriam de tamanho reduzido, pois, dessa forma, evitaria-se o típico eco encontrado em transmissões de telefonia. Mas a principal vantagem que se tem em trabalhar com pacotes de tamanho fixo reside na maior facilidade encontrada em se tratar dados por hardwares baseados em chaveamentos (switches). Apesar de grandes vantagens, têm-se desvantagens como, por exemplo, a quantidade de cabeçalhos, mas, em conexões de alta velocidade, isto deixa ser relevante.

- Endereçamento: Existem 3 formatos de endereçamento que são todos constituídos de 20 bytes e divididos em duas seções: Prefixo de Rede (13 bytes) e End System Part (7 bytes). São eles: DCC (Data Country Code), E.164 (Specific Integrated Service Digital Network Number) e ICD (Internetional Code Designator). Esses endereços são somente utilizados para definição dos Circuitos Virtuais, após isso, esses passam a não mais serem representados nas células e essas passam a ser roteadas pelos VPIs e VCIs.

- Circuitos Virtuais: São definidos dinamicamente ou pelo administrador de rede. No primeiro caso, são chamados SVCs (Switched Virtual Circuits), no segundo são PVCs (Permanent Virtual Circuits) e ficam conectados o tempo todo. Em uma rede ATM deve necessariamente haver uma conexão virtual para que haja transferência de dados. Existem dois tipos de conexão de transporte: Virtual Path e Virtual Channels. No segundo caso (VC), o acesso é unidirecional e feito pela concatenação de uma seqüência de elementos de conexão, no primeiro caso (VP), 
consiste em um conjunto de VCs. Os dois circuitos possuem identificadores associados denominados de VPI e VCI. Para cada VP, tem-se vários VCIs e o mesmo VCI pode ser utilizado em outro VP.

Visto que o IP foi puramente projetado para um transporte de dados eficiente este não seria, portanto, adequado para o tráfego de vídeo e de voz o que guiou o desenvolvimento tecnológico mais para o lado do ATM. Mas deve-se sempre ter o cuidado de observar que embora o ATM tenha sido criado com o objetivo de lidar com todas as espécies de aplicações multimídia, não ocorrerá a substituição do IP e aplicações baseadas nesse protocolo continuaram a usá-lo, rodando sobre ATM.

\section{B.3 - IP}

Internet Protocol (IP) é um protocolo utilizado para transportar informação sob diferentes tipos de rede. Trabalha sem uma conexão, ou seja, a informação é transportada sem que haja estabelecimento de uma conexão entre a fonte e o destino. Cada pacote terá um endereço tanto da fonte como do destino o que é chamado de endereço IP. Existem dois tipos de endereços: IP privado e público. No primeiro, o endereço é globalmete único, ou seja, única fonte, único destino, o que significa que cada máquina conectada à internet pode enviar pacotes para qualquer outra também conectada. Esse protocolo não possui mecanismos de retransmissão, não dá garantias de uma transmissão íntegra e ordenada e descarta um datagrama se este não for entregue ou se passar muito tempo trafegando na internet. Pode-se citar dois protocolos utilizados para o auxílio no transporte fim-a-fim em uma rede IP: TCP e UDP.

Tanto o Transmission Control Protocol (TCP) quanto o User Datagram Protocol (UDP) são protocolos que possuem quatro camadas. Eles podem ajudar, por exemplo, segmantando os dados do usuário para um pacote IP de tamanho variável e adicionando uma seqüência de números a cada pacote. Da seqüência de números, o receptor sabe decodificar e remontar os dados até mesmo se o pacote IP atual chegar em ordem diferente daquela transmitida. A segmentação dos dados do usuário pode ser vista na figura B.1. 


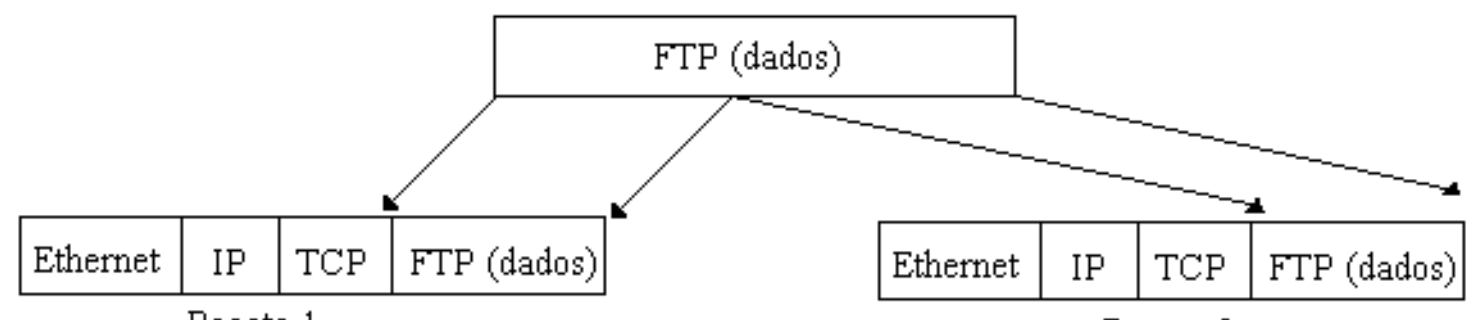

Pacote 1

Pacote 2

Figura B.8 Segmentação de dados.

TCP e UDP fornecem um método de endereçamento para separar as diferentes aplicações dentro de uma rede IP, o que é chamado de port numbers ou, em português, somente portas. Cada aplicação terá uma ou várias portas para identificar a fonte e o destino.

\section{B.3.1 - TCP}

O Transmission Control Protocol é usado para realizar uma transferência confiável full duplex (ambas as direções) de dados entre dois hosts diferentes. Permite a recuperação de pacotes perdidos, a eliminação de pacotes duplicados, a recuperação de dados corrompidos, e pode recuperar a ligação em caso de problemas no sistema e na rede. Também são incluídas como funções do TCP a numeração seqüencial, controle de fluxo, reconhecimento de pacotes e realização de uma checagem de controle para supervisão de dados corrompidos.

Para realização do controle de fluxo, o TCP atribui uma janela de transmissão ao host de origem que limita o número de bytes transmitido por vez. A segurança na transmissão reside no fato do protocolo ser orientado à conexão e trabalhar com números de reconhecimento sequiências e positivos.

Para a conexão do protocolo TCP, ocorrem três fases: estabelecimento da ligação, transferência e término de ligação. O estabelecimento da ligação é realizado em três passos, enquanto que o término é realizado em quatro. Durante a inicialização, são inicializados alguns parâmetros, como o Sequence Number (número de seqüência), para garantir a entrega ordenada e robustez durante a transferência.

O TCP do host de origem transfere os dados em forma de octetos. Cada octeto recebe números em sequiência. O TCP do host de destino analisa esses números para garantir a ordem 
e a integridade da mensagem enviada. Se a transferência for perfeita, o TCP do host destino envia uma mensagem de reconhecimento à origem. Caso contrário, é enviada uma seqüência numérica para o TCP do host origem que informará o tipo do problema, bem como ordenará uma nova transmissão. Os números em sequiência podem ser utilizados, ainda, para eliminar octetos duplos que, por causa da transmissão não orientada à conexão, podem ocorrer.

Podem-se citar alguns protocolos de aplicação do TCP como: TELNET (possibilita o trabalho em um host distante), FTP (transmite arquivos pela Internet) e SMTP (aplicativo de nível superior).

\section{B.3.2 - UDP}

O User Datagram Protocol é utilizado para prover uma rápida transferência de dados entre dois pontos IP finais. A corrupção dos dados também pode ser checada, mas isso é uma função opcional. O protocolo UDP é restringido a portas e sockets, e transmite os dados de forma não orientada à conexão. Esse protocolo é preferencialmente utilizado ao invés do TCP quando a velocidade é mais importante do que a confiabilidade e quando os protocolos superiores ou inferiores já possuem uma função de confiabilidade.

Em geral, os programas que utilizam portas UDP recorrem também à uma porta TCP para enviar as requisições de dados a serem enviados e também para checar periodicamente se o cliente ainda está on-line. São exemplos de protocolos que utilizam UDP: SNMP (usado para monitoramento das redes), RPC (Permite a um host a utilização de funções localizadas em hosts remotos) e TFTP (é utilizado para controle temporal e de integridade, não possui mecanismos de segurança).

\section{B.3.3 - IP versão 4}

Atualmente, IPv4 é a versão utilizada. Essa contém um endereço de 32 bits que é escrito com uma notação decimal onde cada número corresponde a um octeto ou 8 bits. Cada octeto está dentro de uma faixa que vai de 0 (00000000) até 255 (11111111). Um endereço IP é composto de duas partes: Network ID (Net ID) e o Host ID. O primeiro representa a rede na 
qual o host pertence e o segundo identifica o host específico dentro se uma rede particular, sendo que o Net ID sempre vem antes do Host ID e todas a funções de roteamento são baseadas no Net ID.

\section{B.3.4 - IP versão 6}

É a mais atual versão desenvolvida pelo IETF. As vantagens geradas por essa nova versão são descritas abaixo:

- Expansão na capacidade de endereços: Já que nessa versão o endereço é representado por 128 bits e não mais por 32. Além disso, a IPv6 contém um novo tipo de endereço denominado Anycast Address que é usado para enviar pacotes para qualquer grupo de nós em determinada rede.

- Simplificação do formato do cabeçalho que permite uma forma mais eficiente de encaminhamento de pacotes.

- Maior capacidade de etiquetar

- Maior capacidade de autentificação e de privacidade.

\section{B.3.5 - Sockets}

É simplesmente a combinação entre um endereço IP e uma porta que permite um servidor identificar unicamente o processo de um cliente particular, mas não serve com o propósito de identificação já que a mesma porta pode ser utilizada por vários clientes. Por questões de segurança e também para que o endereço seja salvo, algumas redes utilizam um endereço IP privado. Como já dito anteriormente, para que se possa conectar a Internet, é necessário que se tenha um endereço público e, para isso, se faz necessário uma transição desse endereço IP privado para um endereço público. Para isso, utiliza-se a chamada NAT (network address translation) que geralmente é realizada por roteadores conectado a redes externas ou a firewalls. 


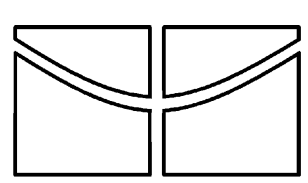

UNIVERSIDADE DE BRASÍLIA

FACULDADE DE TECNOLOGIA

DEPARTAMENTO DE ENGENHARIA ELÉTRICA

ESTUDO DE UMA REDE DE ACESSO VIA FIBRA ÓPTICA

\author{
LUÍZA BASÍLIO LAGE \\ MARIA CLARA ALCÂNTARA DE OLIVEIRA
}

ORIENTADOR: ANTÔNIO JOSÉ MARTINS SOARES

PROJETO FINAL DE GRADUAÇÃO

BRASÍLIA/DF: DEZEMBRO/2006 


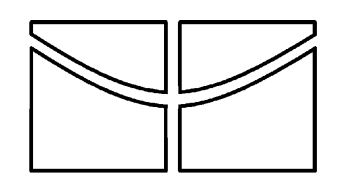

UNIVERSIDADE DE BRASÍLIA FACULDADE DE TECNOLOGIA DEPARTAMENTO DE ENGENHARIA ELÉTRICA

\title{
ESTUDO DE UMA REDE DE ACESSO VIA FIBRA ÓPTICA
}

\author{
LUÍZA BASÍLIO LAGE \\ MARIA CLARA ALCÂNTARA DE OLIVEIRA
}

PROJETO FINAL DE GRADUAÇÃO SUBMETIDA AO DEPARTAMENTO DE ENGENHARIA ELÉTRICA DA FACULDADE DE TECNOLOGIA DA UNIVERSIDADE DE BRASÍLIA, COMO PARTE DOS REQUISITOS NECESSÁRIOS PARA A OBTENÇÃO DO GRAU DE ENGENHEIRO.

APROVADA POR:

ANTÔNIO JOSÉ MARTINS SOARES, ENE/UnB (ORIENTADOR)

FRANKLIN DA COSTA SILVA, ENE/UnB (EXAMINADOR)

MARCO ANTÔNIO BRASIL TERADA, ENE/UnB (EXAMINADOR)

DATA: BRASÍLIA/DF, 18 DE DEZEMBRO DE 2006 
LAGE, LUÍZA BASÍLIO

Estudo de uma Rede de Acesso via Fibra Óptica

[Distrito Federal] 2006

(ENE/FT/UnB, Engenheira, Engenharia Elétrica, 2006).

Projeto Final de Graduação - Universidade de Brasília, Faculdade de Tecnologia. Departamento de Engenharia Elétrica.

OLIVEIRA, MARIA CLARA ALCÂNTARA DE

Estudo de uma Rede de Acesso via Fibra Óptica

[Distrito Federal] 2006

(ENE/FT/UnB, Engenheira, Engenharia Elétrica, 2006).

Projeto Final de Graduação - Universidade de Brasília, Faculdade de Tecnologia. Departamento de Engenharia Elétrica.

\section{REFERÊNCIA BIBLIOGRÁFICA}

LAGE, LUÍZA BASÍLIO (2006). Estudo de uma Rede de Acesso via Fibra Óptica (Projeto Final de Graduação), Departamento de Engenharia Elétrica, Universidade de Brasília, Brasília, DF.

OLIVEIRA, MARIA CLARA ALCÂNTARA DE (2006). Estudo de uma Rede de Acesso via Fibra Óptica. (Projeto Final de Graduação), Departamento de Engenharia Elétrica, Universidade de Brasília, Brasília, DF. 


\section{CESSÃO DE DIREITOS}

NOME DO AUTOR: Luíza Basílio Lage, Maria Clara Alcântara de Oliveira TÍTULO DA DISSERTAÇÃO: Estudo de uma Rede de Acesso via Fibra Óptica GRAU/ANO: Engenheiro/2006.

É concedida à Universidade de Brasília permissão para reproduzir cópias deste Projeto Final de Graduação e para emprestar ou vender tais cópias somente para propósitos acadêmicos e científicos. Os autores reservam outros direitos de publicação e nenhuma parte desta dissertação de graduação pode ser reproduzida sem a autorização por escrito dos autores.

Luíza Basílio Lage

Condomínio Mansões Itaipú

CEP XXXXX-XX - Brasília - DF - Brasil

Maria Clara Alcântara de Oliveira SQS 114 Bloco A apartamento 605

CEP 70377-010 - Brasília - DF - Brasil 


\section{AGRADECIMENTOS}

Agradeço a Deus, por todas as bênçãos em minha vida, por sempre ter iluminado o meu caminho, muitas vezes difícil, mas gratificante, tornando meus sonhos realidade.

Agradeço ao meu pai e à minha mãe, por serem meus exemplos de vida, de luta e dedicação à família e por terem estado sempre presentes, me apoiando e incentivando para que eu pudesse passar com êxito por cada etapa dessa caminhada. À minha irmã Fernanda, meu irmão Filipe e à sobrinha Isabela, pela alegria que trazem à minha vida. A todos os meus familiares: avós, tios, primos e agregados, pelo apoio em todos os momentos.

À avó Vaína (in memorian), grande incentivadora, que sempre vibrou com cada pequena conquista minha.

Grandes agradecimentos aos meus amigos, que souberam entender os momentos em que abri mão da convivência para me dedicar à Engenharia: as Amigaaas: Ana Teresa, Ariane, Cintia, Clarice, Fernanda, Juliana, Larissa e Thaís; os Amigooos: Thiago, Rodrigo, Fabiano e Diego e as amigas super animadas Luana, Patrícia e Elaine.

Agradeço também aos amigos da UnB, que passaram tantas horas ao meu lado, sendo grandes companhias, dentro e fora de sala, e que continuarão fazendo parte dessa história e, sem dúvida, da minha vida: Ana Ravena, Walkíria, Maria Clara, Izumi, Fernanda e Viviane (as EletroGirls), Débora, Andréia, Marcos, Thompson, Francisco, Samuel, Otávio, Danilo Branquinho, André Sterf, Marcello Sasaki, Humberto Bruno e Rodrigo. Tenho que agradecer muito à Clara, minha querida amiga inseparável, pela presença sempre constante na qual pude contar, pelas risadas que demos de tudo e de todos, por me entender sempre e principalmente, pela amizade, que tenho certeza, será eterna.

Agradeço também aos professores pela dedicação e conhecimento não só na realização desta monografia, mas também em minha formação acadêmica.

A todos que verdadeiramente acreditaram que eu era capaz e sempre me deram força e incentivo para continuar lutando. Amo vocês!

Luíza Basílio Lage 


\section{AGRADECIMENTOS}

Primeiramente agradeço a Deus pela vida, pela saúde e pela inteligência. Por ter me dado força nos momentos em que o único pensamento era desistir.

Agradeço a meus pais que me ensinaram a viver com dignidade e iluminaram meu caminho com afeto e dedicação constantes.

Agradeço também a todos os meus professores da Universidade de Brasília, que foram pessoas imprescindíveis que transformaram a ingenuidade em experiência.

Àqueles amigos incondicionais: Andréia, Luana, Amanda, Bruno, Júlia, Camila e Lizane que conseguiram entender minha ausência e me apoiaram na luta por mais esse sonho. Obrigada por estarem sempre presentes.

Agradeço a todos os meu grandes e queridos amigos feitos na Engenharia. As eletrogirls Luíza, Izumi, Ana Ravena, Fernanda, Walkíria e Viviane; os queridos Francisco, Marcos, Thompson, Otávio, Samuel, Danilo Branquinho, Guilherme Solino e Marcello Sasaki todos vocês foram imprecindíveis para essa conquista, amo todos vocês! Um especial para a Luíza, amiga companheira que caminhou junto comigo todo esse tempo, inclusive nesse trabalho, e fez meus dias mais engraçados e felizes.

Não poderia deixar de agradecer também ao meu namorado e também colega de curso Rodrigo, que com sua dedicação e presença tornaram esses dias de luta mais belos.

A todos, que de alguma forma passaram pela minha vida e influenciaram positivamente nessa conquista. O sucesso também é de vocês!! 


\section{DEDICATÓRIA}

Eu, Maria Clara Alcântara de

Eu, Luíza Basílio Lage, dedico este trabalho ao meu pai Luciano, à minha mãe Márcia, aos meus irmãos Fernanda e Filipe, à minha sobrinha Isabela, à minha amiga Clara e aos meus amigos da Elétrica, que tanto me ajudaram nesses cinco anos.
Oliveira, dedico este trabalho a meus amados pais Ataíde e Maria Helena, a meu irmão João, ao meu namorado Rodrigo, as minhas amigas de sempre Luíza, Luana e Andréia e aos meus queridos amigos da Elétrica. Todos foram essenciais para que esse sonho pudesse ser realizado. 



\section{ESTUDO DE UMA REDE DE ACESSO VIA FIBRA ÓPTICA}

\section{RESUMO}

As redes de acesso via fibra óptica já são uma realidade. Por esse motivo, o trabalho que segue se propõe a realizar um estudo das aplicações práticas da fibra óptica com objetivo final de mostrar e exemplificar a rede de acesso óptica.

Para que esses objetivos sejam alcançados, seguem conceituações do sistema de comunicação óptico, dos elementos de uma rede óptica, das técnicas de multiplexação utilizadas, das redes ópticas e, por fim, das redes de acesso via fibra óptica. Além disso, exemplos de redes já implementadas fazem parte do desfecho do trabalho.

Em um segundo plano tem-se também a conceituação de outros tipos de rede acesso existentes para que, dessa forma, sejam feitas comparações. Para complementação conceitual tem-se também um resumo das tecnologias de transmissão utilizadas. 


\section{ABSTRACT}

The usage of optical fiber in the access networks already are a reality. For this reason, the work that follows is a study of the practical applications of the optical fiber with the final goal to show and to exemplify the optical access networks.

In order to reach that goal, there are concepts of the optical communication system, of the elements of an optical network, of the used multiplexing techniques, optical networks and, at last, of the optical access networks. Also, there are examples of already implemented optical access networks.

Other existing types of access networks are also explained, so that comparisons may be made. As a complement, a summary of the used technologies of transmission are also mentioned. 


\section{SUMÁRIO}

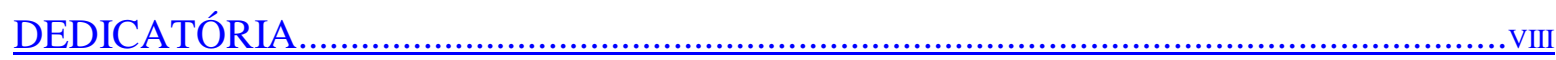

RESUMO.

ABSTRACT.

1 - INTRODUCCÃO

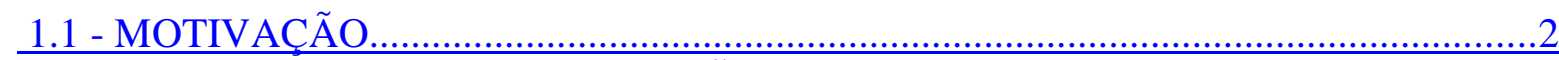

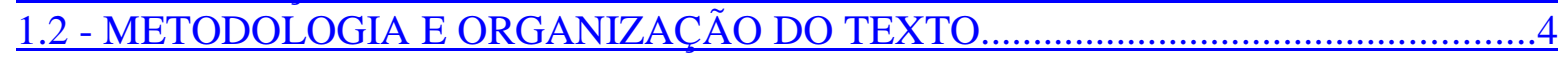

$\underline{2}$ - FUNDAMENTOS DE UM SISTEMA DE COMUNICAÇÃO ÓPTICO..........................5

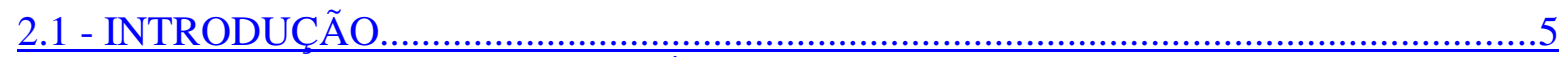

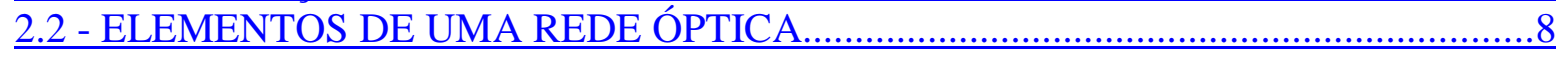

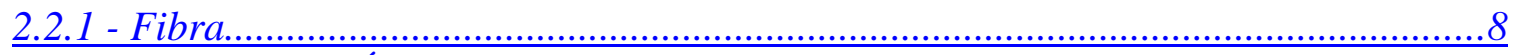

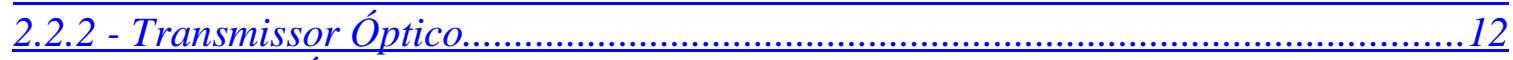

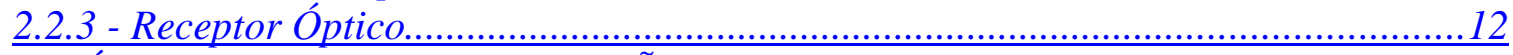

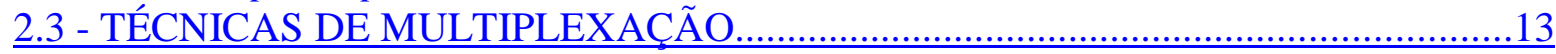

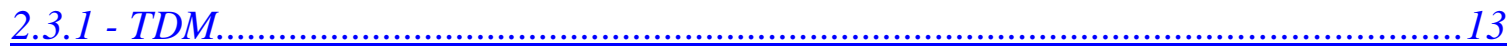

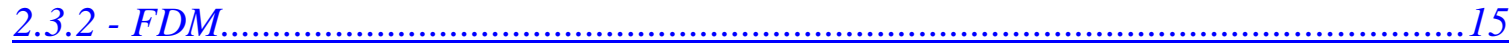

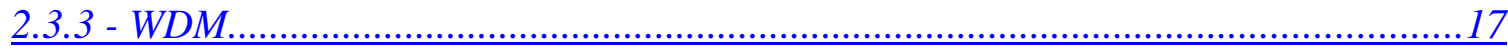

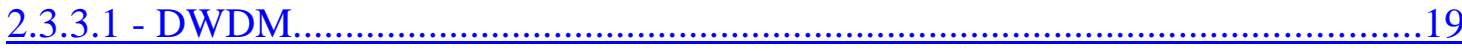

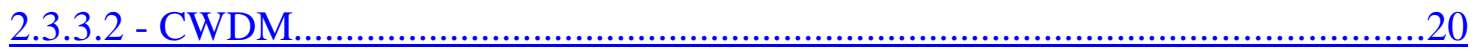

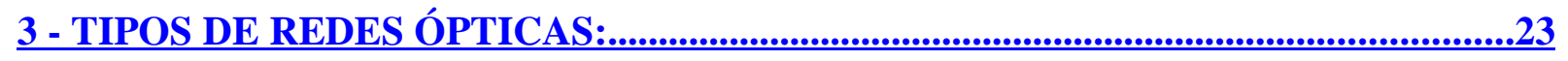

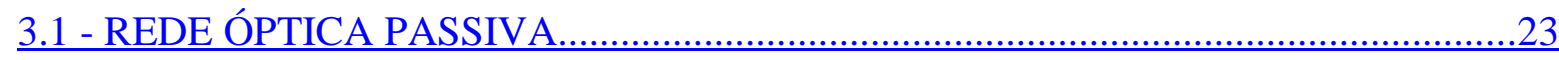

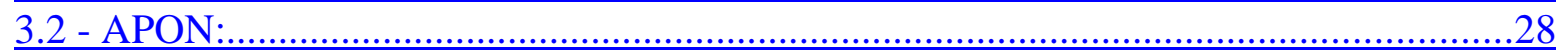

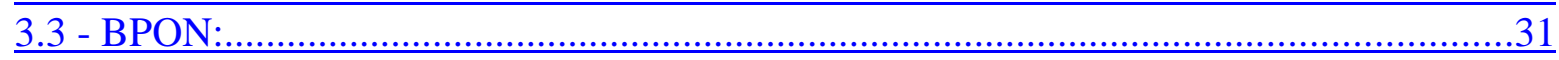

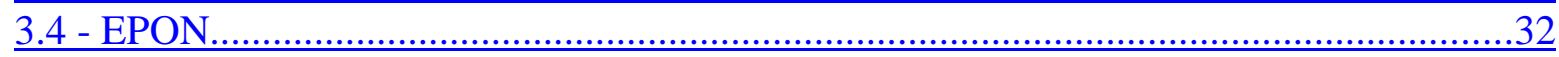

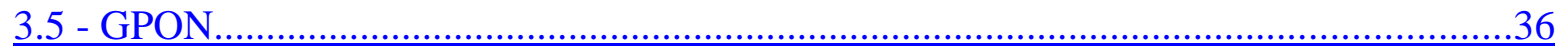

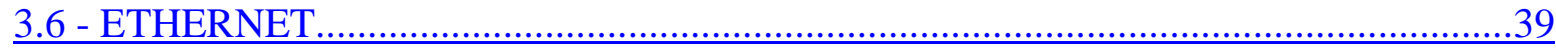

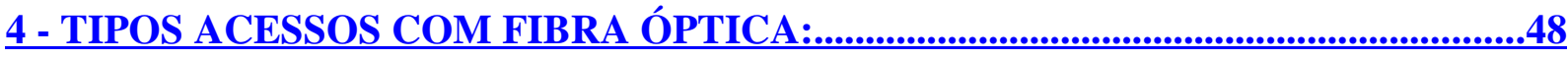

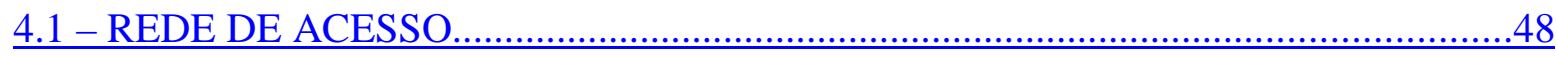

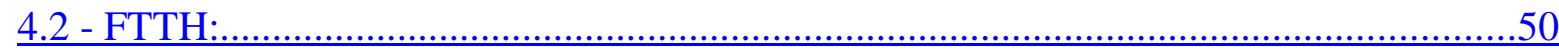

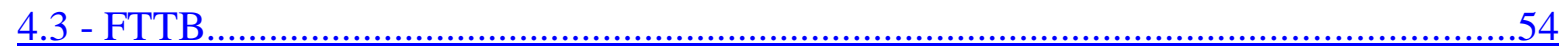

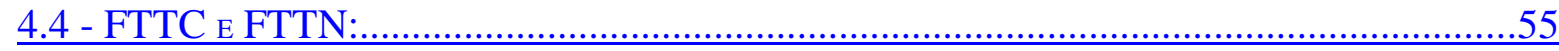

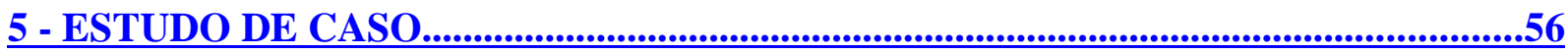

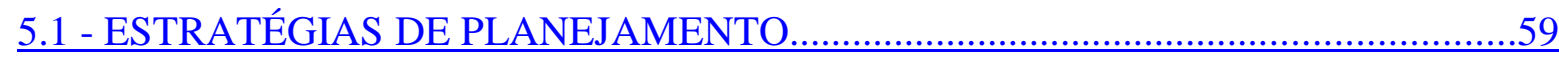

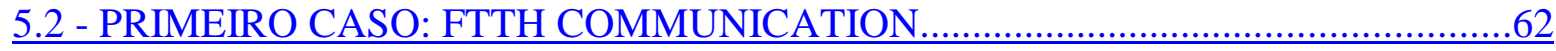

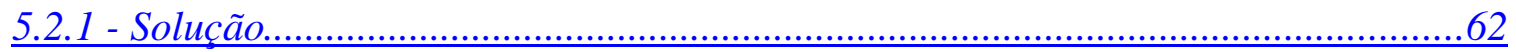

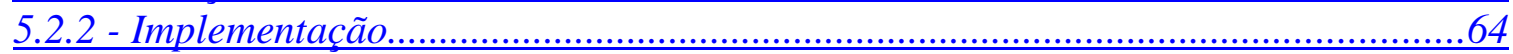

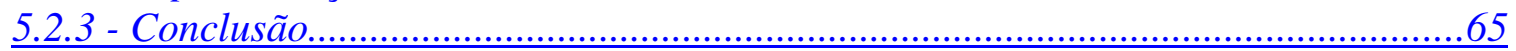

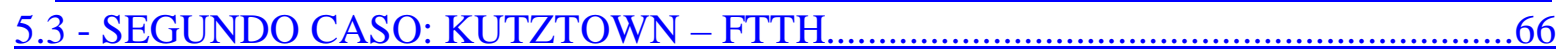

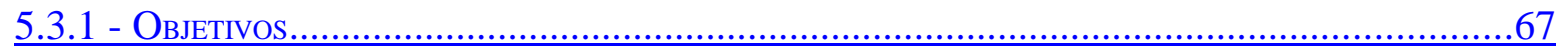

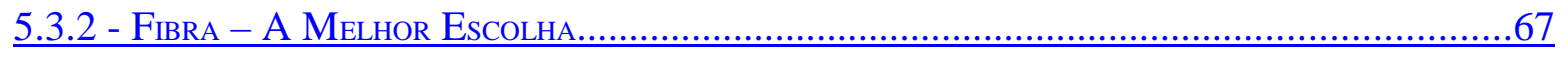

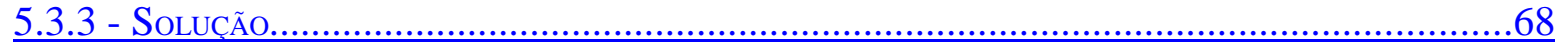




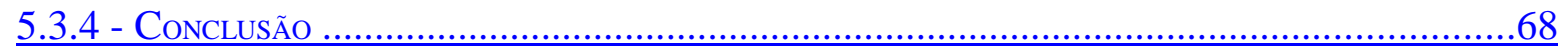

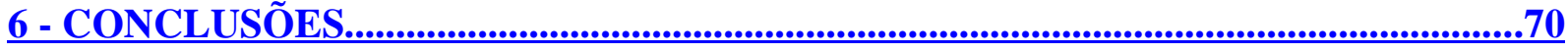

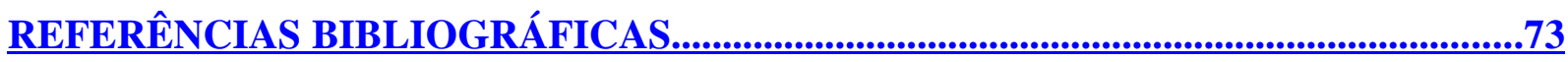

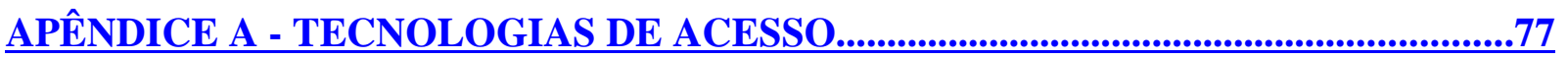

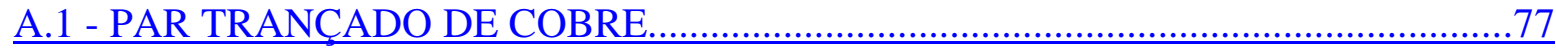

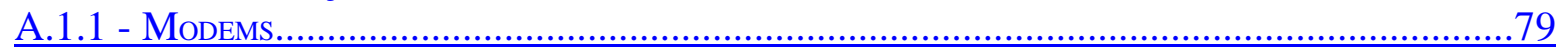

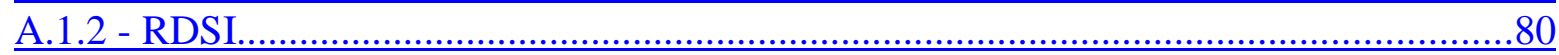

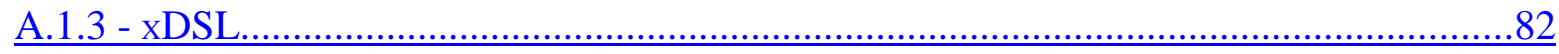

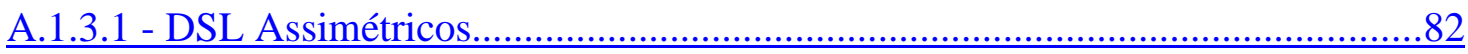

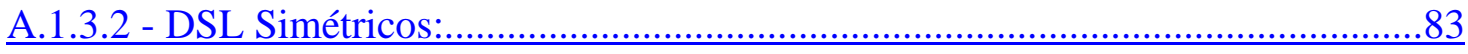

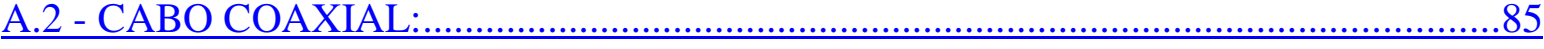

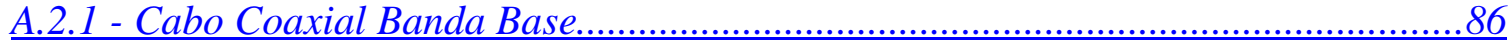

A.2.2 - Cabo Coaxial Banda Larga .......................................................................... 87

等,

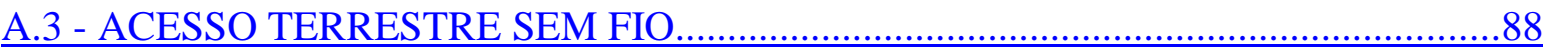

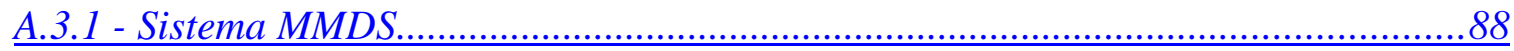

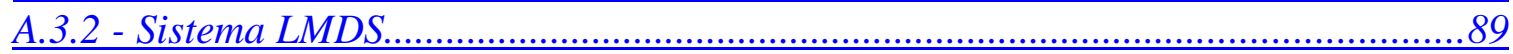

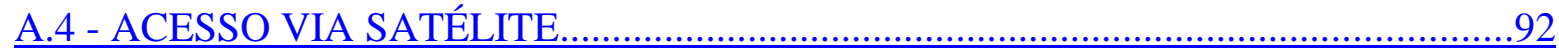

A.5 - SISTEMA PCS (PERSONAL CELLULAR SYSTEM) ......................................93

A.5.1 - Arquitetura do sistema faixa estreita..........................................................95

A.5.2 - Arquitetura do sistema faixa larga ........................................................ 96

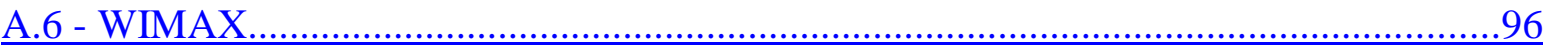

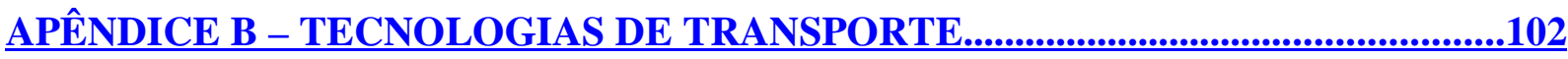

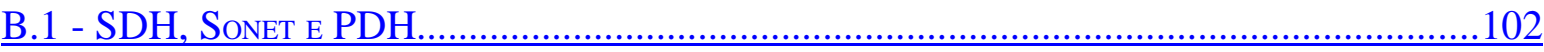

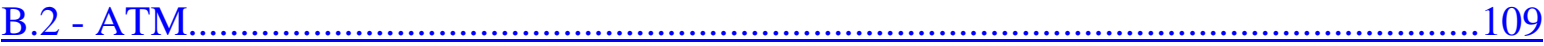

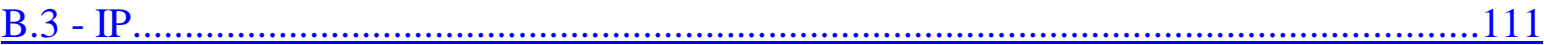

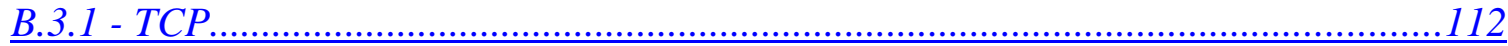

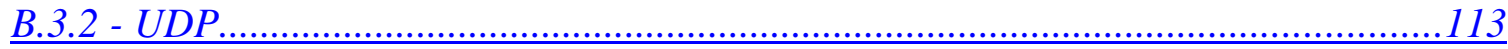

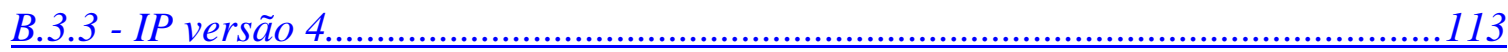

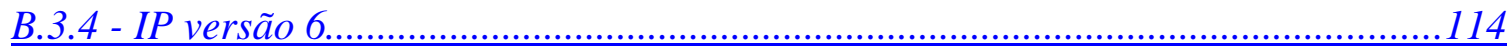

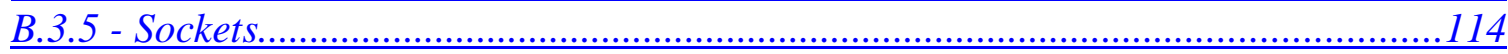

\section{ÍNDICE DE TABELAS}




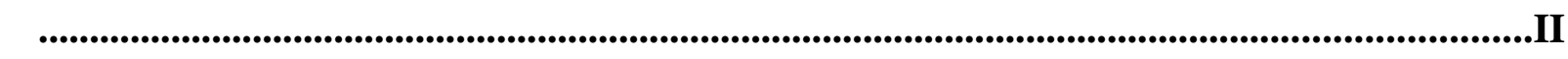

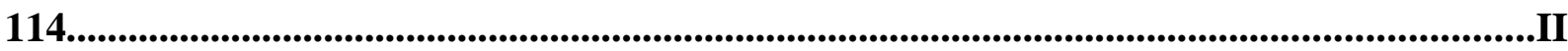

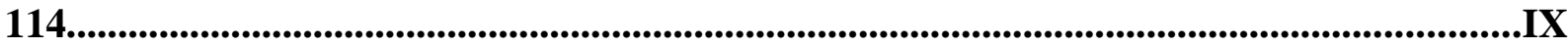

TABELA 3.1 RECOMENDAÇÕES IEEE PARA O PADRÃO ETHERNET..................39

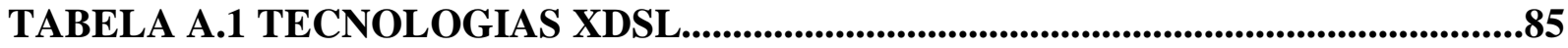

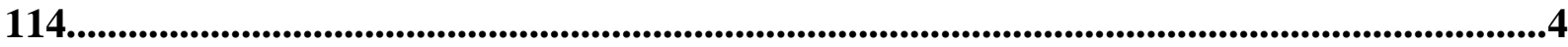

TABELA A.2 ESPECIFICAÇÕES DA RECOMENDAÇÃO IEEE 802.16.....................97

TABELA B.1 COMPARAÇÃO ENTRE AS TAXAS DA SONET E DA SDH...............104 


\section{ÍNDICE DE FIGURAS}

FIGURA 2.1 SISTEMA DE COMUNICAÇÕES ELÉTRICA..............................................6

FIGURA 2.2 ELEMENTOS CONSTITUINTES DE UMA REDE DE COMUNICAÇÃO.

FIGURA 2.3 ELEMENTOS BÁSICOS DE UMA REDE ÓPTICA......................................8

FIGURA 2.4 ESTRUTURA DA FIBRA ÓPTICA..............................................................9

FIGURA 2.5 SISTEMA DE MULTIPLEXAÇÃO TDM SÍNCRONO............................14

FIGURA 2.6 SISTEMA QUE UTILIZA FDM...................................................16

FIGURA 2.7 ESPECTRO OCUPADO POR SINAIS EM UM SISTEMA FDM..............16

FIGURA 2.8 TÍPICO ENLACE DE TRANSMISSÃO WDM..............................................17

FIGURA 2.9 DIAGRAMA DE UM SISTEMA WDM SIMPLES........................................18

FIGURA 2.10 CANAIS WDM SENDO DEMULTIPLEXADOS POR UM FILTRO

ÓPTICO.................................................................................................................................19

FIGURE 2.11 BANDA PASSANTE DO CWDM PARA UM DISPOSITIVO DE 8

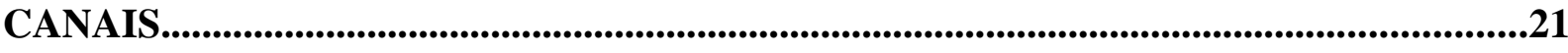

FIGURA 2.12 APLICAÇÃO UNIDIRECIONAL DE CWDM...........................................21

FIGURE 2.13 APLICAÇÃO BIDERECIONAL DO CWDM................................................22

FIGURA 3.1 ESTRUTURA BÁSICA DE UMA REDE PON..............................................23

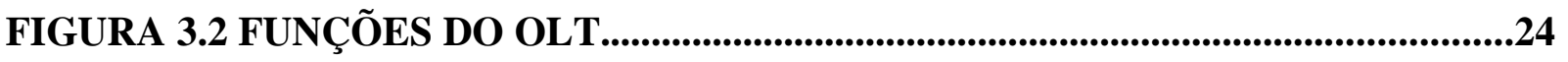

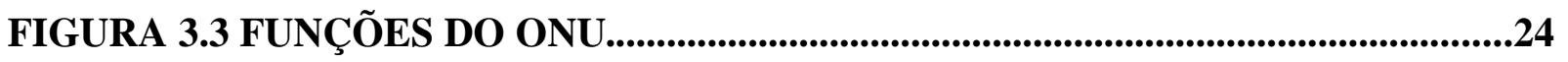

FIGURA 3.4 TOPOLOGIA EM ANEL.........................................................................................26

FIGURA 3.5 TOPOLOGIA EM ÁRVORE..........................................................................26

FIGURA 3.6 TOPOLOGIA EM BARRAMENTO...................................................................27

FIGURA 3.7 VISÃO GERAL DE UMA REDE PON COMPLETA.................................27

FIGURA 3.8 ATM-PON ARQUITETURA..................................................................28

FIGURA 3.9 VISÃO GERAL DA FUNCIONALIDADE DA ATM-PON...........................29

FIGURA 3.10 FORMATO BÁSICO DO FRAME ENTRE OLT E ONT..........................30

FIGURA 3.11 REPRESENTAÇÃO DE UMA REDE BPON.................................................32 
FIGURA 3.12 REPRESENTAÇÃO DE UMA REDE EPON.................................................33

FIGURA 3.13 FORMATO DO FRAME DO TRÁFEGO DOWNSTREAM....................34

FIGURA 3.14 FORMATO DO FRAME DO TRÁFEGO DOWNSTREAM......................35

FIGURA 3.15 REDE EPON COM DOIS COMPRIMENTOS DE ONDA.......................35

FIGURA 3.16 REDE EPON COM TRÊS COMPRIMENTOS DE ONDA.........................36

FIGURA 3.17 EXEMPLO DE UMA REDE GPON................................................................37

FIGURA 3.18 ESTRUTURA DO QUADRO ETHERNET................................................41

FIGURA 3.19 ANÁLISE ECONÔMICA DO METRO ETHERNET FÓRUM PARA A

TECNOLOGIA ETHERNET NO ACESSO.....................................................................45

FIGURA 3.20 COMPARAÇÃO ENTRE O PADRÃO 802.3AH E OS OUTROS

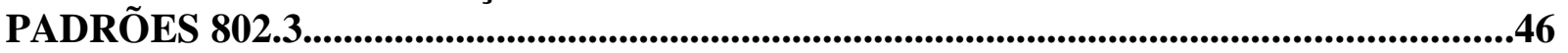

FIGURA 4.1 ELEMENTOS DA REDE DE ACESSO........................................................48

FIGURA 4.2 DIFERENTES ARQUITETURAS DO FTTX..............................................50

FIGURA 4.3 ARQUITETURA PTP EM FTTH..........................................................................51

FIGURA 4.4 ARQUITETURA PON EM FTTH....................................................................52

FIGURA 4.5 REDE PON COM SPLITTER CENTRAL...........................................53

FIGURA 4.6 REDE PON COM SPLITTER DISTRIBUÍDO OU CASCATEADO..........53

FIGURA 5.1 PENETRAÇÃO DO ACESSO BANDA LARGA ....................................56

FIGURA 5.2: ESTIMATIVA DE USUÁRIOS DE FTTH....................................................56

FIGURA 5.3: PREVISÃO DE IMPLEMENTAÇÃO DE FTTH NA EUROPA................57

FIGURA 5.4 SITUAÇÃO DE FTTH NO JAPÃO.........................................................58

FIGURA 5.5 NÚMERO DE USUÁRIOS FTTX NOS EUA..............................................58

FIGURA 5.6 DETALHE NO FDH....................................................................................63

FIGURA 5.7 KUTZTOWN..................................................................................................66

FIGURA A.1 TECNOLOGIAS DE ACESSO À REDE DE COMUNICAÇÃO...............77

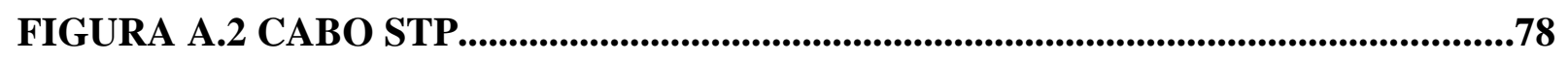

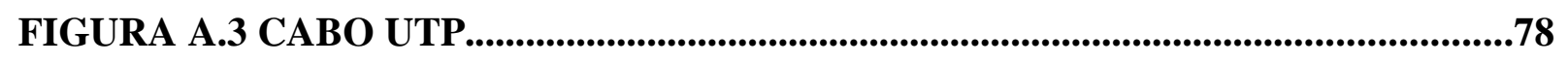

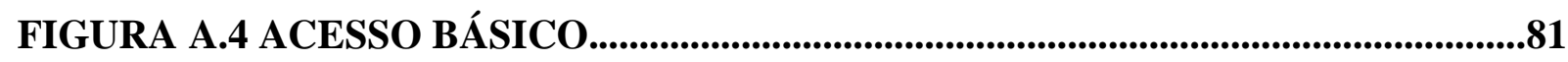

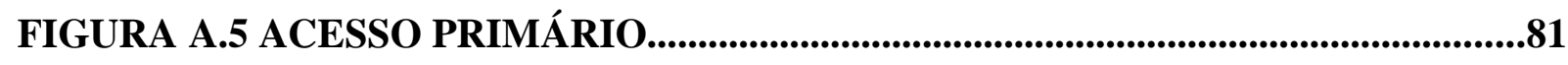

FIGURA A.6 GRÁFICO CAPACIDADE VS DIATÂNCIA (XDSL)................................84

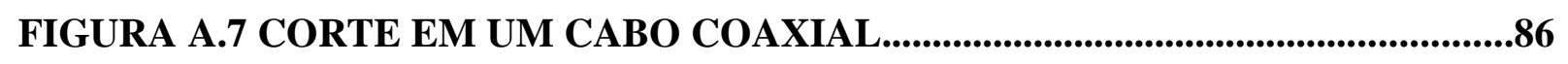

FIGURA A.8 CABO COAXIAL BANDA BASE.........................................................8

FIGURA A.9 CABO COAXIAL BANDA LARGA...........................................................88 
FIGURA A.10 ARQUITETURA TÍPICA DE UMA REDE MMDS. .89

FIGURA A.11 POLARIZAÇÃO DAS ANTENAS EM UMA CÉLULAS LMDS. H (POLARIZAÇÃ̃ HORIZONTAL, V (POLARIZAÇÃO VERTICAL).............................90

FIGURA A.12 ARQUITETURA DO SISTEMA LMDS.......................................................92

FIGURA A.13 CONFIGURAÇÃO TÍPICA PARA SE PROVER DTH INTERNET DELIVERY UTILIZANDO-SE DVB...............................................................................93

FIGURA A.14 MODELO DE UTILIZAÇÃO PARA O WIMAX..........................................99

FIGURA A.15 ESTIMATIVA DE PREÇO DOS CPES WIMAX.........................................100

FIGURA A.16 SERVIÇOS SUPORTADOS PELO WIMAX................................................101

FIGURA B.1 MULTIPLEXAÇÃO DE VÁRIOS CANAIS DE VOZ................................102

FIGURA B.2 MEIOS DE TRANSMISSÃO DE NOVOS SERVIÇOS.................................103

FIGURA B.3 ESTRUTURA ORGANIZACIONAL DA PDH..............................................103

FIGURA B.4 ESTRUTURA DA REDE SDH.............................................................106

FIGURA B.5 CAMADAS DA REDE SDH...............................................................................106

FIGURA B.6 ESTRUTURA DO QUADRO DA REDE SDH................................................107

FIGURA B.7 TOPOLOGIAS DE REDE.....................................................................109

FIGURA B.8 SEGMENTAÇÃO DE DADOS........................................................................112

\section{LISTAGEM DE SIGLAS}

ADM - Add/Drop Multiplexers 
ADSL - Full Rate Asymmetrical Digital Subscriber Line

AOEN - All-Optical Ethernet Networks

APAC - Asia Pacific

APD - Avalanche Photo Diode

APON - Asynchronous Transfer Mode Passive Optical Network

ARQ - Automatic Retransmission Request

ATM - Asynchronous Transfer Mode

BPON - Broadband Passive Optical Network

CAPEX - Capital expenditures

CATV - Community Antenna Television

CDMA -Code Division Multiple Access

$\mathrm{CO}$ - Central Office

CPE - Customer Premises Equipment

CSMA/CD - Carrier Sense Multiple Access/Colision Detection

CWDM - Coarse Wavelength Division Multiplexing

DCC - Data Country Code

DiffServ - Differentiated Services

DLC - Digital Loop Carrier

DSL - Digital Subscriber Line

DSLAM - Digital Subscriber Line Access Multiplexer

DTH - Direct to Home

DWDM - Dense Wavelength Division Multiplexing

DXC - Digital Cross-Connects

E.164 - Specific Integrated Service Digital Network Number

EDFAs - Erbium Doped Fiber Amplifiers

EFMC - Ethernet in the First Mile Copper

EFMF - Ethernet in the First Mile Fiber

EFMP - Ethernet in the First Mile Passive Optical Network

ELAN - Ethernet Local Area Network

EPON-Ethernet based Passive Optical Network

ER - Estações Remotas 
ERB - Estação Rádio Base

FDD - Frequency Division Duplex

FDM - Frequency Division Multiplexing

FSAN - Full Service Access Network

FTP - File Transfer Protocol

FTTB - Fiber-To-The-Building

FTTC - Fiber-To-The-Curb

FTTCab - Fiber-To-The-Cabinet

FTTH - Fiber-To-The-Home

GFP - Generic Framing Protocol

GPON - Gigabit Passive Optical Network

GE-PON - Ethernet based Passive Optical Network

HDSL - High Data Rate Digital Subscriber Line

HDSL2 - High Data Rate Digital Subscriber Line Second Generation

HDSL4 - High Data Rate Digital Subscriber Line Fourth Generation

HSI - High-Speed Internet

ICD -International Code Designator

IDSL - Integrated Services Digital Network Digital Subscriber Line

IEEE - Institute of Electrical and Electronics Engineers

IP - Internet Protocol

ITU-T - International Telecommunications Union

LASERS - Light Amplification by Estimulated Emission of Radiation

LCP - Local Convergence Point

LED - Light Emitting Diode

LMDS - Local Multipoint Distribution System

LTM - Line Terminal Multiplexer

MMDS - Multipoint Multichannel Distribution System ou Serviço de Distribuição Multiponto

Multicanal

MPEG - Moving Picture Experts Group

NAP - Network Access Point

OEO - Óptico-Elétrico-Óptico 
OFDM - Orthogonal Frequency-Division Multiplexing

OFDMA - Orthogonal Frequency Division Multiplexing Access

OLT - Optical Line Terminal

ONT - Optical Network Terminal

ONU - Optical Network Units

OPEX - Operating Expenditures

PCM - Pulse Code modulation

PCS - Personal Celular System

PIN - Diodo

PMP - Point-Multipoint

PON - Passive Optical Network

PTP - Peer-to-peer

PVCs - Permanent Virtual Circuits

QoS - Quality of Service

RADSL - Rate Adaptive Digital Subscriber Line

RDSI - Rede Digital de Serviços Integrados

RPC - Remote Procedure Call

S/N - Sinal-Ruído

SCMA - Subcarrier Multiple Access

SDH - Synchronous Digital Hierarchy

SDSL - Symmetric Digital Subscriber Line

SHDSL - Symmetric High-Bitrate Digital Subscriber Line

SLA - Service-level Agreement

SMTP - Simple Mail Transfer Protocol

SNMP - Simple Network Management Protocol

SONET - Synchronous Optical Network

STP - Shielded Twisted-Pair

SVCs - Switched Virtual Circuits

TCP - Transmission Control Protocol

TDD - Time Division Duplex

TDM - Time Division Multiplexing 
TDMA - Time Division Multiple Access

TFTP - Trivial File Transfer Protocol

UDP - User Datagram Protocol

UTP - Unshielded Twisted-Pair

VDSL - Very High Bit Rate Digital Subscriber Line

VDSL2 - Very High Bit Rate Digital Subscriber Line Second Generation

VLAN - Virtual Local Area Network

VOD - Video-on-Demand

VoIP - Voice over Internet Protocol

WAN - Wide Area Network

WDM - Wavelength Division Multiplexing

WDM - Wavelength Division Multiplexing

WDMA - Wave Division Multiple Access

WiMax - Worldwide Interoperability for Microwave Access

WMAN - Wireless Metropolitan Area Network 



\section{1 - INTRODUÇÃO}

O mercado atual de telecomunicações, com sua crescente oferta de serviços (tradicionais e de valor agregado) ao usuário final, tem levado as operadoras a migrar suas redes de acesso para tecnologias mais flexíveis e de maior capacidade.

A rede de acesso é a parcela de uma rede pública comutada que conecta o nó de acesso aos usuários individuais. De uma forma mais simples, é a última ligação, em uma rede, entre as premissas do cliente e o primeiro ponto de conexão com a infra-estrutura da rede - a Point Of Presence (PoP) ou a sede (Central Office - CO). A rede de acesso atual é predominantemente constituída de fios de cobre, o par trançado, e foi considerada como tendo um dos mais importantes papéis no ato de prover serviços de transmissão de dados.

A rede de acesso óptica promete uma largura de banda extremamente grande, na casa de diversos gigabits por segundo (Gbps), o que provavelmente aumentará ainda mais com o avanço da tecnologia. Esta maior disponibilidade de largura de banda abre a possibilidades de novas arquiteturas para prover serviços de banda larga. Tomando a rede de acesso como a parte mais importante na entrega dessa largura de banda, é necessário colocar alguma variedade de equipamentos, nas premissas do cliente, para gerenciar ou controlar a quantidade de dados transmitidos sobre uma conexão de acesso.

Há, hoje em dia, uma percepção geral de que a fibra é um recurso escasso. Entretanto, a falta da fibra disponível para serviços de acesso ópticos novos não é o principal fator no mercado. De fato, a fibra é agora um recurso prontamente disponível para as redes de acesso, especialmente em áreas urbanas ou metropolitanas. Estima-se que em 1999 aproximadamente 65 milhões de quilômetros de fibra óptica estavam instaladas nos Estados Unidos e que 70 por cento estavam nos mercados metropolitanos superiores dos ILECs (Incumbent Local Exchange Carriers) e CLECs (Competitive Local Exchange Carriers). A quantidade de fibra instalada por CLECs foi de mais do que o dobro entre 1999 e 2002. Tudo isso aponta para um mercado grande e endereçável para os serviços de alta velocidade baseados no mercado óptico, com potencial de crescimento significativo.

A infra-estrutura óptica está provando ser uma parte vital do ambiente econômico rapidamente mutável de hoje. A movimentação para a interconectividade assim como o crescimento exponencial no tráfego dos dados, em conseqüência das aplicações novas de 
negócio, conduzirá à adoção do acesso óptico, pois esse tipo de acesso ajuda não só os usuários finais como também os fornecedores de serviço a se conectarem de forma cada vez mais rápida e eficiente às informações.

Por esses motivos, este trabalho busca a conceituar e apresentar as vantagens de termos hoje uma rede de acesso via fibra, o que é feito por intermédio de comparações com as demais redes de acesso existentes.

\section{1 - MOTIVAÇÃO}

A motivação surge do fato de acreditarmos ser o acesso via fibra a melhor solução para fornecer serviços de banda larga e serviços agregados, o que faz dessa uma evolução necessária.

Uma tecnologia é atraente quando pode substituir a rede existente assim como aumentar a viabilidade econômica de aplicações novas da rede. Os novos serviços de banda larga estão exigindo a substituição da tecnologia e aumentando a competitividade para que as operadoras os possam entregar com alta velocidade, no acesso local.

A demanda, a busca constante por melhorias tecnológicas e a regulação estão rompendo significativamente com o cenário das telecomunicações, apresentando fornecedores de serviço com tremendas oportunidades, assim como precipitando mudanças enormes na rede.

A infra-estrutura existente não manteve o ritmo do crescimento exponencial de tráfego da rede. As novas aplicações de negócio tais como o e-comércio, a videoconferência de alta qualidade, a tele-medicina, as transferências de grandes pacotes de dados, os espelhos de dados, carrier hotels, e o armazenamento de dados estão guiando a necessidade por serviços de banda cada vez mais larga. Novas espécies de fornecedores de serviço, tais como ISXs (Internet Service Exchanges), ASPs (Application Service Providers) e SSPs (Storage Service Providers) estão emergindo, experimentando um rápido crescimento em seus negócios e formando um mercado a parte.

$\mathrm{O}$ aumento rápido na demanda por largura de banda forçou também provedores a escolher rapidamente entre algumas tecnologias: DSL (Digital Subscriber Line), ATM 
(Asynchronous Transfer Mode) e SONET/SDH, IP (Internet Protocol) sobre uma rede óptica síncrona. Todas essas tecnologias provêm um acesso banda larga. Infelizmente, protocolos mal combinados se desenvolveram entre a empresa e os usuários. A complexidade e a redundância dos equipamentos requeridos e uma falta da integração com o legado complicam mais e mais, tendo por resultado a frustração do usuário e a incerteza em um scramble para suportar as demandas do acesso empregando uma mistura complexa das tecnologias. Os usuários finais e os novos provedores consideram que não há nenhuma alternativa à base de acesso via fibra e esforçam-se dentro dos limites finitos das facilidades de cobre para levar as LAN aos níveis de altíssima velocidade.

O rápido crescimento da rede está forçando os provedores a repensar sobre as plantas de negócio, custo-benefício e as estratégias de distribuição em cima das quais oferecerão produtos futuros aos usuários finais. O ato de telecomunicações de 1996, que abriu eficazmente estes mercados, deu início subitamente a uma nova competição, entre as empresas, pelo acesso. As dimensões do competidor tais como o custo, a qualidade do serviço (QoS), o reconfigurabilidade e a capacidade futura definem os aspectos da batalha por clientes.

Como a regulação abriu as portas para que novos provedores forneçam o serviço local, os modelos econômicos tradicionais estão, também, sendo afetados. $\mathrm{O}$ crescimento do rendimento dos serviços de voz é relativamente fácil e as margens estão caindo rápida e subitamente. Como continuar a fornecer serviços de voz é importante para o fluxo de dinheiro atual, os provedores devem se mover no sentido de fornecer serviços de dados com elevada margem, arquiteturas de multiserviços, e aplicações de valor agregado, a fim de atrair e reter clientes melhorando o custo benefício. Por outro lado, as necessidades dos usuários residem na capacidade do acesso de alta velocidade. Eles necessitam de novas extensões tecnológicas de rede, ou seja, protocolos, topologias e geografias independentes.

As plataformas de acesso ópticas são projetadas para ajudar aos novos fornecedores no rompimento com mercado de telecomunicações atual para seu próprio sucesso. A estrutura do mercado recompensa os produtos e as soluções que têm o poder inerente de empurrar redes ópticas além do domínio dos backbones, fornecendo o acesso via fibra para a ligação de alta performance, o que é crucial para os mais novos serviços em redes de dados. 
Esta nova era do acesso óptico controlado será marcada pelos fornecedores que conseguirem ganhar a vantagem fornecendo as arquiteturas de alta velocidade que elevem o desempenho da rede acima e além das exigências crescentes de tráfego de dados dos clientes.

Estas soluções novas de acesso óptico são projetadas para permitir que os fornecedores de serviço dirijam-se a estas oportunidades eficazmente. Os equipamentos novos podem construir uma ponte entre as arquiteturas de voz e de dados orientados com plataformas de banda larga e protocolos independentes. As novas características de alocação de banda permitem que os provedores suportem protocolos diferentes e possam otimizá-los para uma aplicação particular. Através da separação criada para transmitir protocolos individualmente, cada um em seu próprio comprimento de onda, as necessidades para tunneling ou para na conversão de protocolo são minimizadas. Com estas características novas, os provedores podem fornecer e aumentar largura de banda através de software, melhor do que com equipamentos de reestruturação física. Podem, até mesmo, permitir que os clientes controlem quanta banda adicionam ou removem de sua capacidade da rede.

\section{2 - METODOLOGIA E ORGANIZAÇÃO DO TEXTO}

No capítulo 2 segue uma breve conceituação de sistemas de comunicações ópticos. Em seguida, conceituam-se os elementos de uma rede óptica e as técnicas de multiplexação.

Após esse conceito inicial, segue uma descrição de vários tipos de redes ópticas, capítulo 3, a fim de levantar dados para a rede de acesso óptica que, por sua vez, é detalhada no capítulo 4.

Para fins de ilustrações práticas, o capítulo 5 segue com a apresentação de dois estudos de caso, bem como as considerações econômicas envolvidas, que embasarão as conclusões finais.

Para finalizar, o apêndice A apresenta uma breve conceituação de diferentes tecnologias de acesso, a título de comparação. No apêndice $\mathrm{B}$, tem-se um resumo explicativo sobre as tecnologias de transmissão citadas no texto, a título de complementação. 


\section{2 - FUNDAMENTOS DE UM SISTEMA DE COMUNICAÇÃO ÓPTICO}

\section{1 - INTRODUÇÃO}

Como característica geral, todo sistema de telecomunicações possui os seguintes elementos básicos que formam um canal de transmissão: transmissor, meio de transmissão e receptor. Um equipamento é denominado transceptor quando possui a capacidade de transmitir e receber mensagens.

Os sistemas de telecomunicações podem ser divididos em bidirecional e unidirecional: no sistema bidirecional, há necessidade de troca de informações entre receptor e transmissor, a exemplo de uma simples conversa entre duas pessoas; no sistema unidirecional, não há essa necessidade de troca, como na radiodifusão sonora ou de sons e imagens (televisão).

Os sistemas de telecomunicações também podem ser classificados da forma a seguir:

- Simplex: quando a transmissão é unidirecional no meio de transmissão

- Semi-Duplex: quando a transmissão é bidirecional, porém é executada alternadamente em cada sentido.

- Duplex: quando a transmissão é bidirecional e simultânea.

Um sinal, transmitido via fibra, pode ter sua qualidade de recepção deteriorada por dois principais fatores: interferências e atenuação. As interferências são causadas por outros sinais, os ruídos, que podem deformar o original e torná-lo incompreensível. Para solucionar esse problema, pode-se aumentar a sensibilidade do receptor ou aumentar a intensidade do sinal (aumentar a relação sinal-ruído). A atenuação é devido ao aumento da distância entre transmissor e receptor, sendo a capacidade de recuperar a informação inversamente proporcional à distância.

Para resolver o problema da distância, utilizam-se transprovedores de informação, a chamada portadora. A informação passa a ser traduzida em símbolos que são mais facilmente transportados (codificação). Após o estabelecimento do código a ser utilizado, a informação é então colocada na portadora por intermédio do modulador e, após percorrer o caminho por um 
meio de transmissão, alcança o receptor. A mensagem recebida precisa ser decodificada para que se recuperem os símbolos da portadora, o que é conseguido por meio do demodulador.

Se, mesmo com toda a técnica descrita, a distância for tão grande que a deterioração ainda ocorra, pode-se instalar estações repetidoras, e a distância entre o transmissor e a repetidora é chamada de enlace. Essas estações, apesar de viabilizarem a transmissão da informação, geram algumas desvantagens, a maior delas sendo a demora na transmissão.

Quando se trabalha com sinais elétricos, pode-se dar o mesmo tratamento à voz, dados e imagens, o que permite padronizar, quantificar, transportar, agrupar e distribuir a informação de maneira muito mais rápida e eficiente.

Um sistema de telecomunicação baseado em sinais elétricos pode ser representado pelo diagrama de blocos da figura 2.1:

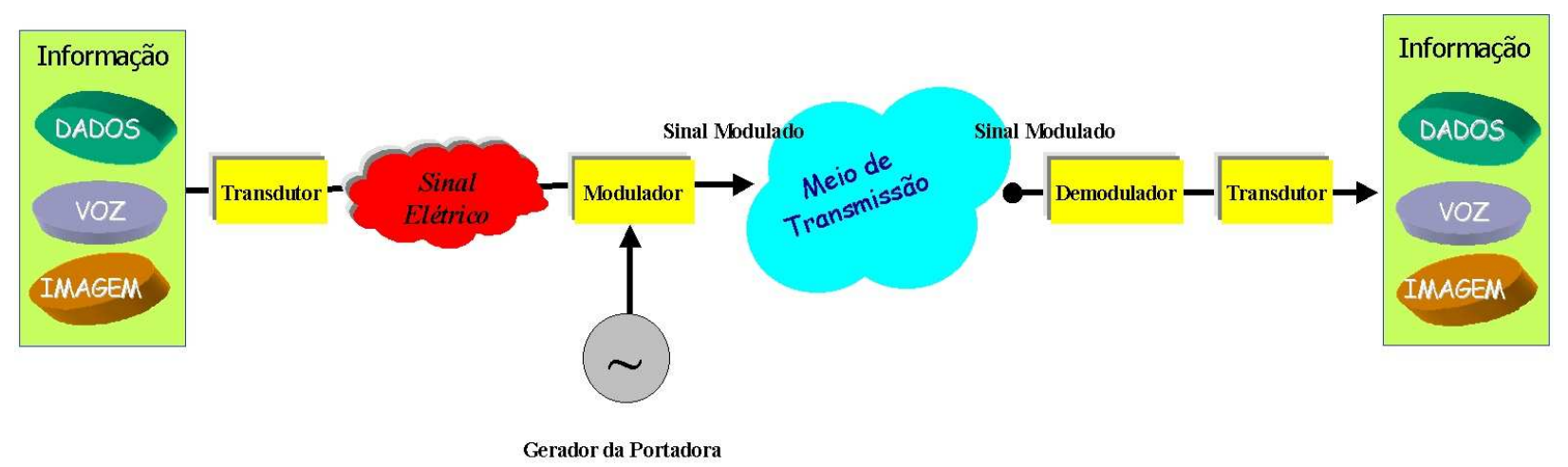

Figura 2.1 Sistema de comunicações elétrica.

Para que haja a troca de dados entre usuários, é criada uma rede de comunicação, que é composta por elementos que farão essa conexão. Há vários meios desses usuários se conectarem, como fibra óptica, par trançado, microondas e tecnologias sem fio. No Apêndice A, são abordados os meios de acesso usando cobre e via rádio. A figura 2.2 ilustra uma visão de uma rede de comunicação.As principais tecnologias de transporte usadas nas redes de comunicação são apresentadas no Apêndice B. 


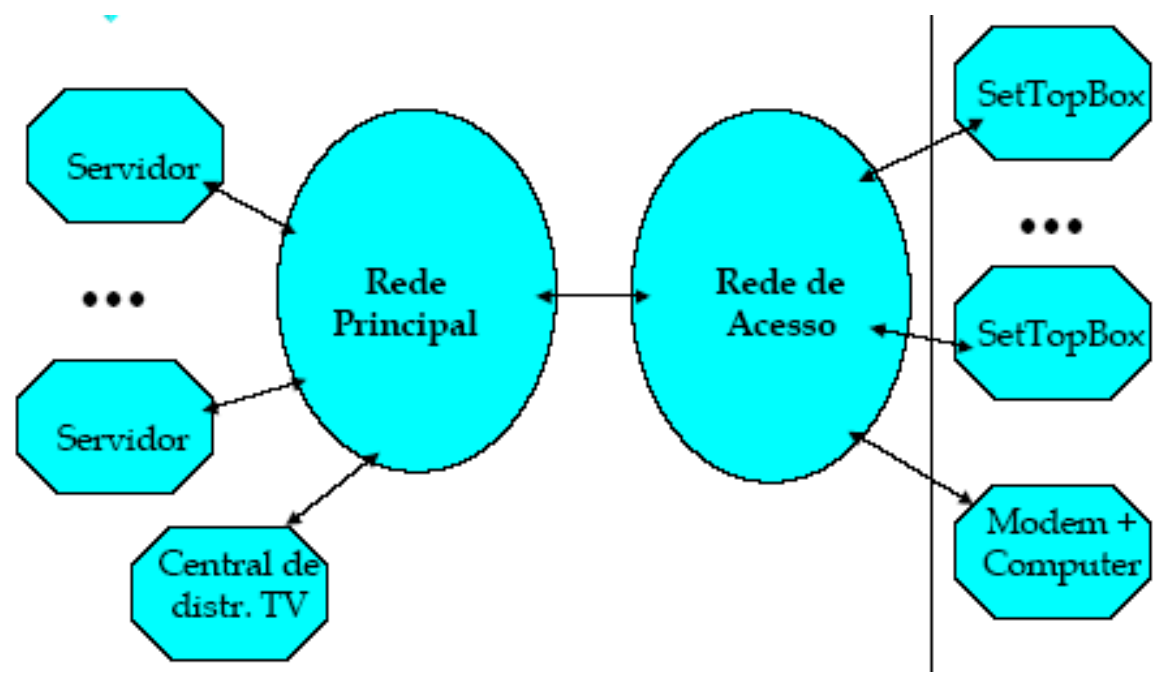

Figura 2.2 Elementos constituintes de uma rede de comunicação.

A enorme capacidade de transmissão dos sistemas ópticos é uma das principais características desses sistemas e também um dos principais motivos de sua utilização e estudo.

As redes ópticas podem utilizar tanto a fibra óptica quanto o ar como meio de transmissão. $\mathrm{O}$ foco desse estudo são as redes com fibra óptica.

As redes de telecomunicações, que até recentemente utilizavam principalmente pares de fios de cobre ou cabos coaxiais, estão mudando para a utilização de fibras ópticas para transmissão. Os tipos de redes ópticas utilizadas em telecomunicações são:

- Acesso: utilizada para usuários que necessitam de banda larga.

- Local (LAN): pequenas redes, no mesmo local, seja ele uma residência, um escritório, etc.

- Metropolitanas (MAN): redes utilizadas em uma metrópole.

- Estaduais: redes de longa distância dentro de um estado.

- Nacionais: redes de longa distância dentro de um país.

- Internacionais: redes de ultralonga distância, que interligam continentes, geralmente usando cabos ópticos submarinos. 


\section{2 - ELEMENTOS DE UMA REDE ÓPTICA}

Um sistema de comunicações óptico é constituído de alguns elementos básicos, Figura 2.3, que serão comentados a seguir:

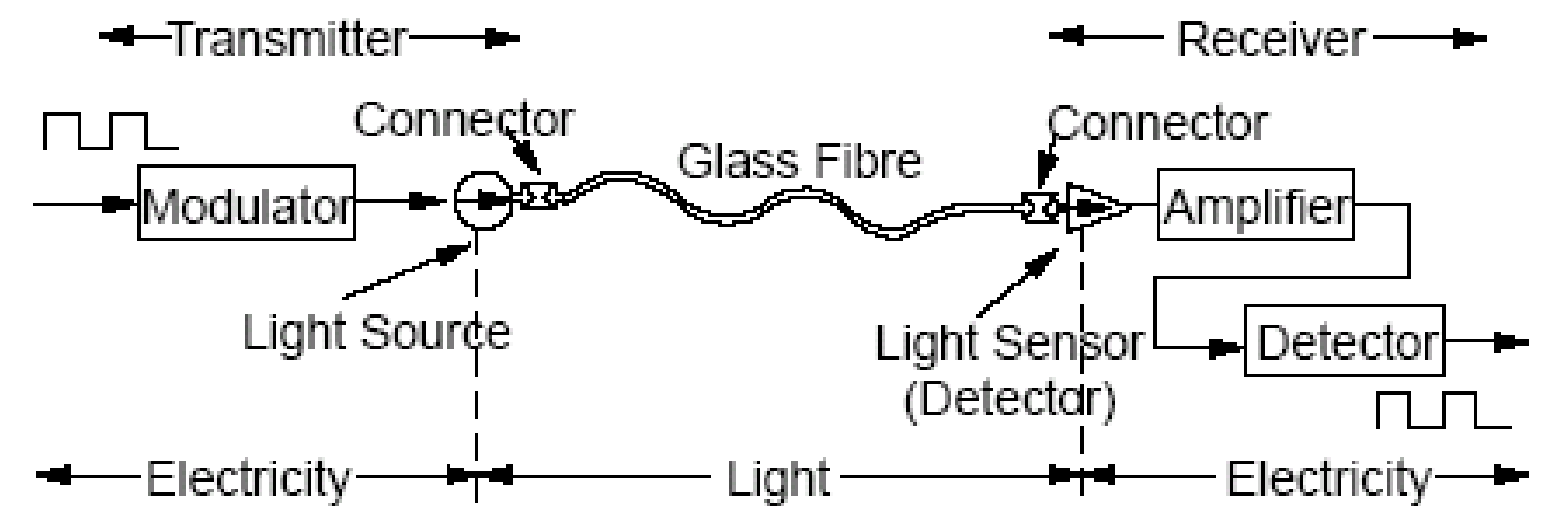

Figura 2.3 Elementos básicos de uma rede óptica.

\subsection{1 - Fibra}

A fibra óptica foi inventada pelo físico indiano Narinder Singh Kanpany, é constituída por um filamento composto de material dielétrico, geralmente plástico ou sílica, com a capacidade de transmitir luz através de sua longa estrutura cilíndrica, transparente e flexível. A fibra tem dimensões variáveis, dependendo da aplicação, mas sempre comparáveis às de um fio de cabelo e apresenta imunidade a interferências eletromagnéticas. [11]

As fibras são utilizadas como meio de transmissão de ondas eletromagnéticas utilizando-se como princípio fundamental, independentemente do material usado ou da aplicação, o fenômeno físico denominado reflexão total da luz. Para tanto, é lançado um feixe de luz em uma extremidade da fibra e, pelas características ópticas do meio, esse feixe percorre a fibra através de consecutivas reflexões. Para reflexão total, a luz deve sair de um meio mais refringente para um meio menos refringente com um ângulo de incidência igual ou maior que o ângulo limite. Esse meio de transmissão é denominado de "guiado". 
A fibra é composta de uma região central chamada de núcleo e uma região periférica denominada de casca. O índice de refração do material do primeiro é maior que o índice do segundo para que seja garantida reflexão total.

A seção em corte transversal mais usual do núcleo é a circular, porém fibras ópticas especiais podem ter um outro tipo de seção (por exemplo, elíptica), figura 2.4.

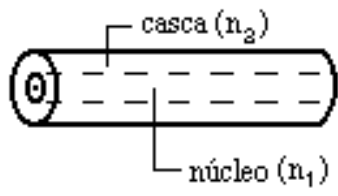

a) estrutura cilindrica

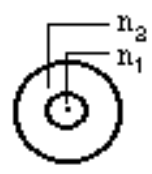

b) seçäo trarswersal

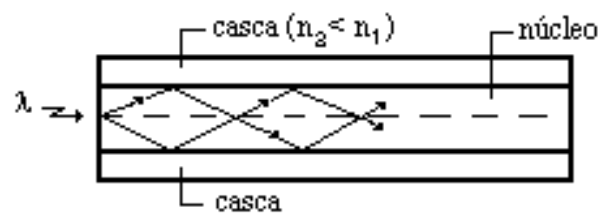

c) corte longitudiral

Figura 2.4 Estrutura da fibra óptica.

A capacidade de transmissão (banda passante) de uma fibra óptica é função do seu comprimento, da sua geometria e do seu perfil de índices de refração. Podem ser definidas duas categorias de fibras dependendo da forma como a luz se propaga no interior de cada núcleo: Multimodais e Monomodais.

As Fibras Multimodais são aquelas onde o diâmetro do núcleo permite que a luz tenha vários modos de propagação. Essas fibras podem também ser classificadas em Índice Gradual ou Degrau dependendo da variação do índice de refração entre o núcleo e a casca.

As Fibras Monomodais requerem conectores de maior precisão e dispositivos de alto custo por isso são mais adequadas para aplicações que envolvam grandes distâncias. O núcleo é feito tão pequeno quanto necessário para que haja apenas um modo de propagação da luz. Também podem ser classificadas quanto ao índice de refração do núcleo em relação à casca: Índice Degrau Standard, Dispersão Deslocada (Dispersion Shifed) ou Non-Zero Dispersion.

Abaixo encontra-se o resumo da vantagens da fibra: 
- A fibra, por ser composta de material dielétrico, é imune a interferências eletromagnéticas, podendo ser utilizada em ambientes nos quais outros tipos de condutores não poderiam ser utilizados;

- Não existe nenhuma possibilidade de ocorrência de incêndios devido ao rompimento de uma fibra, já que somente há luz em seu interior;

- Alto grau de segurança para a informação transportada, pois as fibras não irradiam significativamente a luz propagada;

- Pequeno tamanho e peso, sendo mais facilmente manuseados e instalados. Esse fato também contribui para diminuir o problema de espaço e de congestionamento de dutos nos subsolos das grandes cidades e em grandes edifícios comerciais.

- As fibras ópticas apresentam atualmente perdas de transmissão extremamente baixas. Desse modo, com fibras ópticas, é possível implantar sistemas de transmissão de longa distância com um espaçamento muito grande entre repetidores, o que reduz significativamente a complexidade e custos do sistema.

- A produção de fibras ópticas em larga escala tende a tornar o custo da fibra mais baixo do que outros materiais, como o cobre.

A fibra óptica, como qualquer outro meio, não possui apenas vantagens. Seguem algumas das desvantagens:

- As fibras quando não estão protegidas por encapsulamento são bastante frágeis, quebrando com facilidade;

- Devido ao fato da fibra ter dimensões pequenas, sua instalação é bastante dificultada e, se for feita de forma incorreta, pode causar uma grande atenuação ou até mesmo o bloqueio da transmissão;

- Não há padrões definidos para conectores, interfaces, dispositivos.

- Os sistemas com fibras ópticas requerem alimentação elétrica independente para cada repetidor, não sendo possível a alimentação remota através do próprio meio de transmissão. 
O espalhamento Rayleigh, que é o espalhamento provocado devido a nãohomogeneidades no silício e de natureza aleatória, é a principal causa de atenuação na fibra. Outras causas de atenuação na fibra são:

- Absorção devido a impurezas na fibra, que absorvem parte da energia óptica e a dissipa em forma de calor - esse tipo de atenuação é desprezível, devido às técnicas de purificação do vidro.

- Deformações mecânicas, que provocam a absorção da luz na casca protetora da fibra;

- Perdas por reflexão, que ocorrem na entrada e saída da luz da fibra;

Na fibra há também o fenômeno da dispersão, quando há atrasos relativos na propagação dos modos e componentes espectrais que transportam a energia luminosa. A dispersão é percebida através do alargamento do pulso no sinal digital e na diminuição da variação do sinal no caso analógico.

As fibras ópticas são geralmente encapsuladas pelo cabo óptico para que haja melhor resistência à instalação, manuseio, impacto, esmagamento e vibrações, para que a fibra possua melhor estabilidade das características numa grande faixa de temperatura e também para prevenir as curvaturas que possam causar atenuação.

Deve-se ter cuidado especial com as emendas na fibra, para que a atenuação seja baixa. Existem três tipos de emendas ópticas:

- Emenda por Fusão: as fibras são fundidas entre si;

- Emenda Mecânica: as fibras são unidas por meios mecânicos;

- Emenda por Conectorização: são aplicados conectores ópticos, nas fibras envolvidas na emenda.

As emendas ópticas, sejam por fusão ou mecânicas, apresentam uma atenuação muito menor que um conector óptico. 


\subsection{2 - Transmissor Óptico}

O transmissor óptico é composto por um dispositivo emissor de luz, um modulador e um acoplador. O dispositivo emissor de luz, elemento ativo básico do sistema, é o responsável pela tarefa de conversão eletro-óptica dos sinais. A capacidade de transmissão (assim como a potência emitida por um transmissor óptico) é função do tipo de dispositivo emissor de luz utilizado, sendo os com LASERS (Light Amplification by Estimulated Emission of Radiation) geralmente superiores aos com LED's (Light Emitting Diode), a custo de uma maior complexidade do transmissor.

Inicialmente, nos sistemas ópticos, foram utilizados como fonte de luz LEDs que operavam entorno de $850 \mathrm{~nm}$. Quando surgiram os LASERS, além deste comprimento de onda, começou-se a utilizar comprimentos de onda por volta de $1310 \mathrm{~nm}$ e, posteriormente $1550 \mathrm{~nm}$. As faixas em torno dos comprimentos de onda de 850, 1300 e de $1500 \mathrm{~nm}$ são denominadas de janelas de transmissão. Essas janelas de transmissão são utilizadas por possuírem baixas perdas devido ao espalhamento Rayleigh.

O modulador é responsável por inserir a informação a ser transmitida na portadora óptica e o acoplador é o dispositivo responsável por inserir a luz na fibra óptica.

\subsection{3 - Receptor Óptico}

O receptor óptico compõe-se de um dispositivo fotodetector, de um estágio de amplificação e filtragem, de um acoplador e de um demodulador. O dispositivo que converte o sinal luminoso em sinal elétrico é outro elemento ativo básico do sistema, o fotodetector. Geralmente são utilizados os diodos PIN e os fotodiodos avalanche (APD). O demodulador é o responsável por retirar a informação. A qualidade de um receptor óptico é medida pela sua sensibilidade, que especifica a potência luminosa mínima necessária para determinado desempenho em termos de relação sinal- ruído $(\mathrm{S} / \mathrm{N})$ ou de taxa de erros de transmissão.

Além das fontes convencionais de ruído, associadas aos estágios eletrônicos, afetam o desempenho dos receptores ópticos as fontes de ruído características do processo de conversão opto-eletrônica. De um modo geral, os receptores ópticos com fotodiodos de avalanche, mais complexos, apresentam desempenho superior aos com fotodiodos PIN. 


\section{3 - TÉCNICAS DE MULTIPLEXAÇÃO}

O grande e constante aumento na demanda por largura de banda e o fato de que lançar novas fibras tem um custo muito elevado implicam que se devem encontrar formas de aumentar a capacidade das fibras já instaladas. Existem duas maneiras fundamentais de se aumentar a capacidade de uma fibra. A primeira é aumentar a taxa de bits o que requer equipamentos eletrônicos de alta velocidade, mas muitos dados podem ser multiplexados em uma seqüência de bits de alta velocidade por meio da técnica TDM (Time Division Multiplexing). A outra maneira de aumentar a capacidade do sistema é usando a técnica WDM (Wavelength Division Multiplexing).

\subsection{1 - TDM}

TDM é uma técnica que divide a largura de banda total do enlace em vários canais para permitir o transporte simultâneo de vários sinais. A distribuição da banda por esses canais é

feita pela atribuição de um intervalo de tempo, denominado de Time-Slot, fixo para cada um. É utilizado apenas com sinais binários provenientes de modulação por código de pulso (PCM), sem se importar se a origem do sinal é analógica ou digital.

Uma das escolhas chave no TDM é o modo de transferência que será utilizado. A transferência síncrona é uma modalidade em que os sinais dos dados são emitidos em intervalos precisos que são regulados pelo clock do sistema (mostrado na figura 2.5), ou seja, todos os slots de tempo são de igual tamanho. Não são requeridos pulsos adicionais de começo ou de final. O Asynchronous Transfer Mode (ATM) é um protocolo orientado a conexão que pode distribuir e comutar o tráfego em velocidades mais elevadas. Um TDM também pode ser síncrono e assíncrono ao mesmo tempo. 


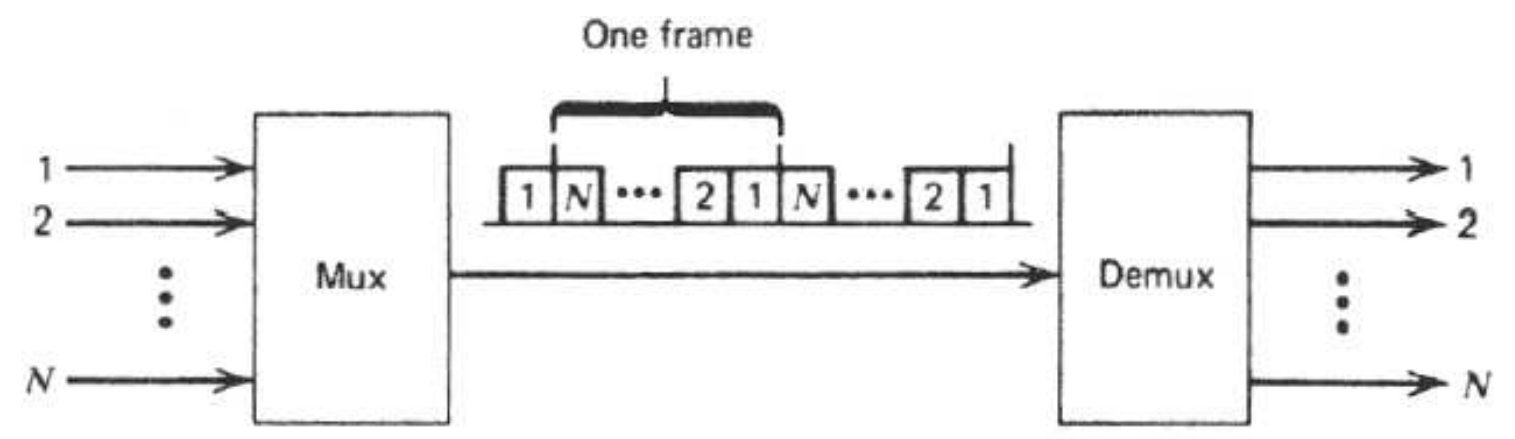

Figura 2.5 Sistema de multiplexação TDM síncrono.

A associação de intervalos é obtida quando cada canal origina a informação de entrada do multiplexador o que é armazenado em um buffer de memória denominado bloco de sincronismo. As funções do multiplexador, como a amostragem de cada canal de entrada a taxas com velocidades compatíveis às requeridas pelo sistema, devem então ser realizadas. Nesta taxa o circuito multiplexador pode amostrar o primeiro bit de informação dos canais 1 a $\mathrm{N}$ (último canal) e adicionar um overhead de informação de volta ao primeiro canal, antes que o próximo bit de informação do canal 1 entre. Este multiplexador pode aceitar um ou mais bits binários de cada canal ao mesmo tempo e gerar, depois, vários pulsos que compensam a transmissão do sinal. O bit de overhead é utilizado para que o demultiplexador, no lado do receptor, possa identificar os canais, que são separados e reconstruídos.

Uma das vantagens do TDM em relação ao FDM é que esse se torna mais eficiente a partir da não utilização de banda de guarda, porém, alguma ineficiência pode ser gerada pois um pequeno número de bits é adicionado ao conjunto de pulsos transmitido, para prover ao multiplexador e demultiplexador sincronismo e detecção de erro, bem como alguns poucos bits extras para gerenciamento em sistemas de comunicação em redes. Um outro aspecto desvantajoso para o TDM é o custo da codificação digital PCM.

Nos circuitos de redes comutadas tais como a rede de telefone comutada pública (PSTN), existe a necessidade transmitir chamadas de múltiplos assinantes ao longo do mesmo meio da transmissão. Para tanto, empregam-se TDM, pois esse permite que os interruptores criem canais dentro do meio de transmissão. Um sinal de voz padrão tem uma largura de faixa de 64 kbit/s, determinado pelo critério da amostragem de Nyquist. TDM captura frames dos sinais de voz e multiplexa eles em um frame de TDM que funcione com uma largura de banda mais elevada. Cada frame de voz dentro de um frame de TDM é chamado de canal. Em 
sistemas europeus, os frames de TDM contêm 30 frames digitais da voz e, em sistemas americanos, os frames de TDM contêm 24 frames digitais da voz. Ambos os padrões contêm também o espaço extra para sinalização e dados de sincronização.

Há três escolhas de cabos para os multiplexadores TDM. A fibra monomodo permite que somente um modo se propague. A fibra tem um diâmetro de núcleo muito pequeno (aproximadamente $8 \mu \mathrm{m}$ ) e permite a transmissão do sinal em larguras de faixa extremamente elevadas e transmissão a longas distâncias. A fibra multimodo suporta a propagação de múltiplos modos e tem um diâmetro de núcleo típico de 50 a $100 \mu \mathrm{m}$ o que permite o uso de fontes de luz baratas como o LED (diodo emissor de luz). O alinhamento e o acoplamento do conector são menos críticos do que com fibra monomodo. As distâncias de transmissão e a largura de banda também são menores do que com a fibra monomodo devido à dispersão.

\subsection{2 - FDM}

Em 1930 as companhias de telefone começaram a combinar sinais de voz analógicos sobre uma linha usando FDM. Durantes os anos 60, FDM foi substituído por métodos digitais utilizando-se TDM. Companhias de TV a cabo também utilizaram o FDM para transmitir vários canais sobre o mesmo fio.

Em um sistema FDM (Frequency Division Multiplexing) pode-se transmitir múltiplos sinais simultaneamente sobre um único caminho de transmissão. Cada canal de informação é associado a uma única freqüência portadora com fase ou amplitudes diferentes, sendo depois multiplexados em um único canal de transmissão através de uma matriz de resistores, depois amplificado.

O sinal resultante é composto por vários outros sinais com portadoras discretas, também chamadas de canais intermediários, que são separadas no receptor por filtros e demoduladores, cada um sintonizado em uma freqüência de portadora específica.

As figuras 2.6 e 2.7 mostram como a divisão da frequiência é feita no caso em que três fontes estão se comunicando com três usuários. Note que cada transmissor modula a informação da sua fonte dentro de um sinal que está em uma sub-banda de freqüência diferente. Os sinais são então transmitidos dentro de um canal comum. 


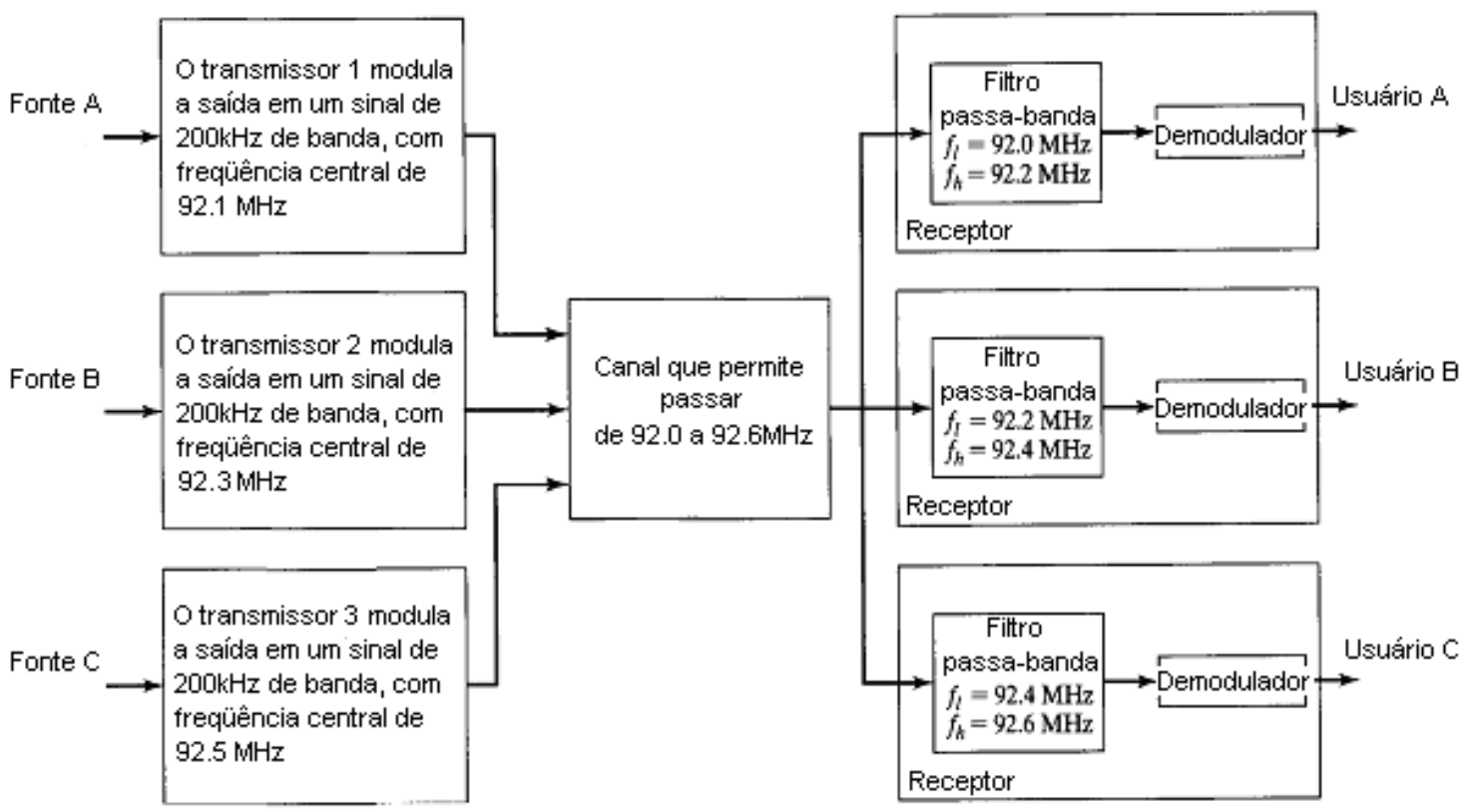

Figura 2.6 Sistema que utiliza FDM.

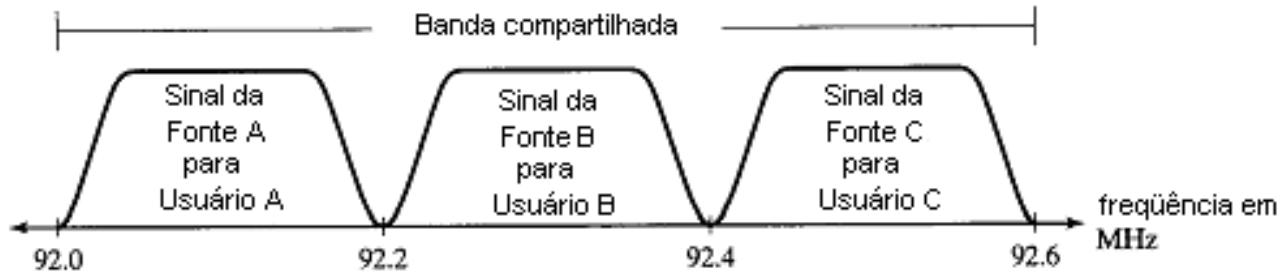

Figura 2.7 Espectro ocupado por sinais em um sistema FDM.

O FDM tem vantagens e desvantagens quando comparado com o TDM. A principal vantagem é que, ao contrário do TDM, o FDM não é sensível a atrasos de propagação. As técnicas de equalização necessárias para o FDM não são tão complexas quanto aquelas necessárias no TDM. Algumas desvantagens incluem a necessidade de um filtro passa-banda o que é relativamente caro e de projeto e construção complicados. Por outro lado, o TDM utiliza circuitos lógicos mais simples e baratos. Outra desvantagem é que em muitos sistemas de comunicações o amplificador do transmissor possui características não-lineares e amplificações não-lineares conduz ao surgimento de componentes espectrais que podem 
interferir em outros canais de FDM. Assim, se faz necessário a utilização de amplificadores lineares mais complexos. Logo, no caso de sistemas ópticos, que possuem fontes não-lineares, o FDM não é muito utilizado.

\subsection{3 - WDM}

WDM (Wavelength Division Multiplexing) é uma técnica de modulação onde múltiplos sinais são carregados juntos por um sinal multiplexado de acordo com a separação por comprimento de onda (cor) da luz, figura 2.8. Os canais do WDM são separados por comprimento de onda para evitar ligação cruzada quando são multiplexados por uma fibra óptica não-linear. Os comprimentos de onda podem ser individualmente distribuídos através de uma rede ou individualmente recuperados por componentes seletivos de comprimento de onda.

O WDM e o FDM são baseados nos mesmos princípios com a diferença que o WDM se aplicada aos comprimentos de onda na fibra óptica e o FDM se aplica na transmissão elétrica analógica. O sistema óptico do WDM é completamente passivo e confiável diferentemente do FDM que é elétrico (ativo).

O WDM permite que se utilize uma ampla largura de banda da fibra, embora vários dispositivos, sistemas e incrementos da rede limitem a utilização da banda completa da fibra.

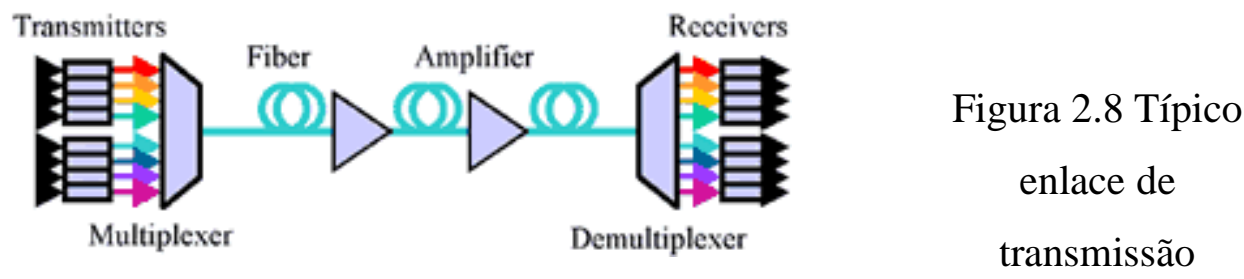

WDM.

O roteamento e a detecção dos diferentes sinais podem ser realizados independentemente, com o comprimento de onda que determina o trajeto de comunicação agindo como o endereço da assinatura da origem, do destino ou da distribuição. Os componentes requeridos são conseqüentemente, seletivo em comprimentos de onda, reservando para a transmissão, a recuperação, ou a distribuição de comprimentos de onda específicos. 
Em um sistema WDM simples, figura 2.9, cada laser deve emitir luz em um comprimento de onda diferente, luz essa multiplexada junto em uma única fibra óptica. Após serem transmitidos através de uma fibra óptica de elevada largura de banda, os sinais ópticos combinados devem ser demultiplexados na extremidade de recepção distribuindo o sinal óptico total a cada ponto de saída e, então, requerendo que cada receptor recupere seletivamente somente um comprimento de onda usando um filtro óptico ajustável.

Cada laser é modulado em uma dada velocidade, e a capacidade agregada total que está sendo transmitida ao longo da fibra é o total da soma das taxas de bits dos lasers individuais. Um exemplo do aumento da capacidade do sistema é a situação em que dez sinais de 2,5 Gbps podem ser transmitidos em uma fibra, produzindo uma capacidade do sistema de 25 Gbps. Este paralelismo no comprimento de onda acaba com o problema dos dispositivos óptico-eletrônicos típicos, que não têm larguras de banda que excedam alguns poucos gigahertz, a menos que sejam complexos e caros. As exigências da velocidade para os componentes óptico-eletrônicos individuais são, conseqüentemente, deixadas de lado, mesmo que uma quantidade significativa de largura de faixa total da fibra esteja sendo utilizada.

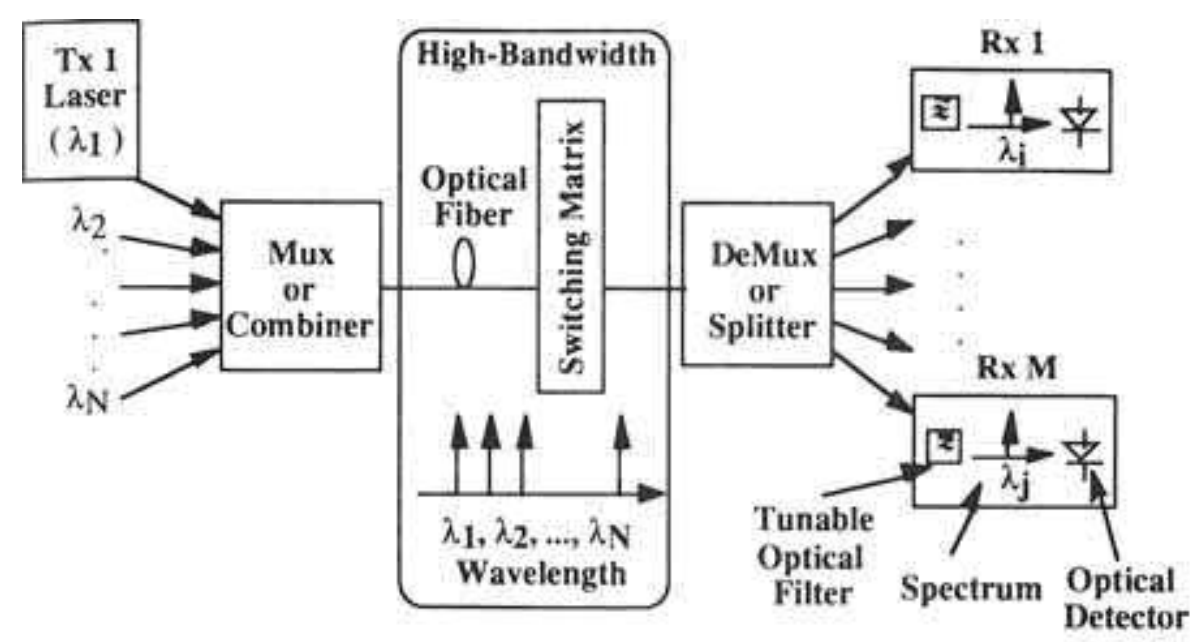

Figura 2.9 Diagrama de um sistema WDM simples.

O conceito de demultiplexação de um comprimento de onda usando um filtro óptico é ilustrado na figura 2.10. A figura mostra quatro canais de entrada (input) de um filtro óptico que tem uma função não-ideal de transmissão. O pico da transmissão do filtro é centrado no canal desejado, neste caso,..desse modo transmite esse canal e bloqueia todos os outros 
restantes. Por causa da função de transmissão não-ideal do filtro, alguma energia óptica da vizinhança do canal escapa através do filtro, e pode causar interferência inter canal ou linha cruzada (cross-talk). Este cross-talk tem o efeito de reduzir a razão de contraste do sinal selecionado, mas pode ser minimizado aumentando a separação espectral entre os canais.

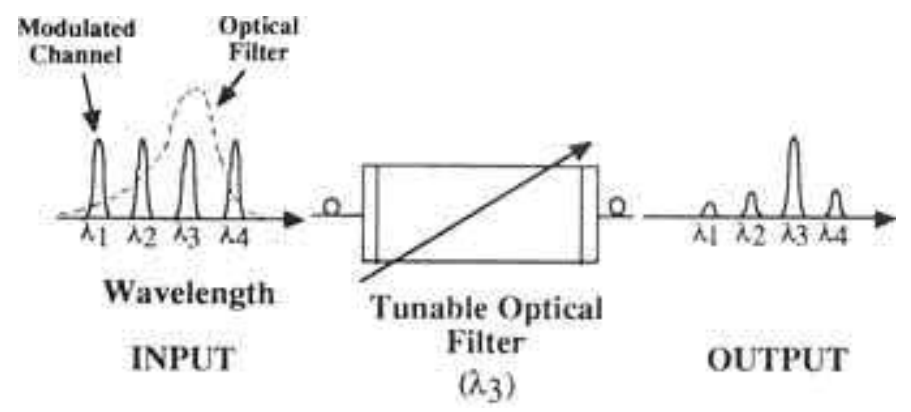

Figura 2.10 Canais WDM sendo demultiplexados por um filtro óptico.

Os sistemas WDM são divididos em dois segmentos: dense and coarse WDM. Sistema com mais de oito comprimentos de onda por fibra são geralmente considerados como Dense WDM (DWDM), enquanto aqueles que possuem menos de oito comprimentos de onda por fibra são classificados em Coarse WDM (CWDM). As tecnologias CWDM e DWDM são baseadas no mesmo conceito de utilizar múltiplos comprimentos de ondas de luz em uma mesma fibra, mas as duas tecnologia diferem quanto a distância entre dois comprimentos de onda diferentes, número de canais e na habilidade de amplificar sinais no espaço óptico.

\subsubsection{1 - DWDM}

O DWDM (Dense Wavelength Division Multiplexing) normalmente se refere aos sinais ópticos multiplexados dentro da faixa de $1550 \mathrm{~nm}$ para que, dessa forma, se aumente as potencialidades (e diminua o custo) dos EDFAs (Erbium Doped Fiber Amplifiers) que são eficazes para comprimentos de ondas entre $1530 \mathrm{~nm}$ e $1560 \mathrm{~nm}$. Os EDFAs foram originalmente desenvolvidos para substituir os regeneradores OEO (óptico-elétrico-óptico) do $\mathrm{SDH}$, que se tornaram praticamente obsoleto. Esses EDFAs podem amplificar todo sinal óptico dentro de sua faixa de operação até mesmo a taxa de bit modulada. Em se tratando de sinais com vários comprimentos de onda, como o EDFA tem energia suficiente disponível, ele 
consegue amplificar qualquer sinal óptico que foi multiplexado na sua banda de amplificação (embora a densidade de sinal seja limitada pela escolha do formato de amplificação). Então, os EDFAs permitem que uma ligação óptica de canal único seja transformada em uma taxa de bit substituindo apenas os equipamentos no final da ligação e retendo o EDFA existente, ou uma série deles, ao longo da rota de transporte. Além disso, ligações ópticas que possuem um único comprimento de onda usando EDFAs podem, similarmente serem transformadas em uma ligação WDM com um custo relativamente baixo. O custos desses EDFAs é compensado pelo número de canais pois, esse número é igual ao número de canais que ele pode multiplexar dentro da faixa de $1500 \mathrm{~nm}$.

\subsubsection{2 - CWDM}

O desenvolvimento do CWDM (Coarse Wavelength Division Multiplexing), uma tecnologia intermediária, respondeu à demanda crescente da rede de fibra óptica. Com uma capacidade menor que o DWDM, CWDM permite que um número modesto de canais, tipicamente oito ou menos, seja empilhado na região de $1550 \mathrm{~nm}$ da fibra chamada de faixa $\mathrm{C}$. Para reduzir dramaticamente o custo, CWDM utiliza lasers com uma ampla tolerância de \pm 3 nm. Os sistemas DWDM utilizam canais espaçados perto de 0,4 nm, o CWDM utiliza um espaçamento de $20 \mathrm{~nm}$. O amplo espaçamento acomoda as variações dos comprimentos de onda do laser, que ocorrem enquanto a temperatura ambiental varia. As variações do laser sobre a transmissão são de $\pm 0,06 \mathrm{~nm} /{ }^{\circ} \mathrm{C}$. A transmissão $\mathrm{CWDM}$ pode ocorrer em um de oito comprimentos de onda: tipicamente $1470 \mathrm{~nm}, 1490 \mathrm{~nm}, 1510 \mathrm{~nm}, 1530 \mathrm{~nm}, 1550 \mathrm{~nm}, 1570$ $\mathrm{nm}, 1590 \mathrm{~nm}, \mathrm{~nm}$ 1610. A figura 2.11 ilustra a banda passante do CWDM para um dispositivo de oito canais. 


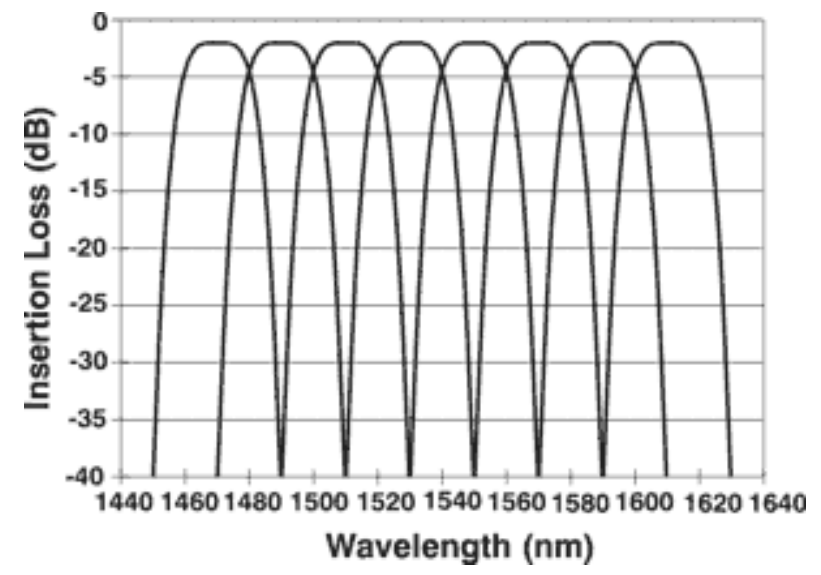

Figure 2.11 Banda passante do CWDM para um dispositivo de 8 canais.

A perda de inserção para um dispositivo de oito canais é aproximadamente $2 \mathrm{~dB}$ por extremidade. A largura da banda passante é em torno de $13 \mathrm{~nm}$ no ponto de perda de $-0,5 \mathrm{~dB}$. Os demultiplexadores de CWDM têm, tipicamente, uma perda de inserção mais elevada e a perda de isolação significativamente melhor. Os multiplexadores têm uma perda de inserção mais baixa e uma perda de isolação mais pobre. A isolação não importa em uma aplicação unidirecional porque o multiplexador combina diversas saídas do transmissor. A figura 2.12 ilustra uma aplicação unidirecional de CWDM.

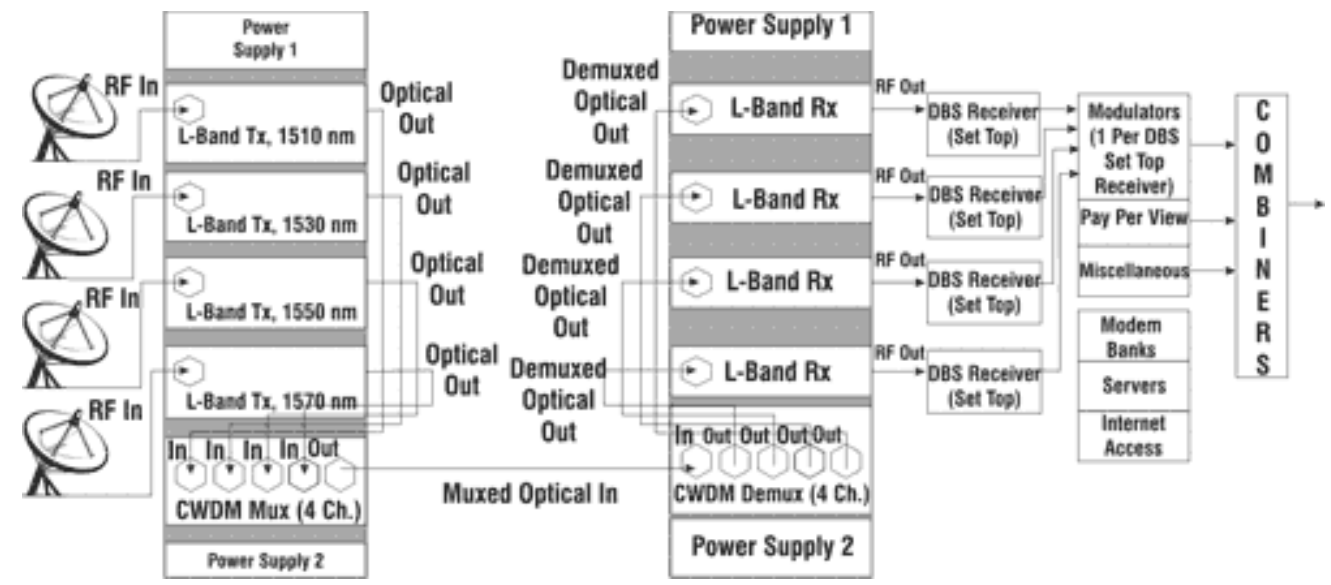

Figura 2.12 Aplicação unidirecional de CWDM.

Em uma aplicação bidirecional, ilustrada na figura 2.13, qualquer entrada em qualquer extremidade da fibra pode ser uma entrada ou uma saída, requerindo alta isolação do demultiplexador para garantir que o sistema irá trabalhar sem interferência entre os canais. 


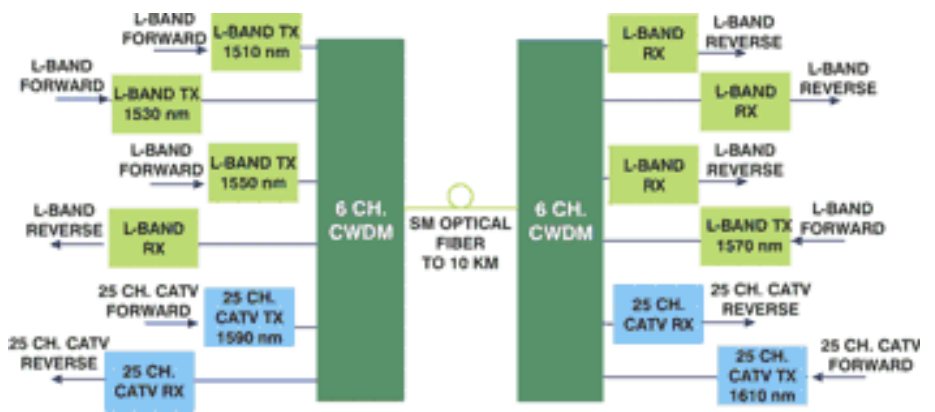

Figure 2.13 Aplicação biderecional do CWDM. 


\section{3 - TIPOS DE REDES ÓPTICAS:}

\section{1 - REDE ÓPTICA PASSIVA}

Uma rede PON (Passive Optical Network) apresenta topologia ponto-multiponto. É formada por equipamentos OLT (Optical Line Terminal), localizados nas bordas dos anéis ópticos das redes de transporte SDH, e também por equipamentos ONU (Optical Network Units) ou ONT (Optical Network Terminal), figura 3.1.

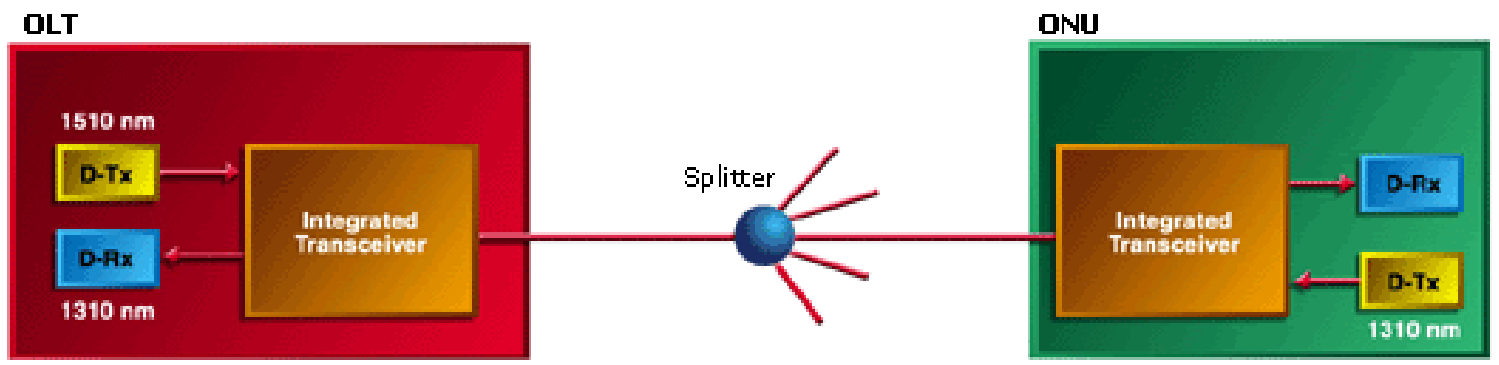

Figura 3.1 Estrutura básica de uma rede PON.

O OLT é o equipamento que viabiliza os serviços para o usuário, controla a qualidade do serviço (Qos) e o SLA (Service-level Agreement). SLA é um contrato informal entre um provedor e um cliente em que são definidos os termos de responsabilidade do portador ao cliente e o tipo e de extensão da remuneração se aquelas responsabilidades não forem cumpridas. O OLT também realiza a multiplexação dos diferentes usuários. A alocação de banda, que antigamente era realizada de forma semelhante ao TDM, atualmente ocorre de forma dinâmica e a reutilização da banda considera os perfis de tráfego, as políticas de QoS e SLAs, figura 3.2. 


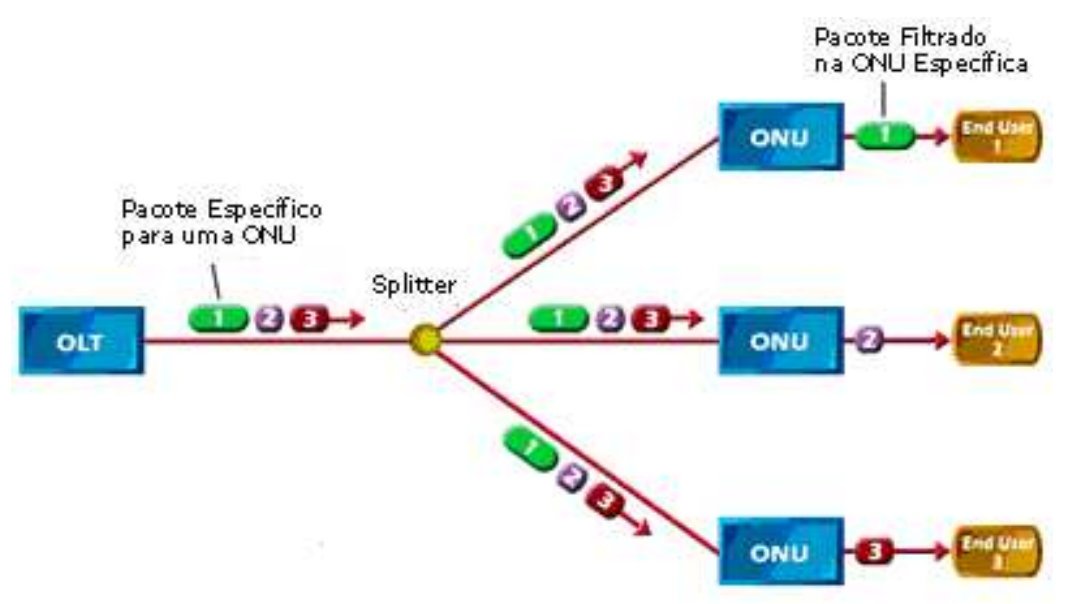

Figura 3.2 Funções do OLT.

O ONU é um equipamento utilizado para converter o sinal óptico em sinal elétrico, que será encaminhado para as portas padrões dos equipamentos de aplicação do usuário final, como: ATM, Ethernet, IP etc, Figura 3.3:

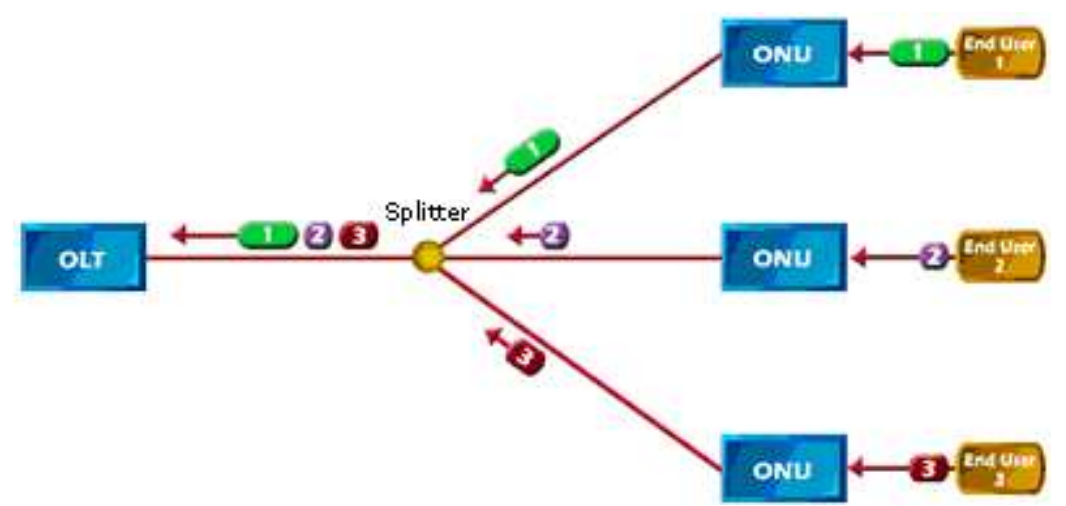

Figura 3.3 Funções do ONU.

O sinal óptico de uma fibra é enviado para um ou mais divisores passivos, denominados splitters, e retransmitida para vários equipamentos ONU's. Cada ONU irá então receber e transmitir sinais em um canal próprio com a banda dinamicamente alocada e QoS e SLAs individuais. Os sinais transmitido e recebido operam com comprimentos de onda diferentes, permitindo, dessa forma, que a operação ocorra sobre uma única fibra. A OLT irá avaliar esses QoS e SLAs e a disponibilidade do segmento PON que ele opera. Após isso, a alocação dinâmica é aplicada. Esse processo pode prover banda entre $1 \mathrm{Mbps}$ e $10 \mathrm{Gbps}$ aos usuários. 
Algumas vantagens da tecnologia PON são apresentadas a seguir.

- Baixo custo: por não existir elementos ativos ocorre economia de energia, de espaço entre os sites e de manutenção;

- É feita por compartilhamento da capacidade da fibra óptica;

- Tem grande ganho de escala no atendimento à demanda dos usuários;

- Flexibilidade e otimização do uso da fibra que é conseguido pela alocação dinâmica da banda;

- Diversificação dos serviços;

- Viabilidade de criação de uma maior variedade de portifólio que faz o balanceamento das várias opções ofertadas.

A PON trabalha, basicamente, em duas formas diferentes: upstream e downstream. Considera-se upstream todos os pacotes que se originam no cliente e se dirigem à operadora e downstream todos os pacotes que se originam na rede e se dirigem para o cliente. Quando o splitter faz upstream, a distribuição pode ser feita usando-se vários métodos, como TDMA (Time Division Multiple Access), WDMA (Wave Division Multiple Access), CDMA (Code Division Multiple Access) ou SCMA (Subcarrier Multiple Access). Geralmente é utilizado o TDMA para upstream devido à sua simplicidade e menor custo. No caso do downstream, as recomendações do ITU-T utilizam o TDM, que associa cada cliente com seus respectivos time slots.

$\mathrm{Na}$ arquitetura ponto-multiponto, uma única fibra é compartilhada por vários pontos finais e não existem elementos ativos. Entre as opções de topologias, têm-se em anel, árvore e barramento. [32]

A topologia em anel é aquela onde duas ONUs são conectadas a uma OLT, o que gera dois segmentos PONs que podem ser chamados de PON A e PON B. As outras ONUs são conectadas de forma serial a partir da primeira ONU do segmento, o que forma um barramento óptico. Dessa forma, cada ONU de cada barramento funcionará como um derivador óptico ativo. As últimas ONUs são, então, conectadas entre si fechando o anel lógico, figura 3.4. Essa topologia possui vantagens como redundância da rede e possibilidade de configuração do custo métrico de tráfego. 


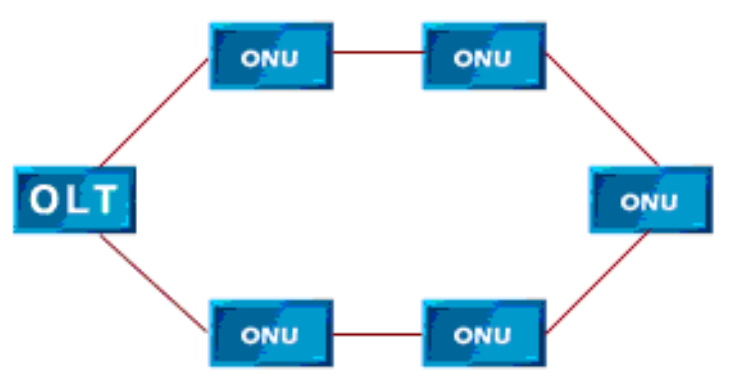

Figura 3.4 Topologia em anel.

Na topologia em árvore, as ONUs são conectadas a uma OLT por um único segmento PON. A partir dessa OLT conecta-se um segmento de fibra óptica (Deep Fiber). Esse segmento recebe um derivador passivo (splitter), figura 3.6. O primeiro derivador deve ter, no mínimo, um fator de derivação de 1:2 pois, dessa forma, um splitter criará dois sub-segmentos de fibra. A maior vantagem dessa topologia é que, mesmo que as ONUs estejam relativamente distantes da OLT e/ou concentradas a partir de uma certa distância onde não existam ONUs intermediárias, pode-se lançar alguns quilômetros de segmento de fibra e somente começar a derivação deste segmento a partir desta distância.

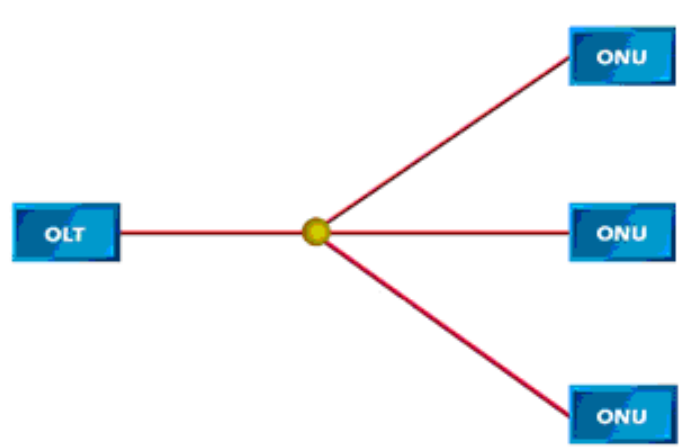

Figura 3.5 Topologia em árvore.

$\mathrm{Na}$ topologia em barramento, as ONUs são conectadas a uma OLT através de um segmento de fibra óptica, que recebe vários derivadores passivos com o fator de derivação de 1:2, ou seja, um splitter cria dois outros segmentos de fibra, figura 3.6. Um dos segmentos servirá de conexão para a ONU e o outro servirá como caminho passante para o próximo spliter. Essa topologia é útil para aplicações de abordagem nas ruas (Fiber To The Curb), no 
qual cria-se um segmento de fibra e instala-se pequenos gabinetes de distribuição nas calçadas ou postes onde estarão os derivadores e/ou ONUs, que farão a conectividade via fibra óptica, cabo coaxial ou wireless para os usuários finais.

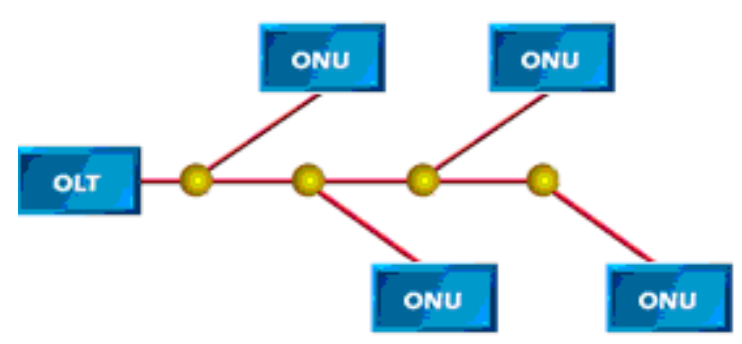

Figura 3.6 Topologia em barramento.

Uma típica rede PON é composta por um misto de topologias vislumbradas de acordo com a estratégia de implementação e com a grande flexibilidade de arquitetura. A figura 3.7 ilustra uma aplicação típica de ganho de escala no atendimento e mix de portifólio com topologia flexível em redes PONs.

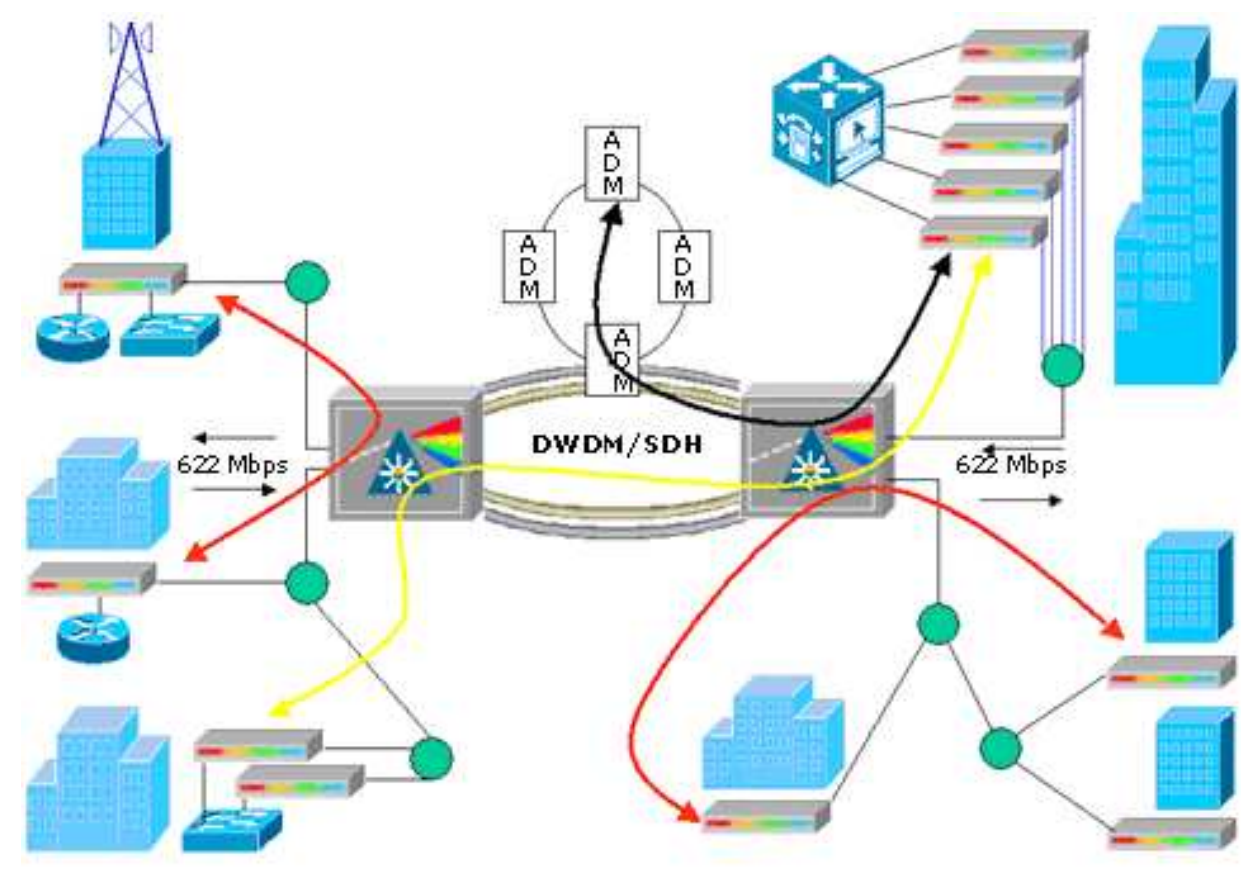

Figura 3.7 Visão geral de uma rede PON completa. 
Existem vários tipos de PON, mas a tecnologia geral é a mesma. As diferenças estão nas especificações e nas camadas altas dos protocolos: APON (ATM PON - 155 Mbps a 622 Mbps), BPON (Broadband PON - 155 Mbps a 1,25 Gbps), EPON ou GE-PON (Ethernet based PON - 1,25 Gbps) e GPON (Gigabit PON - 622 Mbps a 2,5 Gbps).

\section{2 - APON:}

A rede APON foi desenvolvida em 1990, quando havia duas escolhas lógicas para protocolos e planta física: ATM e PON. A primeira porque poderia servir múltiplos protocolos e a segunda porque é a solução óptica mais econômica. Tecnologias que possuem fibra óptica em arquiteturas de rede de acesso como FTTH (fiber-to-the-home), FTTB (fiber-to-thebuilding), FTTCab (fiber-to-the-cabinet) e FTTC (fiber-to-the-curb) oferecem um mecanismo que habilita banda suficiente para oferecer novos serviços e aplicações. ATM-PON pode ser incluída em todas essas tecnologias, figura 3.8.

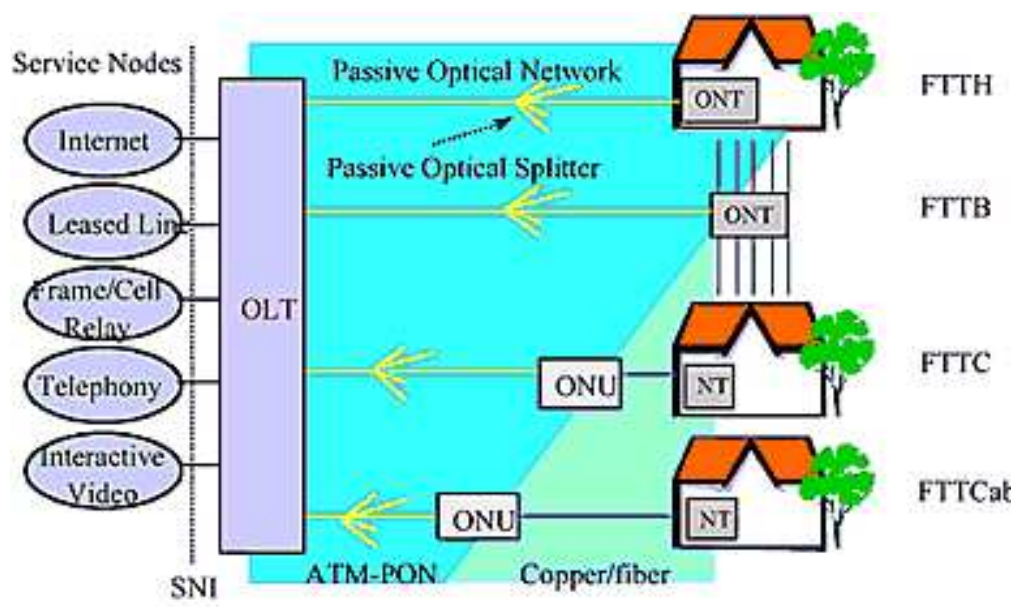

Figura 3.8 ATM-PON arquitetura.

A PON pode ser utilizada nessas arquiteturas, porém, somente nas configurações FTTH e FTTB todos elementos ativos podem ser eliminados da planta externa. As arquiteturas FTTCab e FTTC necessitam de elementos ativos na vizinhança da planta externa. Uma visão geral da função de uma arquitetura ATM-PON é representada na figura 3.9: 

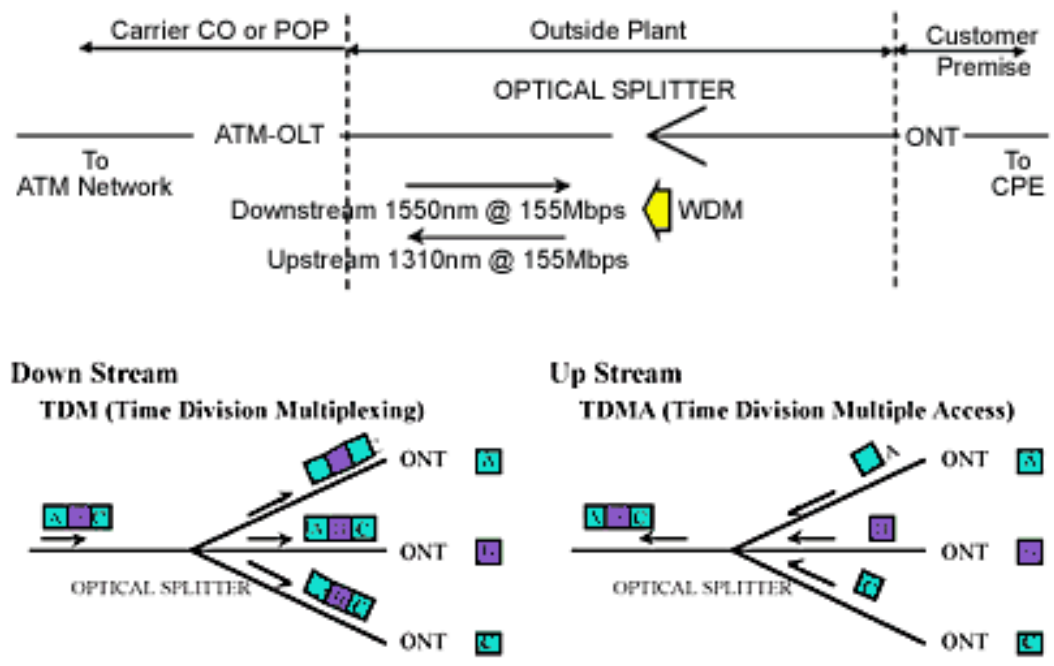

Figura 3.9 Visão geral da funcionalidade da ATM-PON.

Na Figura 3.10, observa-se que o ONT é posicionado próximo ao cliente o que sugere a arquitetura FTTH/B. O ponto de demarcação do provedor seria ao lado do subscritor ONT tipicamente de um formulário T1, Ethernet, RDSI etc.

$\mathrm{O}$ acesso à banda em uma rede PON pode ser obtido por vários métodos, incluindo TDMA, WDMA, CDMA e SCMA. Como mostrado na Figura 3.10, a rede de componentes ATM-PON consiste de OLT, ONT e splitters ópticos passivos. O sinal de uma fibra é dividido entre múltiplos ONTs. Essa divisão passiva requer ações especiais de privacidade e de segurança e um protocolo TDMA se faz necessário no upstream. $\mathrm{O}$ uso de um divisor óptico na arquitetura PON permite que vários usuários compartilhem da mesma banda e dividam custos.

O sistema ATM-PON utiliza uma arquitetura denominada de "dupla estrela". A primeira estrela está localizada na OLT, onde a interface WAN é logicamente compartilhada e comutada para a interface ATM-PON. A segunda estrela está localizada no splitter onde a informação, passivamente compartilhada, é entregue para cada ONT. O OLT é geralmente localizado no $\mathrm{CO}$ (central office) e é o ponto de interface entre o sistema de acesso e os pontos de serviços dentro da rede do provedor. Quando o conteúdo dos dados da rede encontra o OLT, ele é comutado diretamente para o splitter passivo usando TDM no downstream. 
O ONT filtra as células e recupera somente aquelas que são endereçadas a ele. Cada célula ATM tem 28 bits de endereço associado com o VPI/VCI. Dessa forma, primeiramente o OLT enviará uma mensagem para o ONT avisando que este deve a aceitar as células contendo determinados VPI/VCI.

Como o TDMA é usado no upstream, cada ONT é sincronizado em tempo com outro ONT em um processo denominado ranging. Basicamente, o OLT deve determinar a distância entre os ONT para que possa ser assumido um time slot ótimo no qual ocorra uma transmissão sem interferência por parte dos outros ONTs. O OLT mandará, então, mensagens via células de operação, administração e manutenção de camada física (PLOAM) para avisar ao TDMA sobre os time slots pertencentes aquele ONT. Dessa forma, o ONT adaptará o serviço de interface para o ATM e enviará para a rede PON usando o protocolo TDMA. Como ATMPON é um serviço independente, todos os serviços legados e futuros podem ser facilmente transportados.

O formato básico do frame entre o OLT e ONT para uma taxa de transmissão simétrica $155 \mathrm{Mbps}$ é mostrado na figura 3.10.

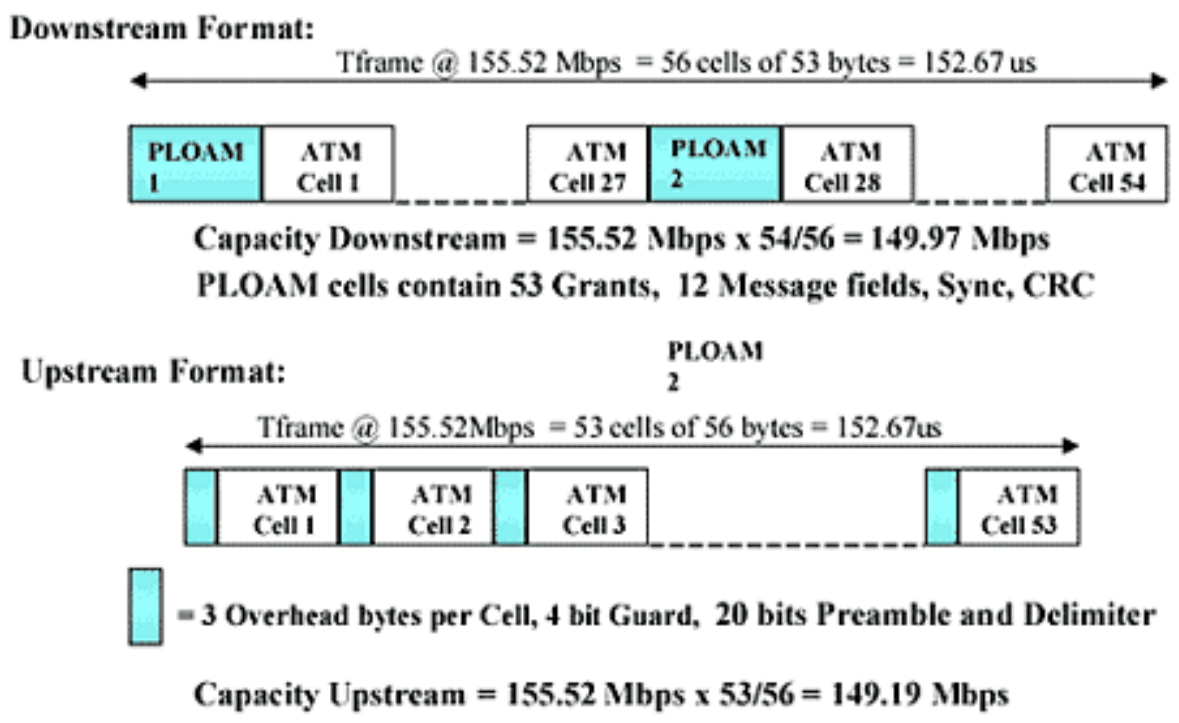

Figura 3.10 Formato básico do frame entre OLT e ONT.

Pode-se observar, pela figura 3.11, que a capacidade de payload no downstream é reduzida para 149,97 Mbps devido às células PLOAM. Estas células são responsáveis pela alocação de banda, sincronização, controle de erro, segurança, ranging e manutenção. 
No upstream a capacidade é reduzida para 149,19 Mbps porque há 3 bytes de redundância por célula ATM, além disso, há células PLOAM no upstream. Aquela taxa é definida pelo OLT para cada ONT, dependendo da funcionalidade requerida. A taxa mínima de PLOAM no upstream é de um PLOAM a cada $100 \mathrm{~ms}$. Isso iguala para 1 PLOAM a cada 655 frames, que se torna irrisório. Os 3 bytes de overhead contêm um mínimo de 4 bits de tempo de guarda para ter distância, em tempo, suficiente para que não haja colisões entre células de ONTs diferentes. Este tamanho de campo é programável pelo OLT e existem dois tipos: preâmbulo e delimitação. O primeiro é usado para adquirir sincronização de bit e recuperação de amplitude. O segundo usado para indicar o começo da célula que está chegando.

Dado que uma única fibra é usada tanto para upstream como para downstream, dois comprimentos de ondas de luz são usados $-1.550 \mathrm{~nm}$ para o downstream e $1.310 \mathrm{~nm}$ para o upstream. Embora um único comprimento de onda também pudesse ser usado, dois proporciona um melhor isolamento óptico entre transmissores e receptores. A conversão eletro-óptica das células ATM ocorre de forma direta, sendo, a seguir, enviadas para a rede PON. Devido ao broadcast natural da rede PON, técnicas de criptografia foram desenvolvidas para prevenir brechas de segurança. No upstream, o ONT utiliza o TDMA e, novamente, ocorre a conversão eletro-óptica das células ATM para transporte através de PON. Um típico sistema ATM-PON pode ter até 64 usuários numa única fibra compartilhando 155 Mbps.

\section{3 - BPON:}

É uma configuração de rede baseada na ATM-PON. As especificações iniciais da PON utilizadas pela FSAN (Full Service Access Network) utilizam-se de ATM como a segunda camada de sinalização. O uso do termo APON faz que os usuários acreditem que apenas os serviços ATM podem ser providos para os usuários finais. Em função desse fato, FSAN decidiu modificar o nome para Broadband PON ou BPON. O sistema BPON oferece inúmeros serviços incluindo acesso a Ethernet e distribuição de vídeo. Acrescenta suporte para WDM, banda em upstream é alocada de forma mais rápida, dinâmica e durável. A figura 3.11 representa a rede $\mathrm{BPON}$. 


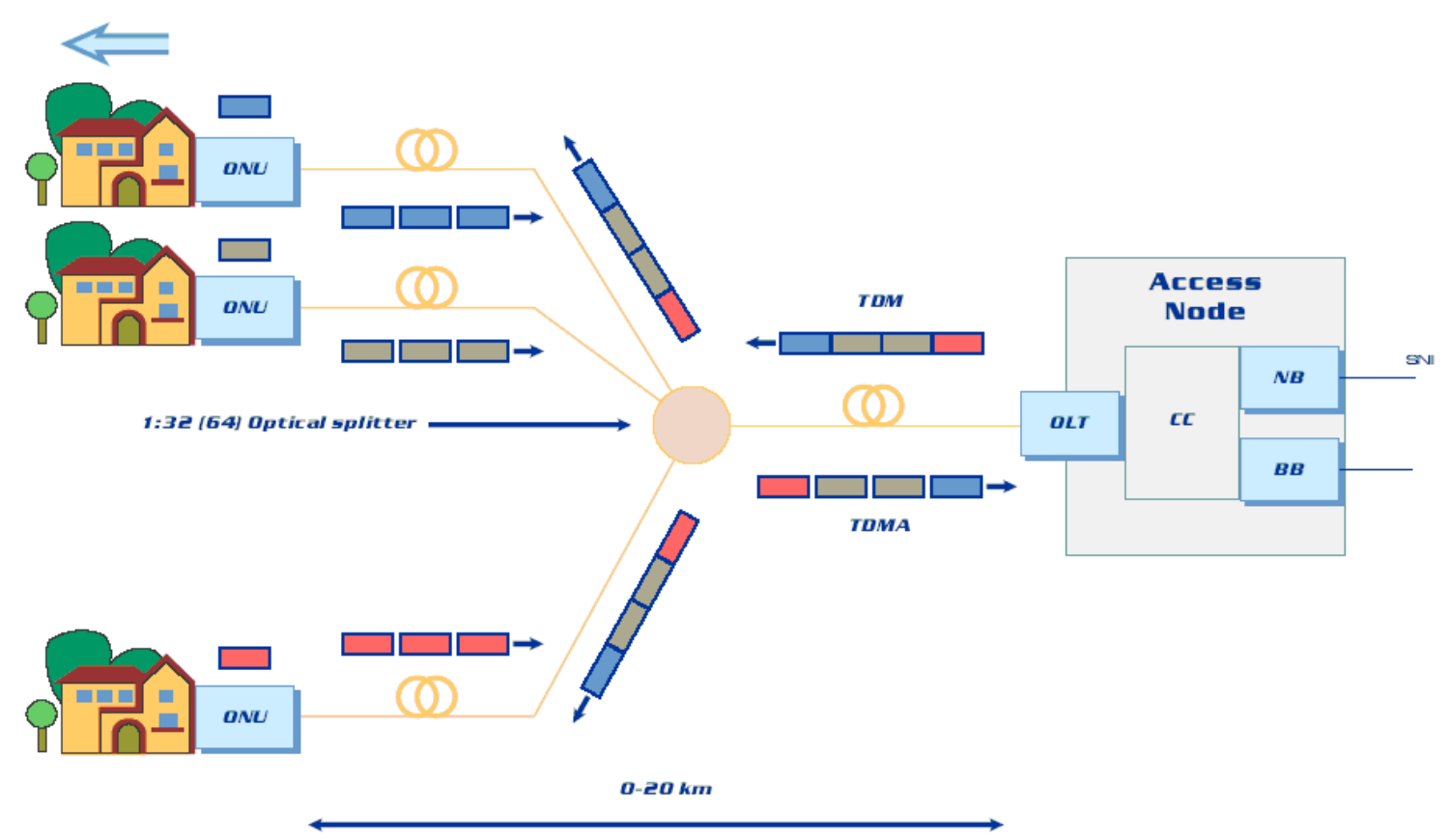

Figura 3.11 Representação de uma rede BPON.

\section{4 - EPON}

Os elementos passivos de uma EPON estão alocados em uma rede de distribuição óptica (também conhecida como outside plant) e incluem fibra monomodo, splitters, conectores e splices, figura 3.12. Os OLTs e as múltiplas ONUs estão alocados nos pontos finais da PON. Os sinais ópticos podem passar por várias fibras ou serem combinados em uma única fibra através dos splitters, dependendo da posição na qual a luz está viajando dentro da PON. [19] 


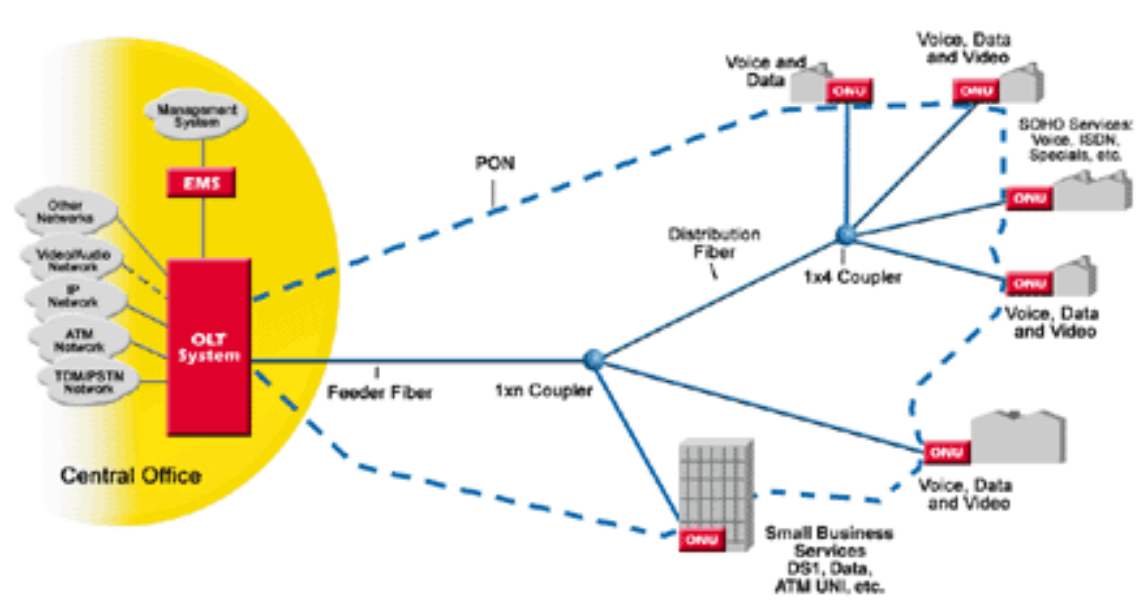

Figura 3.12 Representação de uma rede EPON.

As EPONs são mais simples, mais eficientes e mais baratas que as demais soluções para multiserviços de acesso. As principais vantagens são apresentadas a seguir:

- Banda maior que 1,25 Gbps, o que gera outras vantagens como maior número de usuários por PON, maior largura de banda por usuário, contagens mais elevadas do split, potencial para distribuição de vídeo e melhor QoS;

- Custos mais baixos conseguidos através da arquitetura simples, da operação mais eficiente e menor custo de manutenção necessário;

- Maior rendimento podendo suportar dados, vídeo e voz.

A grande diferença entre EPON e APON reside no fato de que, no primeiro caso, os dados são transmitidos em pacotes de tamanho variáveis de até 1.518 bytes dependendo do protocolo 802.3 do IEEE, enquanto, no segundo caso, há transmissão de pacotes de tamanhos fixos de 53 bytes por pacote. Este formato representa uma dificuldade e ineficiência para APONs no que diz respeito ao transporte de tráfegos formatados de acordo com o IP. As chamadas IPs para dados devem ser segmentadas em pacotes de tamanhos variáveis de até 65.535 bytes. Para um APON carregar tráfego IP, os pacotes devem ser quebrados em segmentos de 48 bytes com 5 bytes de cabeçalho cada um. Este processo consome tempo e gera custos para o OLT e ONU. Além disso, 5 bytes de banda são consumidos para cada segmento de 48 bytes, gerando um oneroso overhead que é geralmente referido a taxa de 
células ATM. Em contraste, Ethernet foi desenvolvido para carregar tráfego IP, o que reduz drasticamente o overhead relativo ao ATM.

No EPON, o processo de downstream do OLT para vários ONUs é fundamentalmente diferente da transmissão upstream de vários ONUs para o OLT. No downstream, os dados são enviados via broadcast do OLT para múltiplos ONUs em pacotes de tamanho variáveis de até 1.518 bytes. Cada pacote carrega um cabeçalho que o identifica. Além disso, alguns pacotes podem ser endereçados para todos os clientes na forma de broadcast ou a um particular grupo de clientes na forma de multicast. No splitter, o tráfego é dividido em 3 sinais separados, cada um carregando todos os pacotes de determinado ONU. Quando os dados encontram o ONU apropriado, os pacotes endereçados corretamente são aceitos e os demais descartados.

No upstream, o tráfego é feito utilizando a tecnologia TDM, na qual cada time slot de transmissão é dedicado a um cliente. Os times slots são sincronizados para que os pacotes upstrem do ONU não interfiram nos dados pertinentes ao fluxo da outra ONU que compartilham a mesma fibra. Ou seja, ONU-1 transmite pacote no primeiro time slot, ONU-2 transmite no segundo time-slot e assim por diante.

O tráfego downstream é segmentado em frames de intervalos fixos (time slots), cada um deles contendo múltiplos pacotes de tamanhos variados. Informações de clock, na forma de marca de sincronização são incluídas no começo de cada frame. $O$ marcador de sincronização é feito através de um byte transmitido a cada 2 segundos para sincronização entre a ONU e as OLTs, figura 3.13.

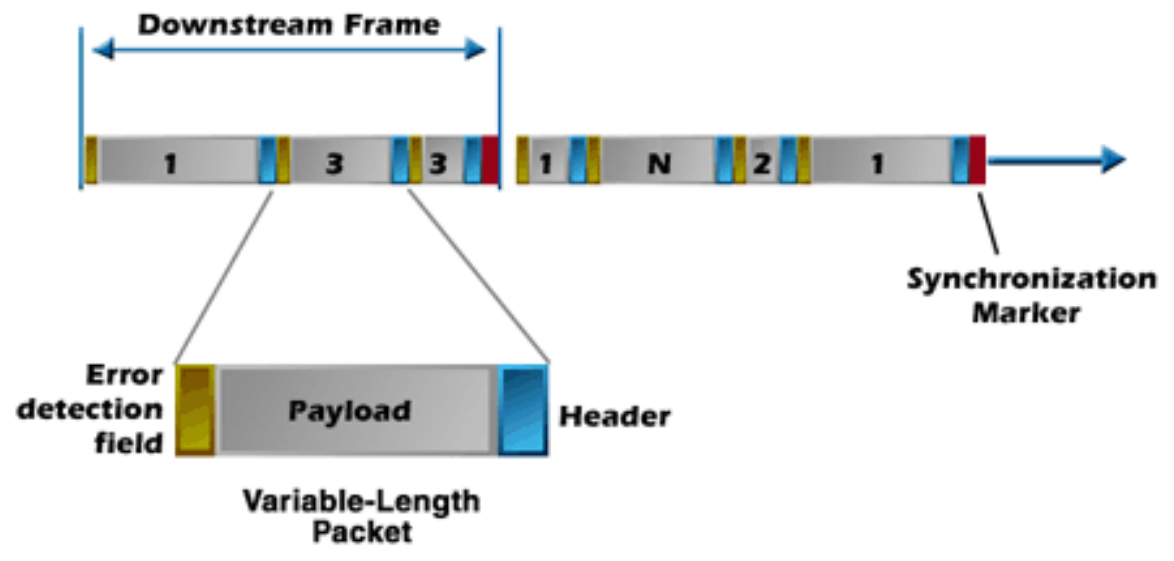

Figura 3.13 Formato do frame do tráfego downstream. 
O tráfego upstream, assim como o downstream, também é segmentado em frame, e cada frame é novamente segmentado em time slots específicos de cada ONU. Os frames upstream são formados por um intervalo de transmissão contínua de $2 \mathrm{~ms}$. Um cabeçalho de frame identifica o começo de cada frame upstream, figura 3.14.

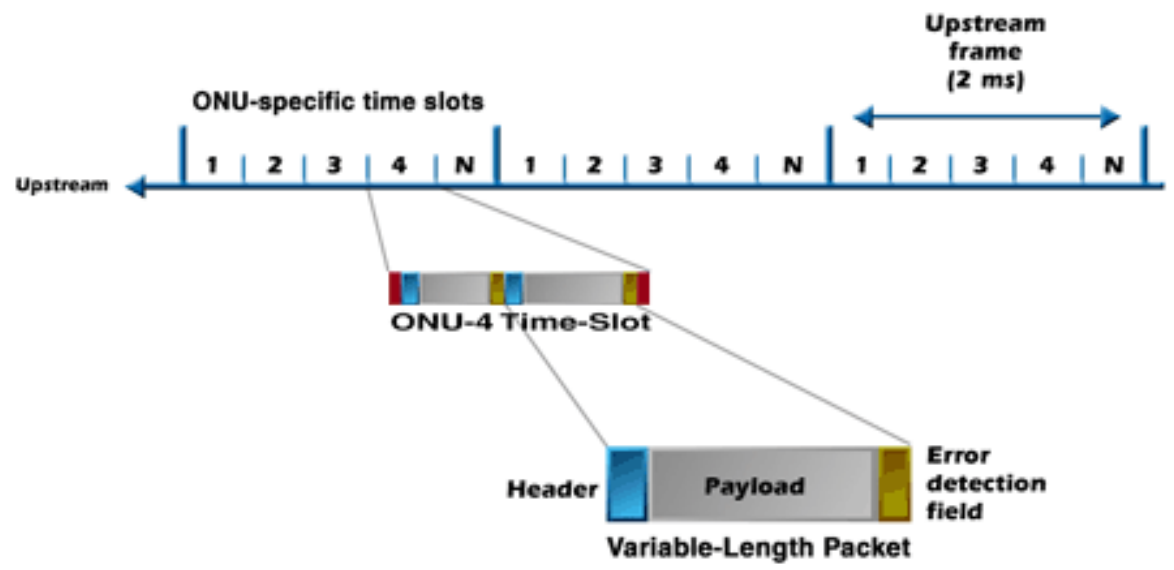

Figura 3.14 Formato do frame do tráfego downstream.

As redes EPONS podem ser implementadas utilizando-se tanto dois quanto três comprimentos de ondas. Utilizam-se dois comprimentos de onda quando o objetivo é a entrega de dados, voz e comutação de vídeo digital sobre IP. Três comprimentos de onda são exigidos para proporcionar radiofreqüência, serviços de vídeo ou DWDM.

$\mathrm{Na}$ arquitetura de dois comprimentos de onda, o comprimento de $1.510 \mathrm{~nm}$ transporta dados, vídeo e voz, enquanto um comprimento de onda de $1.310 \mathrm{~nm}$ é usado para transportar video-on-demand (VOD), figura 3.15.

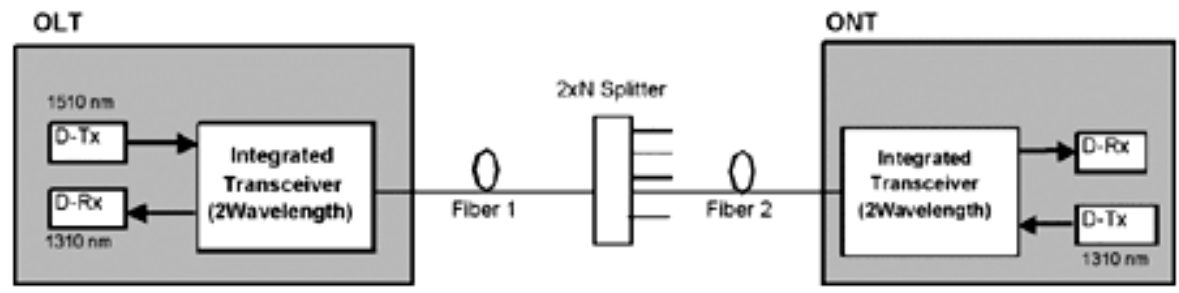

Figura 3.15 Rede EPON com dois comprimentos de onda.

$\mathrm{Na}$ arquitetura de três comprimentos de onda, $1.510 \mathrm{~nm}$ e $1.310 \mathrm{~nm}$ são os comprimentos de onda usados no downstream e no upstream, respectivamente, enquanto 
$1.550 \mathrm{~nm}$ é reservado para o downstream em vídeo. O vídeo é codificado como MPEG-2 e é transportado através de uma modulação de quadratura de amplitude (QAM). Usando esta configuração, o PON proporciona uma distância efetiva de até $18 \mathrm{~km}$ para 32 divisões (ou clientes em localidades diferentes), como ilustra a figura 3.16.

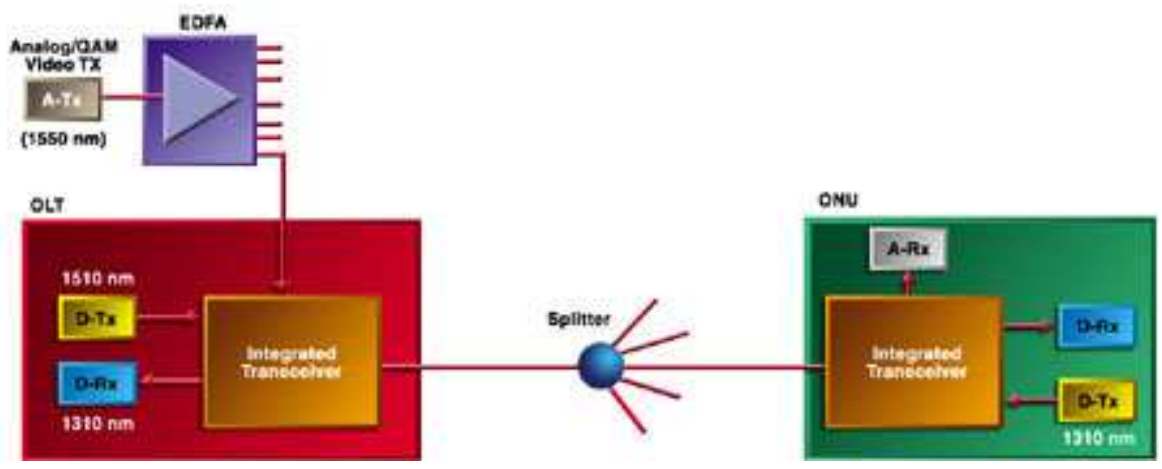

Figura 3.16 Rede EPON com três comprimentos de onda.

As redes EPONs podem oferecer vantagens de custo e de performance que permitem o provedor entregar serviços de nova geração sobre uma plataforma econômica. Porém, um grande desafio técnico para os vendedores encontra-se em aumentar as capacidades da Ethernet para garantir que o serviço de voz em tempo real e o serviço de vídeo sobre IP possam ser entregues sobre uma única plataforma com o mesmo QoS e com a facilidade da gerência do ATM ou do SDH. Para solucionar esse problema, os vendedores estão abordando o problema de vários e diferentes ângulos. Estão, por exemplo, implementando métodos como o DiffServ (differentiated Services) e 802.1p, que provêm tráfico para diferentes níveis de serviço.

\section{5 - GPON}

A GPON emergiu como uma solução nova no mercado de acesso óptico, oferecendo uma elevada taxa de bit ao permitir o transporte de múltiplos serviços, especificamente dados e TDM em formatos originais, e em uma eficiência extremamente elevada, figura 3.17. 


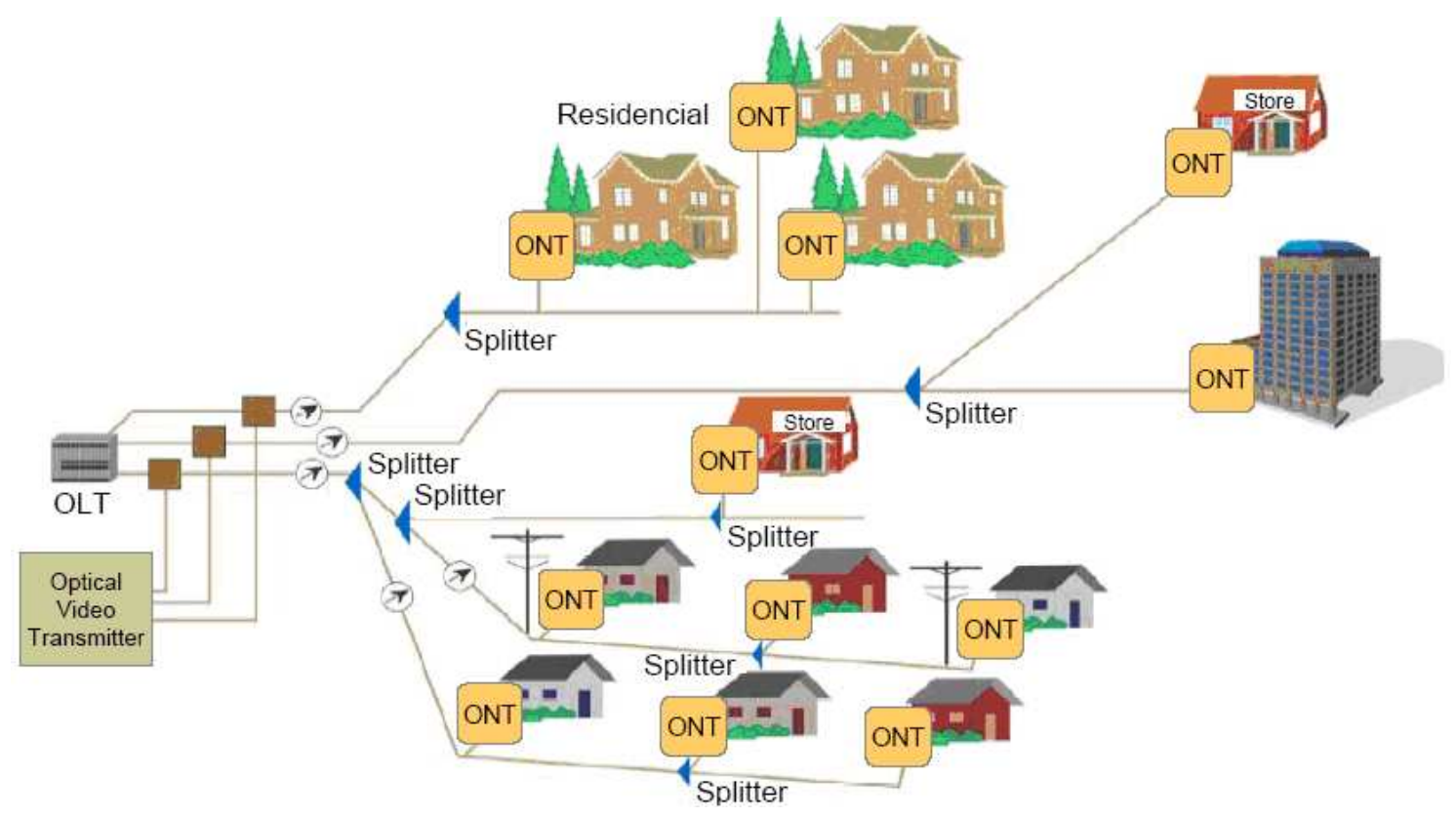

Figura 3.17 Exemplo de uma rede GPON.

GPON ou Gigabit PON é a segunda geração de protocolo publicado pelo ITU-T como uma série de recomendação G.984. O protocolo suporta diversas velocidades de downstream e de upstream, sendo as mais típicas de 1,24 Gbps downstream e $622 \mathrm{Mbps}$ upstream. GPON é baseado em um protocolo denominado de GFP (Generic Framing Protocol). O objetivo é eliminar ou, pelo menos, reduzir significativamente as edições em torno do ATM. Onde o ATM introduziu ineficiências, segmentando tudo em pilhas de 48/53 de byte, o GFP emite frames ou células de comprimento variável com até 65.535 bytes em um frame. Isto permite que a GPON carregue frames de Ethernet com muito mais eficiência do que APON ou BPON e quase tão eficiente quanto EPON. Mas nada é realmente novo: o GFP usa uma técnica da época dos modens de 300 baud desenvolvidos pela Digital Equipment Corporation (DEC). Um protocolo chamado DECNet precede cada pacote com uma contagem dos bytes restantes no pacote. Com isso, o problema era indicar onde o pacote começou e onde a contagem de byte estava. Caracteres especiais eram necessários para endereçar este problema, o que dificultou o sistema.

A IBM foi procurada para corrigir esse problema e criou o código do SDLC e do NRZ/NRZI com seus caracteres especiais encaixados na transmissão. Estes caracteres especiais delinearam o começo e a extremidade de cada mensagem e, dessa forma, uma contagem de byte não era mais necessária. Esse paradigma durou até hoje. 
A GFP resolve a exigência se encontrar, de forma impressionantemente correta, o começo de um pacote (e da contagem de byte). Emitem simplesmente a contagem de byte de 16 bits e um 16 bit CRC. O frame de GFP procura dois bytes e então calcula o CRC depois, compara-o aos dois bytes seguintes. Se forem iguais significa que a contagem de byte foi encontrada e pode-se continuar a ler o pacote. Caso contrário, move-se para o byte seguinte e inicia-se o processo outra vez. Isso pode ser mais simples e mais eficiente do que o ATM. Naturalmente, esta é uma simplificação de um protocolo complicado, que também oferece muitas outras características interessantes que se dirigem aos desafios do ATM hoje. O protocolo é definido pelo ITU-T G.7041. ITU G.984.x é o padrão em desenvolvimento.

Para o ano 2008, GPON é vista como a tecnologia mais relevante de PON pelo EMEA (Europa Mideast e África) com a EPON e a BPON representando um papel menor. GPON surgirá como a principal tecnologia na América do Norte, no momento em que BPON ainda tiver a maior parte do mercado. APAC continuará a ser o maior mercado regional para EPON, mas espera-se que a GPON emirja por lá também, conseguindo cerca de $25 \%$ do mercado até 2008.

A GPON apresenta diversas vantagens quando comparada às outras tecnologias de PON:

- GPON comparado a EPON: A tecnologia de GPON segura o tráfego de TDM naturalmente sem nenhuma necessidade de algum mecanismo encapsulador que utiliza o protocolo GFP. Além disso, a GPON é sincronizada por sua natureza. Isto conduz a uma eficiência de banda maior que $90 \%$ com uma largura de banda de até 2,5 Gbps na PON. EPON fornece a eficiência de banda menor que 50\% por um máximo da largura de banda de 1,25Gbps na PON.

- GPON comparado a APON ou a BPON: A tecnologia GPON permite maiores taxas de divisão e, outra vez, maior largura de banda na PON. Além disso, o uso da largura de banda nas redes GPON tem uma eficiência $20 \%$ maior do que nesses outros casos. 


\section{6 - ETHERNET}

A tecnologia Ethernet tem aproximadamente 30 anos e, nas últimas décadas, tem se tornado uma das tecnologias mais utilizadas, devido a sua velocidade, facilidade de instalação e custo relativamente baixo. [10]

Em 1985, o IEEE publicou a recomendação IEEE 802.3, que define o padrão Ethernet. Após isso, várias outras recomendações foram divulgadas, apresentando melhorias e outras definições do padrão, tabela 3.1:

Tabela 3.1 Recomendações IEEE para o padrão Ethernet.

\begin{tabular}{|l|l|l|}
\hline \multicolumn{1}{|c|}{ Supplement } & \multicolumn{1}{|c|}{ Year } & \multicolumn{1}{c|}{ Description } \\
\hline \hline $802.3 a$ & 1985 & 10 Base-2 (thin Ethernet) \\
\hline $802.3 \mathrm{c}$ & 1986 & $10 \mathrm{Mb} / \mathrm{s}$ repeater specifications (clause 9) \\
\hline $802.3 \mathrm{~d}$ & 1987 & FOIRL (fiber link) \\
\hline $802.3 \mathrm{i}$ & 1990 & 10 Base-T (twisted pair) \\
\hline $802.3 \mathrm{j}$ & 1993 & 10 Base-F (fiber optic) \\
\hline $802.3 \mathrm{u}$ & 1995 & 100 Base-T (Fast Ethernet and autonegotiation) \\
\hline $802.3 \mathrm{x}$ & 1997 & Full duplex \\
\hline $802.3 \mathrm{z}$ & 1998 & 1000 Base-X (Gigabit Ethernet) \\
\hline $802.3 \mathrm{ab}$ & 1999 & 1000 Base-T (Gigabit Ethernet over twisted pair) \\
\hline $802.3 \mathrm{ac}$ & 1998 & VLAN tag (frame size extension to 1522 bytes) \\
\hline $802.3 \mathrm{ad}$ & 2000 & Parallel links (link aggregation) \\
\hline $802.3 \mathrm{ae}$ & 2002 & $10-$ Gigabit Ethernet \\
\hline $802.3 \mathrm{ah}$ & 2004 & Ethernet in the first mile \\
\hline $802.3 a s$ & 2005 & Frame expansion \\
\hline 802.3 at & 2005 & Power over Ethernet Plus \\
\hline
\end{tabular}

Inicialmente, a taxa de transmissão do Ethernet era de 2,94 Mbit/s, mas foi modificada para 10 Mbits. Essa taxa era considerada bastante rápida nos anos 80, mas nos anos 90 houve uma demanda por mais banda. Para suprir essa demanda, foram definidos padrões mais rápidos:

- Fast Ethernet (FE): Possui uma taxa de $100 \mathrm{Mbit} / \mathrm{s}$. Devido à existência de redes que podiam demandar $10 \mathrm{Mbit} / \mathrm{s}$ ou $100 \mathrm{Mbit} / \mathrm{s}$, definiu-se que os equipamentos Ethernet deveriam ser capazes de suportar tais redes, mudando automaticamente a taxa de transmissão. 
- Gigabit Ethernet (GbE): Possui uma taxa de $1 \mathrm{Gbit} / \mathrm{s}$. Sua estrutura é semelhante a de Ethernet e Fast Ethernet, mas utiliza quadros maiores, os chamados jumbo frames, para a transmissão. Ao invés de quadros de 64 a 1.518 bytes, o GbE utiliza quadros com 64 a 9.215 bytes, reduzindo consideravelmente o número de pacotes recebidos e processados pelo host final.

- 10 Gigabit Ehternet (10GbE): Opera de forma semelhante aos Ethernets de taxas menores, mantendo o tamanho dos frames e os protocolos. No entanto, só opera em links ponto-a-ponto em modo full-duplex. Além disso, utiliza apenas fibras ópticas multimodo ou monomodo.

Uma rede Ethernet pode ter dois modos de controle de tráfego: compartilhado (shared) e comutado (switched).

No modo compartilhado, utiliza-se um $H u b$ com um número especificado de portas. Cada porta estará conectada a um único servidor. Forma-se, então, um meio com acesso de apenas um servidor a cada instante. O Hub formará através de suas portas um domínio de colisão. Cada servidor, para acessar o meio, deverá escutá-lo até que um intervalo de silêncio seja verificado. O protocolo que gerencia este acesso é denominado de CSMA/CD (Carrier Sense Multiple Access/Colision Detection).

No modo comutado (switched), utiliza-se um switch. Cada porta do switch possui um domínio de colisão dedicado, isto é, cada servidor conectado a qualquer uma das portas poderá enviar e receber mensagens simultaneamente, sem necessidade de escutar e/ou negociar acesso ao meio.

Nesta configuração, utiliza-se um único domínio de broadcast frames para todas as portas. Este domínio dedica-se a formação de sua tabela de chaveamento através dos endereços das placas de redes dos servidores.

Em conexões metropolitanas e de longa distância e nas taxas de 1 Gbps e 10 Gbps, a tecnologia Ethernet utiliza quase sempre o modo comutado.

O sistema Ethernet consiste de três elementos básicos: 
- Canal Físico : O meio físico é o recurso por onde os sinais elétricos ou ópticos trafegam na rede. A Ethernet define quatro tipos básicos de meio físico: o cabo coaxial fino, cabo coaxial grosso, o par trançado e a fibra óptica.

- Regras de Controle: Um conjunto de regras embarcadas em cada interface de rede que permite, de forma compartilhada, o acesso ao meio físico pelas estações conectadas na rede.

- Quadro Ethernet (frame): O quadro ethernet é formado por campos de endereçamento, um campo de tamanho variável de dados úteis e um campo para verificação de erros de bits. As seções do quadro Ethernet são mostrados na figura 3.18 .

\section{ETHERNET FRAME FORMAT}

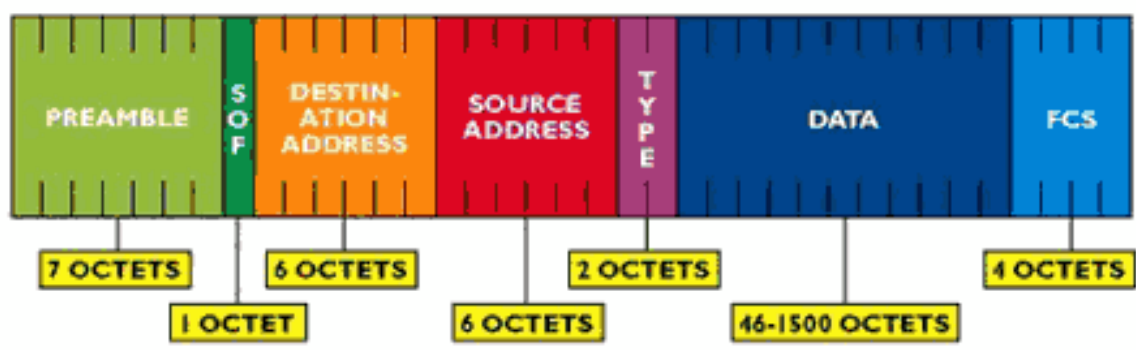

IEEE 802.3 frame format replaces the TYPE field with a LENGTH field for values up to 1500 IEEE 802 . IQ inserts 4 octets - a type code and VLAN tag

Figura 3.18 Estrutura do quadro Ethernet.

Em 1998, o IEEE aprovou o padrão 802.3ac que define o formato das extensões do frame, para suportar a marcação (tagging) de Virtual Local Area Network (VLAN) sob redes Ethernet. O protocolo de VLAN permite inserção de um identificador, ou uma "tag", no formato do frame Ethernet, para identificar a VLAN à qual o frame pertence. Isso permite a frames de estações serem alocados como grupos lógicos. Esse arranjo traz vários benefícios, como facilidade na administração da rede, permite a formação de grupos de trabalho, aumenta a segurança da rede e provê limite do domínio de broadcast. [30]

O Ethernet pode ser transmitido em vários tipos de meios e cada tipo possui uma nomeação que tem três partes: 
- 10, 100, 1000: especificam a velocidade de transmissão;

- Base: vem de baseband, que é o tipo de transmissão feita no Ethernet;

- 5, 2, T etc: especifica o meio físico;

Alguns tipos de meios de transmissão de Ethernet sã apresentados a seguir.

- 10Base5: o 10Base5 é o sistema original Ethernet suporta taxa de transmissão a $10 \mathrm{Mb} / \mathrm{s}$ sobre cabo coaxial grano $(10 \mathrm{~mm})$;

- 10Base2: suporta a taxa de transmissão de $10 \mathrm{Mbps}$ sobre fino (5 mm) cabo coaxial fino. Ele é também conhecido como "thin Ethernet", ou "cheapernet" (Ethernet barata). Foi a primeira variação física no tipo de mídia a ser adotada após o padrão original thick Ethernet.

- 10Base-T: suporta uma taxa transmissão de $10 \mathrm{Mbps}$ sobre dois pares telefônicos de par trançado de categoria 3 ou melhores, também conhecidos como par trançado graduado para voz. O largo uso dos cabos de par trançado fez do 10Base-T a versão mais popular da Ethernet. O 10Base-T usa um par de cabos para transmitir dados, e outro par para receber dados.

- 10Broad36: o 10Broad36 suporta uma taxa de transmissão da ordem de 10 Mbps sobre um sistema de cabo banda larga. O "36" do nome refere-se a expansão total de 3.600 metros suportada entre duas estações.

- 10Base-F: o padrão 10Base-F define operações sobre fibra óptica com a taxa de 10 Mbps. A identificação "10Base-F" refere-se coletivamente a três tipos de segmentos de fibra óptica: 10Base-FL, 10Base-FB e 10Base-FP. As três implementações de 10Base-F não são compatíveis com outras interfaces de fibra.

- 100Base-TX: suporta transmissão taxa da ordem de $100 \mathrm{Mbps}$ sobre dois cabos de par trançado. Ele usa um par de cabos para transmitir dados e o outro par para receber os dados. Os dois pares de cabos são embutidos dentro de um único cabo, onde freqüentemente constam mais dois pares de cabos. Se presentes, os dois pares adicionais de cabos devem permanecer sem uso, pois o 100Base-TX não foi projetado para tolerar anomalias do tipo "cross talk" que pode ocorrer quando o cabo é compartilhado com outros sinais. 
- 100Base-FX: suporta taxa transmissão a $100 \mathrm{Mbps}$ sobre dois cabos de fibra óptica. Ele aceita um tamanho máximo de segmento da ordem de 412 metros para links half-duplex, e 2.000 metros ou mais para links de full-duplex. O 100Base-FX é essencialmente a versão em fibra do padrão 100Base-TX. O cabeamento de par trançado e os conectores usados no 100Base-TX são substituídos com cabeamento em fibra óptica e conectores 100Base-FX.

- 100Base-T4: suporta taxa transmissão de 100 Mbps sobre cabeamento de quatro pares de par trançado de categoria 3 ou melhor. Ele permite que a Ethernet de 100 Mbps possa ser levada para o cabeamento barato de categoria 3 em oposto ao cabeamento de categoria 5 requerido pelo 100Base-TX

- 100Base-T2: é o único padrão Ethernet que suporta taxa de transmissão a 100 Mbps sobre cabeamento de dois pares de par trançado, categoria 3. Se o cabo tem mais do que dois pares, ele também permite que os pares adicionais possam ser usados em outros serviços como telefone digital, conexões 10Base-T, ou mais conexões 100Base-T2.

- 1000Base-LX: o "L" no 1000Base-LX é o indicativo para "long", como ele usa lasers com longo comprimento de onda para transmitir dados sobre cabos de fibra óptica. Os lasers de tamanho de onda longos especificados pelo padrão operamem comprimento de onda da ordem de 1.270 a 1.355 nanômetros. Ambos, fibras de multimodo e monomodo são suportadas. Os lasers de comprimento de ondas longos são mais caros que os lasers de comprimento de ondas curtos, mas trazem a vantagem de poderem atingir distâncias maiores.

- 1000Base-SX: O "S" no 1000Base-SX significa "short" como ele usa lasers com comprimento curto de onda para transmitir dados sobre cabo de fibra óptica. Os lasers especificados pelo padrão operam em comprimento de onda na faixa de 770 a 860 nanômetros. Somente fibra óptica multimodo é suportada. Lasers de comprimento de onda curto têm a vantagem de serem mais baratos do que os lasers de comprimento de ondas longos.

- 1000Base-CX: O "C" no 1000Base-CX é de cobre. Usa cabos especialmente protegidos, balanceados com jumper de cobre também chamados de "twinax" ou "short haul cobre ". O tamanho do segmento está limitado a somente 25 metros 
com restrições com o 1000Base-CX para conectar equipamento em pequenas áreas como cabines de cabos.

- 1000Base-T: O padrão 1000Base-T foi definido pelo grupo de trabalho IEEE 802.3ab e formalmente liberado em junho de 1999. O padrão suporta Gigabit Ethernet sobre cabeamento até 100 metros de categoria 5 cobre balanceado.

Como visto, o padrão Ethernet pode ser transmitido em vários meios. No entanto, há o padrão Ethernet óptico, que representa a combinação e a extensão de duas tecnologias existentes, Ethernet e sistemas ópticos. Esta união usa o melhor de ambos, Ethernet e sistemas ópticos e amplia suas potencialidades para criar um novo paradigma que fundamentalmente muda a maneira que os provedores de serviços e as corporações planejam, controlam e operam suas redes. É uma tecnologia que combina a onipresença, a flexibilidade e a simplicidade do Ethernet com a confiabilidade e a velocidade dos sistemas ópticos.

O Ethernet óptico, entretanto, é mais do que apenas o Ethernet mais os sistemas ópticos. Os participantes dos padrões da indústria, assim como os fabricantes, têm desenvolvido soluções de Ethernet óptico específicas que são mais do que meramente transportar Ethernet sobre sistemas ópticos. Em conseqüência, o Ethernet Óptico redefine o desempenho e a economia de ambos, o provedor de serviços e as redes corporativas em diversas maneiras.

Primeiro, o Ethernet óptico simplifica a rede, removendo as complexidades de endereçamento da rede e outros problemas de complexidade da rede, tais como os existentes com as redes baseadas em Frame Relay (FR) e em Asynchronous Transfer Mode (ATM).

Também, o Ethernet óptico remove a necessidade de múltiplas conversões de protocolos que criam grandes dores de cabeça aos operadores da rede com respeito à gerência - porque é Ethernet fim-a-fim. As múltiplas conversões de protocolos também impedem o bom desempenho da rede introduzindo latência e jitter na rede. A latência e o jitter são dois atributos importantes que descrevem o prognóstico e o atraso em uma rede e determinam quais serviços e aplicações podem ser oferecidas eficazmente.

A simplicidade da rede Ethernet óptica também se estende para o provisionamento e a reconfiguração da rede. A largura de faixa do Ethernet óptico pode ser aumentada ou diminuída sem um atendimento técnico e permite mudanças da rede sem reconfigurar cada elemento da rede. 
Além da simplicidade, a velocidade é um atributo chave do Ethernet óptico. Com o Ethernet óptico, o estrangulamento da largura de faixa é eliminado. A conectividade do Ethernet óptico permite velocidades de acesso de até 10 Gbips (gigabits-por-segundo). A largura de faixa também está disponível em fatias mais granulares. Os enlaces de acesso podem ser aumentados/ diminuídos em incrementos/ decrementos de $2 \mathrm{Mbps}$ para fornecer a largura de faixa de $2 \mathrm{Mbps}$ até $10 \mathrm{Gbps}$ ou qualquer valor intermediário.

Além disso, as topologias do Ethernet óptico permitem uma maior confiabilidade do que as redes de acesso atuais podem fornecer. Por exemplo, os seguintes tipos de soluções de Ethernet Óptica: Ethernet sobre SDH (Synchronous Digital Hierarchy), Ethernet sobre DWDM (Dense Wave Division Multiplex) e Ethernet sobre RPR (Resilient Packet Ring) fornecem a recuperação do tráfego em menos de 50 mili-segundos no evento de uma falha, tal como uma interrupção do enlace óptico. Esta disponibilidade elevada garante um tempo superior nas redes que fornecem aplicações de missão crítica.

Finalmente, a Ethernet Óptica é significativamente mais barata do que as redes atuais. As economias de custos podem ser vistas em ambos, as economias de custos operacionais e investimentos. Para o acesso, foi realizada uma pesquisa pelo Metro Ethernet Fórum, que pode ser vista na figura 3.19 .

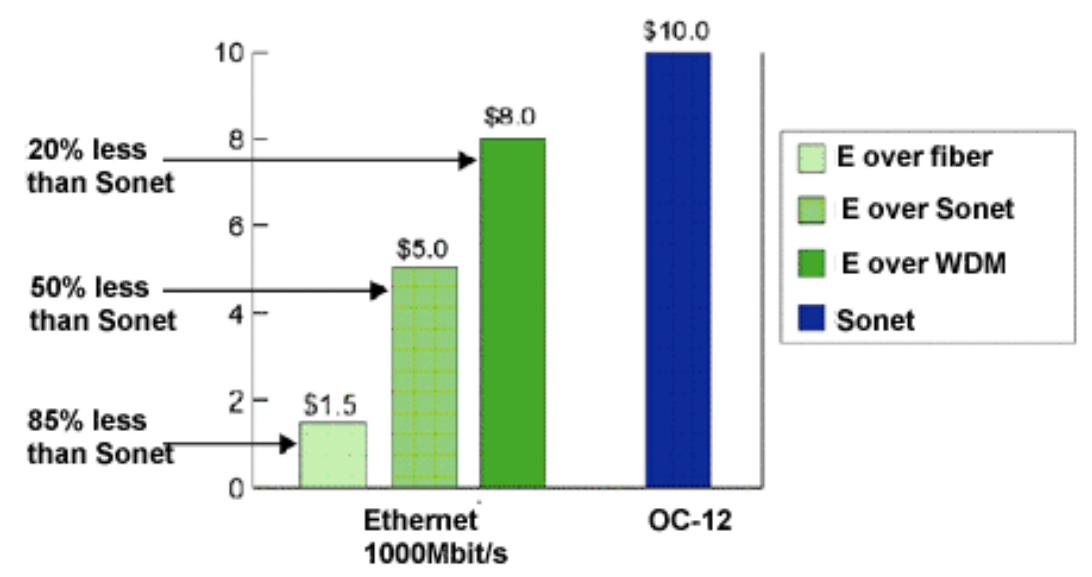

Figura 3.19 Análise econômica do Metro Ethernet Fórum para a tecnologia Ethernet no acesso.

O Ethernet óptico fornece um trajeto de transmissão transparente permitindo que os provedores de serviços aumentem seu faturamento e diminuam os custos enquanto continuam a suportar os serviços legados. 
O Ethernet óptico permite que as corporações ganhem a vantagem competitiva de suas redes reduzindo seus custos, fornecendo informação mais rápida, aumentando a produtividade dos empregados e melhorando a utilização dos recursos.

A utilização do Ethernet na rede de acesso é devido à demanda por serviços que necessitam de altas taxas de transmissão. O padrão IEEE 802.3ah, finalizado em Junho de 2004, provê uma resposta a esses requisitos. A figura 3.20 mostra o posicionamento das novas definições do Ethernet com relação aos padrões anteriores.

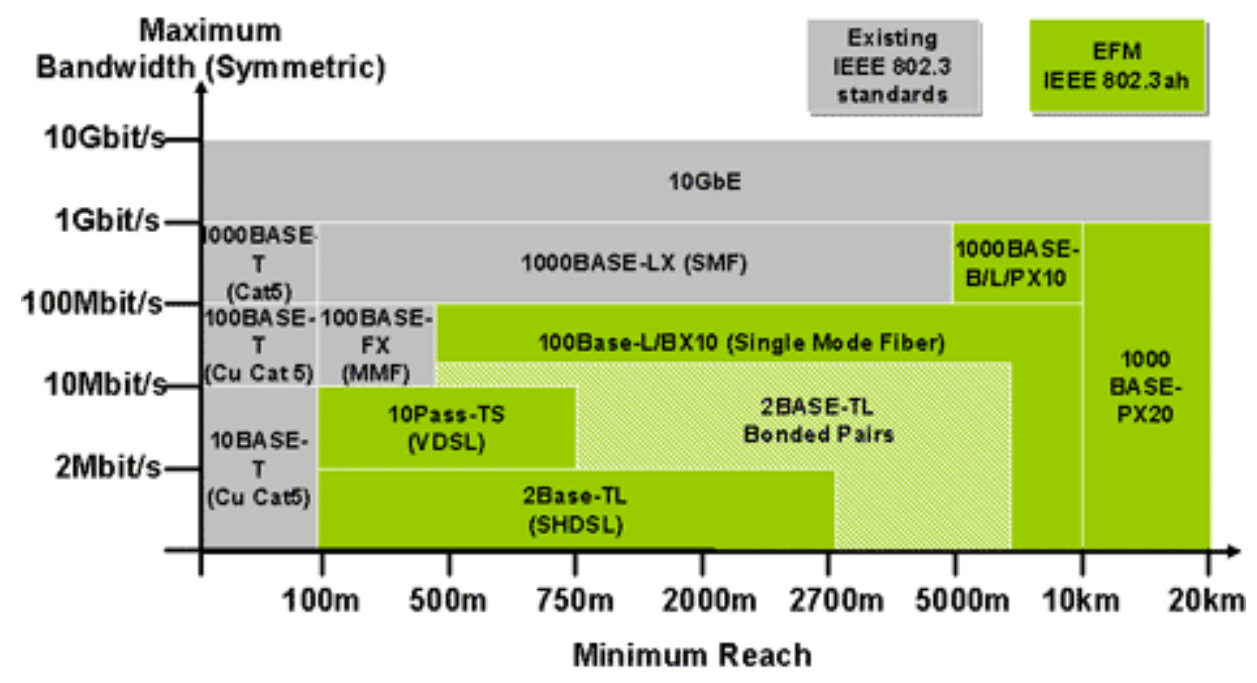

Figura 3.20 Comparação entre o padrão 802.3ah e os outros padrões 802.3.

O padrão define os meios que permitem a transmissão, alcançando de $100 \mathrm{~m}$ a $20 \mathrm{~km}$, provendo bandas de $2 \mathrm{Mbit} / \mathrm{s}$ a $1 \mathrm{Gbit} / \mathrm{s}$. O padrão 802.3ah especifica:

- Ethernet in the First Mile PON (EFMP), também conhecida como EPON: Provê transmissão simétrica ponto-multiponto de $1 \mathrm{Gbit} / \mathrm{s}$ sobre fibra monomodo, com alcance de 10 a $20 \mathrm{~km}$.

- Ethernet in the First Mile Fiber (EFMF): Provê 100 a 1000 Gbit/s em uma conexão ponto-a-ponto sobre fibra monomodo, com alcance de até $10 \mathrm{~km}$.

- Ethernet in the First Mile Copper (EFMC): Utiliza par-trançado de cobre em conexão ponto-a-ponto, para prover $10 \mathrm{Mbit} / \mathrm{s}$ numa distância de $750 \mathrm{~m}$ (com tecnologia VDSL) ou $2 \mathrm{Mbit} / \mathrm{s}$ numa distância de $2.700 \mathrm{~m}$ (com tecnologia SHDSL). 
O padrão 802.3ah também define soluções híbridas e especifica um sistema de operação e manutenção que torna o acesso Ethernet uma tecnologia de padrão de operadoras (carrier-grade). 


\section{4 - TIPOS ACESSOS COM FIBRA ÓPTICA:}

\section{1 - REDE DE ACESSO}

A rede de acesso é a parte da rede de comunicação que conecta o usuário final a um ponto de terminação na planta ligado ao nó de acesso. A rede de acesso é definida de forma a fornecer ao usuário as diferentes aplicações que ele deseja e que seja economicamente viável para a operadora de telecomunicações. $\mathrm{O}$ investimento principal das telecomunicações é feito na rede de acesso e pode até mesmo exceder $50 \%$ do capital total investido em determinada área. Os elementos da rede de acesso são mostrados na figura 4.1.

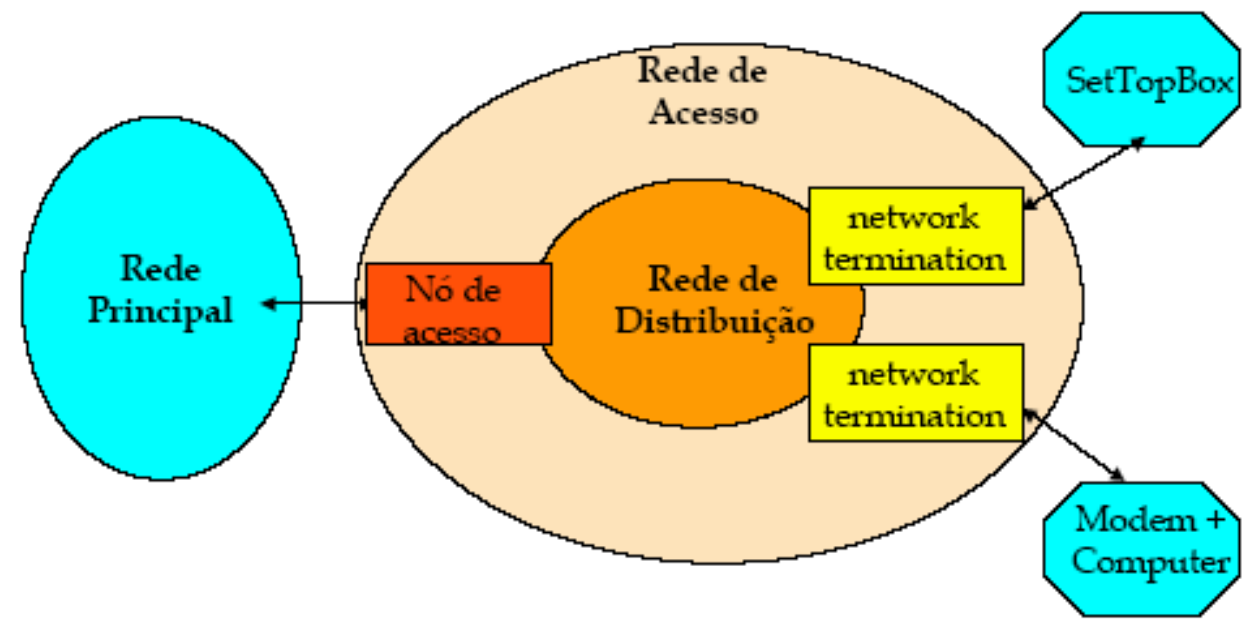

Figura 4.1 Elementos da rede de acesso.

O Nó de Acesso é o ponto de conexão à rede principal. Suas funções principais são de conversão de velocidade de transmissão e conversão de protocolo.

A rede de distribuição possui tipos diferenciados como: wireless, fibra óptica, cabo de par trançado, cabo coaxial ou até mesmo a combinação desses. Além disso, possui diferentes topologias, como em estrela e barramento.

O network termination é o ponto de demarcação entre o domínio público e o privado e pode ser passivo, apresentando somente a função de conexão, ou ativo, apresentando as funções de conversão de sinais e conversão de protocolos. 
Nunca antes na história uma rede de acesso foi tão importante a ponto de fazer com que os fornecedores procurassem novas maneiras para entregar serviços de banda larga a seus usuários finais. Serviços esses que geram novos rendimentos ajudam-lhes a reter e a atrair novos clientes além de aumentar os lucros. A fibra é vista como a melhor alternativa, em longo prazo, de acesso às tecnologias broadband, seria uma tecnologia que permite não somente que se gere novos serviços, mas também permite que os se obtenha significantes e duradouras reduções em despesas de operação além de se deslocar as despesas de tecnologias mais velhas para tecnologias que, apesar de serem mais novas, são mais baratas.

O maior fator de excitação em torno da rede de acesso por fibra é o que se chama de Triple Play, a oportunidade de oferecer de uma só vez aos clientes finais serviços de alta velocidade de dados, de voz e de vídeo. O mercado para o Triple Play é grande e crescente e inclui não só residências como também negócios em prédios comerciais. Os centros comerciais dados e os serviços de vídeo, de um único vendedor e em uma única conta, direto no seu próprio escritório. Tendo o Triple Play como principal objetivo, os fornecedores estão explorando a melhor maneira de mover a fibra cada vez mais para perto do usuário.

Todos vêem o Triple Play como um serviço forte e competitivo de se oferecer, agora e no futuro. Vislumbra-se a fibra como a maneira de levar ao usuário não só o Triple Play, mas também outros serviços novos tais como o ensino à distância, jogos interativos e telemedicina. Hoje, as redes de fibra óptica vêm em muitas variedades, dependendo do ponto de terminação: Premise (FTTP), Home (FTTH), Curb (necessitam de mais largura de banda e de muitos outros serviços avançados que somente a fibra poderá entregar quando o Triple Play oferecer a conveniência de receber a voz, os FTTC) ou Node (FTTN). Para simplificar, denominou-se a rede via fibra como FTTx, em que x está para o ponto de terminação. Existe, porém, uma enorme variedade de arquiteturas de FTTx a se considerar. Não existe, hoje em dia, uma arquitetura única que serve para qualquer aplicação. Assim, tem que se tomar uma série de decisões quanto à tecnologia baseadas em seus objetivos finais. Uma consideração preliminar é quando se empregar uma rede ativa (ponto-a-ponto) ou passiva (pontomultiponto). A figura 4.2 mostra as diferentes arquiteturas utilizadas. 


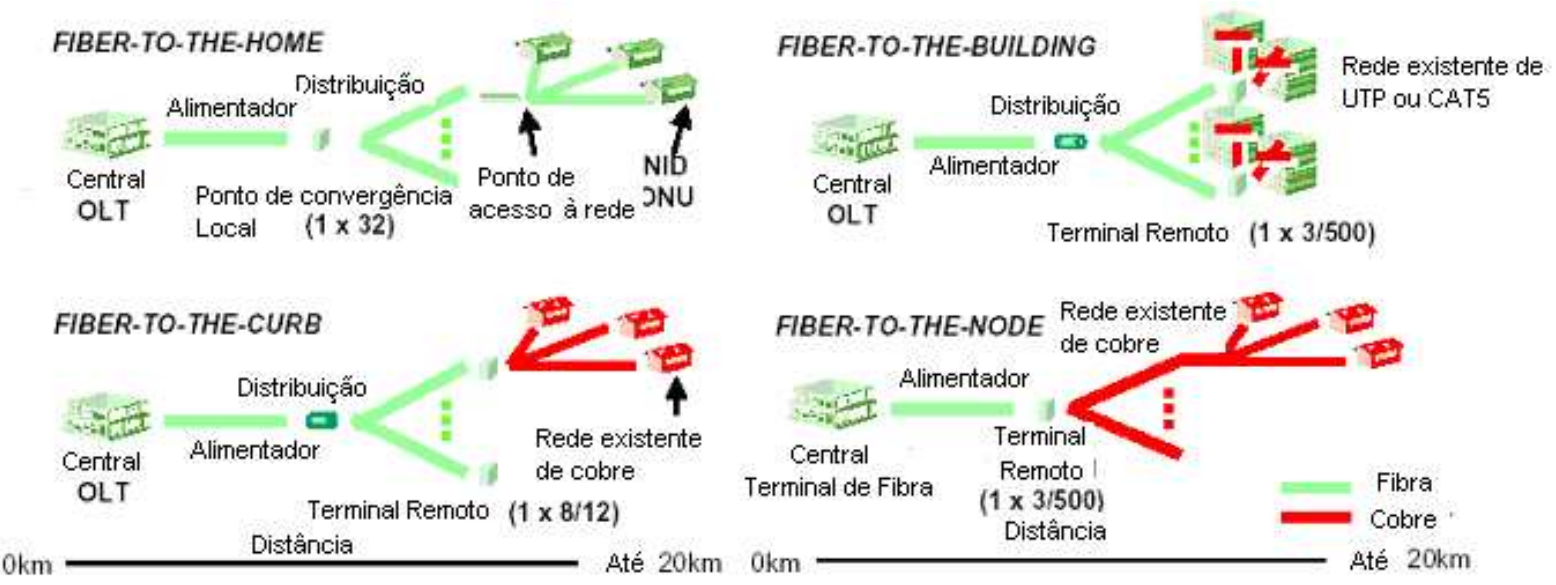

Figura 4.2 Diferentes arquiteturas do FTTX.

A penetração da fibra está fortemente correlacionada ao throughput da largura de banda de cada arquitetura definida e, conseqüentemente, à potencialidade do serviço para o operador. As exigências da largura de banda de cada usuário diferem, mas todos estão crescendo. $\mathrm{O}$ operador deve levar isso em conta quando decide qual arquitetura deve ser utilizada para cada cliente. A penetração da fibra é também um indicador de CAPEX (despesas em investimento) e de OPEX (despesas de operação esperadas). Arquiteturas com alto grau de riqueza de fibra resultarão em um CAPEX mais elevado, mas está praticamente igual ao custo com todas as novas configurações de arquitetura. A alta riqueza de fibra entregará a quantidade máxima de economias de OPEX comparável. As redes FTTH permitem que sejam feitas economias já que ocorrem reduções no custo da rede, da sede e das operações de planta externa assim como o serviço de cliente. A confiabilidade da rede aumenta dramaticamente também, com FTTH assegurando um fluxo constante do rendimento e de satisfação do cliente. [7]

\section{2 - FTTH:}

FTTH é simplesmente os $100 \%$ da distribuição da fibra óptica na rede de acesso. É geralmente desdobrado em duas configurações específicas. Na primeira, a fibra é dedicada a cada usuário na rede de acesso. Isto é chamado de rede ponto-a-ponto (PTP). Na segunda, uma fibra é compartilhada (através de um divisor de potência - splitter) entre um número especifico 
de usuários, tipicamente entre dezesseis e trinta e dois. Isto é denominado de rede óptica passiva (PON), como já mostrado anteriormente. Há vantagens e desvantagens quanto à distribuição das redes em PTP e PON baseadas em custos, na largura de banda e considerações de componentes. As redes de PTP são caracterizadas pelo uso de uma única fibra e um único laser por usuário. São as redes mais simples de FTTH para se projetar. As redes de PTP são às vezes chamadas como as redes all-optical Ethernet (AOEN). A figura 4.35 ilustra diversos exemplos de como as arquiteturas PTP puderam ser desdobradas: uma fibra dedicada tem suas terminações no usuário final e em dispositivos na sede, ou Central Office (CO), para um fornecedor, ou extremidade no caso de um operador da tevê de cabo (CATV) ou de um dispositivo remoto no campo. O dispositivo ou o interruptor remoto no campo são sempre dispositivos ativos e devem ser potencializados. Tanto fibras monomodo quanto multimodo podem ser usadas ao longo de toda a rede. As redes de PTP têm dispositivos eletrônicos ativos no campo, são inerentemente simples, são "fibras-ricas" e não requerem nenhum compartilhamento de fibra ou de largura de banda para o usuário final.

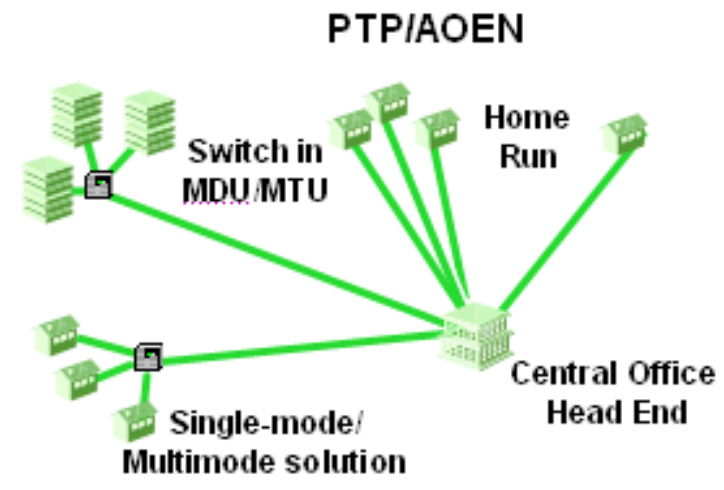

Figura 4.3 Arquitetura PTP em FTTH.

As PONs são caracterizadas pela divisão da fibra óptica uma ou mais vezes no campo, tendo por resultado o compartilhamento da fibra óptica entre usuários múltiplos. A divisão da rede é realizada por um divisor óptico (splitter), que devido a sua natureza, podem introduzir elevadas perdas inerentes na rede. Conseqüentemente, seu uso é limitado por causa das considerações orçamentárias de potência da rede. Uma rede PON terá menos "riqueza óptica" do que uma rede PTP, que não usa splitters. Tipicamente, uma rede PON é capaz de alcançar usuários que estão a 20 quilômetros do transmissor original, que cobrirá 98 por cento da 
população. Uma rede PON não usa nenhum dispositivo eletrônico no campo, é suportada por padrões maduros e é a arquitetura mais extensamente desdobrada de FTTH nos Estados Unidos. A figura 4.4 ilustra as configurações múltiplas de uma rede PON.

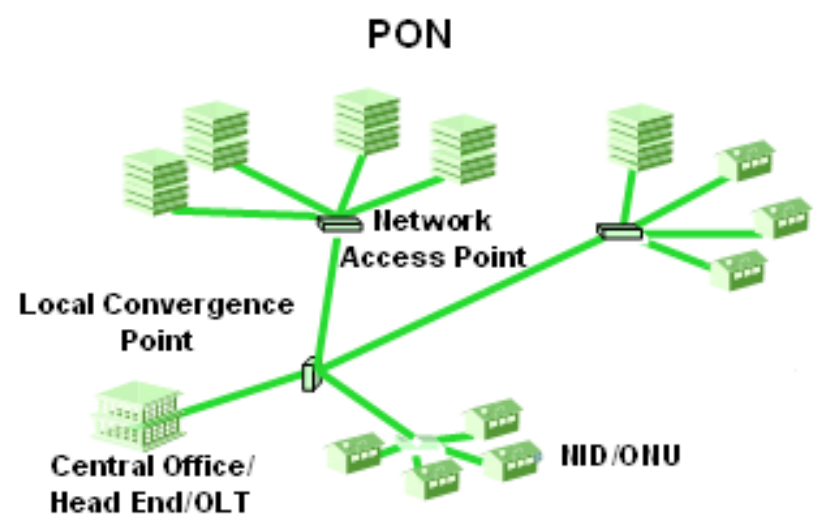

Figura 4.4 arquitetura PON em FTTH.

As operadoras que exploram uma rede PON têm escolhas adicionais de arquitetura a fazer decidindo-se entre um divisor centralizado e um arranjo de divisor distribuído ou cascateado. Ambos são utilizados com intuitos diferentes dependendo dos tradeoffs de suas características específicas.

Primeiramente, todos os splitters podem ter uma posição "central" como pode ser visto na figura 4.4. Nesse caso, os provedores procuram a máxima eficiência no CO/HE e utilizam splitter de 1x32 para maximizar a capacidade compartilhada da rede. Isto resulta em minimizar o número de transmissores usados no CO/HE e nos splitters. Nesse caso, os splitters se situam tipicamente em um armário chamado de LCP, que é o lugar onde as extremidades do cabo de alimentador e o cabo de distribuição começam (daqui cada cliente tem uma fibra dedicada). Quando um cabo da distribuição aproxima-se de um usuário, um ponto de rede (NAP) será usado para alcançar um número pequeno de fibras ópticas no cabo. Deste ponto, os cabos pendentes, contendo geralmente uma a quatro fibras, são usados para conectar ao ONT. A arquitetura com splitters centralizados fornece uma medida melhor da perda total para a PON, aumentando dessa maneira a confiabilidade da rede. Um único divisor 1x32 tem menos perda do que vários outros conectados em cascata, o que melhora o alcance óptico e reduz o número de componentes ópticos. essa forma, é diretamente proporcional ao aumento da confiabilidade da rede através da redução nos pontos da falha. Além disso, o 
splitter centralizado minimiza as despesas em investimento (CAPEX) dos divisores inicialmente na rede. Outra vantagem é a simplicidade da pesquisa na busca de defeitos na rede e da posição de falha que traduzem diretamente em economias de trabalho e tempo.

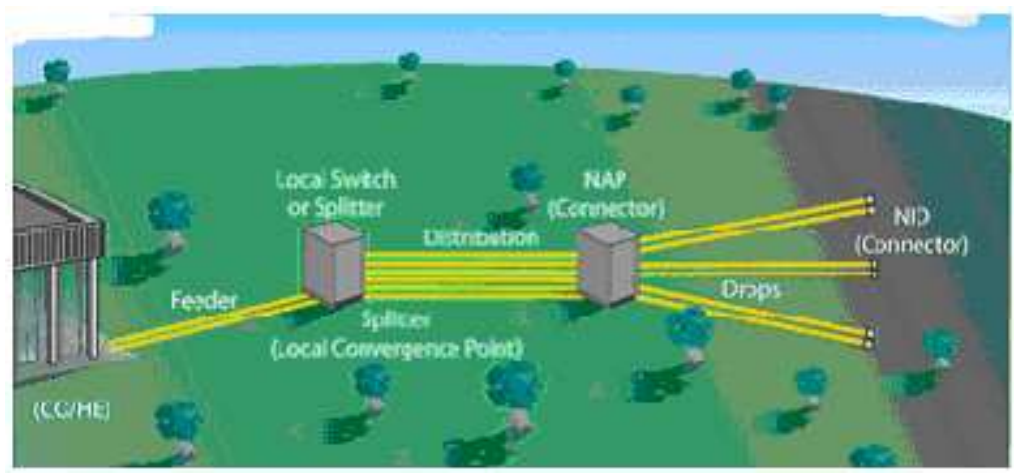

Figura 4.5 Rede PON com splitter central.

Uma configuração de splitters distribuídos ou em cascata introduz os divisores de forma mais profunda na rede, figura 4.6. Como os splitters não são centralizados, a exigência de LCPs fica reduzida ou removida, pois os divisores são incorporados geralmente em cercos modificados ou na parte traseira uniforme no $\mathrm{CO} / \mathrm{HE}$. O compartilhamento de um transmissor entre 32 usuários ainda é conseguido com a distribuição de divisores múltiplos ao longo da rede. Posicionar mais profundamente os divisores pode resultar no "stranding" de recursos enquanto o operador espera por usuários novos na rede ou taxas da tomada é baixa. busca por falhas na rede pode ser mais difícil porque o equipamento de teste deve analisar a disposição dos splitters ao longo do laço óptico. A confiabilidade da rede pode ser afetada pelo maior número de componentes ópticos.

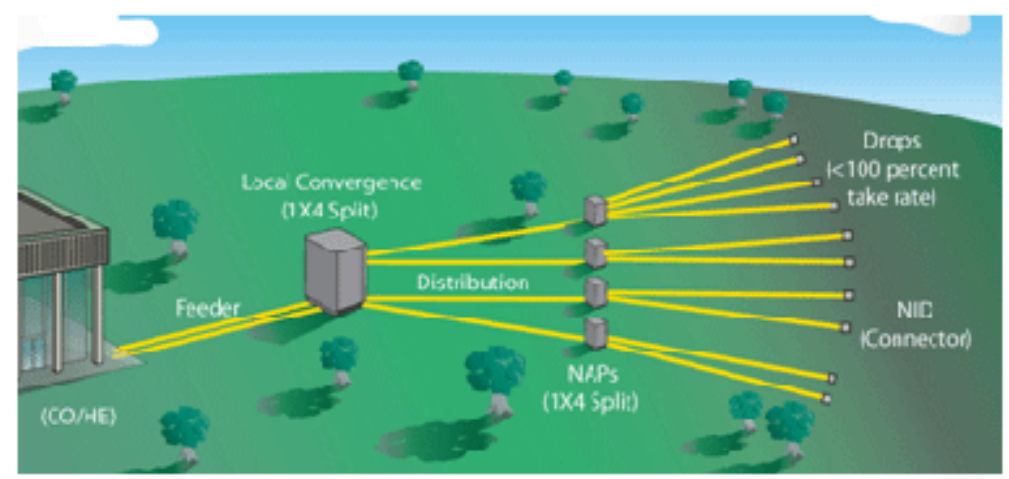

Figura 4.6 Rede PON com splitter distribuído ou cascateado. 
Os padrões de transmissão utilizados em redes FTTH são baseados no ATM e nas tecnologias da Ethernet. Os provedores são extremamente familiarizados com ambas as tecnologias, que suportam uma ampla variedade de serviços. Hoje, a maioria das redes PTP usa a tecnologia da Ethernet e são governadas pelo IEEE 803.2ah. As redes de PTP são simplesmente uma extensão Ethernet usada em espaços metropolitanos e empresariais e estendida na rede de acesso. As taxas de transmissão são limitadas somente ao tipo do transmissor no $\mathrm{CO} / \mathrm{HE}$ e na residência. Como já foi visto, as redes PON oferecem diferentes protocolos com diferentes capacidades: APON, BPON, GPON e EPON.

Então, resumindo, FTTH leva a fibra diretamente nas moradias residenciais individuais. Está completamente livre do cobre na planta exterior e fornece tipicamente um serviço que vai de $30 \mathrm{Mbps}$ até $100 \mathrm{Mbps}$, mas, por causa das características inerentes da fibra óptica, pode fornecer literalmente uma largura de banda infinita.

\section{3 - FTTB}

O FTTB usa tipicamente a arquitetura de PTP na planta exterior, fornecendo uma fibra dedicada a cada edifício ou bloco de edifícios. A fibra é finalizada em um terminal remoto (RT), que é um dispositivo ativo que requer potência e segurança no armário de utilidade. Se o edifício for equipado com cabo CAT5 a cada unidade da moradia, uma rede local do Ethernet (ELAN) está instalada para fornecer uma largura de banda compartilhada de $10 \mathrm{Mbps}$ ou de 100 Mbps. Se somente o par trançado estiver disponível, o RT é uma linha digital multiplexada do usuário final do acesso (DSLAM) e está instalado para fornecer os serviços da largura de banda exigida que oferecem até $50 \mathrm{Mbps}$; as aplicações de hoje de FTTB estão fornecendo aproximadamente $10 \mathrm{Mbps}$. 


\section{4 - FTTC e FTTN:}

As redes FTTC empurram, tipicamente, a fibra para aproximadamente 500 a 1.000 pés $(152,4 \mathrm{~m}$ a $304,8 \mathrm{~m})$ do usuário final, terminando em um RT e servindo entre oito e doze usuários.

As redes FTTN são similares as FTTC quanto a arquitetura. Mas, nas redes FTTN, o RT é posicionado bem mais distante dos usuários, acima a 5.000 pés (1.524 m). Além disso, o mesmo RT serve de três a 500 usuários. Ambos utilizam um par trançado existente fora da planta para se conectar ao cliente. A largura de banda é ditada pela tecnologia de DSL e pelo comprimento do par trançado de cobre. Tanto o DSL (VDSL) quanto o VDSL2 trabalham melhor com maiores comprimentos de par trançado e são predominantemente utilizados nas redes FTTN. No caso das redes FTTC, são mais utilizados DSL2 symmetric (ADSL2), 2+e 2++. Os sinais sobre o cobre degradam significativamente a longas distâncias, afetando diretamente a potencialidade da largura de faixa. Nas circunstâncias mais extremas (quatro a cinco quilômetros), alguns clientes não poderão ser servidos por DSL. Se as condições permitirem, em alguns casos, o portador usará ambos os pares trançados para aumentar o throughput da largura de banda. Ambas as arquiteturas tiveram recursos para o serviço de aproximadamente $20 \mathrm{Mbps}$ no laboratório. Devido a comprimentos de cobre mais curtos em uma rede FTTC, o operador melhorou o excalassilidade da perspectiva da largura de banda. As distribuições em grande escala de FTTC e de FTTN estão sendo planejadas para o futuro. 


\section{5 - ESTUDO DE CASO}

Este capítulo apresenta e discute algumas situações práticas na aplicação de uma rede de acesso de fibra óptica. $\mathrm{O}$ estudo considerado baseia-se em uma análise da situação atual de mercado e das aspirações da população. Leva-se em consideração a concorrência entre tecnologias de acesso e crescimento na demanda por serviços de banda-larga.

Pode-se verificar a penetração do acesso banda larga em diferentes países, em números de acessos por 100 habitantes na figura 5.1:

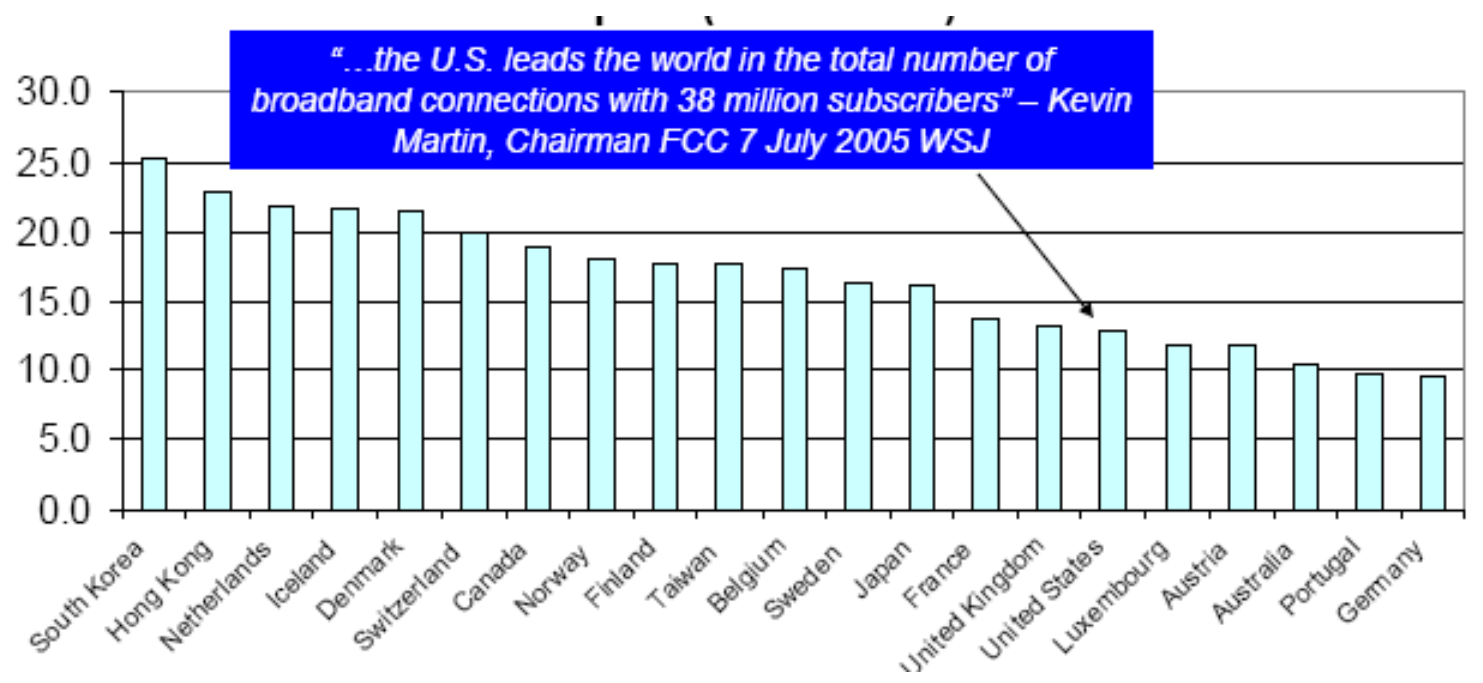

Figura 5.1 Penetração do acesso banda larga

A previsão de utilização de FTTH é bastante promissora, estando ainda em um estágio inicial do crescimento, figura 5.2:

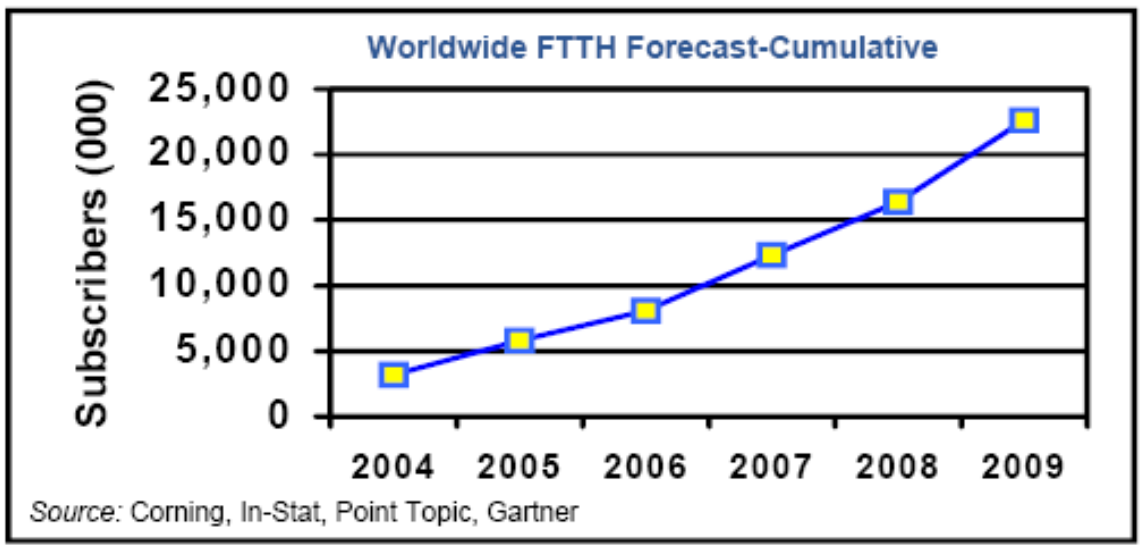

Figura 5.2: Estimativa de usuários de FTTH 
Na Europa, há alguns exemplos de implementação de FTTH:

- Suécia: Na área nordeste foi implementado na região de Västerbottena, com uma população de 260 mil habitantes;

- Finlândia: Há FTTH em aproximadamente 10 mil residências e 2000 estabelecimentos comerciais;

- Países Baixos: Possui vários projetos em Amsterdam, Rotterdam e Kenniswijk.

- França: A France Telecom implementou GPON em aproximadamente 10 mil residências.

A expectativa de implementação de FTTH na Europa é mostrada na figura 5.3:

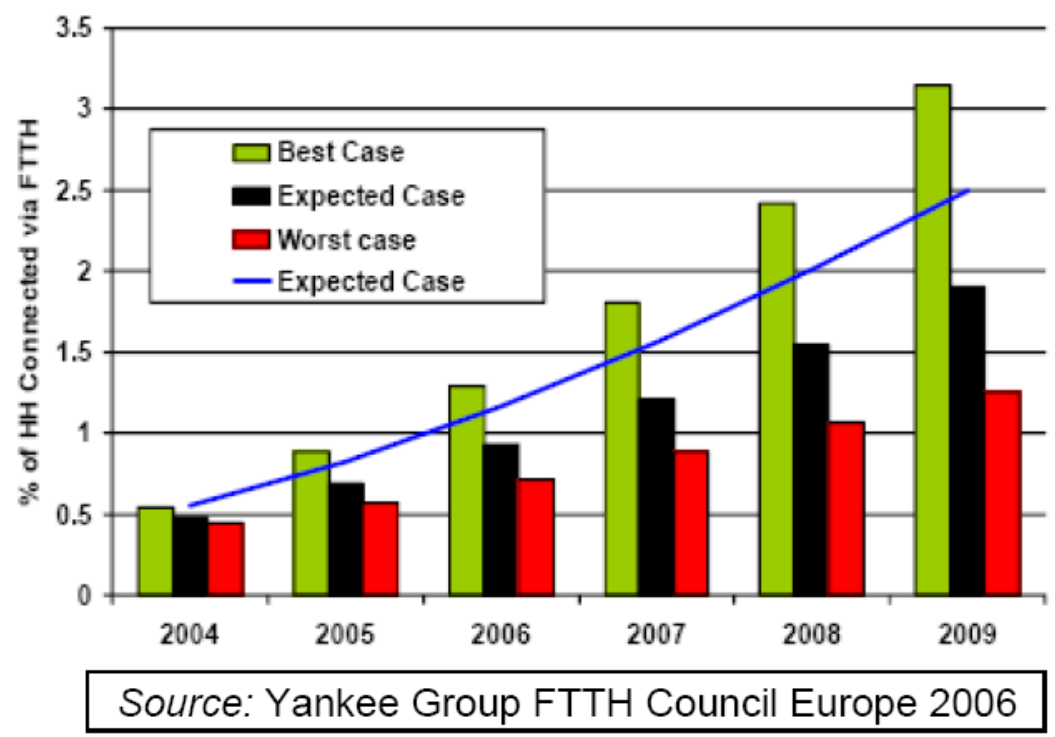

Figura 5.3: Previsão de implementação de FTTH na Europa

A situação de FTTH na Ásia é bastante avançada e o Japão é o líder mundial nesta tecnologia, tendo a quantidade de usuários FTTH ultrapassado a de usuários de modens e ADSL no ano de 2005. Espera-se que os novos usuários de FTTH continuem a uma taxa de 160 mil por mês, Figura 5.4 . 


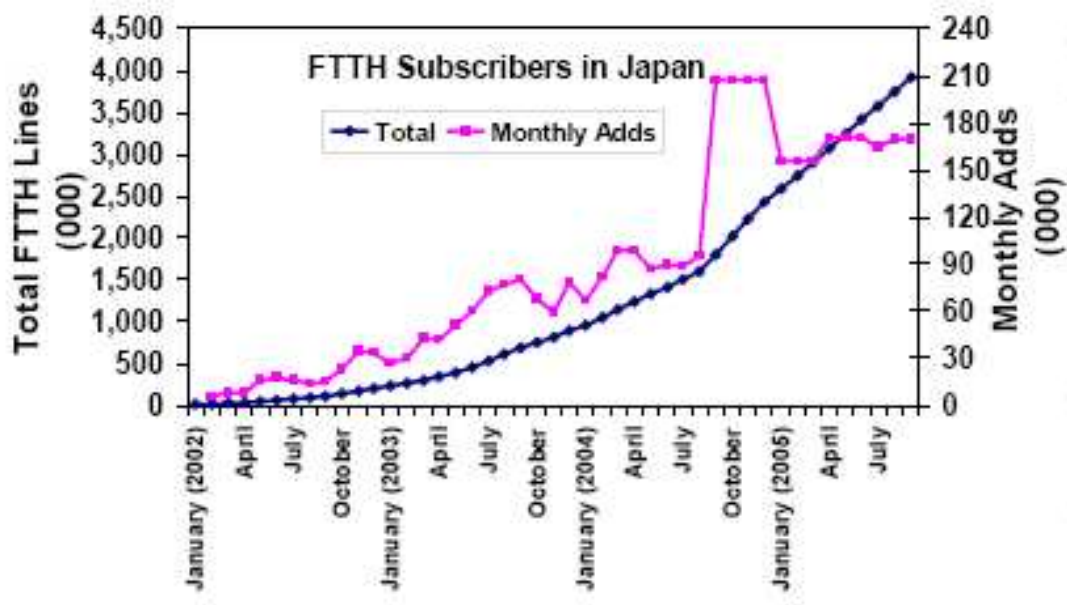

Figura 5.4 Situação de FTTH no Japão.

Além do Japão, tem-se a situação da Korea, que é um país que chegou à saturação do DSL e do cabo, tendo que promover a utilização dos serviços banda larga para utilizar sua banda disponível.

Nos Estados Unidos, o crescimento da utilização da fibra diretamente no acesso foi bastante significativo no ano de 2005, como pode ser visto na figura 5.5.

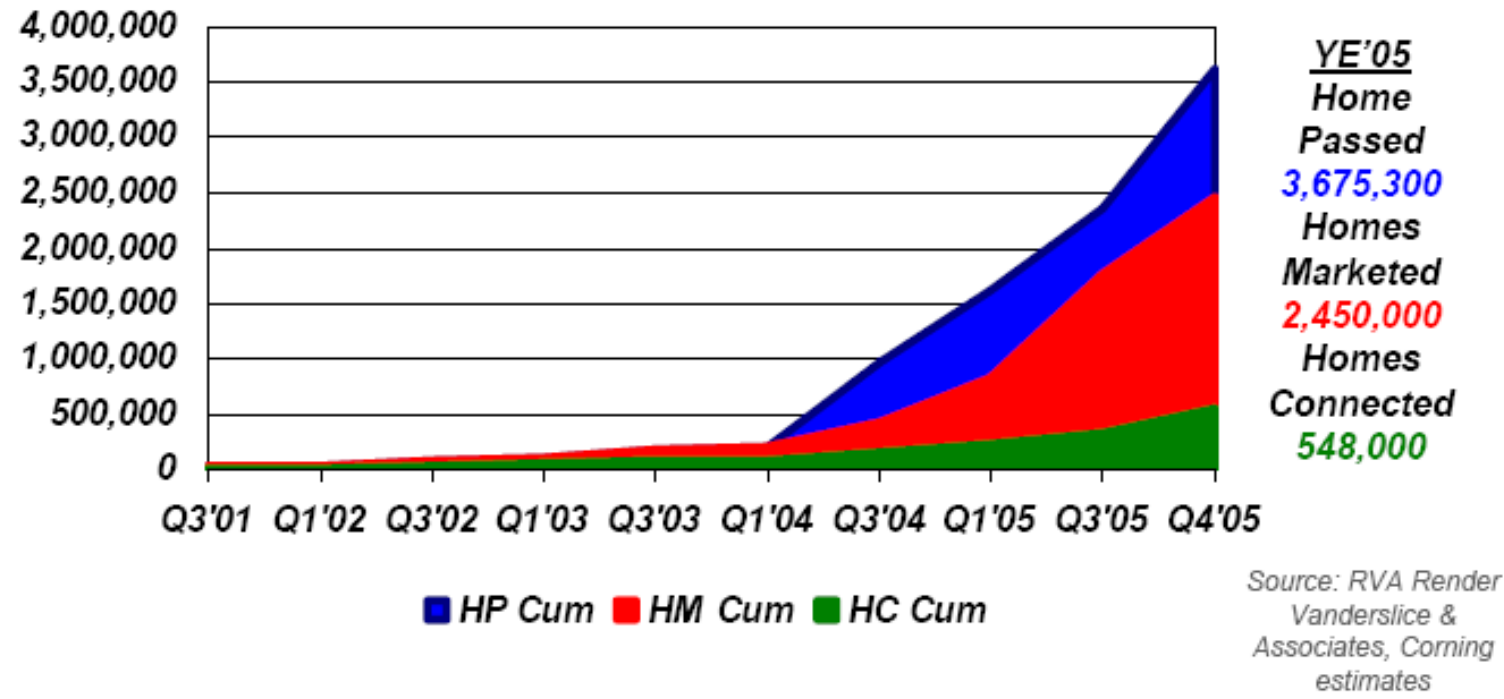

Figura 5.5 Número de usuários FTTx nos EUA.

Na América Latina, há alguns projetos em fase inicial. 
- A Telefônica pretende fazer testes de FTTH, utilizando preferencialmente a tecnologia GPON;

- Há também um projeto em Santa Catarina, financiado pelo BNDES para conectar os usuários de 48 cidades em FTTC;

- A Embratel está realizando um estudo com EPON para conectar 130 mil residências nas maiores cidades brasileiras;

- Em Monterrey, no México, a Interfibra conectou 1200 residências na primeira fase de implementação e pretende chegar a 30 mil residências em uma segunda fase.

Por esses dados, percebe-se que a tecnologia FTTH é uma realidade e está sendo testada e implementada em vários países do mundo.

\section{1 - ESTRATÉGIAS DE PLANEJAMENTO}

A elaboração de estratégias de planejamento envolve a definição de alguns itens importantes. O setor de telecomunicações é hoje extremamente dinâmico e, devido a esse dinamismo, o horizonte para planejamentos de redes de acesso não deve ser longo para que não se comprometam os dados de entrada, como previsões de demandas e serviços, preços, custos e escolha de tecnologias.

A definição dos serviços deve considerar alguns importantes fatores como a Qualidade do Serviço (QoS) exigida, a aceitação do serviço (taxa de penetração) na área em estudo e a sua receita (anual ou mensal) estimada. Essas informações variam ao longo do tempo e devem ser acompanhadas pelo processo de planejamento. No caso das projeções de demanda, por exemplo, há ainda algumas regiões com altos índices de demanda reprimida para o serviço de voz, tanto na telefonia fixa quanto na móvel; quanto às projeções de tarifa, existe uma tendência de queda destes valores em função de um ambiente de maior concorrência e maturidade tecnológica.

A área de atendimento que define uma rede de acesso é aquela delineada por uma central de comutação (CC). A rede pode ser representada por um grafo, composto por arcos e 
nós. Cada trecho da rede (arco do grafo) representa as conexões físicas entre os nós e possui como atributos, por exemplo, quantidade de pares metálicos e dutos disponíveis. Os nós de rede podem ser:

- Nó de CC: corresponde ao prédio onde está localizada a central (ou centrais) de comutação. CT no STFC, CCC no SMC ou POP (provedores de Internet/ comunicação multimídia);

- Nó de Acesso: é um ponto intermediário entre a CC e o usuário (por exemplo, armário de distribuição no STFC e ERB no SMC), onde estão localizados alguns equipamentos ativos da rede;

- Nó de Usuário: é um ponto terminal no sistema, onde se localiza (ou se encontra) o assinante.

Para simplificar o planejamento, pode-se considerar o nó de acesso como ponto de concentração de demanda, ou seja, em cada nó de acesso deve ser conhecida a demanda de todos os serviços considerados, para cada período do planejamento.

A escolha das soluções tecnológicas de acesso só é possível após a definição da variedade de serviços a ser oferecida e do tipo de rede a ser dimensionada. Eleger soluções tecnológicas implica, entre outras coisas, em saber quais são os dispositivos de rede (equipamentos, cabos, infra-estrutura etc.) a serem considerados para efeito de planejamento e como eles são dimensionados nos nós da rede (nós de controle, de acesso e de usuário); é preciso, também, estimar o custo de cada dispositivo considerado, para todos os períodos de planejamento. A atualização dos dados é um fator importante para o estudo de casos em planejamento de redes. Os dados necessários para realização de um estudo de caso são divididos em duas classes: os dados gerais de planejamento, que não possuem relação com a rede a ser estudada, e os dados de rede propriamente ditos. Os dados gerais de planejamento mais relevantes são:

- Dados de custo e dimensionamento dos equipamentos;

- Dados de custo (por unidade de comprimento) dos cabos, tanto metálicos como de fibras ópticas; 
- Dados de infra-estrutura como canalização de dutos (por unidade de comprimento) e sub-dutos e ampliação no centro de fios (obras civis).

Os principais dados de rede a serem levantados pelo planejador são:

- Rede de dutos da área considerada, informando a quantidade de dutos disponíveis em cada arco. A rede de dutos é formada pelos arcos (canalização subterrânea) e os nós de controle

- Quantidade de pares metálicos disponíveis em cada arco;

- Quantidade de fibras disponíveis em cada arco;

- Demanda concentrada em cada nó de acesso, para cada serviço considerado e para cada período de planejamento;

- Localização da CC e dos nós de acesso.

No panorama atual, onde as empresas enfrentam grandes concorrências, é esperado que os objetivos frisados pelos planejadores sejam conflitantes. Por isso, é de extrema importância que o planejamento da rede seja realizado de forma otimizada, utilizando-se modelos matemáticos. Os critérios de otimização mais significativos e prováveis de serem adotados pela empresas operadoras são: maximizar a receita respeitando um limite orçamentário, maximizar a receita a um custo mínimo, maximizar o lucro, atender toda a demanda prevista a um custo mínimo etc.

Um estudo de caso pode ser composto por vários cenários. Um cenário pode planejar a expansão de determinada área de atendimento, já em funcionamento, ou pode planejar a implantação de uma área totalmente nova, chamada situação "green field". Além disso, o cenário pode utilizar uma ou mais soluções tecnológicas, que irão concorrer entre si para a implantação e expansão da rede de acesso. A diversidade de simulações ajuda os planejadores a visualizarem melhor a situação da rede. 


\section{2 - PRIMEIRO CASO: FTTH COMMUNICATION}

O seguinte exemplo foi todo idealizado pela FTTH Communications, que é um fornecedor integrado de voz, de vídeo e de serviços de Internet em Minneapolis. Provendo serviços aos clientes residenciais e comerciais (de negócio) em uma rede toda constituída de fibra, a planta de negócio da FTTH Communications se baseia em uma combinação de baixos custos, de serviços de altíssima qualidade, e de tecnologia de ponta para aumentar o número de usuários finais e a satisfação total dos mesmos.

Os gerentes da organização tinham visto, de outros projetos de FTTH em torno do país, que variar as taxas previamente estabelecidas podem impactar no lucro e drenar o capital de usos mais produtivos, tais como a criação de serviços avançados. O desafio era criar uma infra-estrutura que mantivesse o investimento tão perto quanto possível da receita e, ao mesmo tempo, oferecer custos de operação reduzidos, de modo que o investimento em novos serviços fosse possível.

\subsection{1 - Solução}

A FTTH Communications achou que a melhor arquitetura para prover o serviço era uma rede óptica passiva (PON) com os splitters passivos centralizados nos hubs de distribuição da fibra (FDH - Fiber Distribution Hubs). Os splitters eram 1x32 especificados para espelhar a capacidade portuária nos OLTs. Com nenhum splitter nos terminais de acesso (AT) mais perto das casas, a FTTH Communication pode maximizar o uso das portas em cartões caros de OLT.

Para ilustrar, a companhia usa cartões OLT de quatro portas no centro de dados. Cada porta suporta 32 casas, cada cartão de OLT suporta, então, um total de 128 casas. Cada vizinhança é suportada por seu próprio FDH, até 1.152 casas. Os primeiros 32 usuários da vizinhança são conectados ao mesmo splitter 1x32 no FDH. Este splitter é suportado pelo cartão número 1 de OLT no centro de dados. Quando o $33^{\circ}$ usuário é adicionado, o splitter seguinte no FDH é posto em uso, que utiliza então a porta de número dois no cartão de OLT número 1 . Somente quando o $129^{\circ}$ usuário assina o serviço aparece uma exigência de comprar e transferir o serviço para o cartão número 2 de OLT no centro de dados. 
Esta arquitetura de splitters centralizados adia eficazmente a despesa para mais perto da geração de rendimento. A arquitetura alternativa, splitters tanto nos FDHs quanto nos ATs, é uma proposta relativamente cara. Na proposta anterior, 128 usuários finais de 1.152 casas podem ser servidos com um único cartão OLT quando os splitters são centralizados no FDH. Contudo com os splitters estão tanto nos FDHs quanto nos ATs, serão necessários cartões adicionais de OLT no centro de dados, o que resultará em usuários sendo espalhados através de mais cartões OLT do que seja necessário para a contagem do cliente. De fato, com qualquer taxa abaixo de 100\%, quando os splitters são colocados em FDHs e em Ats, haveria sempre portas inutilizadas e encalhadas em cartões, caros, de OLT.

O FDH oferece também o benefício adicional de custos mais baixos caso seja necessário fazer um up-grade nos serviços, isso porque são utilizados conectores, não talas, para adicionar usuários e serviços. Caso o negócio cresça, a FTTH Communications fará economias operacionais porque o up-grade do serviço pode ser feito mais rapidamente e com os técnicos menos-hábeis e mais baratos.

Analisando o FDH utilizado, observa-se a possibilidade de utilizar mais sete splitters 1x32. O cabo de distribuição está finalizado com segurança em uma espécie de estacionamento até que um usuário esteja ativado, figura 5.6. Neste FDH novo, um usuário é ativado, mostrado pelo ponto vago no "estacionamento" e no cabo de distribuição etiquetado.

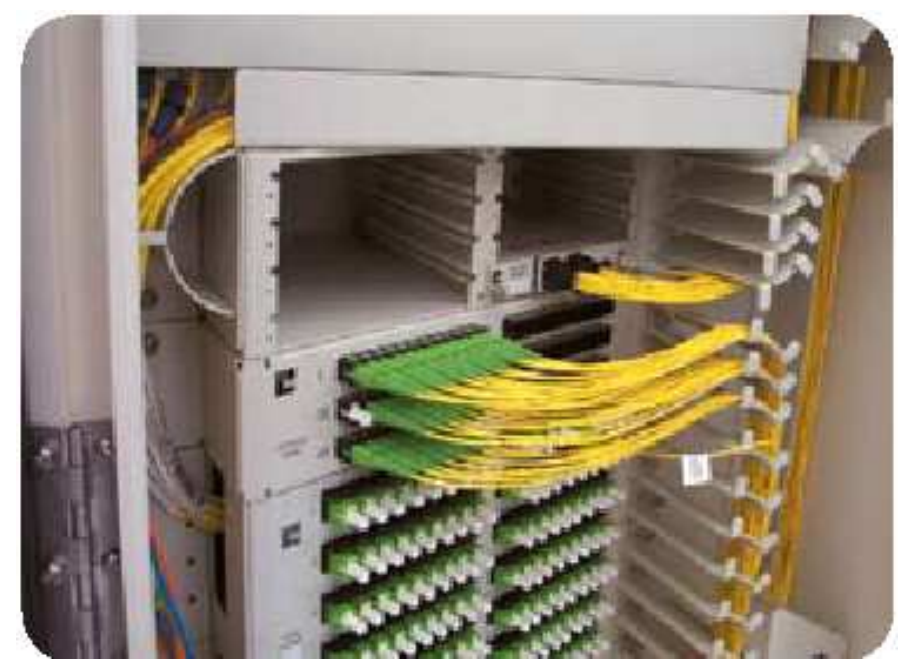

Figura 5.6 Detalhe no FDH. 
Então, o principal benefício da solução encontrada pela ADC é a possibilidade de espelhamento da capacidade das portas de OLT com os splitters 1x32 centralizados, a alta densidade e FDHs fáceis de manejar. Esta arquitetura centralizada do splitter 1x32, permitida pelo projeto do $\mathrm{FDH}$, atrasa investimentos importantes na planta externa e reserva mais investimento em serviços principais de borda para os usuários.

\subsection{2 - Implementação}

John Schultz, gerente geral da FTTH Communications disse que havia um problema com o tipo de arquitetura na qual o splitter ficava de forma distribuída nos ATs. Muito dinheiro é gasto enterrando e há uma enorme subutilização de equipamentos eletrônicos nos pontos finais. Como configurações iniciais, a FTTH Communications tinha colocado splitters nos ATs e nos FDHs e o serviço de up-grade com talas, uma estratégia de distribuição que provou ter uma cara implementação. "A aquisição por parte do cliente nunca é lógica. Colocar splitters no ATs era um desperdício de dinheiro e ainda encarecia um eventual processo de upgrade" disse Schultz.

Dessas lições anteriores, FTTH Communications chegou à conclusão que splitters centralizados nos FDHs eram melhores tanto no sentido operacional como no custo de implementação. Contudo, quando diversos vendedores ofereceram um $\mathrm{Hub}$ centralizado para a distribuição da fibra com os splitters 1x32, as características originais do FDH balançaram a decisão de compra do ADC.

"Se você construir a planta externa corretamente, você pode realmente abaixar os custos. Isso está nos permitindo a gastar o dinheiro com novas tecnologias para os usuários”.

De fato, a FTTH Communications está no processo de substituir um cabinet mais velho que foi configurado com os splitters que não possuem nenhuma gerência para o cabo de fibra. "Nós quisemos eliminar os pontos de falha na rede. Abrigando os splitters, o cabo de distribuição e o cabo de alimentação em um cabinet sem gerência de fibra era realmente um péssimo projeto. Nós sabemos que a gerência apropriada da fibra significa menos problemas para serem tratados" disse Schultz.

Com este projeto do cabinet, o serviço de up-grade requer agora conectores de acoplamento, o que se torna melhor do que se fazer emendas. $\mathrm{O}$ uso dos conectores no FDH 
dá a FTTH Communications uma rede que pode ser construída à medida que precisa crescer. Essa é uma solução que permite a adição fácil de usuários e a instalação da eletrônica de headend paralelamente ao crescimento.

"É realmente ruim investir muito dinheiro logo no começo sem saber se haverá rendimento para cobri-lo. Este é a arquitetura certa e o produto certo para suportá-la. Financeiramente falando, dentro de um ponto de vista operacional e de projeto, nós temos a melhor solução disponível" disse Schultz.

Schultz achava que o projeto prático e lógico do FDH mostraria retornos, dentro de alguns anos, em termos de velocidade no serviço de up-grade, custos reduzidos para o serviço de up-grade e uma confiabilidade mais elevada na rede PON. Contudo o valor do FDH tornou-se aparente antes mesmo que o primeiro usuário fosse inserido no serviço.

"Nossa distribuição inicial era uma instalação muito simples" disse Schultz. "Emendar era um tipo de exploração pessoal, assim como eram o roteamento e o armazenamento da fibra. Esta foi uma das razões pela qual optamos pela ADC - eles são líderes na gerência de cabo de fibra" disse. Até mesmo a documentação que faltou do primeiro FDH enviado a FTTH Communications não causou nenhum problema, que necessitasse de edição, com a instalação. "Os caras realmente entenderam. Este era um produto totalmente novo para eles contudo, a instalação inteira ocorreu sem qualquer tipo de problema" disse Schultz.

\subsection{3 - Conclusão}

A FTTH Communications encontrou na ADC um sócio com o mesmo objetivo: abaixar os custos empurrando as despesas em investimento para o mais distante possível. Estes eram os objetivos de projeto do FDH. Contudo, o principal benefício obtido, de acordo com Schultz, foi conseguir que os usuários ficassem satisfeitos. "Se você constrói a planta externa de maneira correta, você pode realmente abaixar os custos. Isto está permitindo que nós gastemos o capital com novas tecnologias para os usuários, tais como o VDO (vídeo on demand) e a TV interativa. Nós gastamos menos com planta externa e, assim, nós podemos gastar mais em serviços" disse Schultz. 


\section{3 - SEGUNDO CASO: KUTZTOWN - FTTH}

Os Borough of Kutztown, Pensilvânia, é uma comunidade avançada - casa de mais de 5.000 residentes e posicionada estrategicamente entre Allentown e Reading. A comunidade de Kutztown é também uma cidade universitária, com a universidade de Kutztown - uma das principais escolas de negócio do nordeste - nas proximidades.

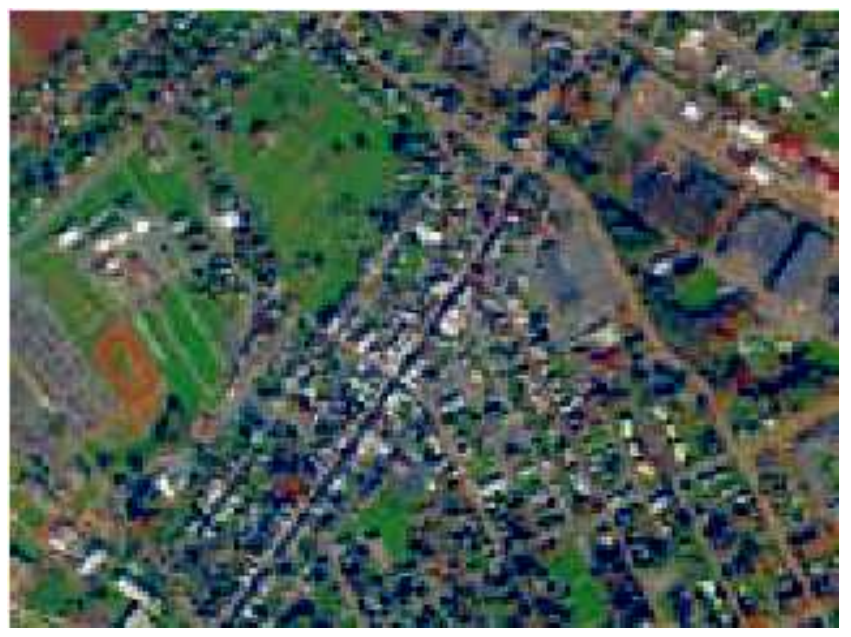

Figura 5.7 Kutztown

Quando os Borough of Kutztown e as autoridades municipais de Kutztown olharam para o futuro, eles perceberam a necessidade expandir os serviços públicos atuais para fornecer serviços mais avançados de voz, de vídeo e de dados aos cidadãos que moravam ou tinham negócios dentro de sua comunidade. Estes serviços incluem serviços de voz e conectividade à tradicional Internet de 10-100 Mbps, com um objetivo de fornecer também os serviços mais avançados que existem em termos de vídeo e de música (incluindo vídeo-ondemand e a televisão interativa) e a rede virtual confidencial (VPN). Os serviços novos tais como uma Intranet de banda larga para a comunidade, a leitura automatizada de medidor e outros serviços de gerência de energia estão sendo executados atualmente. 


\subsection{1 - Objetivos}

Os Borough ficaram tão convencidos do valor que estes serviços poderiam fornecer a seus cidadãos que criaram um programa chamado Hometown Utilicom que tinha os seguintes objetivos:

- Construir uma loja que funcionasse durante as $24 \mathrm{~h}$ do dia, assim como consolidar o faturamento e a manutenção para todos os serviços municipais e de telecomunicações;

- Oferecer serviços de valor agregado próximos ao cliente, incluindo um menu completo de serviços e de opções diversas de faturamento e de pagamento;

- Permitir a oferta de serviços avançados, tais como serviços de Internet wireless, monitoração de dispositivos, serviços de segurança tanto para a casa quanto para os negócios e avançadas formas de modelamento e armazenamento de dados.

\subsection{2 - Fibra - A Melhor Escolha}

Os Borough of Kutztown decidiram que uma rede de acesso via fibra direto na casa, FTTH, era a melhor solução de infra-estrutura para atender as necessidades de seus cidadãos agora e no futuro. De frente com tecnologias alternativas que poderiam tirar vantagem da tradicional infra-estrutura de cobre, os Borough sentiram que as soluções baseadas na tecnologia do cobre não eram a melhor solução para as demandas de serviços de hoje, e que uma solução baseada em cobre restringiria um up-grade futuro da rede para os cidadãos de Kutztown. Além disso, as soluções baseadas em cobre limitariam também a habilidade dos Borough de entregar os serviços avançados à comunidade, que aumentariam finalmente o valor de propriedade e diferenciariam os Borough of Kutztown das comunidades vizinhas.

Além disso, Kutztown descobriu que uma solução de FTTH complementaria o seu sistema elétrico municipal já existente, permitindo que eles fizessem uso do seu útil serviço público de pólo, dos serviços de atribuição e de equipamentos de construção, assim como sua competente equipe técnica de funcionários de campo para a construção, do serviço e a 
manutenção, de sua equipe de funcionários de escritório a serviço do cliente e dos serviços de marketing e de faturamento. Com estes serviços, o Hometown Utilicom podia transformar-se um enorme sucesso.

\subsection{3 - Solução}

Após terem conduzido uma avançada pesquisa de negócio tecnológica e uma análise de caso completa, os Borough of Kutztown e a autoridade municipal de Kutztown procuraram uma firma para fornecer um retorno contendo a solução, de FTTH, com o melhor custobenefício. Tirando vantagem das suas experiências e da sua perícia industrial na área de telecomunicações, o grupo Atlantic Engenharia podia oferecer aos Borough a solução pontoa-ponto que eles procuravam - combinando os equipamentos eletrônicos de FTTH da Optical Solutions com toda a infra-estrutura de planta externa da Corning Cable Systems.

Trabalhando junto com a Atlantic engenharia, a Corning Cable Systems forneceu aos Borough of Kutztown uma solução de infra-estrutura passiva completa para sua distribuição de FTTH, incluindo o cabo óptico, os fechamentos da tala e os acopladores e os splitters.

"Parte de nossa estratégia em construir uma rede FTTH reside em se construir um recurso físico chave que seja uma fonte de geração contínua de rendimento" diz Caruso frank, diretor de tecnologia de informação, para os Borough of Kutztown. "Esta aproximação nos permitirá manter os rendimentos de telecomunicações dentro dos Borough, também poderemos controlar as taxas que nossos cidadãos têm que pagar. Além disso, nós acreditamos que a construção de uma rede com um melhor custo benefício, mas de elevado grau de confiança, melhorará a avaliação e a habilidade de crédito dos Borough para solicitar maiores quantidades de dinheiro para projetos futuros".

\subsection{4 - Conclusão}

Com programação agressiva de distribuição do FTTH de Kutztown, os benefícios de se trabalhar com a Corning Cable Systems e com o grupo Atlantic Engenharia em uma solução 
de FTTH tornaram-se evidentes. O próximo relacionamento de trabalho entre as duas companhias assegurou que a rede de FTTH estivesse projetada para um desempenho livre de problemas e de altíssima confiabilidade, dessa forma, não haveria a necessidade de possíveis modificações na integração ou na qualidade de campo o que poderia resultar em uma distribuição atrasada ou em perda de desempenho.

"Trabalhando com uma indústria que é líder de mercado na infra-estrutura óptica passiva, assim com a Corning Cable Systems, nós sabíamos que estávamos abastecendo a cidade de Kutztown com uma solução de altíssima confiança - sustentada por mais de 150 anos de qualidade e reputação da marca Corning" disse James Salter, principal executivo oficial do grupo Atlantic Engenharia.

Juntas, a Corning Cable Systems e a Atlantic Engenharia estão fazendo do sonho da cidade de Kutztown uma realidade, fornecendo a seus cidadãos uma rede com um alto custo benefício que suprirá as suas necessidades de agora e do futuro e que permitirá que os mesmos se beneficiem dos serviços de melhoria de qualidade vida enquanto emergem. 


\section{6 - CONCLUSÕES}

No início, as redes de acesso banda larga eram baseadas em DSLAMs ATM, principalmente devido à ampla implantação de redes de agregação ATM e à visão que havia, durante os anos 90, sobre o importante papel que cumpriria a tecnologia ATM nas redes do futuro. Hoje em dia, o ATM é uma tecnologia madura, robusta e estável que fornece variadas ferramentas para a gerência de tráfego e controle da qualidade de serviço, mas, devido a seu elevado custo, complexidade e rigidez para transportar serviços de dados, têm motivado a busca por uma tecnologia alternativa. Como resultado desta busca, tem-se o processo atual de adoção da Ethernet como tecnologia de fato para os equipamentos de agregação das linhas DSL e, inclusive, para as redes de transporte metropolitano (Carrier Ethernet). Entra-se, então, em um segundo estágio em que, as redes de acesso de banda larga deixaram de crescer com DSLAMs ATM e têm continuado sua expansão com a tecnologia Ethernet (ou IP-DSLAMs).

A Ethernet apresenta algumas vantagens importantes como preço baixo, simplicidade e a alta capacidade, mas, a principal delas, é a naturalidade com que as aplicações de dados (IP) podem ser transportadas, o que faz dela uma excelente opção para as redes de acesso e de transporte.

Há apenas alguns anos, o serviço de Internet de alta velocidade era visto como um serviço de valor agregado e representava um fator diferenciador para as operadoras. Hoje, oferecer somente o acesso de Internet de alta velocidade não é suficiente para competir com operadoras de TV a cabo, as quais estão oferecendo ao cliente final "pacotes" de serviço (voz, Internet e TV) a preços muito competitivos. O "Triple-Play" transformou-se no objetivo de curto prazo das operadoras tradicionais de telecomunicações, que precisam atualizar suas redes (de acesso, transporte e core) para suportar as larguras de banda requeridas pelas novas aplicações. A fim de oferecer um pacote atrativo de serviços "Triple-Play" (Internet, IPTV e voz - seja VoIP ou TDM), é requerida uma largura de banda de pelo menos 8 a $10 \mathrm{Mbps}$. Cada canal de IPTV consome hoje entre 4 e 6 Mbps com codificação MPEG-2 e entre 2,5 e 3,5 Mbps com MPEG 4. Para competir com o serviço oferecido pelas operadoras de CATV, devese poder oferecer a cada usuário pelo menos 2 ou 3 canais de IPTV simultâneos. Se considerar-se, além disso, acesso a Internet (HSI) a 2 Mbps, será necessária uma largura de 
banda de downstream de aproximadamente 8 a 10 Mbps por usuário no acesso (2 canais IPTV MPEG-4 + Internet + voz).

A tecnologia ADSL2+ pode suportar larguras de banda maiores do que o ADSL tradicional, mas esta capacidade depende fortemente de fatores tais como a distância que se encontra o usuário final, a qualidade do par do cobre, a quantidade das linhas ADSL dentro de um cabo multipar (crosstalk) etc. Estimativas feitas por diversas operadoras na Europa e América Latina falam de velocidades de $10 \mathrm{Mbps}$ a distâncias de até 2 quilômetros atingíveis com o ADSL2+. Isto implica que para implantações massivas de IPTV, é necessária uma tecnologia alternativa que suporte estes níveis de largura de banda a distâncias maiores que 2 quilômetros.

A evolução do mercado e das aplicações indica que, no futuro, a tendência será chegar com fibra até a casa de cada usuário (FTTH), permitindo assim suportar aplicações que irão requer grandes larguras de banda como, por exemplo, televisão de alta resolução (HDTV, 8-12 Mbps por canal). Os sistemas de PON já foram disponibilizados, por diversos fabricantes. Esses oferecem, a um bom custo-benefício, uma escala variada de serviços de vídeo, de voz e de dados. Funcionam e são confiáveis. As redes ponto-multiponto já se tornaram uma tecnologia madura, enquanto as redes PONs são apenas uma aplicação mais nova desta tecnologia. O vídeo pode ser carregado da mesma forma que em sistemas de HFC, como transmissão analógica e como sinais digitais modulados. Pode, também, ser carregado como pacotes de IP (IPTV). O serviço de voz pode ser TDM ou baseado em padrões de VoIP. Os dados podem ser armazenados com muita eficiência e a habilidade de oferecer centenas de Megabits/segundo de velocidades de throughput permitirá que mais aplicações sejam desenvolvidas. É importante lembrar que uma vez que a fibra está enterrada e os serviços em andamento, outros serviços podem ser adicionados relativamente sem custo. O cobre é a tecnologia de hoje, fibra será pelos 50 anos seguintes.

Falando de Brasil, tem-se um cenário que sofreu diversas modificações desde a privatização do setor de telecomunicações. A concorrência entre as empresas operadoras do sistema é o ponto alto desse processo, que pode beneficiar os usuários, tanto aqueles que já assinavam algum serviço quanto os novos compradores de serviços de telecomunicações. A ANATEL tem um papel importante nesta nova condição de prestação privada de serviços de telecomunicações. Como o objetivo das operadoras do sistema é obter lucro, a qualidade do 
serviço prestado nem sempre é o esperado. É o que vem acontecendo no Brasil: a gama de serviços modernos de telecomunicações aumentou, mas a qualidade e o custo dos serviços oferecidos ainda deixam a desejar. Por isso, a agência reguladora deve estar em constante alerta para fiscalizar e garantir os direitos dos assinantes.

O crescimento intenso e incessante das demandas e a necessidade de tomar decisões importantes em espaços curtos de tempo exigem agilidade por parte das operadoras. Visando aumentar a receita e a participação no mercado, as operadoras vêm apostando em novas tecnologias, capazes de oferecer serviços inovadores e competitivos, mas o mercado latino americano ainda não está preparado para implantações massivas de FTTH, devido a seu elevado custo em infra-estrutura e equipamentos. Entretanto, em curto prazo, algumas operadoras já planejaram implantações iniciais de fibra com tecnologia GPON, mas na modalidade FTTB (Fiber to the Building) e FTTC (Fiber to the Curb).

É nessa linha de pensamento que o trabalho foi realizado e os objetivos principais cumpridos: enumerar as tecnologias existentes e mostrar, com isso, as vantagens de uma rede de acesso via fibra e sua importância na evolução das telecomunicações.

No trabalho exposto, foram apresentados exemplos de redes FTTH desenvolvidas e já implementadas ao redor do mundo, assim como considerações econômicas a respeito dessas implementações. Uma interessante continuação desse trabalho seria um estudo para uma possível implementação desse cenário no Brasil visto que diversas operadoras já solicitaram estudos semelhantes para fornecedores. 


\section{REFERÊNCIAS BIBLIOGRÁFICAS}

[1] http://en.wikipedia.org/wiki/MMDS

[2] http://inventabrasilnet.t5.com.br/ripper.htm

[3] http://kb.iu.edu/data/aesi.html

[4] http://lw.pennnet.com/articles/lw_onlinearticles.cfm

[5] http://magda.elibel.tm.fr/refs/telecom/sdh.pdf

[6] http://pt.wikipedia.org/wiki/Fibra \%C3\%B3ptica

[7] http://www.americasnetwork.com/americasnetwork/article/articleDetail.jsp?id=143906

[8] http://www.ampnetconnect.com/Portugal/fibraoptica.htm

[9] http://www.anatel.gov.br/INDEX.ASP?LINK=/AJUDA/DUVIDAS/TVC_MMDS/MMD $\underline{\text { S.HTM?COD }=79}$

[10] http://www.cisco.com/univercd/cc/td/doc/cisintwk/ito_doc/ethernet.htm

[11] http://www.clubedohardware.com.br/artigos/371

[12] http://www.corningcablesystems.com/web/pubnet/ftppub.nsf/download/migration.pdf/\$FI

LE/migration.pdf

[13] http://www.erg.abdn.ac.uk/.../digital-video/dsm-cc.html

[14] http://www.ericsson.com/technology/tech_articles/SDH.shtml 
[15] http://www.espacoacademico.com.br/007/07mendes.htm

[16] http://www.fiber-optics.info

[17] http://www.flexlight-networks.com/

[18] http://www.ftthcouncil.org/?t=84\&category=2

[19] http://www.iec.org/online/tutorials/epon/topic03.html

[20] http://www.iec.org/online/tutorials/lmds/

[21] http://www.iec.org/online/tutorials/sdh/

[22] http://www.imec.be/wwwinter/mediacenter/en/SR2005/html/142453.html

[23] http://www.lightreading.com/document.asp?doc id=86747

[24] http://www.maxarte.com.br/eduardocustodiohp/Redes/FibrasOpticas.htm

[25] http://www.maxarte.com.br/eduardocustodiohp/Redes/RDSI.htm

[26] http://www.mscmc.org/Docs/Slides/050223/050223Nulty-paper.pdf

[27] http://www.rnp.br/ arquivo/sci/2005/nakamura-roberto novastecnologias.pdf\#search = \%22GPON\%20gigabit\%20passive\%20optical\%20network\%22

[28] http://www.rnp.br/newsgen/0203/fibras_opticas.html\#ng-3-5

[29] http://www.tcil-india.com/new/new site/white\%20paper/FTTH\%20revised\%20prsntation 
$\mathrm{ppt \# 301,41}$

[30] http://www.tech-faq.com/lang/pt/ethernet.shtml

[31] http://www.tech-faq.com/lang/pt/mmds-multichannel-multipoint-distribution$\underline{\text { service.shtml }}$

[32] http://www.teleco.com.br

[33] http://www.uem.mz/ictproj/emunet/slide18.htm

[34] http://www.unicamp.br/unicamp/unicamp_hoje/ju/agosto2003/ju224pg03.html

[35] http://www.usenix.org/publications/library/proceedings/als00/2000papers/papers/full_ papers/ong/ong html/node5.html

[36] http://www.vitesse.com/technologies/index.php?id=11

[37] http://www.wcai.com/lmds.htm

[38] http://www.wcai.com/mmds.htm

[39] http://www.wcai.com/pt/especial.htm

[40] http://www.webopedia.com/TERM/M/MMDS.html

[41] http://www.xilinx.com/esp/wired/optical/collateral/PON_LRE.pdf 


\section{APÊNDICES}




\section{APÊNDICE A - TECNOLOGIAS DE ACESSO}

As tecnologias de acesso podem ser classificadas em acesso por fio ou acesso sem fio. Cada um desses dois grupos possui subdivisões como mostrado na figura A.1.

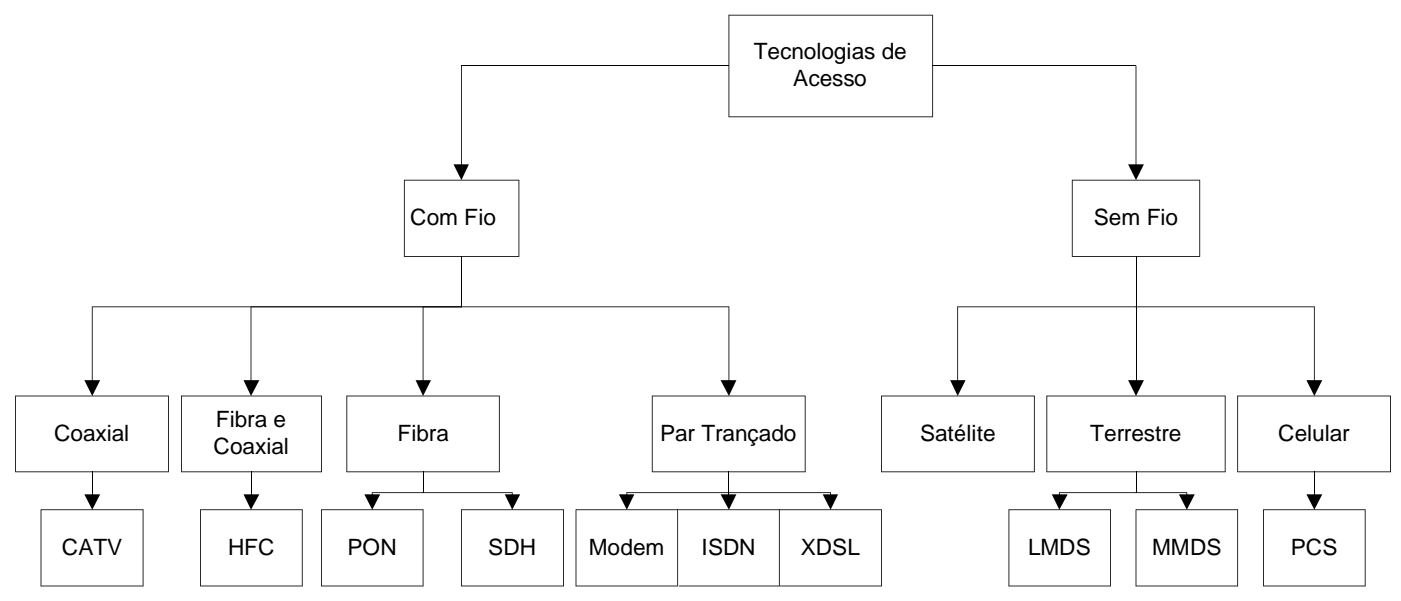

Figura A.1 Tecnologias de acesso à rede de comunicação.

No início do desenvolvimento dos sistemas de comunicação utilizou-se o acesso com fío via par trançado, no sistema telefônico.Esse é, até hoje, o meio de transmissão mais utilizado. Em seguida, começou-se a empregar os cabos coaxiais e as fibras ópticas, principalmente para a difusão de imagens. Atualmente, esses sistemas estão sendo adaptados para suportarem plenamente as redes de dados.

Os sistemas wireless (sem fio) utilizam ondas eletromagnéticas para comunicação e têm provocado verdadeira revolução na sociedade, permitindo serviços como Rádio, Televisão, Comunicações via Satélite e, mais recentemente, com os sistemas celulares que propiciam mobilidade às comunicações.

\section{A.1 - PAR TRANÇADO DE COBRE}

Em sua forma mais simples, o cabo de par trançado é constituído por filamentos isolados de cobre torcidos. Esses fios são enrolados em espiral para que haja uma redução do 
ruído, através do efeito de cancelamento, no ruído além de manter constantes as propriedades elétricas do meio. $\mathrm{O}$ efeito de cancelamento reduz a diafonia entre os pares de fios e diminui o nível de interferência eletromagnética/ radiofreqüência. $\mathrm{O}$ número de tranças nos fios pode ser variado a fim de reduzir o acoplamento elétrico.

Há dois tipos de cabos de par trançado: par trançado não-blindado (UTP, Unshielded Twisted-Pair) e par trançado blindado (STP, Shielded Twisted-Pair).

O cabo STP, além de possuir uma malha blindada global que para aumentar a imunidade às interferências eletromagnética/ radiofrequência externas, possui uma blindagem interna que envolve cada par trançado cujo objetivo é reduzir a diafonia, figura A.2. Um cabo STP geralmente possui dois pares trançados blindados, impedância característica de 150 Ohms e pode alcançar uma largura de banda de $300 \mathrm{MHz}$ em 100 metros de cabo.

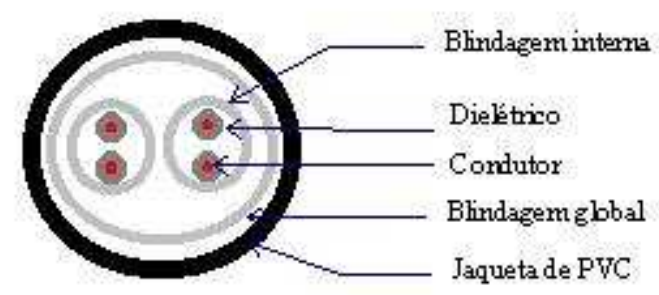

Figura A.2 Cabo STP.

Os pares trançados não-blindados (UTP) possuem um alto desempenho em termos de qualidade e baixo custo de aquisição e instalação. A figura A.3 mostra um exemplo de cabos UTP.

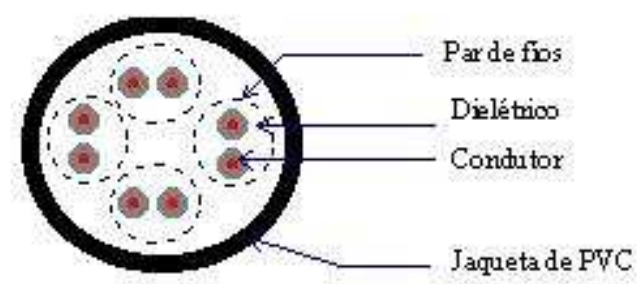

Figura A.3 cabo UTP. 
Para que um cabo UTP transporte de forma confiável sinal a $10 \mathrm{Mbps}$, se faz necessário muito cuidado e muita habilidade para a instalação do sistema. Também os cabos UTP a 100 Mbps (UTP cat.5), têm que ser cuidadosamente planejados e instalados. Mesmo custando mais barato do que qualquer outro tipo de cabo de rede local, as despesas com mão de obra ainda são altas nesse tipo de sistema.

A desvantagem do par trançado é a sua susceptibilidade à interferência e ruído, incluindo "cross-talk" de fiação adjacente. Em sistemas de baixa freqüência, a imunidade a ruído é tão boa quanto no cabo coaxial.

Pode-se utilizar o par trançado para transmitir tanto sinais analógicos quanto sinais digitais. A taxa de transmissão varia de acordo com as condições dos cabos e a tecnologia utilizada.

Os três tipos de acesso que fazem uso do par trançado são os Modems, RDSI e o xDSL.

\section{A.1.1 - Modems}

Modem, de modulador e demodulador, são dispositivos eletrônicos que modulam um sinal digital em uma onda analógica, pronta a ser transmitida pela linha telefônica, e que demodulam o sinal analógico e o reconverte para o formato digital original. De modo geral, o Modem nada mais é do que o aparelho que converte os dados que chegam da Internet para o computador.

A grande vantagem oferecida pelo modem é permitir acesso a Internet e ao mesmo tempo liberar a linha telefônica.

Quase todos os modems para uso pessoal utilizam a técnica de transmissão assíncrona. É um método de intercâmbio de informações entre dois computadores diferentes, que operam de maneira independente e não compartilham nenhuma informação de sincronia. Geralmente, os sinais dos modems que utilizam a rede telefônica são assíncronos, porque seria mais caro e mais difícil sincronizar sinais através do sistema telefônico, onde os sinais podem ser redirecionados a qualquer momento, sem aviso. Assim, também são utilizadas técnicas de compressão e correção de erro. 


\section{A.1.2 - RDSI}

A Rede Digital de Serviços Integrados (RDSI) é uma tecnologia que permite o tráfego simultâneo de dados e de voz em velocidades de até $128 \mathrm{kbps}$. Trata-se de um serviço disponível em centrais telefônicas digitais, que permite acesso à Internet e baseia-se na troca digital de dados, onde são transmitidos pacotes por multiplexagem (possibilidade de estabelecer várias ligações lógicas numa ligação física existente) sobre par trançado. [25]

Fisicamente, é formado por um par de fio de cobre de forma semelhante às linhas analógicas mas, nesse caso, não é usada a mesma fiação, já que as linhas analógicas possuem bobinas de carga que impedem a transmissão dos sinais digitais, além de os cabos da linha RDSI não poderem possuir mais que $16 \mathrm{~km}$ da central telefônica por causa do nível de ruído.

A estrutura de transmissão RDSI utiliza três tipos de canais:

- canais B duplex, de $64 \mathrm{kbps}$

- canais D duplex, de 16 ou 64 kbps;

- canais H duplex, de 384 kbps (H0), 1.536 kbps (H11) e 1.920 kbps (H12).

Em linhas RDSI só podem ser instalados diretamente aparelhos telefônicos, fax e modems que tenham a tecnologia RDSI. É possível instalar aparelhos convencionais (analógicos) à linha RDSI através de adaptador (normalmente a companhia telefônica instala este adaptador em locais dotados de linhas RDSI). O RDSI não deixa de ser uma modalidade de conexão discada. A diferença é que a taxa de transmissão pode chegar até $128 \mathrm{kbps}$. Essa tecnologia divide a linha telefônica em dois canais independentes de 64 kbps cada. Por meio deles, é possível ter acesso à Internet e receber ligações telefônicas simultaneamente. Mas, quando isso ocorre, a velocidade de navegação cai pela metade.

Por meio do uso de um equipamento adequado, uma linha telefônica convencional é transformada em dois canais de $64 \mathrm{kbps}$, onde é possível usar voz e dados ao mesmo tempo, sendo que cada um ocupa um canal. Também é possível usar os dois canais para voz ou para dados. 
É possível usar duas formas de comunicação na RDSI: acesso básico e acesso primário. O acesso básico utiliza dois canais de dados (B channels) de $64 \mathrm{kbps}$ e um canal de sinalização de 16 kbps (D channel), figura A.4.

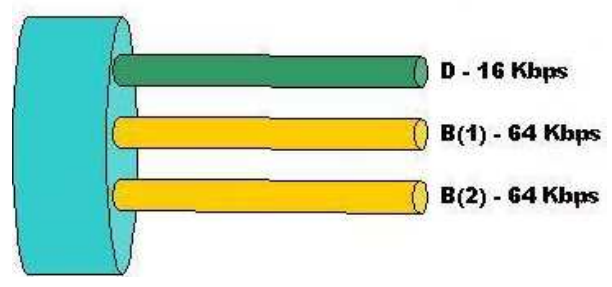

Figura A.4 Acesso básico.

No acesso primário, são utilizados 30 canais de dados, com taxa de transmissão total de 2.048 kbits e 1 canal de sinalização de 64 kbps, figura A.5.

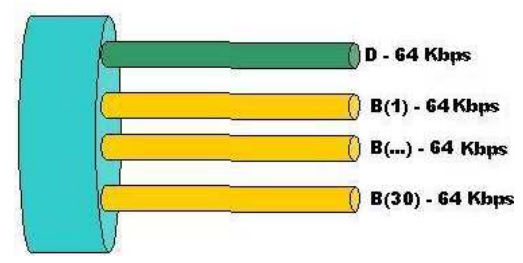

Figura A.5 Acesso primário.

A vantagem desse sistema é que se trata da modalidade de acesso por banda larga mais barata do mercado. A desvantagem é o fato do serviço ainda ser cotado pela companhia telefônica, ou seja, não deixa de ser um acesso discado no qual o usuário continua pagando pelos pulsos. Outra desvantagem é que a velocidade está limitada a $128 \mathrm{kbps}$, o que é equivalente aos planos mais básicos oferecidos nas demais modalidades de acesso por banda larga. Além disso, o provedor não cobra somente a mensalidade de acesso RDSI ele ainda oferece a infra-estrutura de servidores de correio eletrônico (com suporte), conteúdo para banda larga e outros serviços.

A tecnologia RDSI perdeu força nos últimos anos principalmente por conta da adoção dos padrões xDSL, em especial o ADSL, que oferecem taxas de transmissão superiores. 


\section{A.1.3 - xDSL}

Digital Subscriber Line, ou simplesmente DSL, é uma família de tecnologias que fornecem um meio de transmissão digital de dados, aproveitando a rede de telefonia que chega na maioria das residências.

As tecnologias DSL oferecem várias vantagens na comunicação de banda larga. A vantagem mais importante é o preço, que se torna muito mais barato pelo fato de que DSL é oferecida através da rede legada de cobre. Uma outra vantagem é que o tráfego de dados é transmitido simultaneamente com o tráfego de voz. O tráfego de dados é direcionado a uma rede de pacotes e a voz é direcionada à rede PSTN.

Há alguns tipos de xDSL, que diferem principalmente nos seguintes aspectos: velocidade (taxa de bits); Line Coding (codificação); número de linhas (1 par trançado ou 2 pares trançados) e Alcance.

Os tipos de DSL são classificados em assimétricos, quando as taxas de download e upload são diferentes, e simétricos, quando as taxas são iguais.

\section{A.1.3.1 - DSL Assimétricos}

- ADSL (Full Rate asymmetrical DSL): oferece diferentes taxas de upload e download e podem ser configuradas até $6 \mathrm{Mbps}$ da rede para o usuário. Esse tipo de DSL é o predominante no uso comercial e residencial. É conviniente para Internet e para aplicações que necessitam de maiores taxas no downstream, como video-on-demand. Há, também, uma recomendação do ITU (Recommendation G.992.5) que especifica o ADSL2Plus, com banda duas vezes maior que o ADSL, chegando a 20 Mbps downstream em distâncias pequenas.

- G.lite ADSL (ou simplesmente G.lite): O padrão G.lite foi desenvolvido para atender às necessidades de plug-and-play do mercado. G.lite é uma versão de banda intermediária do ADSL, que permite uma velocidade de 1,5 Mbps downstream e 500 kbps upstream. Essa tecnologia tem pouca utilização comercial. 
- RADSL (rate adaptive DSL): É uma tecnologia não-padronizada. É importante notar que o padrão ADSL também permite que o modem seja flexível quanto às taxas de transmissão.

- VDSL (very high bit rate DSL): Transmite até $26 \mathrm{Mbps}$, a distâncias de até 50 metros. Na maioria dos casos, as linhas VDSL serão a parte final de um acesso com fibra até um cabinet. Estão sendo realizados testes para utilizar o VDSL para a transmissão de vídeo. VDSL pode também ser configurado no modo simétrico.

- VDSL2 (VDSL 2 $2^{\mathrm{a}}$ geração): A recomendação do ITU (Recommendation G.993.2) especifica 8 perfis de VDSL2 para diferentes tipos de aplicações, como transmissão simétrica de até $100 \mathrm{Mbps}$ em loops de até $100 \mathrm{~m}$ (utilizando uma banda de $30 \mathrm{MHz}$ ), transmissão simétrica de 10-30 Mbps em loops com uma distância intermediária (utilizando banda de $12 \mathrm{MHz}$ ) e operação assimétrica com taxa de downstream de 10-30Mbps em loops de 1 a $3 \mathrm{~km}$ (utilizando uma banda de 8,5 MHz). VDSL2 inclui a maioria das facilidades do ADSL2. Sua performance é melhor do que VDSL.

\section{A.1.3.2 - DSL Simétricos:}

- SDSL (symmetric DSL): SDSL é uma versão proprietária de DSL, cujas taxas podem variar de $128 \mathrm{kbps}$ a 2,32 Mbps. SDSL é um termo utilizado para designar várias implementações específicas de empresas sobre o par trançado e que provém taxas simétricas de transmissão.

- SHDSL (ou G.shdl) é o estado-da-arte em termos de transmissão DSL com taxas simétricas. SHDSL tem um alcance $20 \%$ melhor que versões anteriores de DSL, causa bem menos crosstalk em sistemas de transmissão que estão no mesmo cabo e a interoperabilidade é facilitada, por ser uma tecnologia padronizada SHDSL pode ter taxas de $192 \mathrm{kbps}$ a 5,7 Mbps, maximizando as taxas para cada usuário. G.shdsl especifica operação via 1 par trançado ou 2 pares trançados para operar em loops longos. SHDSL é utilizado para aplicações de dados nas quais é necessária uma alta taxa de upstream. Essa tecnologia está sendo utilizada principalmente por usuários empresariais. 
- HDSL (high data rate DSL): Essa tecnologia permite taxas de até 2,3 Mbps nas duas direções. Essa tecnologia não permite o service telefônico na mesma linha e pode usar 1, 2 ou 3 pares trançados.

- HDSL2 (HDSL 2a geração): Essa tecnologia permite taxa de 1,5 Mbps para cada lado, suportando voz, dados e video usando ATM ou linha privada de services sobre o cobre. HSDL2 difere do HDSL, pois HDSL2 usa um par trançado enquanto o HDSL usa dois.

- HDSL4: HDSL4 é basicamente o mesmo que HDSL2, mas alcança aproximadamente $30 \%$ mais do que HDS ou HDSL 2, utilizando dois pares trançados, ao invés de 1 par no HDSL.

- IDSL (integrated services digital network DSL): Essa é uma forma de DSL que suporta taxas de transmissão de $144 \mathrm{kbps}$, simétrica. Ela difere pelo fato de transmitir através do DLC (Digital Loop Carrier): um dispositivo remoto geralmente colocado próximo ao usuário, para simplificar a distribuição de cabos e fios da empresa de telefonia. IDSL difere da RDSI pelo fato de que está sempre disponível, mas utiliza o mesmo modem utilizado para a RDSI.

A relação entre as capacidades de cada tecnologia DSL e as distâncias é apresentada na figura A.6:

xDSL Capacity vs. Distance

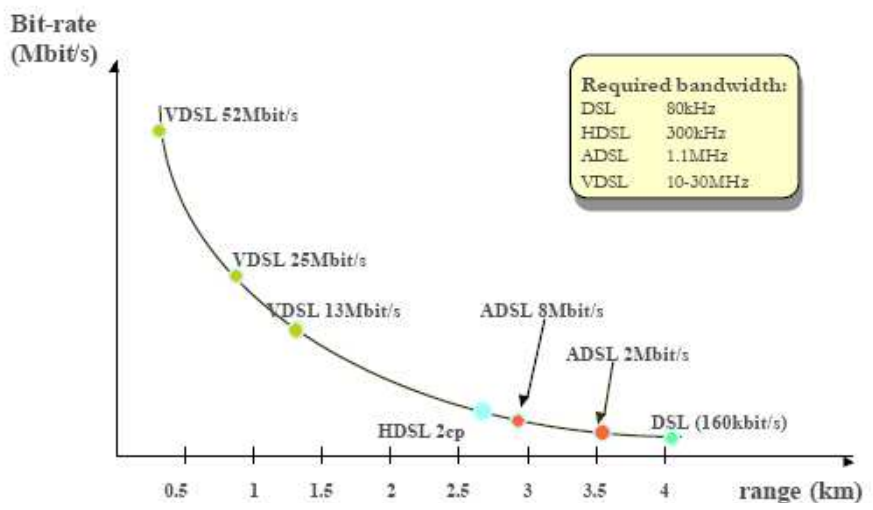

Figura A.6 Gráfico capacidade Vs diatância (xDSL). 
As velocidades típicas de download de uma linha DSL variam de $128 \mathrm{kbps}$ até 52 Mbps dependendo da tecnologia implementada, conforme os dados da tabela A.1.

Tabela A.1 Tecnologias xDSL

\begin{tabular}{|c|c|c|c|c|}
\hline Tecnologia & Taxa Upstream & Taxa Downstream & Distância Max. & No. pares \\
\hline ADSL-1 & 16-64 kbps & 1.5-2.0 Mbps & $6 \mathrm{~km}$ & 1 \\
\hline ADSL-2 & $640 \mathrm{kbps}$ & 6.144 Mbps & $4 \mathrm{~km}$ & 1 \\
\hline $\begin{array}{ll}\text { VDSL } & \text { (Very } \\
\text { High } & \text { Speed } \\
\text { DSL) } & \end{array}$ & 13 a $52 \mathrm{Mbps}$ & Em padronização & $\begin{array}{l}\text { Mais curta que } \\
\text { ADSL }\end{array}$ & \\
\hline $\begin{array}{l}\text { RADSL (Rate } \\
\text { Adaptive DSL) }\end{array}$ & $\begin{array}{l}\text { Ajustável em função } \\
\text { da qualidade do par } \\
\text { trançado }\end{array}$ & $\begin{array}{l}\text { Ajustável em função } \\
\text { da qualidade do par } \\
\text { trançado }\end{array}$ & & \\
\hline $\begin{array}{l}\text { HDSL (High } \\
\text { Data Rate DSL) }\end{array}$ & $1.5 \mathrm{Mbps}$ & $1.5 \mathrm{Mbps}$ & $4 \mathrm{~km}$ & 2 \\
\hline $\begin{array}{l}\text { SDSL } \\
\text { (Symmetrical } \\
\text { DSL) }\end{array}$ & 64 kbps - 2 Mbps & 64 kbps - 2 Mbps & $4 \mathrm{~km}$ & 1 ou 2 \\
\hline
\end{tabular}

\section{A.2 - CABO COAXIAL:}

Criado com a finalidade de transportar fluxo de bits de uma máquina à outra, o cabo coaxial pode ser utilizado tanto em redes locais quanto em transmissões de longa distância. O cabo coaxial também é geralmente utilizado para ligar o televisor aos serviços do operador de televisão por cabo. [2]

Consiste num pequeno tubo de cobre coberto por um material isolante, que é envolto por um condutor cilíndrico com um diâmetro superior sob a forma de bainha. O núcleo é formado por um fio de cobre rígido ou flexível e o condutor externo é coberto por uma capa plástica protetora, veja a figura A.7: 


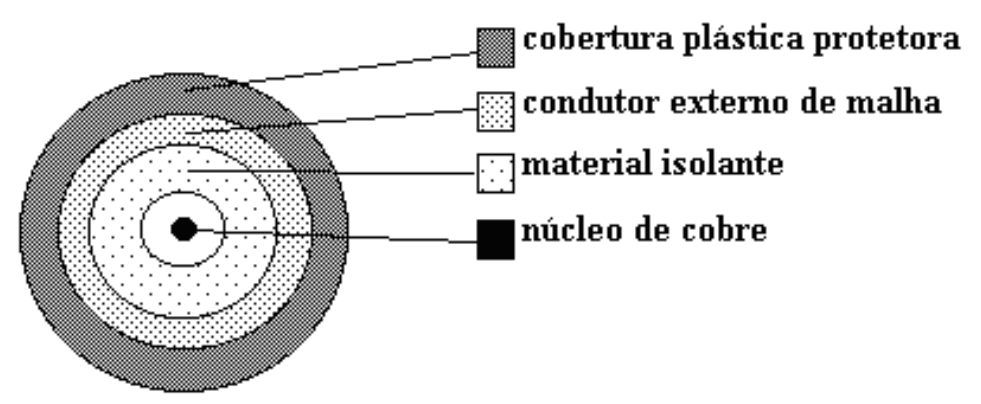

Figura A.7 Corte em um cabo coaxial.

Essa forma de construção do cabo coaxial lhe garante uma boa combinação de alta banda passante e boa imunidade a ruídos. A banda passante depende do tamanho do cabo. Para altas taxas de transmissão, deve-se utilizar cabos mais curtos, mas, se o importante é a distância, utiliza-se cabos mais longos com menores taxas. Para um cabo de 1 km, tem-se uma taxa de mais ou menos $10 \mathrm{Mbps}$.

Os tipos de cabos coaxiais são: Cabo em Banda Base e Cabo em Banda Larga.

\section{A.2.1 - Cabo Coaxial Banda Base}

Também chamado de Cabo Coaxial Fino tem impedância de 50 ohms e é amplamente utilizado em redes locais. O método de acesso a redes locais é o de detecção de portadora, com detecção de colisão. O tamanho de cada segmento pode variar entre $45 \mathrm{~cm}$ e $185 \mathrm{~m}$ chegando a um número máximo de 5 segmentos, ou seja, o comprimento do cabo pode chegar a $925 \mathrm{~m}$. Quando a rede não tem repetidores, o tamanho máximo se reduz a $300 \mathrm{~m}$. A taxa de transmissão depende do tamanho do cabo, mas geralmente varia de 1 a 50 Mbps. O modo de transmissão é Half-Duplex, e utiliza o Código Manchester por pulsos de corrente contínua. A instalação é facilitada por ser um cabo fino e flexível. Usa-se conectores do tipo $\mathrm{T}$ e sua imunidade a EMI/RFI é de $50 \mathrm{~dB}$. A figura A.8 ilustra esse tipo de cabo. 


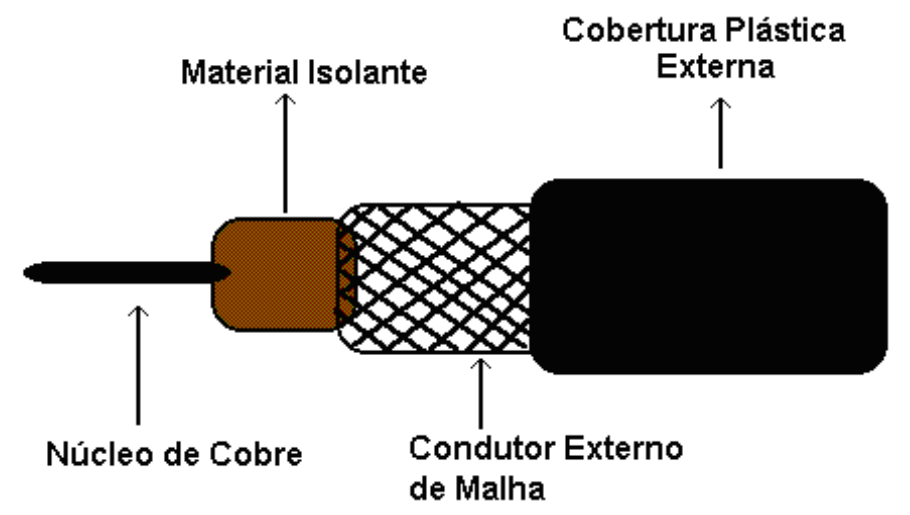

Figura A.8 Cabo Coaxial Banda Base.

\section{A.2.2 - Cabo Coaxial Banda Larga}

Também chamado de Cabo Coaxial Grosso tem impedância de 75 ohms e pode ser utilizado tanto em redes locais como em redes de longa distância, com método de acesso FDM (Frequency-division multiplexing). $\mathrm{O}$ tamanho de cada segmento pode variar entre 2,5 $\mathrm{m}$ e $500 \mathrm{~m}$ chegando a um número máximo de 5 segmentos, ou seja, o comprimento do cabo pode chegar a $2.500 \mathrm{~m}$, mas os tamanhos geralmente recomendados são múltiplos de 23,4 - 70,2 ou 117 metros. A taxa de transmissão depende do tamanho do cabo, mas geralmente varia de 100 a 150 Mbps. O modo de transmissão é Full-Duplex, feito por variação em sinal de frequência de rádio. Possui uma capacidade de 1.500 canais com 1 ou mais equipamentos por canal. A velocidade de propagação é de 0,77 vezes a velocidade da luz no vácuo. Sua imunidade a EMI/RFI é de $85 \mathrm{~dB}$, mas, para $500 \mathrm{~m}$ de cabo, a atenuação não pode exceder 8,5 dB medido a $10 \mathrm{MHz}$ ou 6,0 dB medido a $5 \mathrm{MHz}$. Sua instalação é mais complicada pelo fato do cabo ser grosso e não flexível, por isso, requer prática e pessoal especializado. O conector pode ser do tipo Derivador Vampiro ou pode-se utilizar transceptores (detecta porta elétrica do cabo). A figura A.9 ilustra esse tipo de cabo. 


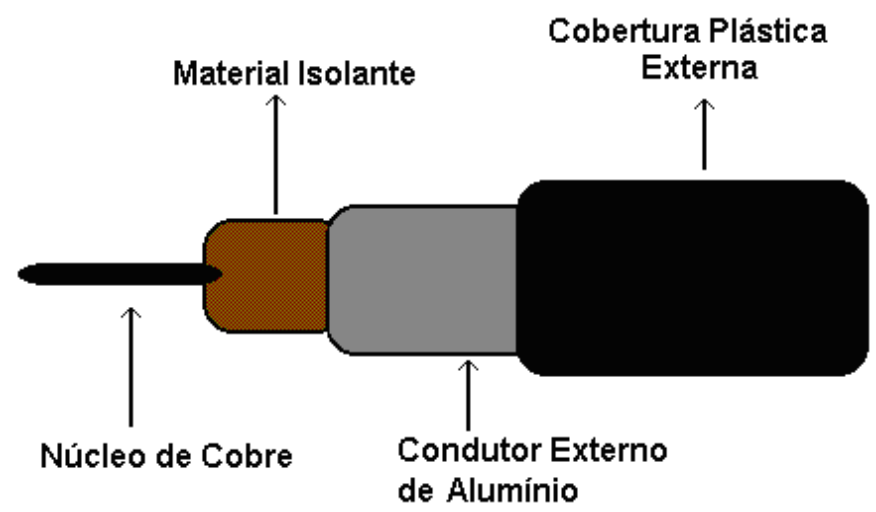

Figura A.9 Cabo Coaxial Banda Larga.

\section{A.3 - ACESSO TERRESTRE SEM FIO}

\section{A.3.1 - Sistema MMDS}

O MMDS (Multipoint Multichannel Distribution System ou Serviço de Distribuição Multiponto Multicanal), também chamado de Wireless Cable, pode ser descrito como uma das modalidades de serviço especial de TV por assinatura, que utiliza uma faixa de microondas (2.500 a $2.680 \mathrm{MHz}$ ) para transmitir sinais aos clientes que se encontram dentro da área de prestação de serviço. O sistema é formado por um equipamento head-end (equipamento de recepção de sinal de satélite, transmissor de rádio, antena transmissora e outros equipamentos de transmissão) e um equipamento receptor para cada assinante (antena, conversor de freqüência e dispositivo de ajuste alto), figura A.10. [1]

Uma das vantagens proporcionadas é que os sinais do MMDS cobrem uma área com raio de até 50 quilômetros, levando a programação tanto às áreas urbanas quanto às periféricas. Além disso, permite transmissão de programação local, pois o head-end está situado no local da prestação do serviço. Sua capacidade é de até 31 canais analógicos ou de cerca de 180 canais digitais. O número de canais digitais transmitidos pode aumentar com as novas tecnologias que vem surgindo. Outra vantagem é a portabilidade proporcionada pelo sinal de microondas, que permite a recepção do sinal em qualquer ponto da área de cobertura, em geral toda a cidade, o assinante podendo mudar de endereço sem ter problemas em transferir o serviço. 
Como desvantagem tem-se o fato da capacidade de canais do MMDS ser menor que a do cabo, porque o sistema dispõe de uma faixa limitada do espectro de radiofrequiências. Porém, essa capacidade pode ser aumentada com a digitalização dos sinais. Por outro lado, a instalação de um novo sistema de MMDS em uma cidade tem custo menor que o sistema de cabo porque não há o custo relativo a cabos e as antenas e receptores são colocados nas residências apenas na medida em que surgem novos assinantes.

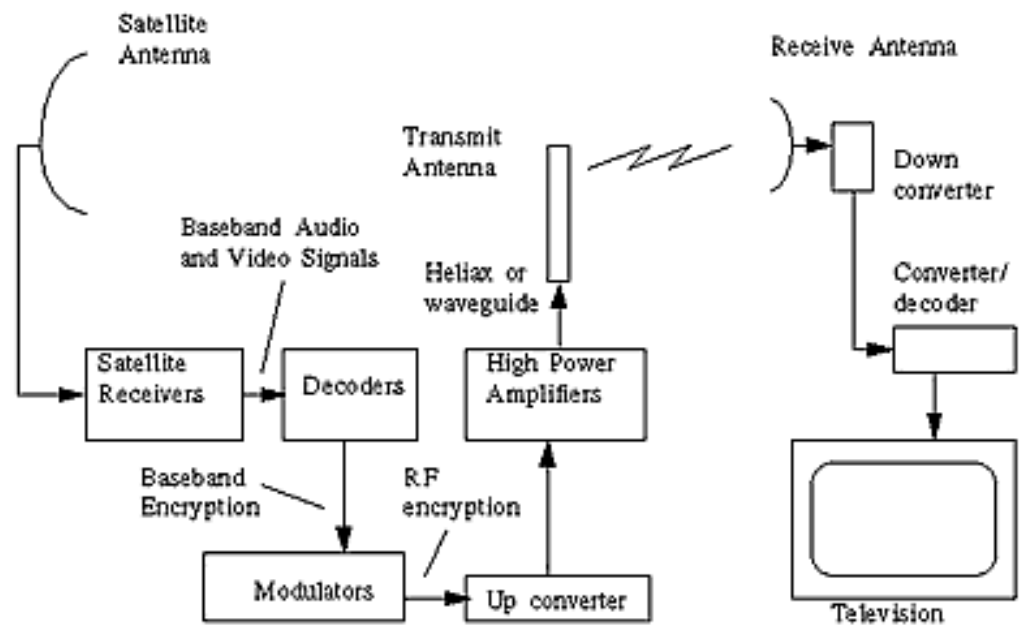

Figura A.10 Arquitetura típica de uma rede MMDS.

\section{A.3.2 - Sistema LMDS}

O LMDS (Local Multipoint Distribution System) foi desenvolvido em 1986 e é um sistema de comunicação de ponto a multiponto que utiliza ondas eletromagnéticas em freqüências em torno de 28 ou $40 \mathrm{GHz}$. Essa configuração ponto multiponto forma células com o objetivo de se otimizar a cobertura de uma determinada localidade. Dada a banda larga disponível, o LMDS pode dar suporte a uma grande variedade de serviços simultâneos: televisão multicanal (difusão, PPV, vídeo on demand), telefonia, dados, serviços interativos multimídia (tele-educação, telemedicina, acesso à Internet em banda larga etc.). [20]

Cada célula LMDS é composta por uma ERB (Estação Rádio Base) e por diversas ER (Estações Remotas). Existem dois tipos de ERBS: ominidirecionais e setorizadas. No primeiro caso, utiliza-se uma única antena para prover uma cobertura de $360^{\circ}$, no segundo caso, cada 
setor possui uma antena específica. As células setorizadas são vantajosas, pois podem oferecer a banda total de cada rádio para determinado setor, o que gera aumento na banda total da célula. Outra vantagem é que a potência dos transmissores das células setorizadas podem ser menor já que as antenas possuem alto ganho. Para que não haja interferência entre células ou setores adjacentes usa-se o recurso da inversão de polarização como mostrado na figura A.11.

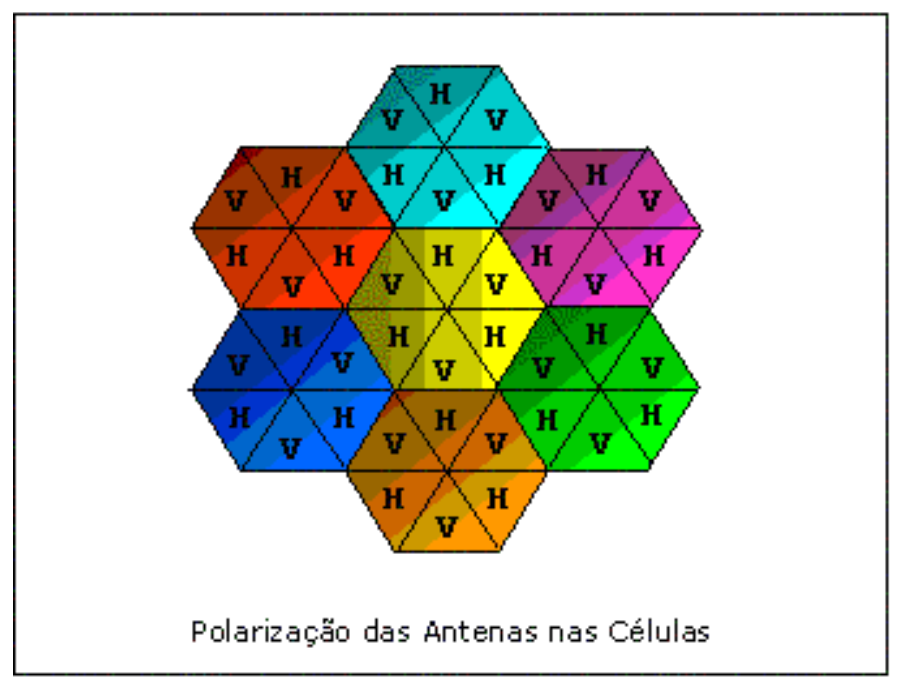

Figura A.11 Polarização das antenas em uma células LMDS. H (polarização horizontal, V (polarização vertical).

Algumas vantagens do sistema LMDS quando comparado aos sistemas a cabo e também ao MMDS, são representadas a seguir.

- O sistema LMDS permite oferecer, com grande confiabilidade e qualidade de sinal, praticamente os mesmos serviços que as redes de fibra óptica e cabo coaxial. É através desse que se pode denominar a esta tecnologia como "vias aéreas da informação (ou sistema de informações via ar)".

- Como no LMDS não é necessário cabear, as grandes vantagens potenciais do sistema são:

- Pode-se oferecer o serviço e gerar receitas muito antes em toda a área de cobertura (de 6 a 18 meses, frente a 5-7 anos para completar uma rede de cabo); 
- Pode-se oferecer o serviço de forma economicamente viável, se não a $100 \%$ da população, mas a grande parte da mesma (principalmente aquela que está dispersa e que em nenhum caso se pode oferecer serviço via cabo de forma rentável);

- Por último, não menos importante, o operador com LMDS teria custos reduzidos para manter e operar a planta, já que não há uma rede a ser mantida (somente uns poucos repetidores por célula).

- Outra possibilidade menos radical que a de substituir o cabo por LMDS, consistiria em utilizar esta tecnologia desde o princípio, enquanto se vai cabeando, de forma que se daria serviço muito antes à população e se geraria recursos que permitiriam auto financiar a construção da rede de cabo. À medida que se fosse completando a mesma, poder-se ir substituindo a conexão de LMDS pela rede de cabo.

- Por último, comparando o LMDS com o MMDS, sendo que com esse último tem um maior alcance e o mesmo não sofre com a interferência da chuva, mesmo tendo uma largura de banda menor (somente $200 \mathrm{MHz}$ frente a $1 \mathrm{GHz}$ do LMDS), a necessidade de visibilidade direta entre emissor e receptor com MMDS (o que no LMDS não é em muitos casos necessário por causa das reflexões de sinal de microondas em obstáculos naturais), e a dificuldade no MMDS para reutilizar frequências entre células adjacentes - que é possível com o LMDS - tornam o LMDS tecnologia muito mais atrativa para a provisão de serviços de telecomunicações interativos e de banda larga.

A figura A.12 mostra a arquitetura de um sistema LDMS. 


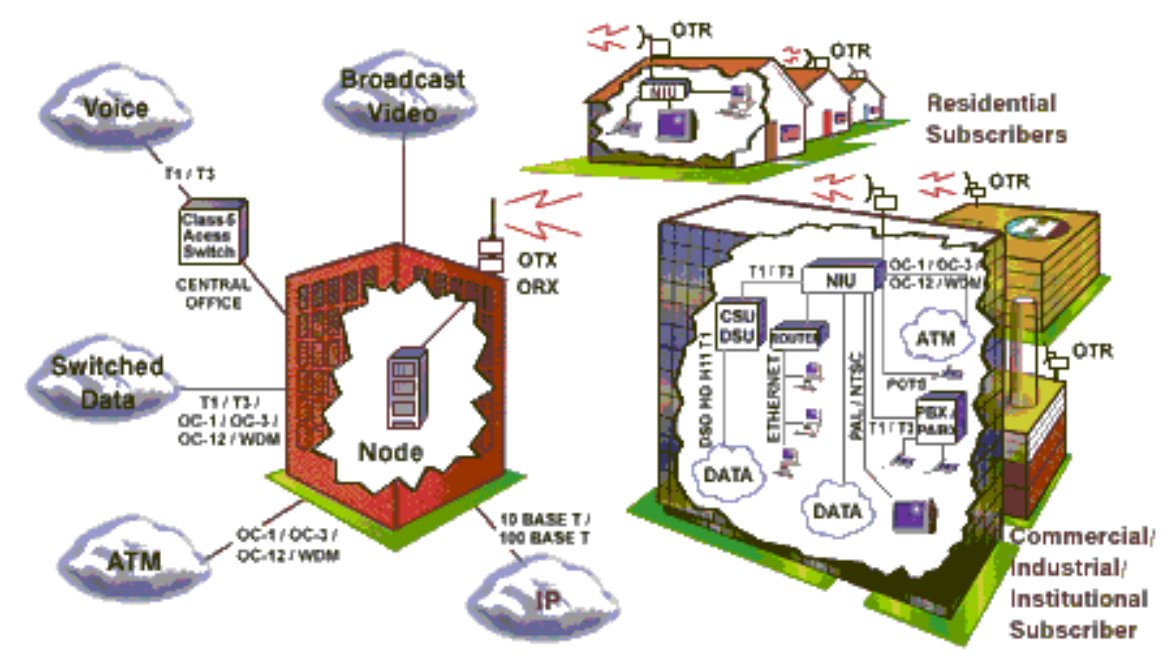

Figura A.12 Arquitetura do sistema LMDS.

\section{A.4 - ACESSO VIA SATÉLITE}

O DTH (Direct to Home) ou Sistema de Distribuição de Sinais de Televisão e de Áudio por Assinatura via Satélite tem como objetivo a distribuição de sinais de televisão ou de áudio, ou dos dois, através de satélites, a assinantes localizados na área de prestação de serviço. Como é um sistema de TV paga, o assinante tem que instalar em sua casa uma antena parabólica e um receptor/decodificador, chamado IRD (Integrated Receiver/Decoder), para receber os canais diretamente de um satélite geoestacionário, figura A.13.

O DTH é uma tecnologia unidirecional, ou seja, só permite receber dados (downloads), necessitando de uma linha telefônica convencional para fazer a transmissão de dados (upload). Possui taxa de recepção máxima de 400 kbps e necessita de hardware específico.

Entre suas vantagens está a cobertura nacional ou mesmo continental, com mais de 180 canais digitais, e a rápida implantação. Uma outra grande vantagem está na excelente qualidade de som e de imagem, melhor aproveitamento do caro espaço que ocupam nos satélites. Isso se deve ao fato de todos os serviços de DTH no Brasil - DirecTV, Sky e Tecsat na banda $\mathrm{KU}$, e Digisat na banda $\mathrm{C}$ - usarem sinais digitais.

Como desvantagens, tem-se o fato de que, contrariamente às tecnologias de cabo e MMDS, o DTH não viabiliza a inserção de programas de conteúdo local, pois a programação é a mesma para todos os assinantes, em toda a área de cobertura. O custo inicial do sistema é 
elevado, pois envolve o aluguel de espaço em satélites e montagem de uma rede nacional de distribuição e de venda. Além disso, em dias de chuvas fortes não é possível utilizar o serviço no caso do satélite ficar encoberto.

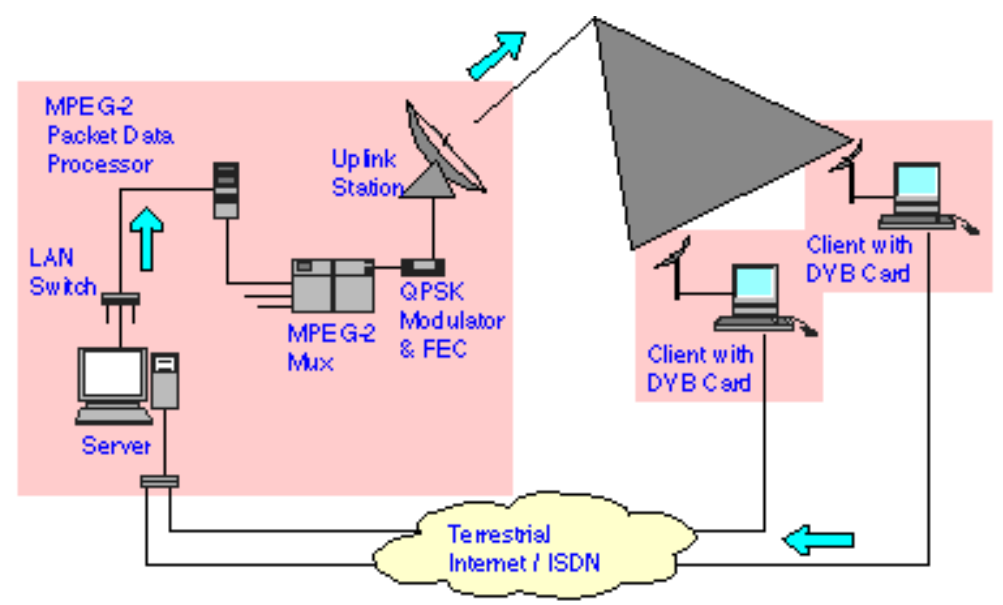

Figura A.13 Configuração típica para se prover DTH Internet delivery utilizando-se DVB.

\section{A.5 - SISTEMA PCS (PERSONAL CELLULAR SYSTEM)}

O sistema de comunicações móvel trabalha com o conceito de células que seriam o resultado da divisão de uma área geográfica em pequenas áreas.

O compartilhamento de recursos é uma forma muito eficiente de se obter alta capacidade em uma rede de comunicações. No que diz respeito a comunicações móveis, os recursos são os canais disponíveis ou, de forma mais ampla, a banda de frequiências. $\mathrm{O}$ mecanismo de acesso deve permitir que qualquer terminal acesse o sistema, provendo um sistema de acesso troncalizado. Se canais são designados a usuários por demanda, o esquema é chamado de Acesso Múltiplo com Alocação por Demanda (DAMA, Demand-Assigned Multiple Access), ou simplesmente Múltiplo Acesso.

De acordo com a forma com que o espectro é disponibilizado aos usuários, tem-se a classificação geral de sistemas em faixa estreita e faixa larga. Em um sistema faixa estreita, a faixa de freqüências é subdividida em várias faixas menores, os canais, que são alocadas sob demanda aos usuários. Em sistemas faixa larga, toda ou grande parte da banda de freqüências é disponibilizada aos usuários, como um único bloco. 
Há três formas básicas de se realizar múltiplo acesso, nomeadas de acordo com o mecanismo chave usado para implementá-las.

- Múltiplo Acesso por Divisão de Freqüiência (FDMA): Sendo a mais antiga das técnicas de acesso, baseia sua ortogonalidade na separação de freqüências, colocando cada usuário em uma portadora distinta durante todo o tempo. Transmissor e receptor devem estar sintonizados na mesma freqüência e o canal estará disponível $100 \%$ do tempo de uso para aquele usuário/serviço. É utilizada em radiodifusão, telefonia celular analógica e em outros sistemas mais antigos. As desvantagens são desperdício de energia, pois o canal fica alocado durante todo o tempo mesmo que não haja informação para se transmitir.

- Múltiplo Acesso por Divisão de Tempo (TDMA): temos na maioria dos sistemas tem-se a mesma estrutura de divisão de freqüências dos sistemas FDMA. A ortogonalidade das informações é garantida, além da separação em frequiência, pelo fato de que o tempo é dividido em time slots, e cada time slot é atribuído a somente um usuário por acesso. Visto que a transmissão é feita de forma interrompida, transmitindo-se num instante e ficando mudo no tempo restante, são utilizada técnicas de codificação e compressão de voz ou dados para que a informação seja adequadamente transmitida utilizando-se as taxas disponíveis. A vantagem de um sistema como este é que, para se aumentar a taxa de transmissão por usuário, basta que este utilize mais de uma janela simultaneamente. Isto limitaria a quantidade global de acessos ao sistema, mas é capaz de oferecer taxas mais elevadas para aqueles que as necessitem;

- Múltiplo Acesso por Divisão de Código (CDMA): baseiam a ortogonalidade entre os acessos nos diferentes códigos empregados para espalhamento. O sinal de espalhamento é composto de símbolos chamados chips. A sequiência de chips deve ser o mais aleatória possível, e em sistemas comerciais por ser gerada através de um algoritmo, é chamada de pseudo-aleatória ou pseudo-randômica. Além disso, as sequiências utilizadas deverão ser ortogonais entre si. 
Enquanto o FDMA e o CDMA são, respectivamente, técnicas faixa estreita e faixa larga por natureza, o TDMA permite ambas as formas de implementação.

Para a implementação de comunicação bidirecional full-duplex, pode-se utilizar divisão no tempo (TDD - Time Division Duplex) ou na freqüência (FDD - Frequency Division Duplex). No TDD, as duas direções de comunicação utilizam uma mesma faixa de freqüências comum, mas instantes de tempo distintos. Por outro lado, no FDD, cada sentido utiliza faixas distintas de frequiências, separadas convenientemente para evitar interferências, permitindo um full duplex real, pois a informação pode trafegar nos dois sentidos simultaneamente. O TDD requer sincronização e tempo de guarda entre slots de ambos os sentidos, também para evitar interferência. Observa-se que o TDD, por utilizar a mesma faixa de freqüências, permite que a comunicação mantenha a mesma qualidade em ambos os sentidos.

\section{A.5.1 - Arquitetura do sistema faixa estreita}

Em geral, a arquitetura faixa estreita está associada a sistemas com alta capacidade - o número de canais em que a banda é dividida dá uma dimensão da capacidade do sistema quanto ao número de usuários - mas, muitas vezes, baixa qualidade de transmissão - muitos canais significa banda pequena para cada canal. Nesse sentido, há um esforço para que se utilize técnicas de modulação que permitam qualidade de voz aceitável sem que se aumente a banda ocupada pelos canais, ou até, que se reduza a banda ocupada. Outro aspecto é a necessidade de se utilizar filtros estreitos para minimizar a interferência de canal adjacente, o que contribui para o aumento no custo de equipamento. E ainda, em sistemas faixa estreita, o sinal propagante sofre o chamado desvanecimento não seletivo em freqüência, ou seja, quando ocorre um desvanecimento toda a informação contida no canal é afetada, pois o canal é, em geral, muito estreito. 


\section{A.5.2 - Arquitetura do sistema faixa larga}

As técnicas de acesso que se utilizam dessa arquitetura são o TDMA faixa larga e o CDMA, sendo que este último freqüentemente usa toda a faixa disponível. Como grande vantagem dessa abordagem, pode-se citar o fato de que a banda utilizada é maior que a banda dentro da qual ocorre desvanecimento não seletivo. Ou seja, o sinal faixa larga experimenta desvanecimento seletivo em freqüência e, então, apenas uma fração das freqüências que o compõem é afetada pelo desvanecimento. Da mesma forma, interferências também podem ser minimizadas com o uso dessa arquitetura.

\section{A.6 - WIMAX}

O WiMax (Worldwide Interoperability for microwave access) é uma organização formada por empresas fornecedoras de equipamentos de telecomunicações e operadoras para promover e certificar a compatibilidade e a interoperabilidade dos equipamentos de acesso wireless com as especificações IEEE 802.16 e ESTSI HIPERMAN. O padrão 802.16 acabou por ser reconhecido pelo nome da organização que o promove, WiMax.

O padrão 802.16 é uma tecnologia wireless de redes metropolitanas (WMAN) que provê um acesso de banda larga alternativo ao cabo, DSL, fibra. O WiMax é uma evolução da tecnologia de comunicação sem fio que promete o ideal de uma plataforma comum padronizada para o transporte de vídeo, voz, imagens e dados com segurança e QoS num ambiente wireless.

O padrão especifíca duas faixas no espectro de frequência: 2 a $11 \mathrm{GHz}$ para situações sem visada direta (NLOS - non line of sight), atingindo até 8 quilômetros, e 10 a $66 \mathrm{GHz}$ para situações com visada direta (LOS - line of sight), atingindo até 50 quilômetros, cabendo aos

fabricantes e órgãos regulamentadores decidir quais serão as frequências utilizadas. As extensões do padrão podem ser vistas na Tabela A.2: 
Tabela A.2 Especificações da recomendação IEEE 802.16.

\begin{tabular}{|c|c|c|c|}
\hline NOME & CLASSIFICAÇÃO & PONTOS PRINCIPAIS & STATUS \\
\hline 802.16 & Interface Aérea & $\begin{array}{c}\text { Padrẫo para WirelessMAN (interface aérea para acesso } \\
\text { banda larga fixo), redes metropolitanas sem fio }\end{array}$ & $\begin{array}{c}\text { Publicada em Abril } \\
\text { de } 2002\end{array}$ \\
\hline $802.16 a$ & Interface Aérea & Expansão do escopo para frequências de 2 a $11 \mathrm{GHz}$. & $\begin{array}{c}\text { Publicada em Abril } \\
\text { de } 2003\end{array}$ \\
\hline $802.16 \mathrm{c}$ & Interface Aérea & $\begin{array}{c}\text { Define os perfis do sistema para } 10 \text { a } 66 \mathrm{GHz} \text { e a } \\
\text { interoperabilidade da interface aérea }\end{array}$ & $\begin{array}{l}\text { Publicada em } \\
\text { Janeiro de } 2003\end{array}$ \\
\hline 802.16REVD & Interface Aérea & Convertido no padrẫo $802.16 \mathrm{~d}$ & $\begin{array}{c}\text { Aprovada como } \\
802.16-2004 \text { em } \\
\text { Junho de } 2004\end{array}$ \\
\hline 802.16 .2 & Coexistência & $\begin{array}{c}\text { Definiçỗes para a coexistência de sistemas de acesso } \\
\text { banda larga de } 10 \text { a } 66 \mathrm{GHz} \text {. }\end{array}$ & $\begin{array}{c}\text { Publicada em } \\
\text { Setembro de 2001; } \\
\text { substituída pela } \\
802.16 .2-2004\end{array}$ \\
\hline $802.16 .2 a$ & Coexistência & $\begin{array}{l}\text { Expansẫo do escopo para frequências de } 2 \text { a } 11 \mathrm{GHz} \text { e } \\
\text { mais recomendaçốes de sistemas ponto-a-ponto }\end{array}$ & $\begin{array}{c}\text { Convertida e } \\
\text { publicada como } \\
802.16 .2-2004 \mathrm{em} \\
\text { Março de } 2004\end{array}$ \\
\hline $802.16 /$ ConfD1 & Conformidade & $\begin{array}{l}\text { Especificaçẫo de protocolos de testes para a } \\
\text { implementaçẫo de } 10 \text { a } 66 \mathrm{GHz}\end{array}$ & $\begin{array}{c}\text { Publicada em } \\
\text { Agosto de } 2003\end{array}$ \\
\hline $802.16 /$ Confl02 & Conformidade & Estrutura e propósito de testes para 10 a $66 \mathrm{GHz}$ & $\begin{array}{c}\text { Publicada em } \\
\text { Fevereiro de } 2004\end{array}$ \\
\hline $802.16 / \operatorname{Confl} 3$ & Conformidade & Testes de conformidade de rádio para 10 a $66 \mathrm{GHz}$ & $\begin{array}{c}\text { Aprovada em Maio } \\
\text { de } 2004\end{array}$ \\
\hline $802.16 /$ ConfD4 & Conformidade & $\begin{array}{l}\text { Especificação de protocolos de testes para a } \\
\text { implementaçẫo a partir de } 11 \mathrm{GHz} \text {. }\end{array}$ & Em aberto \\
\hline
\end{tabular}

O 802.16d (ratificado em Junho de 2004) é o padrão de acesso sem fio de banda larga fixa (também conhecido como WiMax Fixo) e teve os primeiros equipamentos homologados em Janeiro de 2006 pelo laboratório espanhol Cetecom. Este padrão pode ser referido como WiMax fixo, porque utiliza uma antena montada no local do assinante. O padrão IEEE 802.16 utiliza o OFDM para otimização dos serviços de dados wireless. Os sistemas baseados nos padrões 802.16 emergentes são as únicas plataformas padronizadas de redes wireless de áreas metropolitanas (WMAN) baseadas em OFDM.

O 802.16e (ratificado em Dezembro de 2005) é o padrão de acesso sem fio de banda larga móvel - WiMax Móvel (assegurando conectividade em velocidades de até $100 \mathrm{~km} / \mathrm{hora}$ ) e cujos equipamentos estarão disponíveis no mercado em meados de 2007. A grande diferença entre o WiMAX "Nomâde" (ou Fixo) e o Móvel é que o primeiro é apenas portátil (não comuta - não possui handoff - entre estações radio-base em altas velocidades) e o segundo é móvel (comuta - possui handoff - entre estações radio-base em velocidades de até $100 \mathrm{Km} / \mathrm{h}$ ). O padrão 802.16e utiliza o Acesso Múltiplo por Divisão Ortogonal da Freqüência (OFDMA), que é similar ao OFDM pelo fato de que ele divide as portadoras em várias sub-portadoras. No entanto, o OFDMA vai além ao agrupar diversas sub-portadoras em sub-canais. Um único 
cliente ou estação de assinante poderá transmitir utilizando todas as sub-portadoras no espaço da portadora, ou múltiplos clientes poderão transmitir, sendo que cada um utiliza uma parcela do número total de sub-canais simultaneamente.

O padrão possui a camada física adaptativa, ou seja, ele altera a modulação (Ex: 16 QAM, QPSK, 64 QAM) e codificação do equipamento de acordo com as condições do canal. Permite correção de erro e suporte a antenas adaptativas. A taxa de transmissão depende da modulação e dos códigos usados, variando entre 1 Mbps e 75 Mbps.

Os equipamentos WiMAX que operam em faixas de frequiência sem licença utilizarão a duplexação por divisão de tempo (TDD). Os equipamentos operando em faixas de freqüência licenciadas utilizarão o TDD ou a duplexação por divisão da frequiência (FDD).

O WiMax apresenta três modos de operação,todos os três em sua camada física, quais sejam: single carrier, OFDM 256, ou OFDMA 2K. O modo mais comumente utilizado é o OFDM 256.

O WiMax provê o suporte a duas topologias: Ponto-Multiponto (PMP - PointMultipoint) e Malha (Mesh). A topologia ponto-multiponto permite apenas a comunicação entre a estação base e as estações assinantes, ou seja, toda comunicação de uma estação de assinante passa sempre pela estação base. Esta foi a primeira topologia desenvolvida para as redes WiMAX. Na topologia em malha, o tráfego pode ser roteado através das estações assinantes, passando diretamente entre elas sem passar pela estação base. A topologia pontomultiponto é mais barata, pois reduz-se a complexidade e a necessidade de equipamentos mais sofisticados (roteadores e comutadores) nas estações dos assinantes. Em síntese, a topologia PMP é bastante semelhante a uma rede de telefonia celular, com a exceção de que, por enquanto, os assinantes são fixos. Assim, devido as limitações de linha de visada, em grandes cidades, torna-se díficil atender a todos os clientes em potencial. Para aumentar a quantidade de usuários, sem acrescentar novas BSs (de custo elevado), a topologia mesh surge como uma alternativa interessante. $\mathrm{Na}$ arquitetura mesh, cada estação funciona como um "nó repetidor" distribuindo tráfego para os seus vizinhos.

As possibilidades de utilização da tecnologia WiMax podem ser vistas na figura A.14. 


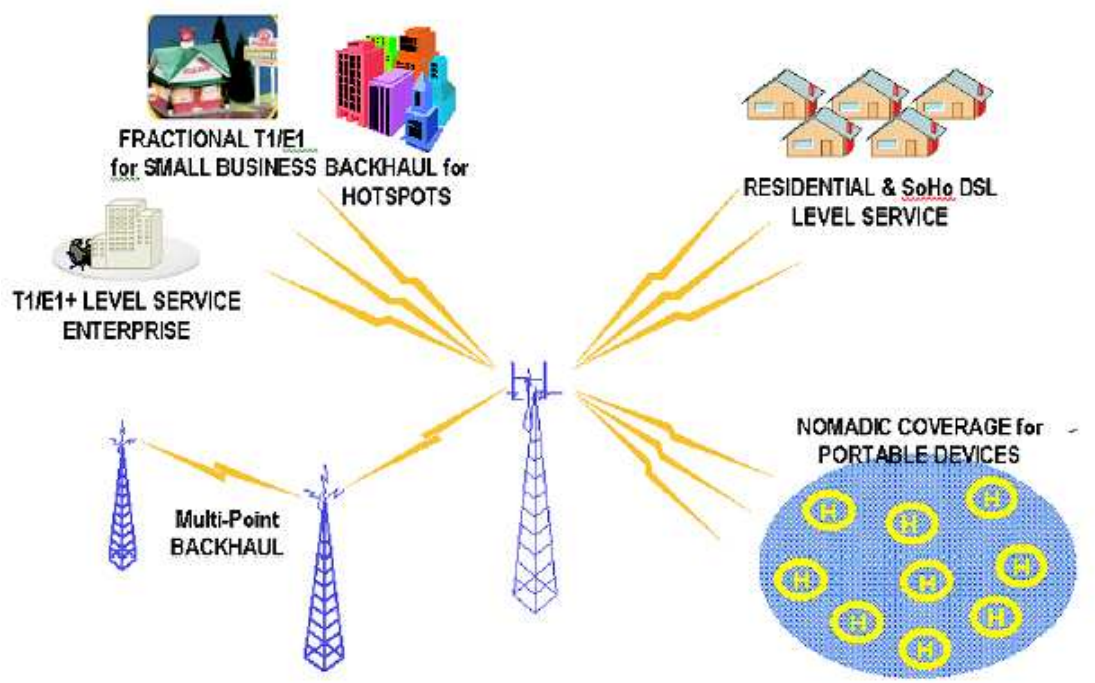

Figura A.14 Modelo de utilização para o Wimax

O que impulsiona a indústria em direção ao WiMax é a combinação entre um custo potencialmente baixo e a flexibilidade da tecnologia.

Um dos principais elementos da tecnologia é a interoperabilidade dos equipamentos, resultando nas facilidades para os provedores de serviço para obter equipamentos de diferentes fornecedores, permitindo uma maior competitividade, tornando os preços dos equipamentos mais baixos.

O fato de possibilitar o acesso quando não há linha de visada é uma vantagem, que possibilita maiores áreas de cobertura, com necessidade de instalar poucas estações-base, com um simples planejamento de freqüências, torres menores e maiores facilidades para a instalação dos CPEs, figura A.15. A grande área de cobertura é possível graças às técnicas utilizadas para permitir a recepção sem visada, como diversidade, codificação no espaço e no tempo e Automatic Retransmission Request (ARQ). 


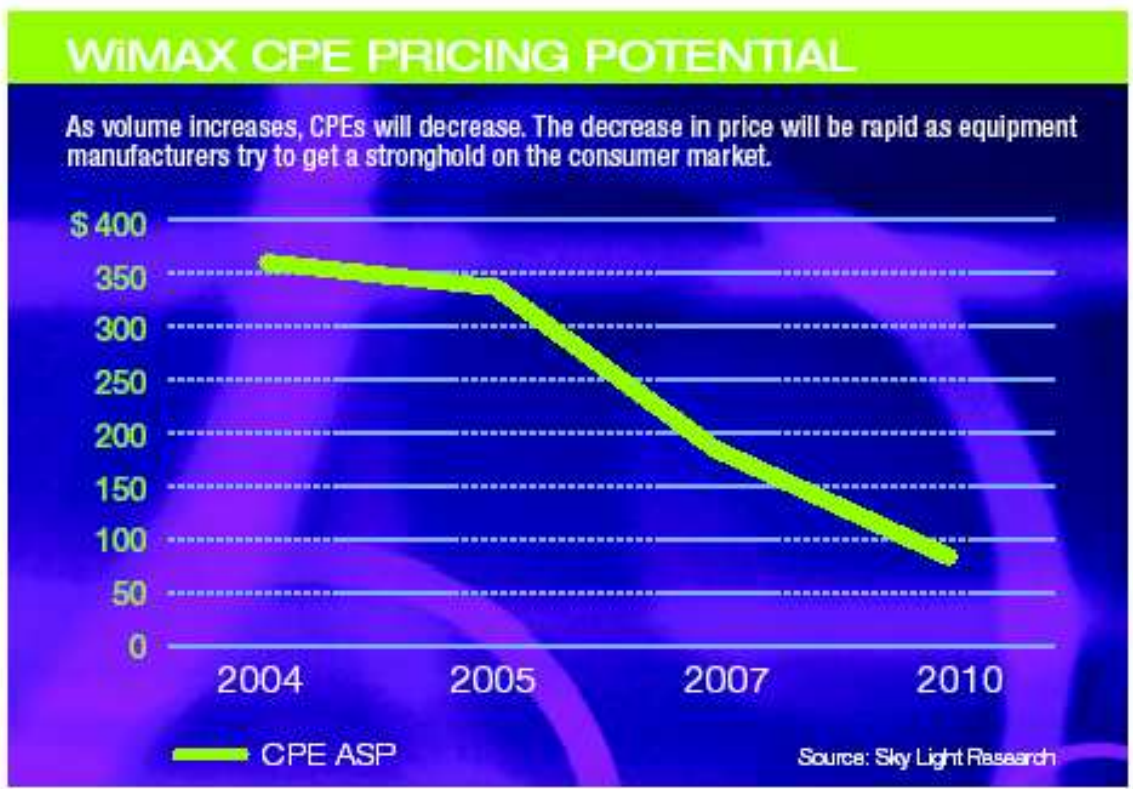

Figura A.15 Estimativa de preço dos CPEs WiMax.

O padrão WiMax utiliza um protocolo de concessão-requisição de acesso que não permite colisão de dados, e, portanto, utiliza a largura de banda disponível com mais eficiência. Nenhuma colisão significa nenhuma perda de largura de banda devido à transmissão de dados. Todas as comunicações são coordenadas pela estação base.

O padrão foi projetado para operação em classe de operadora. Conforme mais usuários são integrados, eles devem compartilhar a largura de banda agregada, e sua capacidade individual diminui linearmente. Além disso, possui larguras de banda de canal flexíveis entre 1,5 e $20 \mathrm{MHz}$ para facilitar a transmissão por longas distâncias e para diferentes tipos de plataformas de assinantes.

$\mathrm{O}$ acesso às áreas muito remotas, ou que sejam muito difíceis ou dispendiosas de alcançar com as infra-estruturas cabeadas tradicionais (como a fibra) tornam o WiMax uma solução bastante viável.

Enquanto os padrões para o WiMax não são completamente definidos, principalmente para o WiMax móvel, as operadoras e fornecedores realizam testes e começam a fazer projetos e implementações comerciais para ganhar experiência nessa nova tecnologia. Apesar de ainda não haver muitos equipamentos certificados e a indústria ainda estar começando a lidar com estes, as operadoras já possuem bastante informações sobre os serviços que seus clientes 
desejam, assim como o quanto eles estão dispostos a pagar por esses serviços. Alguns serviços que poderão ser oferecidos via WiMax são apresentados na Figura A.16.

\begin{tabular}{|c|c|c|c|}
\hline Tipo de Serviço & Tempo Real? & Aplicação & Banda \\
\hline Jogos Interativos & $\operatorname{Sim}$ & Jogos Interativos & 50 a 85 Kbit's \\
\hline \multirow{2}{*}{ VolP, Video Conferência } & \multirow{2}{*}{$\operatorname{Sim}$} & VolP & 4 a $64 \mathrm{Kbit/s}$ \\
\hline & & VideoFone & 32 a $284 \mathrm{Kbit} / \mathrm{s}$ \\
\hline \multirow{3}{*}{ Streaming } & \multirow{3}{*}{ No } & MúsicalFala & 5 a 128 Kbit/s \\
\hline & & Video-clipes & 20 a 384 Kbit/s \\
\hline & & Filmes & $>2 \mathrm{Mbit} / \mathrm{s}$ \\
\hline \multirow{3}{*}{$\begin{array}{l}\text { Tecnologia da } \\
\text { Informação }\end{array}$} & \multirow{3}{*}{ No } & Torpedos & $<250$ bytes \\
\hline & & Navegação Web & $>500 \mathrm{Kbit} / \mathrm{s}$ \\
\hline & & E-mails (com anexos) & $>500 \mathrm{Kbit} / \mathrm{s}$ \\
\hline \multirow{2}{*}{$\begin{array}{l}\text { Downloads de } \\
\text { conteúdo }\end{array}$} & \multirow{2}{*}{ No } & Filmes & $>1 \mathrm{Mbit} / \mathrm{s}$ \\
\hline & & Ponto-a-ponto & $>500$ Kbit/s \\
\hline
\end{tabular}

Figura A.16 Serviços suportados pelo WiMax. 


\section{APÊNDICE B - TECNOLOGIAS DE TRANSPORTE}

\section{B.1 - SDH, Sonet e PDH}

A rede de telefonia desenvolveu-se inicialmente com o intuito de transportar apenas voz. Para isso, eram utilizados fios de cobre e sinais analógicos, utilizando FDM para a transmissão, que permitia que vários sinais pudessem ser transmitidos em um único meio. [21]

A primeira grande mudança na telefonia foi a digitalização do sinal, feita utilizando-se a técnica PCM, no qual é possível representar um sinal de voz na faixa de 300 a $3.400 \mathrm{~Hz}$ por um fluxo digital de $64 \mathrm{kbps}$. Uma taxa de transmissão de $2.048 \mathrm{Kbps}$ é alcançada multiplexando-se, através da técnica TDM, 30 desses canais de voz, juntamente com a sinalização necessária. Essa é a chamada taxa primária, que é utilizada na grande parte do mundo, como o Brasil, excluindo-se Canadá, Estados Unidos e Japão, que utilizam a taxa de $1.544 \mathrm{Kbps}$. Pode-se verificar um processo de digitalização e multiplexação da voz na figura B.1:

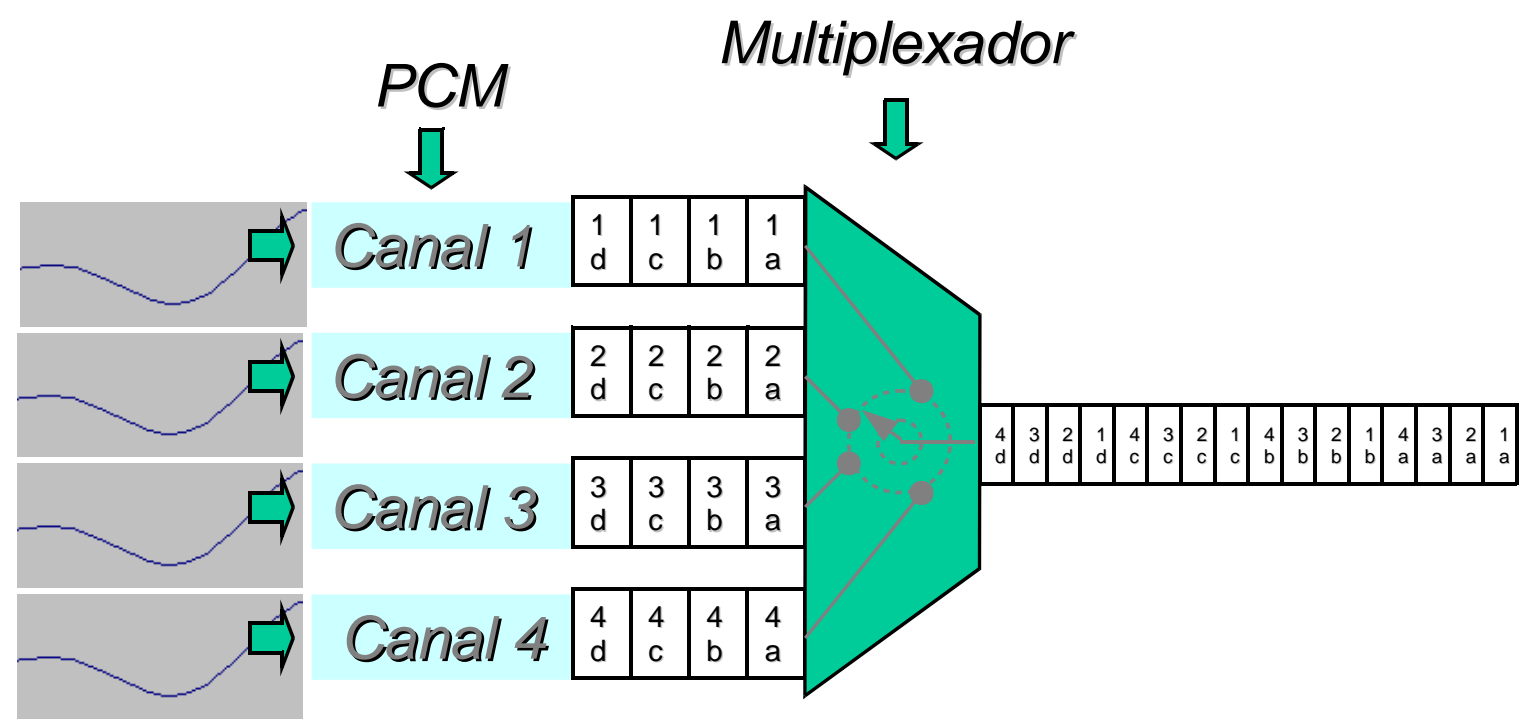

Figura B.1 Multiplexação de vários canais de voz.

Foram modificados os sistemas de transmissão, as centrais e, por fim, o acesso tornouse também digital. Durante os primeiros anos, os sistemas de transmissão utilizaram tecnologias proprietárias, com diferentes formas de multiplexação e manutenção da rede. A digitalização da rede possibilitou a criação de novos serviços, além da voz, como mostrado na figura B.2. 


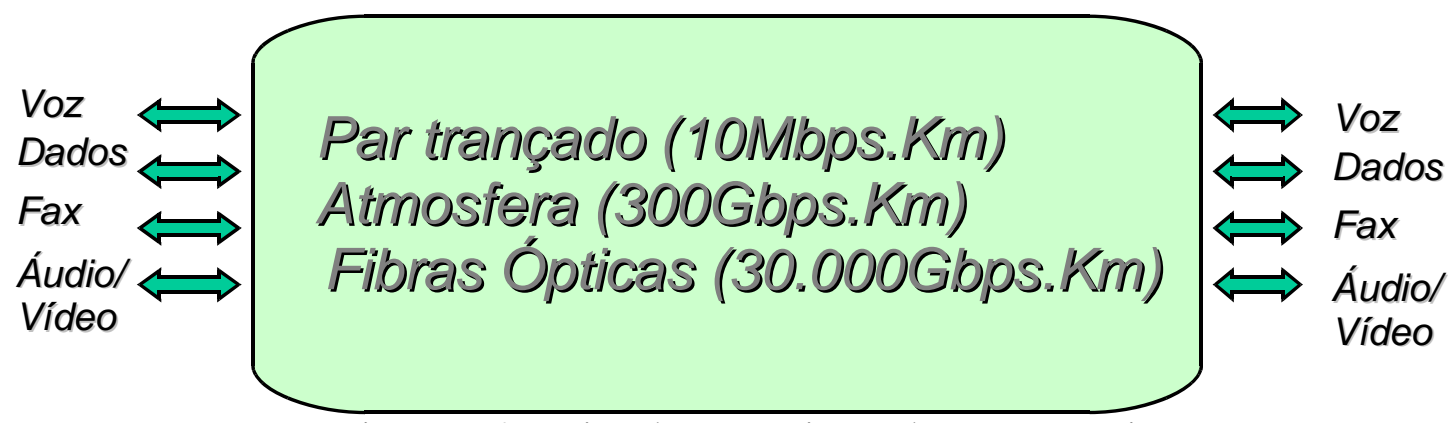

Figura B.2 Meios de transmissão de novos serviços.

À medida que eram criados novos serviços, era requisitada mais banda e novos níveis tiveram de ser definidos, figura B.3.

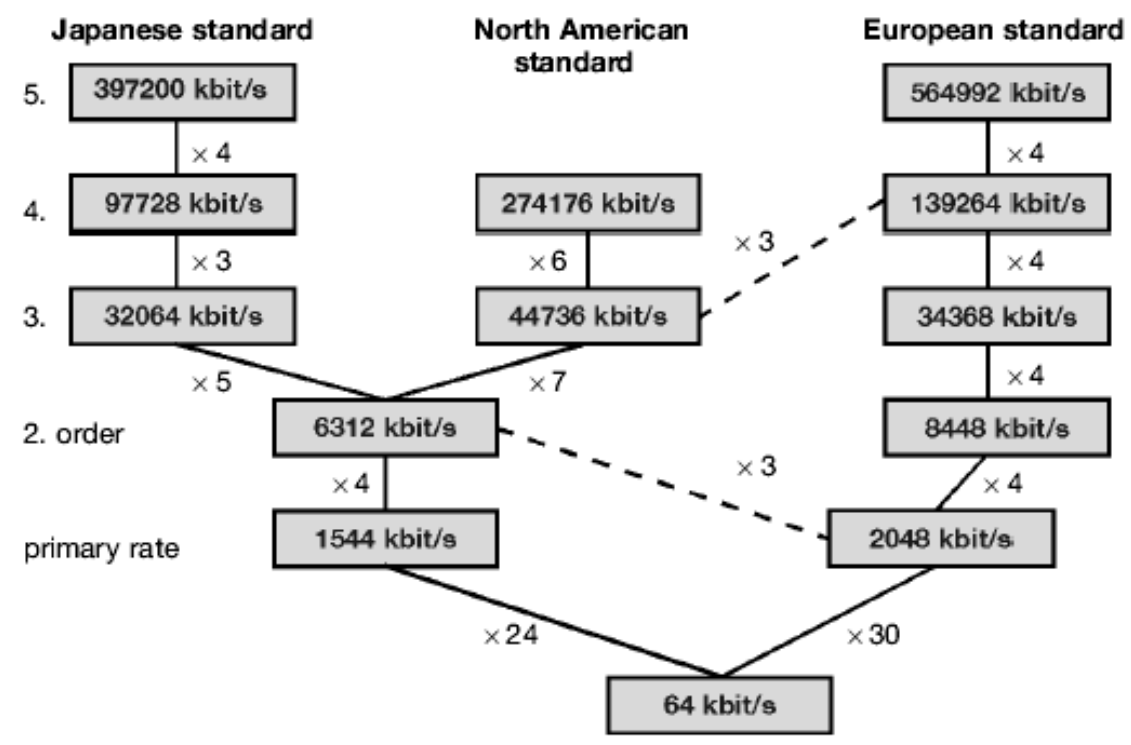

Figura B.3 Estrutura organizacional da PDH.

Criou-se, então, uma rede plesiócrona, a chamada rede PDH (plesiochronous digital hierarchy). Havia, no entanto, a necessidade da introdução de bits "não-significativos" a fim de ajustar as frequiências de relógio que podiam diferir, devido aos diversos caminhos e fontes da informação. Esse processo torna a rede quase síncrona, ou seja, plesiócrona.

O surgimento de novos serviços, que precisavam de uma sincronização em toda a rede, a necessidade da garantia da qualidade de serviço (QoS), o crescente número de diferentes operadores da rede e o grande crescimento da rede demandaram a criação de uma nova hierarquia digital, que eliminasse algumas desvantagens inerentes da rede PDH: 
- A rede PDH não era completamente padronizada;

- A inflexibilidade da rede, que demanda uma demultiplexação complexa para extrair tributários de baixa ordem de uma estrutura de alta ordem;

- Pouco espaço disponível no byte PDH para a administração da rede;

- Falta de possibilidade de monitoramento de performance.

A ECSA - EUA (Exchange Carriers Standards Association) criou, em 1984, o padrão SONET (Synchronous Optical Network), que foi adotado pelos EUA. Após algum tempo, o ITU-T - Europa (antigo CCITT) envolveu-se no trabalho para que um único padrão internacional pudesse ser desenvolvido para criar um sistema que possibilitasse que as redes de telefonia de países distintos pudessem ser interligadas. Foi criado, então, a rede SDH (Synchronous digital hierarchy). Posteriormente, foram realizados alguns ajustes no SONET, de forma a permitir a interconexão entre o SDH e SONET. A correspondência entre SDH e SONET é mostrada na tabela B.1.

Tabela B.1 Comparação entre as taxas da SONET e da SDH.

\begin{tabular}{|l|l|l|l|}
\hline \multicolumn{3}{|c|}{ SONET VS SDH BIT RATES } \\
\hline \multicolumn{3}{|c|}{ SONET } & \multicolumn{1}{c|}{ SDH } \\
\hline SYNCHRONOUS & OPTICAL & BIT RATE & SYNCHRONOUS \\
TRANSPORT SIGNAL & CARRIER & MBPS & TRANSPORT MODULE \\
\hline STS-1 & OC-1 & 51.84 & --- \\
STS-3 & OC-3 & 155.52 & STM-1 \\
STS-9 & OC-9 & 466.56 & -- \\
STS-12 & OC-12 & 622.08 & STM-4 \\
STS-18 & OC-18 & 933.12 & -- \\
STS-24 & OC-24 & 1244.16 & -- \\
STS--36 & OC-36 & 1866.24 & --- \\
STS-48 & OC-48 & 2488.32 & STM-16 \\
STS-192 & OC-192 & 9953.28 & STM-64 \\
\hline
\end{tabular}

*BIT RATES FOR HIGHER ORDER IS N-TIMES THE LOWER ORDER

A rede SDH traz, então, as seguintes vantagens:

- Maiores taxas de transmissão, podendo alcançar até $10 \mathrm{Gbps}$;

- Uma forma simplificada para fazer a inserção ou retirada de tributários de baixa ordem, devido à sincronização da rede; 
- O cabeçalho do frame SDH permite a gerência centralizada da rede, que traz vantagens como o provisionamento de serviços de forma mais rápida e otimização dos recursos da rede;

- Padronização tanto em nível de interfaces como em nível de equipamentos, que leva a um mercado mais competitivo, baixando o custo total da rede;

- Os equipamentos possuem mecanismos de proteção;

- Utilização da banda de forma flexível, dinamicamente.

Apesar dessas vantagens, há algumas desvantagens a serem consideradas:

- O projeto, a instalação e a operação da rede SDH são complexos e devem ser feitos com um planejamento criterioso e detalhado;

- Não há uma padronização dos sistemas de gerência, não possibilitando que equipamentos de fabricantes diferentes sejam monitorados por um único sistema;

$\mathrm{Na}$ rede $\mathrm{SDH}$ há um desacoplamento entre o fluxo de transporte (que define o sincronismo de quadro) e o fluxo dos tributários (que depende de uma série de variáveis aleatórias). Por isso, o início dos quadros dos tributários é definido por ponteiros que são utilizados para as justificações de sincronismo necessárias, podendo ser incrementados ou decrementados. Estes ajustes no sincronismo dos tributários não afetam, entretanto, o sincronismo dos quadros SDH.

O sistema $\mathrm{SDH}$, assim como a maioria dos outros sistemas de telecomunicações, é organizado em camadas. Do ponto de vista de rede, a estrutura é a da figura B.4: 


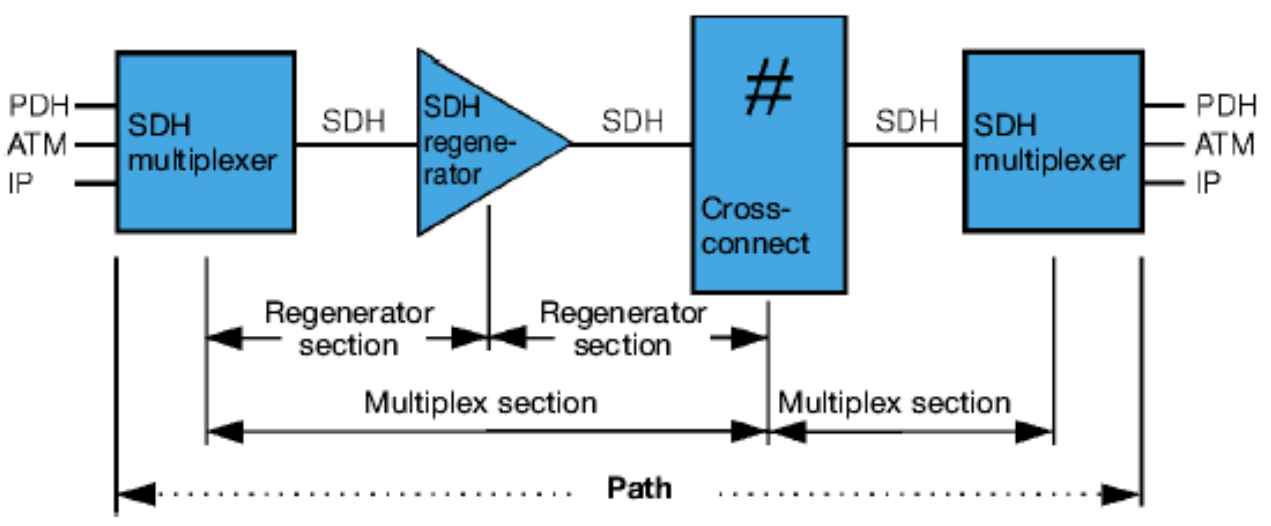

Figura B.4 Estrutura da rede SDH.

A via (path) é o caminho que o sinal percorre entre a origem e o destino. Nesse caminho, é formado o frame $\mathrm{SDH}$, com os sinais da origem, e durante o transporte desse frame, ele é processado pelas camadas adequadas para que possa ser restaurado ou para extrair ou inserir novos serviços. Além disso, cada etapa do processamento inclui informações de administração e supervisão no frame.

O ITU-T subdividiu a rede de transporte SDH em três camadas que são: Camada de Circuito (Circuit Layer Network), Camada de Via (Path Layer Network) e Camada do Meio de Transmissão (Transmission Media Layer Network). Existe uma relação cliente/servidor entre essas camadas, conforme mostrado na figura B.5. Cada camada possui seus próprios procedimentos de operação, manutenção e provisionamento.

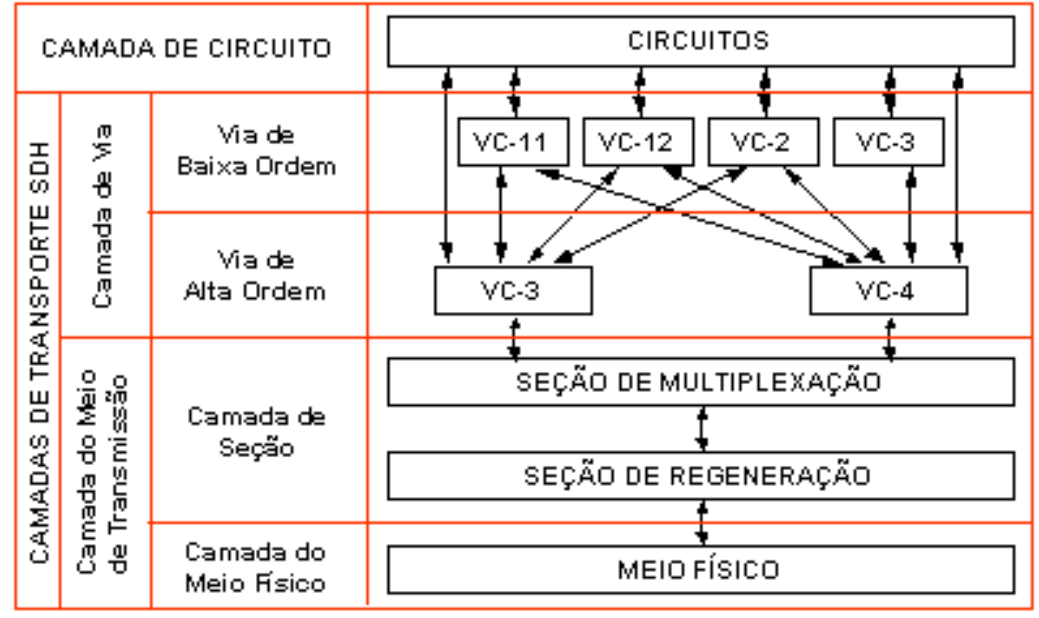

Figura B.5 Camadas da rede SDH. 
- Camada de Circuito - Provê aos usuários serviços de telecomunicações tais como comutação de circuitos e comutação de pacotes. Diferentes camadas de circuito podem ser identificadas de acordo com os serviços fornecidos;

- Camada de Via - É utilizada para dar suporte aos diferentes tipos de camadas de circuito. No caso da SDH, existem dois tipos: a Camada de Via de Ordem Inferior e a Camada de Via de Ordem Superior. A monitoração desta rede de camadas é possível através do POH (Path Overhead) de ordem inferior ou superior; - Camada do Meio de Transmissão - É dividida em camada de seção e camada de meio físico. A camada de seção se ocupa com todas as funções para a transferência de informação entre dois nós na camada de via. A camada de meio físico se ocupa com o meio de transmissão em sí (fibra óptica, rádio ou par metálico), a qual serve à camada de seção.

Na rede SDH a informação é organizada em quadros chamados STM (Synchronous Transport Module), que tem sua estrutura básica representada pela figura B.6.

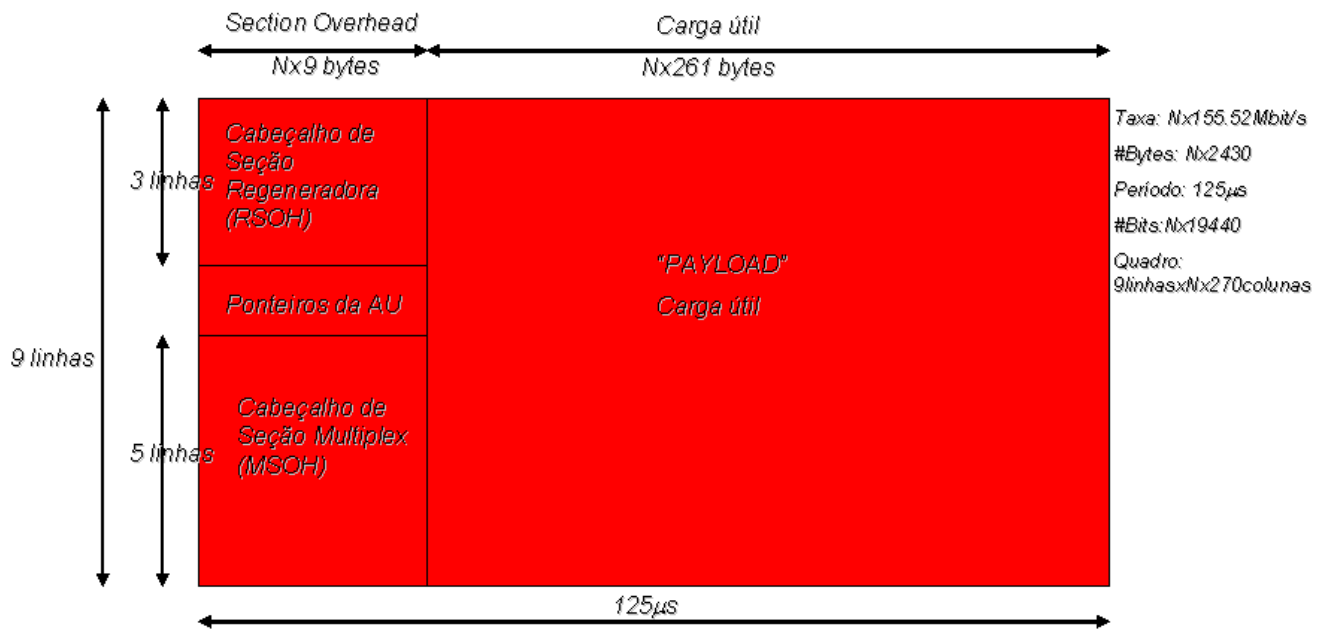

Figura B.6 Estrutura do quadro da rede SDH.

Essa estrutura é formada pela informação (payload), o cabeçalho (overhead ou SOHSession Overhead) e o POH (Path Overhead): 
- $\mathrm{RSOH}$ (Regenerator Section Overhead): é processado em cada equipamento da rede, contém informações de alinhamento de frame, identificação de frame, monitoração de erro de regeneração, alarmes físicos externos ao equipamento, e supervisão de sistema. Contém também um canal de voz, para comunicação de técnicos entre equipamentos.

- MSOH (Multiplex Section Overhead): é processado apenas em equipamentos onde existe inserção (add) ou retirada (drop) de canais multiplexados, contém informações de monitoração e indicação de erros de multiplexação, controle de chaveamento de mecanismos de proteção, monitoração de sincronismo e gerência de sistema.

- POH: processado em cada equipamento, possui os ponteiros que indicam onde se localiza o primeiro byte dos containers virtuais (VCs) dentro da área de informação útil (payload) do frame, e eventuais bytes provenientes de justificação desses VCs.

As topologias de rede geralmente utilizadas são mostradas na figura B.7:

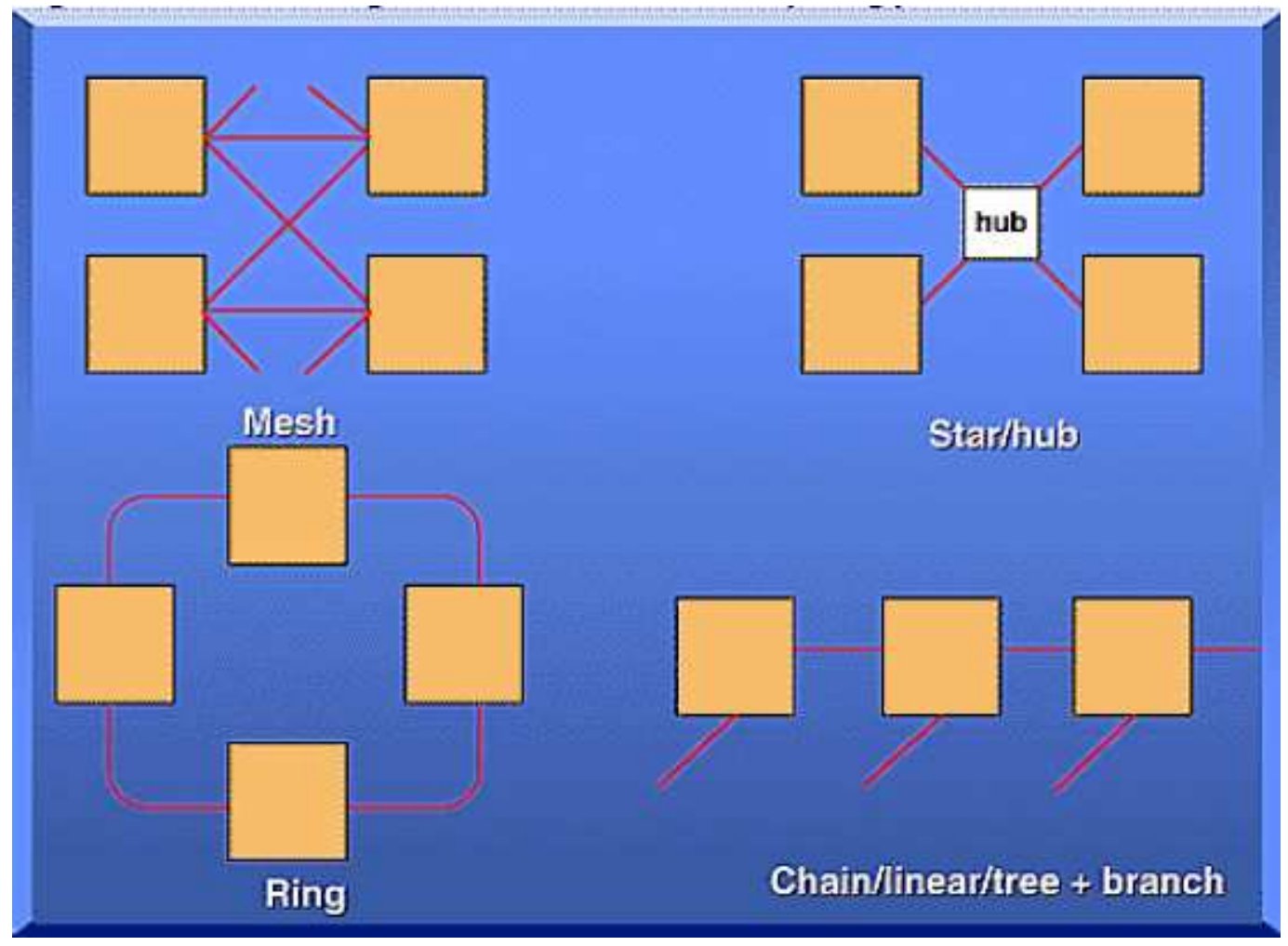


Figura B.7 Topologias de rede.

As atuais redes SDH são construídas basicamente com a utilização de quatro diferentes tipos de elementos de redes:

- Regeneradores: A regeneração é o processo em que o sinal digital degradado tem as características de amplitude, formas de onda e de sincronismo adequadas aos limites especificados para a sua retransmissão. O regenerador (REG) regenera o sinal agregado STM-N e o retransmite.

- Multiplexador Terminal de Linha (Line Terminal Multiplexer - LTM): Multiplexa/ demultiplexa sinais tributários de 2 Mbps, 34 Mbps, 140 Mbps e STM1,formatando/terminando o sinal agregado STM-1.

- Multiplexador Deriva/Insere (Add/Drop Multiplexers - ADM): O ADM (multiplexador insere/deriva) tem a capacidade de acessar qualquer um dos sinais constituintes do sinal agregado STM-N, sem a necessidade de demultiplexar e terminar o sinal completo. Sinais plesiócronos e síncronos de baixa taxa de bits podem ser extraídos ou inseridos em feixes de bits de alta velocidade SDH por meio de ADM's. Esta característica torna possível projetar estruturas em anel, que possuem a vantagem de comutação de caminhos de back-up automáticos dentro de um anel num determinado evento ou falha.

- Cross Conexão Digital (Digital Cross-Connects - DXC): Este elemento de rede possui a maior variedade de funções. Ele permite o mapeamento de tributários de sinais PDH em VC's (virtual containers) tão bem quanto a comutação de vários containers, até VC-4 (inclusive).

\section{B.2 - ATM}

Assynchronous Transfer Mode (ATM) foi concebida para integrar dados, voz e vídeos em uma única rede. Seu desenvolvimento se deu tanto pela necessidade de flexibilidade quanto pelo progresso tecnológico e conceitual de sistemas. Nos últimos anos ela começou a 
ser utilizada para redes locais e corporativas, mas sua concepção inicial tinha sido feita como uma técnica de multiplexação e comutação de alta velocidade para redes públicas.

Para se definir uma rede ATM é preciso introduzir alguns conceitos básicos, são eles: células, endereçamento e circuitos virtuais.

- Células: Nas redes de comutação por pacotes, como os protocolos IP e Ethernet, o encapsulamento de pacotes ocorre de uma forma variável, ou seja, o tamanho dos pacotes é variável; no caso das redes ATM, esses pacotes têm tamanhos fixos, de 53 bytes (sendo 48 de dados e 5 de cabeçalho) e são denominados células. Antes de se definir o tamanho das células, a idéia básica que norteou a decisão foi a de que essas seriam de tamanho reduzido, pois, dessa forma, evitaria-se o típico eco encontrado em transmissões de telefonia. Mas a principal vantagem que se tem em trabalhar com pacotes de tamanho fixo reside na maior facilidade encontrada em se tratar dados por hardwares baseados em chaveamentos (switches). Apesar de grandes vantagens, têm-se desvantagens como, por exemplo, a quantidade de cabeçalhos, mas, em conexões de alta velocidade, isto deixa ser relevante.

- Endereçamento: Existem 3 formatos de endereçamento que são todos constituídos de 20 bytes e divididos em duas seções: Prefixo de Rede (13 bytes) e End System Part (7 bytes). São eles: DCC (Data Country Code), E.164 (Specific Integrated Service Digital Network Number) e ICD (Internetional Code Designator). Esses endereços são somente utilizados para definição dos Circuitos Virtuais, após isso, esses passam a não mais serem representados nas células e essas passam a ser roteadas pelos VPIs e VCIs.

- Circuitos Virtuais: São definidos dinamicamente ou pelo administrador de rede. No primeiro caso, são chamados SVCs (Switched Virtual Circuits), no segundo são PVCs (Permanent Virtual Circuits) e ficam conectados o tempo todo. Em uma rede ATM deve necessariamente haver uma conexão virtual para que haja transferência de dados. Existem dois tipos de conexão de transporte: Virtual Path e Virtual Channels. No segundo caso (VC), o acesso é unidirecional e feito pela concatenação de uma seqüência de elementos de conexão, no primeiro caso (VP), 
consiste em um conjunto de VCs. Os dois circuitos possuem identificadores associados denominados de VPI e VCI. Para cada VP, tem-se vários VCIs e o mesmo VCI pode ser utilizado em outro VP.

Visto que o IP foi puramente projetado para um transporte de dados eficiente este não seria, portanto, adequado para o tráfego de vídeo e de voz o que guiou o desenvolvimento tecnológico mais para o lado do ATM. Mas deve-se sempre ter o cuidado de observar que embora o ATM tenha sido criado com o objetivo de lidar com todas as espécies de aplicações multimídia, não ocorrerá a substituição do IP e aplicações baseadas nesse protocolo continuaram a usá-lo, rodando sobre ATM.

\section{B.3 - IP}

Internet Protocol (IP) é um protocolo utilizado para transportar informação sob diferentes tipos de rede. Trabalha sem uma conexão, ou seja, a informação é transportada sem que haja estabelecimento de uma conexão entre a fonte e o destino. Cada pacote terá um endereço tanto da fonte como do destino o que é chamado de endereço IP. Existem dois tipos de endereços: IP privado e público. No primeiro, o endereço é globalmete único, ou seja, única fonte, único destino, o que significa que cada máquina conectada à internet pode enviar pacotes para qualquer outra também conectada. Esse protocolo não possui mecanismos de retransmissão, não dá garantias de uma transmissão íntegra e ordenada e descarta um datagrama se este não for entregue ou se passar muito tempo trafegando na internet. Pode-se citar dois protocolos utilizados para o auxílio no transporte fim-a-fim em uma rede IP: TCP e UDP.

Tanto o Transmission Control Protocol (TCP) quanto o User Datagram Protocol (UDP) são protocolos que possuem quatro camadas. Eles podem ajudar, por exemplo, segmantando os dados do usuário para um pacote IP de tamanho variável e adicionando uma seqüência de números a cada pacote. Da seqüência de números, o receptor sabe decodificar e remontar os dados até mesmo se o pacote IP atual chegar em ordem diferente daquela transmitida. A segmentação dos dados do usuário pode ser vista na figura B.1. 


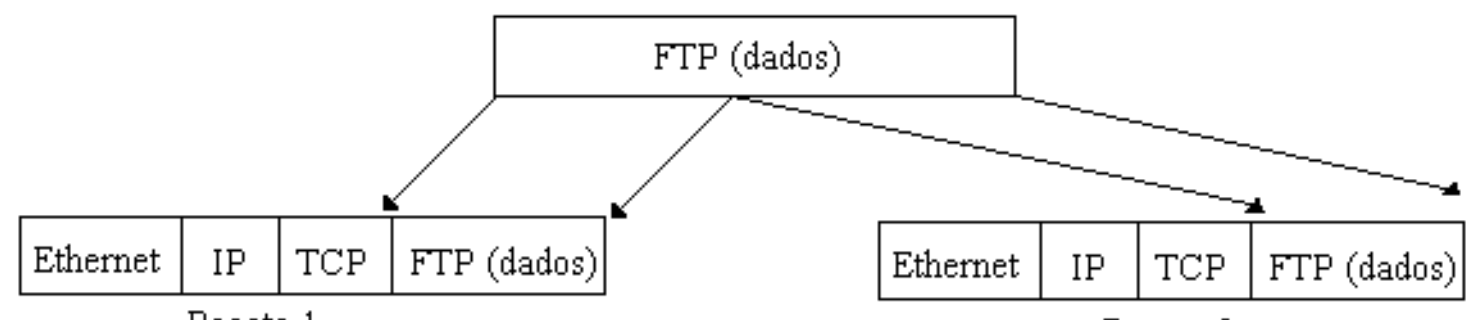

Pacote 1

Pacote 2

Figura B.8 Segmentação de dados.

TCP e UDP fornecem um método de endereçamento para separar as diferentes aplicações dentro de uma rede IP, o que é chamado de port numbers ou, em português, somente portas. Cada aplicação terá uma ou várias portas para identificar a fonte e o destino.

\section{B.3.1 - TCP}

O Transmission Control Protocol é usado para realizar uma transferência confiável full duplex (ambas as direções) de dados entre dois hosts diferentes. Permite a recuperação de pacotes perdidos, a eliminação de pacotes duplicados, a recuperação de dados corrompidos, e pode recuperar a ligação em caso de problemas no sistema e na rede. Também são incluídas como funções do TCP a numeração seqüencial, controle de fluxo, reconhecimento de pacotes e realização de uma checagem de controle para supervisão de dados corrompidos.

Para realização do controle de fluxo, o TCP atribui uma janela de transmissão ao host de origem que limita o número de bytes transmitido por vez. A segurança na transmissão reside no fato do protocolo ser orientado à conexão e trabalhar com números de reconhecimento sequiências e positivos.

Para a conexão do protocolo TCP, ocorrem três fases: estabelecimento da ligação, transferência e término de ligação. O estabelecimento da ligação é realizado em três passos, enquanto que o término é realizado em quatro. Durante a inicialização, são inicializados alguns parâmetros, como o Sequence Number (número de seqüência), para garantir a entrega ordenada e robustez durante a transferência.

O TCP do host de origem transfere os dados em forma de octetos. Cada octeto recebe números em sequiência. O TCP do host de destino analisa esses números para garantir a ordem 
e a integridade da mensagem enviada. Se a transferência for perfeita, o TCP do host destino envia uma mensagem de reconhecimento à origem. Caso contrário, é enviada uma seqüência numérica para o TCP do host origem que informará o tipo do problema, bem como ordenará uma nova transmissão. Os números em sequiência podem ser utilizados, ainda, para eliminar octetos duplos que, por causa da transmissão não orientada à conexão, podem ocorrer.

Podem-se citar alguns protocolos de aplicação do TCP como: TELNET (possibilita o trabalho em um host distante), FTP (transmite arquivos pela Internet) e SMTP (aplicativo de nível superior).

\section{B.3.2 - UDP}

O User Datagram Protocol é utilizado para prover uma rápida transferência de dados entre dois pontos IP finais. A corrupção dos dados também pode ser checada, mas isso é uma função opcional. O protocolo UDP é restringido a portas e sockets, e transmite os dados de forma não orientada à conexão. Esse protocolo é preferencialmente utilizado ao invés do TCP quando a velocidade é mais importante do que a confiabilidade e quando os protocolos superiores ou inferiores já possuem uma função de confiabilidade.

Em geral, os programas que utilizam portas UDP recorrem também à uma porta TCP para enviar as requisições de dados a serem enviados e também para checar periodicamente se o cliente ainda está on-line. São exemplos de protocolos que utilizam UDP: SNMP (usado para monitoramento das redes), RPC (Permite a um host a utilização de funções localizadas em hosts remotos) e TFTP (é utilizado para controle temporal e de integridade, não possui mecanismos de segurança).

\section{B.3.3 - IP versão 4}

Atualmente, IPv4 é a versão utilizada. Essa contém um endereço de 32 bits que é escrito com uma notação decimal onde cada número corresponde a um octeto ou 8 bits. Cada octeto está dentro de uma faixa que vai de 0 (00000000) até 255 (11111111). Um endereço IP é composto de duas partes: Network ID (Net ID) e o Host ID. O primeiro representa a rede na 
qual o host pertence e o segundo identifica o host específico dentro se uma rede particular, sendo que o Net ID sempre vem antes do Host ID e todas a funções de roteamento são baseadas no Net ID.

\section{B.3.4 - IP versão 6}

É a mais atual versão desenvolvida pelo IETF. As vantagens geradas por essa nova versão são descritas abaixo:

- Expansão na capacidade de endereços: Já que nessa versão o endereço é representado por 128 bits e não mais por 32. Além disso, a IPv6 contém um novo tipo de endereço denominado Anycast Address que é usado para enviar pacotes para qualquer grupo de nós em determinada rede.

- Simplificação do formato do cabeçalho que permite uma forma mais eficiente de encaminhamento de pacotes.

- Maior capacidade de etiquetar

- Maior capacidade de autentificação e de privacidade.

\section{B.3.5 - Sockets}

É simplesmente a combinação entre um endereço IP e uma porta que permite um servidor identificar unicamente o processo de um cliente particular, mas não serve com o propósito de identificação já que a mesma porta pode ser utilizada por vários clientes. Por questões de segurança e também para que o endereço seja salvo, algumas redes utilizam um endereço IP privado. Como já dito anteriormente, para que se possa conectar a Internet, é necessário que se tenha um endereço público e, para isso, se faz necessário uma transição desse endereço IP privado para um endereço público. Para isso, utiliza-se a chamada NAT (network address translation) que geralmente é realizada por roteadores conectado a redes externas ou a firewalls. 